\title{
Development of a Testing Protocol for C7 Carbon Fiber Core Conductors
}

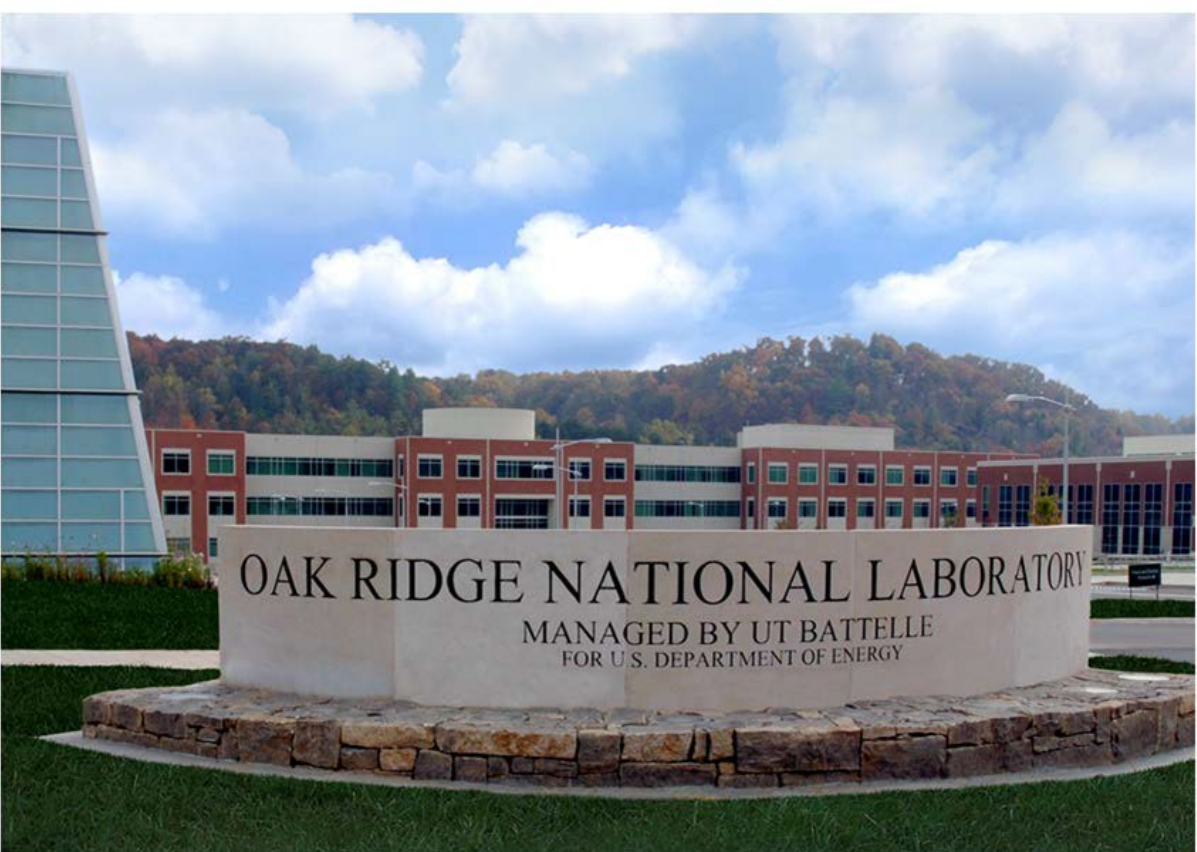

Approved for public release.

Distribution is unlimited.

Jy-An John Wang

OAK RIDGE NATIONAL LABORATORY

MANAGED BY UT-BATTELLE FOR THE US DEPARTMENT OF ENERGY 


\title{
DOCUMENT AVAILABILITY
}

Reports produced after January 1, 1996, are generally available free via the U.S. Department of Energy (DOE) Information Bridge.

Web site http://www.osti.gov/bridge

Reports produced before January 1, 1996, may be purchased by members of the public from the following source.

\author{
National Technical Information Service \\ 5285 Port Royal Road \\ Springfield, VA 22161 \\ Telephone 703-605-6000 (1-800-553-6847) \\ TDD 703-487-4639 \\ Fax 703-605-6900 \\ E-mail info@ntis.fedworld.gov \\ Web site http://www.ntis.gov/support/ordernowabout.htm
}

Reports are available to DOE employees, DOE contractors, Energy Technology Data Exchange (ETDE) representatives, and International Nuclear Information System (INIS) representatives from the following source.

Office of Scientific and Technical Information

P.O. Box 62

Oak Ridge, TN 37831

Telephone 865-576-8401

Fax 865-576-5728

E-mail reports@adonis.osti.gov

Web site http://www.osti.gov/contact.html

\begin{abstract}
This report was prepared as an account of work sponsored by an agency* of the United States Government. Neither the United States government nor any agency thereof, nor any of their employees, makes any warranty, express or implied, or assumes any legal liability or responsibility for the accuracy, completeness, or usefulness of any information, apparatus, product, or process disclosed, or represents that its use would not infringe privately owned rights. Reference herein to any specific commercial product, process, or service by trade name, trademark, manufacturer, or otherwise, does not necessarily constitute or imply its endorsement, recommendation, or favoring by the United States Government or any agency thereof. The views and opinions of authors expressed herein do not necessarily state or reflect those of the United States Government or any agency thereof.
\end{abstract}

* This report describes research sponsored by the Electric Power Research Institute (EPRI). 
Materials Science and Technology Division

\title{
Development of a Testing Protocol for C7 Carbon Fiber Core Conductors
}

\author{
Jy-An John Wang
}

Date Published: April 2018

\author{
Prepared by \\ OAK RIDGE NATIONAL LABORATORY \\ P.O. Box 2008 \\ Oak Ridge, Tennessee 37831-6285 \\ managed by \\ UT-Battelle, LLC \\ for the \\ U.S. DEPARTMENT OF ENERGY \\ under contract DE-AC05-00OR22725
}




\section{ABSTRACT}

To avoid the high costs and environmental and regulatory challenges of building new lines to meet the power demand, utilities are searching for ways to increase power transmission capacity on existing lines and thereby. This could involve upgrading the network lines with conductors capable of transmitting greater capacity. In recent years, conductor manufacturers have begun producing new conductors that can operate at higher temperatures without violating present electrical clearances to ground and other objects. One new conductor technology is a carbon composite core with PPS polymer matrix and PEEK capping layer composite conductor, manufactured by Southwire Inc. The conductor uses new materials, which have not previously been used for overhead lines.

The project made an initial characterization of the composite core to define the material used in the manufacture of the composite. Several analytical procedures were then conducted to evaluate the physical-chemical impacts on the composite as a result of thermal exposure. These procedures included thermogravimetry, dynamic mechanical analysis, thermal mechanical analyses, and optical microscopy. Mechanical three-point flexural tests, tensile tests, creep tests, and dynamic vibration tests were then performed to estimate the potential degradation after thermal aging.

The report provides the basis to develop a qualification testing protocol for the carbon composite core at targeted service environments. The work covers the design of the qualification testing protocol and the follow-on validation testing to support the proposed methods. The research includes the following approaches: initial characterization, performance of thermal aging, characterization of the aged material, comparison of aged properties or characteristics to the original, and concluding by the findings through the developed qualification procedures.

\section{Keywords}

Advanced conductors

Composite core conductor test

High-temperature low-sag (HTLS) conductors

HTLS conductor aging test

HTLS conductor test protocol Increased transmission capacity 



\section{CONTENTS}

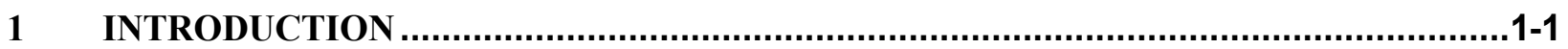

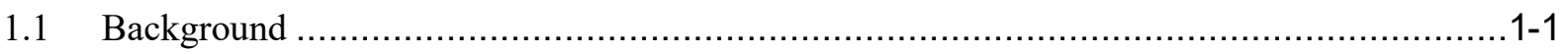

1.2 General Consideration of Thermoplastic Polymers Characterizations ............................. 1-2

1.2.1 Dynamic Mechanical Analysis............................................................

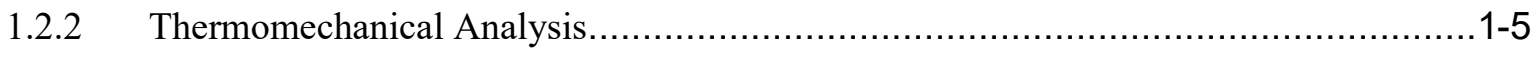

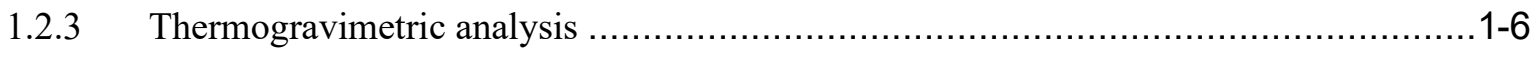

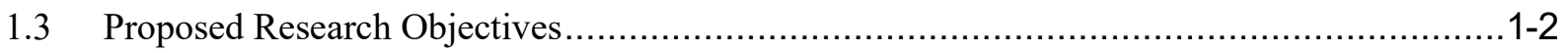

1.4 Proposed Research Tasks Descriptions ........................................................

\section{PRELIMINARY CHARACTERIZATION OF C7 CONDUCTOR CARBON}

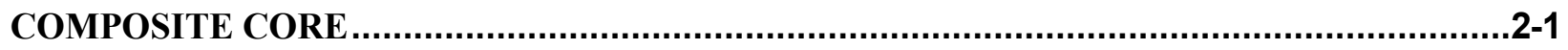

$2.1 \mathrm{C} 7$ overhead conductor system components technical specifications ...............................2-1

2.2 Initial C7 carbon composite core physical examinations ........................................ $2-6$

3 THERMAL AGING EXPERIMENTS AND THERMAL AGING CHARACTERIZATIONS USING TGA, DMA, AND TMA TECHNIQUES .............................

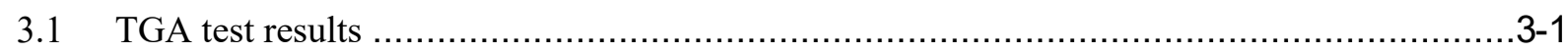

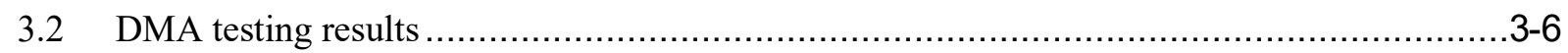

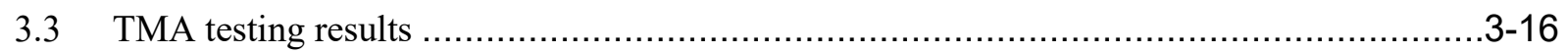

4 THERMAL AGING CHARACTERIZATION USING 3-POINT BENDING TEST ............4-1

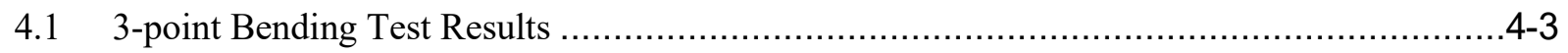

5 THERMAL AGING CHARACTERIZATION USING TENSILE TEST .......................5-1

$5.1 \quad$ Pilot tensile test and sample grip design............................................................ $5-1$

5.2 C7 composite core sample tensile test results at room temperature ...............................5-5

5.3 High temperature $\mathrm{C} 7$ carbon composite core tensile tests ........................................ $5-14$

5.3.1 Tested sample grips located outside the environmental chamber ........................5-14

5.3.2 Sample grips located inside the environmental chamber...................................5-16 
6.1 C7 carbon composite core sample creep testing ................................................... $6-1$

6.2 C7 carbon composite core dynamic stability evaluation ......................................... $6-4$

7 DEVELOPING QUALIFICATION CRITERIA FOR C7 COMPOSITE CORE

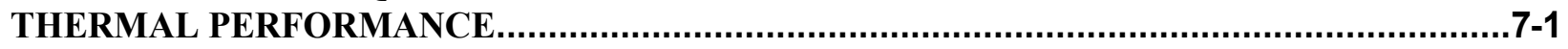

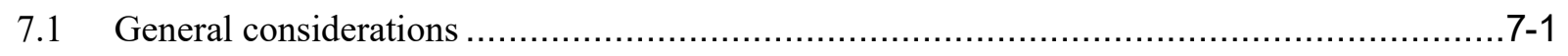

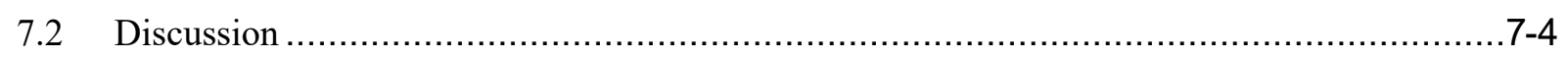

7.2.1 Transition Temperature Estimate for C7 Composite Core Material.........................7-4

7.2.2 Mechanical strength verification at the target service temperature ......................... $7-5$

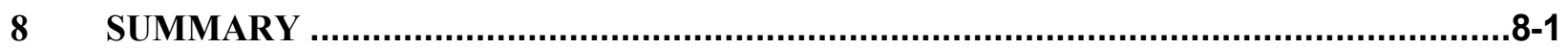

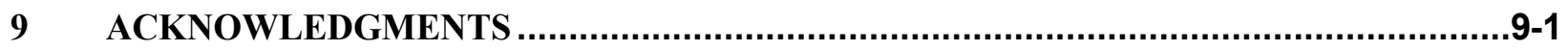




\section{LIST OF FIGURES}

Figure 1 Southwire C7 Composite-core Conductor. [1]

Figure 2. Effect of annealing on loss tangent of an injection molded ABS part. [3] ............................... 1-4

Figure 3. An idealized DMA scan showing types of transitions seen in the DMA 8000. [4] ...............1-5

Figure 4 . The increase in free volume is caused by increased energy absorbed in the chains. This increased free volume permits the various types of chain movement to occur. Below the $\mathrm{Tg}$ various paths with different free volumes exist depending on heat history and processing of the polymer, where the path with the least free volume is the most relaxed.

Figure 5. The glass transition and CTE of polystyrene is shown. The slopes of the baseline are used to calculate the CTE. The Tg is a region of between 90 and $110^{\circ} \mathrm{C}$, for which a $\mathrm{Tg}$ temperature is calculated as shown. [5].

Figure 6 (Left) Thermal key points of different thermoplastic polymers, (Right) the schematic diagram illustrated the determination of $\mathrm{Tg}$ and $\mathrm{Tm}$ from DMA test for semi-crystalline materials, such as PPS and PEEK polymers. [6].

Figure 7 Thermoplastic carbon composite tensile strength at elevated temperature. [6]

Figure 8 Preconditioned tension strength retention for uncapping PPS and PEEK carbon composites, where the uncapped samples were preconditioned at elevated temperature for a set period of time and tensile tested to failure. [6]

Figure 9 Microscopy image of the cross-section of the received C7 composite core samples..............2-6

Figure 10 Typical cross-section images of the received C7 composite core samples.......................2-6

Figure 11 The detailed microscopy images of $\mathrm{C} 7$ carbon composite core samples........................... $2-7$

Figure 12 The detailed images of the C7 carbon fibers observed from fracture PPS regions................2-7

Figure 13 SEM images of PPS matrix of the received C7 carbon composite core sample, light color portions are the PPS matrix and the dark color portions are carbon fibers.

Figure 14 Carbon fiber strands distribution in PPS matrix, which shows the inhomogeneous characteristic of $\mathrm{C} 7$ composite core, where the carbon fiber $(\mathrm{CF})$ volume ratio ranges are from $28 \%$ to $51 \%$ from different sections of $\mathrm{C} 7$ composite core sample.

Figure 15 EDS studies on PPS, PEEK, and carbon fiber portions of C7 carbon composite core.

Figure 16 TGA test results in nitrogen for data up to $700 \mathrm{C}$. The PEEK loses $\sim 45 \%$ of its weight and the PPS loses $\sim 22 \%$ with the $\mathrm{C} 7$ carbon core in between at $\sim 26 \%$. The PEEK loses its volatiles at $555^{\circ} \mathrm{C}$ and the PPS at $525^{\circ} \mathrm{C}$.

Figure 17 TGA test results in air, where the C7 carbon and the PPS were not completely combusted after 2 hours at $700 \mathrm{C}$. The noisiness of the $\mathrm{C} 7$ carbon composite derivative curve might be due to the cylindrical fiber rolling a little bit during combustion.

Figure 18 TGA thermal aging test results in nitrogen, which shows the variations in the mass of $\mathrm{C} 7$ carbon core samples among $100^{\circ} \mathrm{C}, 180^{\circ} \mathrm{C}$, and $210^{\circ} \mathrm{C}$ under nitrogen. 
Figure 19 C7 composite core material DMA Testing, sample \#1; Test temperature ramp at $3^{\circ} \mathrm{C} /$ min from room temperature to $300^{\circ} \mathrm{C}$, with the following parameters: driving force is at $0.1 \mathrm{~N}$, amplitude of $1.4 \mu \mathrm{m}$, and static force of $0.11 \mathrm{~N}$.

Figure $20 \mathrm{C} 7$ composite core material DMA Testing, sample \#2; Test temperature ramp at

$5^{\circ} \mathrm{C} / \mathrm{min}$ from room temperature to $300^{\circ} \mathrm{C}$, with the following parameters: driving force is at

$0.1 \mathrm{~N}$, amplitude of $1.7 \mu \mathrm{m}$, and static force of $0.14 \mathrm{~N}$.

Figure $21 \mathrm{C} 7$ core material DMA Testing, sample \#3; Test temperature ramp at $3{ }^{\circ} \mathrm{C} / \mathrm{min}$ from room temperature to $250^{\circ} \mathrm{C}$, with the following parameters: driving force is at $0.089 \mathrm{~N}$, amplitude of 1.0 micron, and static force of $0.134 \mathrm{~N}$

Figure $22 \mathrm{C} 7$ core material DMA Testing, sample \#4; Test temperature ramp at $5^{\circ} \mathrm{C} / \mathrm{min}$ from room temperature to $300^{\circ} \mathrm{C}$, with the following parameters: driving force is at $0.1 \mathrm{~N}$, amplitude of $1.8 \mu \mathrm{m}$, and static force of $0.14 \mathrm{~N}$.

Figure $23 \mathrm{C} 7$ core material DMA Testing, sample \#5; Test temperature ramp at $3{ }^{\circ} \mathrm{C} / \mathrm{min}$ from room temperature to $300^{\circ} \mathrm{C}$, with the following parameters: driving force is at $0.1 \mathrm{~N}$, amplitude of $1.85 \mu \mathrm{m}$, and static force of $0.14 \mathrm{~N}$.

Figure $24 \mathrm{C} 7$ core material DMA Testing, sample \#6; Test temperature ramp at $3^{\circ} \mathrm{C} / \mathrm{min}$ from room temperature to $300^{\circ} \mathrm{C}$, with the following parameters: driving force is at $0.18 \mathrm{~N}$, amplitude of $2.78 \mu \mathrm{m}$, and static force of $0.27 \mathrm{~N}$.

Figure $25 \mathrm{C} 7$ composite core material DMA Testing, sample \#7; Test temperature ramp at $3^{\circ} \mathrm{C} / \mathrm{min}$ from room temperature to $250^{\circ} \mathrm{C}$, with the following parameters: driving force is at $0.1 \mathrm{~N}$, amplitude of $1.1 \mu \mathrm{m}$, and static force of $0.136 \mathrm{~N}$.

Figure $26 \mathrm{C} 7$ core material DMA Testing, sample \#8; Test temperature ramp at $5^{\circ} \mathrm{C} / \mathrm{min}$ from room temperature to $300^{\circ} \mathrm{C}$, with the following parameters: driving force is at $0.1 \mathrm{~N}$, amplitude of $1.2 \mu \mathrm{m}$, and static force of $0.136 \mathrm{~N}$.

Figure $27 \mathrm{C} 7$ core material DMA Testing, sample \#9; Test temperature ramp at $3{ }^{\circ} \mathrm{C} / \mathrm{min}$ from room temperature to $350^{\circ} \mathrm{C}$, with the following parameters: driving force is at $0.175 \mathrm{~N}$, amplitude of $1.55 \mu \mathrm{m}$, and static force of $0.258 \mathrm{~N}$.

Figure $28 \mathrm{C} 7$ core material DMA Testing, sample \#10; Test temperature ramp at $3^{\circ} \mathrm{C} / \mathrm{min}$ from room temperature to $350^{\circ} \mathrm{C}$, with the following parameters: driving force is at $0.1 \mathrm{~N}$, amplitude of $2.85 \mu \mathrm{m}$, and static force of $0.14 \mathrm{~N}$.

Figure 29 C7 core material DMA Testing, sample \#11 of received EPRI thermal cycling O-temp carbon core aging sample; Test temperature ramp at $5^{\circ} \mathrm{C} / \mathrm{min}$ from room temperature to $350^{\circ} \mathrm{C}$, with the following parameters: driving force is at $0.1 \mathrm{~N}$, amplitude of $3.0 \mu \mathrm{m}$, and static force of $0.12 \mathrm{~N}$.

Figure 30 Comparison of EPRI aging C7 composite core sample DMA test results and baseline C7 carbon core sample DMA test results. Which shows decrease in storage and loss modulus from aging $\mathrm{C} 7$ carbon core sample compared to that of baseline $\mathrm{C} 7$ carbon core sample; and thermal cycling aging sample also shows lower damping than that of the baseline sample. The aging sample DMA test result shows increase in Tg compared to that of baseline sample.

Figure $31 \mathrm{C} 7$ carbon core TMA testing 1 , first cycle ramp at $5^{\circ} \mathrm{C} / \mathrm{min}$ to $225 \mathrm{C}$, force $0.1 \mathrm{~N}$; second cycle: ramp at $5^{\circ} \mathrm{C} / \mathrm{min}$ to $225 \mathrm{C}$, load $0.05 \mathrm{~N}$, sample length $21.21 \mathrm{~mm}$.

Figure $32 \mathrm{C} 7$ Core TMA Testing \#2; first cycle: ramp $10^{\circ} \mathrm{C} / \mathrm{min}$ to $225 \mathrm{C}$, load force $0.05 \mathrm{~N}$; second cycle ramp down $5^{\circ} \mathrm{C} / \mathrm{min}$ to $20 \mathrm{C}$, ramp up $5^{\circ} \mathrm{C} / \mathrm{min}$ to $225 \mathrm{C}$, load $0.02 \mathrm{~N}$, ramp down $5 \mathrm{C} / \mathrm{min}$ to 20C. Sample length $19.59-\mathrm{mm}$. 
Figure 33 TMA C7 carbon Core Testing \#3; first cycle: ramp $10^{\circ} \mathrm{C} / \mathrm{min}$ to $225 \mathrm{C}$, load force $0.05 \mathrm{~N}$; second cycle ramp down $5^{\circ} \mathrm{C} / \mathrm{min}$ to $20 \mathrm{C}$, ramp up $5^{\circ} \mathrm{C} / \mathrm{min}$ to $225 \mathrm{C}$, load $0.02 \mathrm{~N}$, ramp down $5 \mathrm{C} / \mathrm{min}$ to $20 \mathrm{C}$, ramp up $5 \mathrm{C} / \mathrm{min}$ to $325 \mathrm{C}$, load $0.02 \mathrm{~N}$. sample length $8.4-\mathrm{mm}$

Figure 34 Cycle 1: Ramp $10^{\circ} \mathrm{C} / \mathrm{min}$ to $225 \mathrm{C}$, force $0.05 \mathrm{~N}$; Cycle 2: Ramp $5^{\circ} \mathrm{C} / \mathrm{min}$ to $225^{\circ} \mathrm{C}$, load force $0.02 \mathrm{~N}$, sample length $19.6-\mathrm{mm}$.

Figure 35 Cycle 1: Ramp 5C/min to $225 \mathrm{C}$, load $0.05 \mathrm{~N}$; Cycle 2: $5 \mathrm{C} / \mathrm{min}$ to $225 \mathrm{C}$, load $0.02 \mathrm{~N}$. sample length $2.7-\mathrm{mm}$.

Figure 36 Sample length 9.509mm, Cycle 1: Ramp 5C/min to 225C, load 0.1N; Cycle 2: Ramp $5 \mathrm{C} / \mathrm{min}$ to 225 , load $0.05 \mathrm{~N}$.

Figure 37 Aging C7 core Cycle 1: Ramp 10C/min to 225C, load force $0.05 \mathrm{~N}$; Cycle $25 \mathrm{C} / \mathrm{min}$ to $225 \mathrm{C}$, load $02 \mathrm{~N}$. length $6.96-\mathrm{mm}$.

Figure 38 Comparison of microscopy images for $\mathrm{C} 7$ carbon composite core baseline sample and thermally aged samples at $180^{\circ} \mathrm{C}$ and $225^{\circ} \mathrm{C}$, respectively

Figure 39 C7 Carbon Core 3-point Bending Test Sample \#1...............................................4-4

Figure 40 C7 Carbon Core 3-point Bending Test Sample \#2 .............................................................. 4-4

Figure 41 C7 Carbon Core 3-point Bending Test Sample \#3. ........................................... $4-5$

Figure 42 C7 Carbon Core 3-point Bending Test Sample \#4. .............................................4-5

Figure 43 C7 Carbon Core 3-point Bending Test Sample \#5 ........................................... $4-6$

Figure 44 C7 Carbon Core 3-point Bending Sample \#6................................................... $4-6$

Figure 45 Baseline C7 Carbon Core 3-point Bending Test Results.........................................4-7

Figure 46 C7 Carbon Core 3-point Bending Test, aging sample with 180C for 100 hours................4-7

Figure $47 \mathrm{C} 7$ Carbon Core 3-point Bending test, sample aged at $180^{\circ} \mathrm{C}$ for 500 hours....................4-8

Figure $48 \mathrm{C} 7$ Carbon Core 3-point Bending Test, sample aged at $180 \mathrm{C}$ for 1000 hours. ..................4-8

Figure $49 \mathrm{C} 7 \mathrm{Carbon}$ Core 3-point Bending Test, sample aged at $225^{\circ} \mathrm{C}$ - for 100 hours.....................4-9

Figure $50 \mathrm{C} 7 \mathrm{Carbon}$ Core 3-point Bending Test, sample aged at $225^{\circ} \mathrm{C}$ for 100 hours...................4-9

Figure 51 C7 Carbon Core 3-point Bending Tests, including baseline and aging samples. ..............4-10

Figure $52 \mathrm{C} 7$ core 3P bending testing with EPRI thermal cycling aged O-temp-1 sample. ..............4-10

Figure $53 \mathrm{C} 7$ core $3 \mathrm{P}$ bending tests with EPRI thermal cycling aged O-temp-2 sample. .................4-11

Figure 54 C7 Carbon Core 3 Point-bending Tests with EPRI thermal cycling aged O-temp and

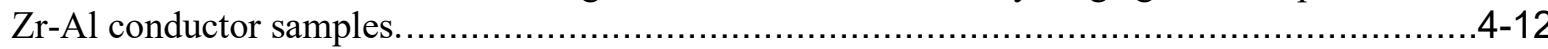

Figure 55 C7 Carbon Core 3 Point-bending Tests with EPRI thermal cycling aged O-temp and $\mathrm{Zr}-\mathrm{Al}$ conductor samples.

Figure 56 C7 Carbon Core 3 Point-bending Tests with EPRI thermal cycling aged O-temp and $\mathrm{Zr}-\mathrm{Al}$ conductor samples.

Figure 57 C7 Carbon Core 3 Point-bending Tests with EPRI thermal cycling aged O-temp and $\mathrm{Zr}$-Al conductor samples; where O-temp shows more thermal softening than $\mathrm{Zr}-\mathrm{Al} \mathrm{C} 7$ samples with lower stiffness and longer sag deflection.

Figure $58 \mathrm{C} 7$ core tensile testing using hydraulic grip clamps of 2 -inch in length. ......................... $5-1$

Figure 59 C7 core pilot tensile test load-stroke history. ................................................................. 5-1

Figure 60 Metallic Materials Tensile Testing General Trends................................................5-2

Figure $61 \mathrm{C} 7$ core tensile test using new grip design with brass insert shows grip slip...................5-3 
Figure 62 Tensile testing using grip w/ thin hard copper insert + epoxy shows grip slip...................5-3

Figure 63 Tensile testing using new grip with thick soft copper insert + epoxy shows slip...............5-3

Figure 64 Final grip design for $\mathrm{C} 7$ core sample tensile testing. ............................................... $5-4$

Figure $65 \mathrm{C} 7$ core tensile testing at $0.0003 \mathrm{in} / \mathrm{sec}$ loading rate .......................................... $5-5$

Figure $66 \mathrm{C} 7$ core tensile testing failure evolutions, from left to right, at $0.0003 \mathrm{in} / \mathrm{sec}$ loading

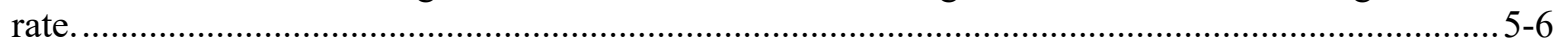

Figure $67 \mathrm{C} 7$ core tensile testing at $0.003 \mathrm{in} / \mathrm{sec}$ loading rate. ...................................

Figure $68 \mathrm{C} 7 \mathrm{core}$ tensile testing at $0.003 \mathrm{in} / \mathrm{sec}$ loading rate..........................................

Figure 69 EPRI C7 (Zr-Al) core tensile testing aged under $180^{\circ} \mathrm{C}$ thermal cycling, $0.003 \mathrm{in} / \mathrm{sec}$

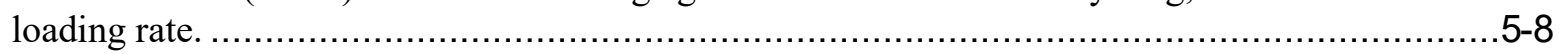

Figure 70 EPRI C7 (O-Temp) core tensile testing aged under $180^{\circ} \mathrm{C}$ thermal cycling, 0.003 $\mathrm{in} / \mathrm{sec}$ loading rate.

Figure $71 \mathrm{C} 7$ core tensile testing at $0.03 \mathrm{in} / \mathrm{sec}$ loading rate.

Figure $72 \mathrm{C} 7$ core tensile testing at $0.3 \mathrm{in} / \mathrm{sec}$ loading rate, where fast brittle fracture at failure site was observed w/o carbon fibers and PPS matrix disintegration in contrast to significant C7 core carbon fibers/PPS matrix disintegration revealed from other lower loading rate tensile tests.

Figure $73 \mathrm{C} 7$ core tensile testing at $0.003 \mathrm{in} / \mathrm{s}$ loading rate, for baseline and EPRI thermal cycle aged samples. Aged EPRI C7 core from Zr-Al conductor has lower ductility compared to aged EPRI C7 core from O-temp conductor.

Figure 74 Comparison of baseline $\mathrm{C} 7$ core tensile testing at different loading rates, which show significant ductility reduction at higher loading rate.

Figure 75 C7-O-temp conductor splice testing, and C7 conductor failed at $40 \mathrm{~K} 1 \mathrm{~b} \ldots \ldots \ldots \ldots \ldots \ldots \ldots \ldots \ldots . . . . . . . . . . . . .12$

Figure 76 C7-O-temp Drake conductor tensile testing, end grip equipped with the Dead-end splice, conductor failed at $32 \mathrm{~K} \mathrm{lb}$. and located inside the Dead-end splice.

Figure 77 C7 Zr-Al Drake conductor tensile testing, with Dead-end grip; conductor failed at 40K lb. and located inside the Dead-end splice.

Figure 78 (Left) High temperature tensile testing set-up, (Right) environmental chamber.

Figure $79 \mathrm{C} 7$ core sample tensile test $\# 3$ at $100^{\circ} \mathrm{C}$

Figure $80 \mathrm{C} 7$ core sample tensile fractured at $180^{\circ} \mathrm{C}$

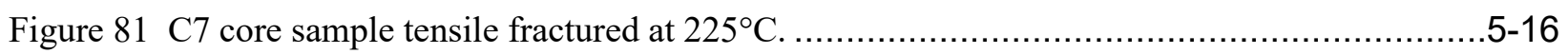

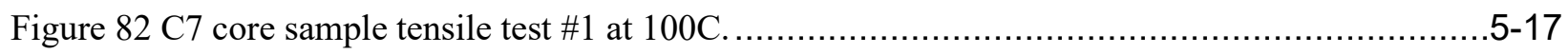

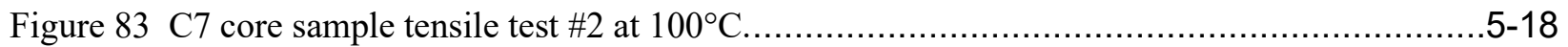

Figure $84 \mathrm{C} 7$ core sample tensile test $\# 4$ at $180^{\circ} \mathrm{C}$; Upon completion of $180 \mathrm{C}$ tensile testing, the C7 core sample was cooled down to RT, followed with tensile test performed at $125^{\circ} \mathrm{C}$, where significant increase in tensile strength at $125^{\circ} \mathrm{C}$ was observed compared to that of $180^{\circ} \mathrm{C}$ testing.

Figure $85 \mathrm{C} 7$ core sample tensile test $\# 5$ at $180^{\circ} \mathrm{C}$

Figure $86 \mathrm{C} 7$ core sample tensile test $\# 6$ at $180^{\circ} \mathrm{C}$

Figure $87 \mathrm{C} 7$ core sample tensile test $\# 7$ at $225^{\circ} \mathrm{C}$.

Figure $88 \mathrm{C} 7$ core sample tensile test $\# 8$ at $225^{\circ} \mathrm{C}$. 
Figure 89 C7 core sample grip temperature effect on C7 core tensile testing results. Significant tensile strength reductions were observed for testing temperature above $100^{\circ} \mathrm{C}$.

Figure 90 (a) Creep test frame including environmental chamber, (b) C7 core creep test sample in the loading train with grip, thermal couples, and LVDTs, (c) Close look of the environmental chamber, where grip is located outside the chamber.

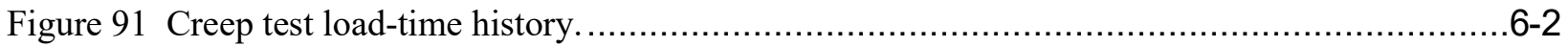

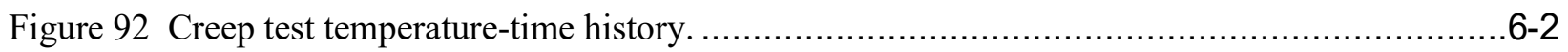

Figure 93 Creep test displacement-time history. ........................................................... $6-2$

Figure 94 Creep test strain-time history at $180^{\circ} \mathrm{C}, 26$-inch long $\mathrm{C} 7$ core sample with 4-inch gage length. The estimated creep strain rate is $-3 \mathrm{E}-05 \% /$ hour.

Figure 95 Creep test strain-time history at $225^{\circ} \mathrm{C}$, 26-inch long $\mathrm{C} 7$ core sample with 4-inch gage length. The estimated creep strain rate is $3 \mathrm{E}-05 \%$ /hour.

Figure 96 General layout of CIRFT tester used for C7 core wires vibration fatigue testing................6-5

Figure $97 \mathrm{C} 7$ core wires vibration fatigue CIRFT testing results. 



\section{LIST OF TABLES}

Table 1 Thermoplastic Polymer Characteristics, used in Composite. [6] ............................................2-1

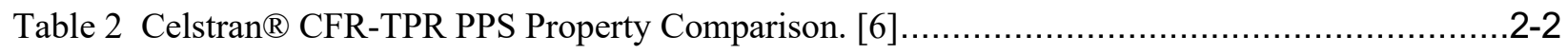

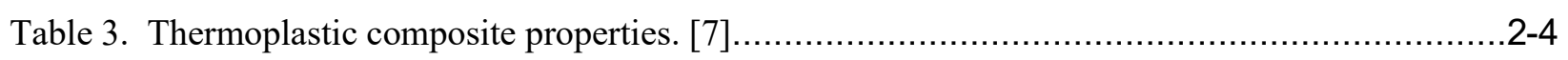

Table 4. Fortron ${ }^{\circledR}$ PPS carbon fiber composite properties - Thermo-Lite ${ }^{\circledR} 4268$ P. [7] ....................2-4

Table 5. C7 Overhead Conductor Technical Specifications. [8] .......................................... $2-5$

Table 6 Temperature profile of $\mathrm{C} 7$ core sample tensile testing ....................................... $5-17$

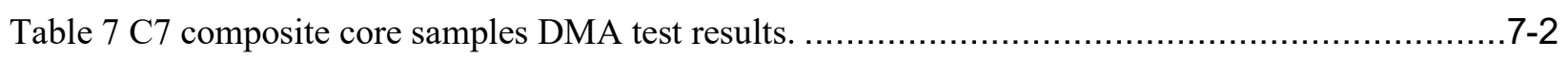

Table 8 C7 composite core samples TMA test results...................................................

Table 9 C7 composite core samples 3 -point bending test results ......................................... $7-3$

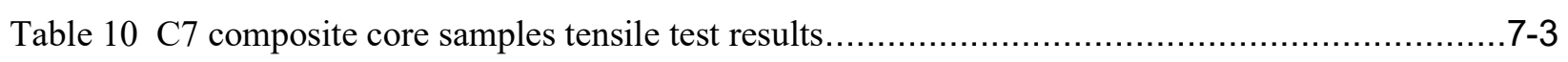




\section{INTRODUCTION}

To avoid the environmental, regulatory and high costs challenges of building new lines to meet the power demand, utilities are searching for ways to increase power transmission capacity on existing lines and thereby. This could involve upgrading the network lines with conductors capable of transmitting greater capacity. In recent years, conductor manufacturers have begun producing new conductors that can operate at higher temperatures without violating present electrical clearances to ground and other objects. One new conductor technology, C7 aluminum conductor, its core is made of carbon fibers with PPS polymer matrix and PEEK capping layer composite, manufactured by Southwire Inc. The C7 conductor composite core materials have not been used previously for overhead lines. Some preliminary background on this C7 composite core conductor provided by Southwire and Composite manufacturer are discussed in this section.

\subsection{Background}

To increase power transmission capacity on existing lines, one approach would involve upgrading the transfer capacity through reconductoring of selected network lines with conductors capable of transmitting greater capacity. This approach can only be adopted if the long-term durability of the constituent equipment can be demonstrated. If the new conductors are used, the maximum operating temperature of overhead lines (Joule effect losses), which is currently around $70-90^{\circ} \mathrm{C}$ in ambient air, would then rise above $100^{\circ} \mathrm{C}$, and could exceed $180^{\circ} \mathrm{C}$. Where Southwire's C7 Overhead Conductor is one of such advanced conductors, as shown in Figure 1.

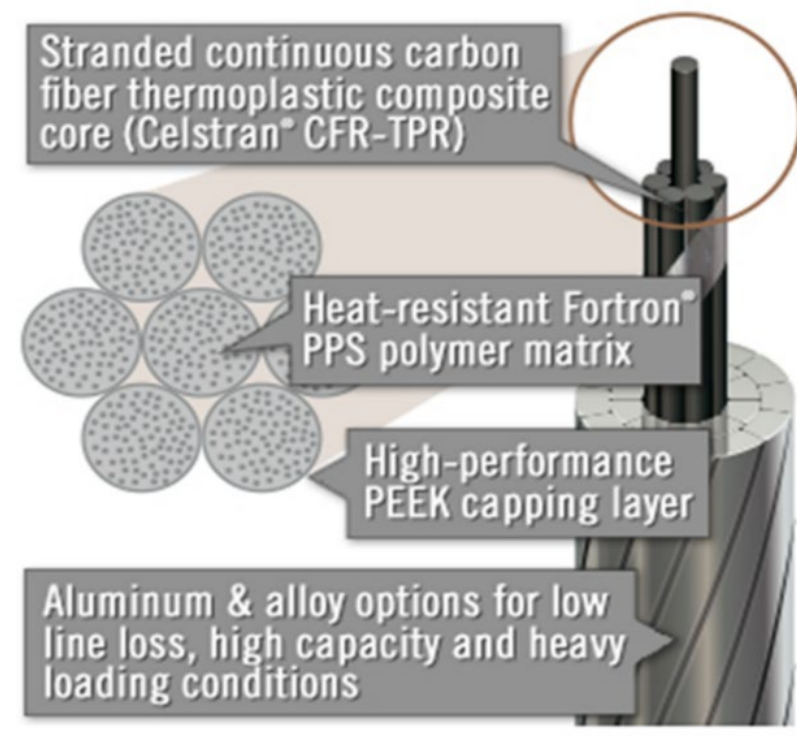

Figure 1 Southwire C7 Composite-core Conductor. [1] 
This Southwire's newest transmission conductor is the result of a partnership with Celanese Corporation - engineers of advanced polymers, resins and thermoplastics. The C7 Overhead Conductor uses Celanese Celstran ${ }^{\circledR}$ CFR-TPR (continuous fiber reinforced thermoplastic strands) composite technology that involves an innovative combination of carbon fiber and a high-temperature Fortron ${ }^{\circledR}$ PPS (polyphenylene sulfide) matrix that is capped with a layer of high-performance PEEK (polyether ether ketone). C7 Overhead Conductor, shown in Figure 1, features a multi-stranded, carbon-fiber composite core. Southwire has claimed that its advanced core and polymer coating provides $\mathrm{C} 7$ Overhead Conductor with high heat resistance and a target 40+ year service life expectancy. [2] Furthermore, regarding C7 overhead conductor performance and installation the vendor also stated that " $\mathrm{C} 7$ Overhead Conductor is engineered to withstand the rigors of installation and operation as stated below:

"Utility providers can reduce new-line costs by installing with standard line tools on existing structures and foundations. Reconductoring is also more affordable, as C7 Overhead Conductor has nearly double the capacity with less sag than same-diameter ACSR.”

The expected good performance of $\mathrm{C} 7$ Overhead Conductor primarily relies on the advanced carbon composite core mechanical performance per vendor's specifications. Nevertheless, the application of the conventional crimping process for building the splice connector of $\mathrm{C} 7$ carbon composite core may need a closer examination to ensure its long-term reliability under lateral compressive clapping stresses.

The purpose of the proposed project is to develop a qualification testing protocol that can effectively evaluate the $\mathrm{C} 7$ Overhead Conductor carbon composite core integrity and reliability at the targeted service environments or beyond.

\subsection{General Consideration of Thermoplastic Polymers Characterizations}

In addition to first-order phase transitions such as melting and vaporization, there are secondorder transitions that occur in certain materials. One of these second-order transitions is the glass transition exhibited by amorphous materials. When amorphous materials are cooled below their glass transition temperatures, they become hard and brittle, like glass; when the amorphous materials are heated above their glass transition temperatures, they are in the rubbery state, where they are soft and flexible.

This glass transition phenomenon is mainly because the molecular chains become entangled and cannot slip pass each other at low temperatures. The temperature at which the molecular chains become 'locked' upon cooling or 'released' upon heating is referred to as the glass transition temperature $(\mathrm{Tg})$.

Rheological testing of thermoplastic materials can be performed on both solid samples and melts. This is important because the choice of material form and physical state is more than a matter of convenience. Where product performance issues usually are related to solid samples properties and process ability issues can be correlated with polymer melt properties. Mechanical spectroscopy is the study of time-dependent responses of stress or strain to various external timedependent mechanical perturbations. [3] Thermoplastic solids, such as PPS and PEEK, are tested using mechanical spectroscopy to study polymer morphology and structure and relate these to end-use performance. Accurate solid-state measurements of the material's Tg, modulus (G') and 
damping $(\tan \delta)$ are used to predict practical use temperatures, impact properties, energy dissipation, stiffness and many other performance properties.

Physically, the Tg is the point at which polymer chains gain enough energy in order to substantially increase their mobility within the polymer matrix and this is reflected in a sharp change in material flexibility and an increase in the sample's heat capacity. The Tg is a key property of thermoplastic systems and often defines the temperature range in which the thermoplastic materials may be used. Parameters that will affect the Tg of a thermoplastic system include the polymer resin and hardener chemical structure, degree of cure, and moisture content. Understanding the glass transition temperature can therefore be critical for determining material suitability for specific applications.

One of the most common methods for measuring a polymer's Tg is by Differential Scanning Calorimetry (DSC), in which the changes in heat capacity through the Tg result in a sigmoidal change in the heat flow signal indicating that a glass transition has occurred. However, this technique often lacks the sensitivity to adequately identify the glass transition temperature, and in some cases may conclude that a material has no glass transition temperature at all. It can also be confounded in complex systems by other thermal transitions occurring in the material.

\subsubsection{Dynamic Mechanical Analysis}

An alternative common method for measuring Tg is by Dynamic Mechanical Analysis (DMA). In this test, the sample is subjected to an oscillatory stress, and the material response is measured. The nature of this response may be used to determine the elastic and viscous properties of the material (storage modulus and loss modulus, respectively), and this can be very sensitive to $\mathrm{Tg}$ as the material rapidly becomes more flexible at the transition temperature. A third parameter, tangent delta is defined as the ratio between the loss modulus and the storage modulus and represents the relative contribution of the viscous vs. elastic properties. During a DMA experiment, the sample temperature is slowly scanned, and the storage modulus, loss modulus, and tan delta are continuously measured. At the glass transition temperature, the storage modulus is observed to decrease sharply, and a peak is observed in both the loss modulus and tan delta signals. Thus, DMA testing is considered the most sensitive method for measuring the glass transition and secondary transitions of polymers. Moreover, rheological properties can be measured continuously as the material undergoes temperature-induced changes from amorphous to crystalline; solid to molten and vice versa.

Figure 2 shows a DMA trace on freshly molded samples and companion pieces annealed under vacuum for eight hours at $180^{\circ} \mathrm{C}$. The storage modulus $\mathrm{G}^{\prime}$ and $\tan \delta$ were measured at a frequency of $1 \mathrm{~Hz}$ and a strain of $0.07 \%$ at temperatures from $120^{\circ} \mathrm{C}$ to $130^{\circ} \mathrm{C}$. Clear differences were found between the annealed and unannealed samples near the main glass transition: the sample with residual strains had a higher $\tan \delta$ over a wide range of temperatures below the glass transition temperature Tg. This relates to the relaxation of the backbone conformations of the oriented styrene-acrylonitrile component in the continuous phase. [3] 


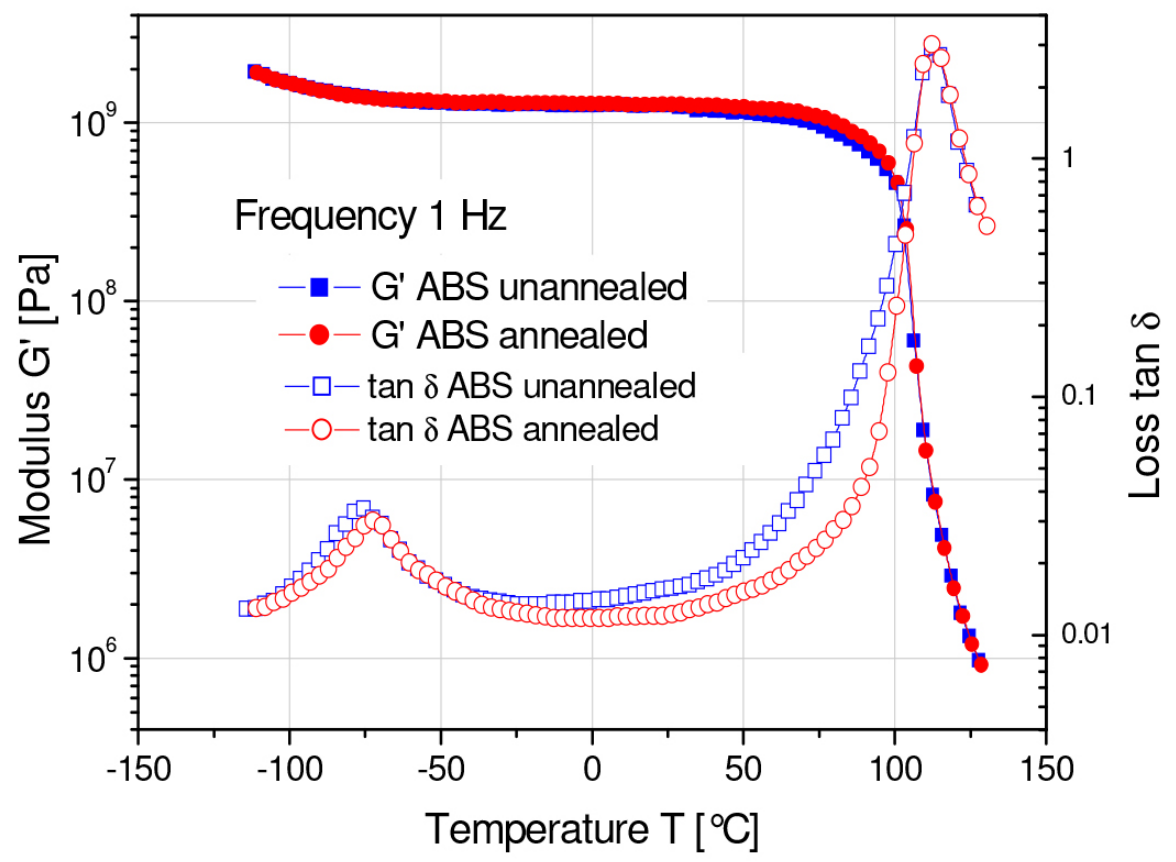

Figure 2. Effect of annealing on loss tangent of an injection molded ABS part. [3]

A quick overview on the rheological properties evolution is provided in Figure 3. [4] Moving from very low temperature, where the molecule is tightly compressed, to a higher temperature, the first changes are the solid-state transitions. This process is shown in Figure 3. As the material warms and expands, the free volume increases so that localized bond movements (bending and stretching) and side chain movements can occur. This is the gamma transition, $\mathrm{T} \gamma$, which may also involve associations with water. As the temperature and the free volume continue to increase, the whole side chains and localized groups of 4-8 backbone atoms begin to have enough space to move and the material starts to develop some toughness. 8 This transition, called the beta transition $T_{\beta}$, is not as clearly defined as described here. Often it is the Tg of a secondary component in a blend or of a specific block in a block copolymer. However, a correlation with toughness is seen empirically. As heating continues, the Tg, or glass transition, appears when the chains in the amorphous regions begin to coordinate large-scale motions. One classical description of this region is that the amorphous regions have begun to melt. Since the Tg only occurs in an amorphous material, in a 100\% crystalline material there would not be a Tg. Continued heating drives the material through the $\mathrm{T}_{\alpha}{ }^{*}$ and $\mathrm{T}_{11}$. The former occurs in crystalline or semi-crystalline polymer and is a slippage of the crystallites past each other. The latter is a movement of coordinated segments in the amorphous phase that relates to reduced viscosity. These two transitions are not universally accepted. Finally, the melt is reached where large-scale chain slippage occurs and the material flows. This is the melting temperature, Tm. For a cured thermoset, nothing happens after the Tg until the sample begins to burn and degrade because the crosslinks prevent the chains from slipping past each other. 


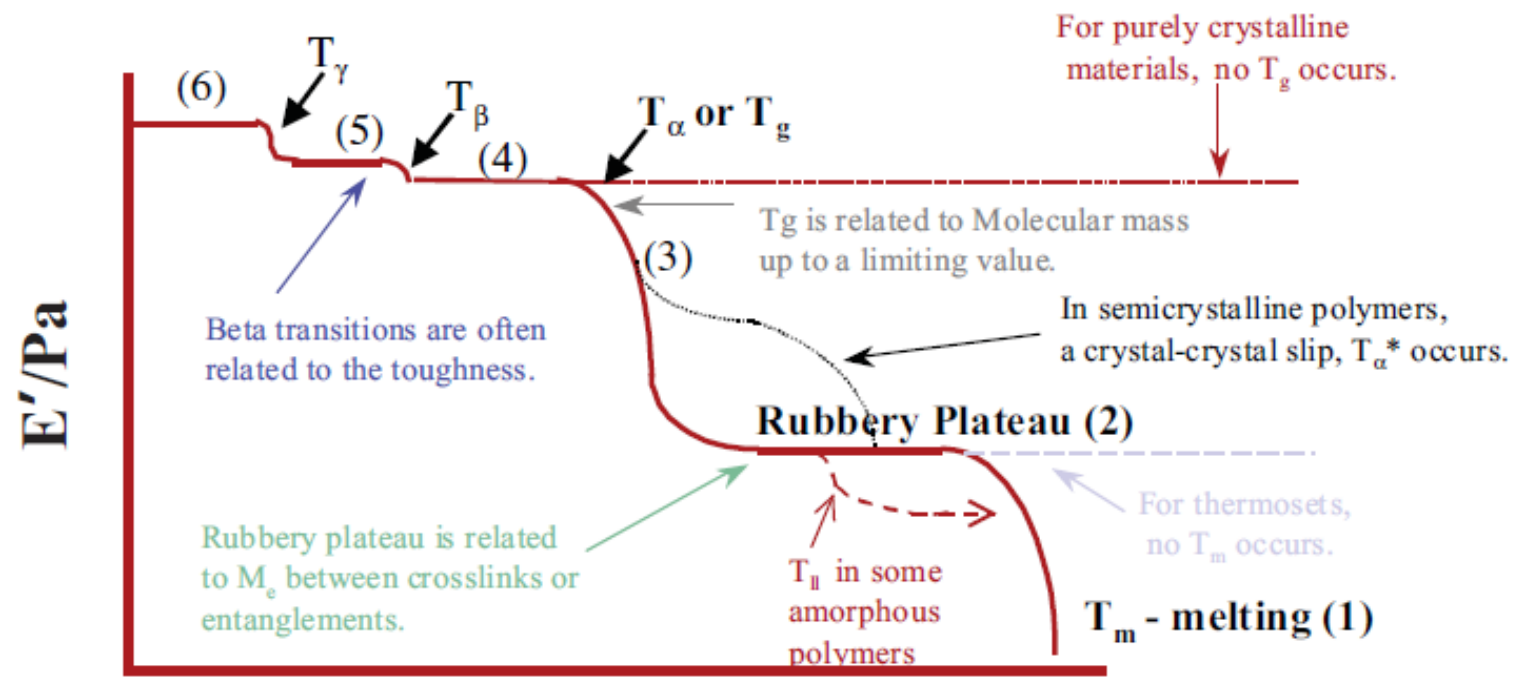

Temperature /K

(6) local bend motions and stretch
(4)

side groups
(3) gradual large main scale chain chain
(2)

(1)

chain

slippage

Figure 3. An idealized DMA scan showing types of transitions seen in the DMA 8000. [4]

\subsubsection{Thermomechanical Analysis}

Thermomechanical Analysis (TMA) is one of the most basic tools of material science that can also be used to assist thermoplastic material characterization. [5] The basis of TMA is the change in the dimensions of a sample as a function of temperature. TMA measurements record changes caused by changes in the free volume of a polymer. Changes in free volume, vf, can be monitored as a volumetric change in the polymer; the loss of stiffness; increased flow; or by the change in relaxation time. The free volume of a polymer, vf, is known to be related to viscoelasticity, aging, penetration by solvents, and impact properties. The Tg in a polymer corresponds to the point in the expansion curve where the free volume begins to allow for greater chain mobility (Figure 4). Seen as an inflection or bend in the thermal expansion curve, this change in the TMA can be seen to cover a range of temperatures, for which the Tg temperature is a somewhat arbitrary indicator calculated by an agreed upon method (Figure 5). This fact seems to be not appreciated by inexperienced users, who often worry why perfect agreement isn't seen in the value of the Tg when comparing different thermal methods. The width of the Tg region can be as important an indicator of changes in the material as the actual temperature.

Experimentally, TMA consists of an analytical train that allows precise measurements of position and can be calibrated against known standards. A temperature control system of a furnace, heat sink and temperature measuring device (most commonly a thermocouple) couples to the sample. Fixtures to hold the sample during the run are normally made of quartz because of its low CTE, although ceramics and invar steels may also be used. Fixtures are commercially available for expansion, three-point bending or flexure, parallel plate, and penetration tests. 

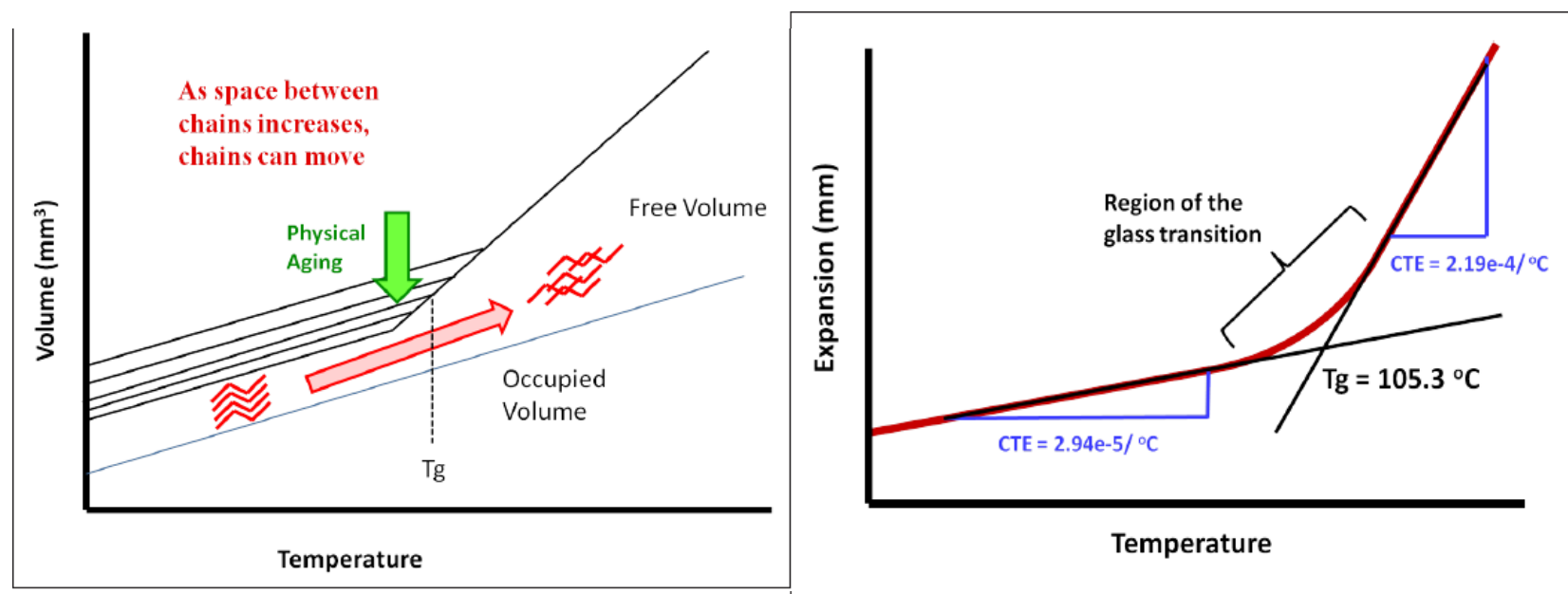

Figure 4. The increase in free volume is caused by increased energy absorbed in the chains, and this increased free volume permits the various types of chain movement to occur. Below the Tg various paths with different free volumes exist depending on heat history and processing of the polymer, where the path with the least free volume is the most relaxed.

Figure 5. The glass transition and CTE of polystyrene is shown. The slopes of the baseline are used to calculate the CTE. The Tg is a region of between 90 and $110^{\circ} \mathrm{C}$, for which a Tg temperature is calculated as shown. [5]

\subsubsection{Thermogravimetric analysis}

Thermogravimetric analysis (TGA) is one of the members of the family of thermal analysis techniques used to characterize a wide variety of materials. TGA provides complimentary and supplementary characterization information to the most commonly used thermal technique, DSC.

TGA measures the amount and rate of change in the mass of a sample as a function of temperature or time in a controlled atmosphere. The measurements are used primarily to determine the thermal and/or oxidative stabilities of materials as well as their compositional properties. The technique can analyze materials that exhibit either mass loss or gain due to decomposition, oxidation or loss of volatiles (such as moisture). It is especially useful for the study of polymeric materials, including thermoplastics, thermosets, elastomers, composites, films, fibers, coatings and paints w.r.t. (1) compositional analysis of multi-component materials or blends, (2) thermal stabilities, (3) oxidative stabilities, (4) estimation of product lifetimes, and (5) decomposition kinetics. 


\subsection{Proposed Research Objectives}

To develop a qualification testing protocol for the carbon composite core at targeted service environments is the primary objective of this project. The work covers the design of the carbon core qualification testing protocol and the follow-on validation testing to support the proposed testing protocols. The research will include the following approaches: initial characterization, performance of thermal aging, characterization of the aged material, comparison of aged properties or characteristics to the original, and concluding by developing acceptance criteria. Due to composite nature of $\mathrm{C} 7$ carbon composite core, the interface shear behavior at PEEK and PPS matrix boundary plays a critical role in overall $\mathrm{C} 7$ core performance. This would limit our options of selecting C7 core sample dimension/geometry to ensure such composite system performance can be effectively characterized from the elected tested sample, and the associated geometry dependent mechanical testing. Thus, the single C7 core wire consisted both PEEK capping layer and PPS matrix with system diameter of 3.45-mm was elected to be the sample profile used in the following analyses and program development. The $\mathrm{C} 7$ core system bonding shear stress effect at interface of PEEK layer and PPS matrix can be effectively characterized through a 3-point bending flexural testing on the C7 core test sample configuration. Thus, 3point bending test was elected as one of the primary mechanical testing protocols used for characterizing the $\mathrm{C} 7$ composite core performance under the targeted service environments.

\subsection{Proposed Research Tasks Descriptions}

\section{Task 1. Review and Evaluate Existing Polyphenylene sulfide (PPS) Polymer and PolyEtherEther Ketone (PEEK) Properties}

In this task, ORNL will review and summarize the various mechanical and chemical properties of carbon composite related to composite core used for Southwire C7 Overhead Conductor. The study shall cover high-temperature performance of the resins (PPS and PEEK) used in composite.

\section{Task 2. Develop Test Protocols to Validate C7 Conductor Carbon Composite Core Performance}

ORNL will develop testing protocols for C7 Overhead Conductor composite core material under targeted temperatures and loading conditions to determine whether the composite core materials can meet its performance requirements. ORNL will identify appropriate material mechanical property in the pilot program development, including time-dependent mechanical properties for C7 Conductor composite core.

The following subjects will be investigated.

a) Stability of the material in service conditions (heat) - study of the thermal degradation (chemical changes in the composite)

b) Impact of the aging phenomenon on the long-term behavior - evaluation of the effect of the chemical change on the long-term mechanical behavior 
c) Impact of the thermal cycling (operation temperatures) and prediction of the service life expectancy.

The proposed approaches for developing testing protocols are detailed below.

1) Sample design and preparation, including a mold for forming the rectangular $\mathrm{C} 7$ carbon composite sample for Dynamic Mechanical Analysis (DMA), Thermogravimetric Analysis (TGA), and Thermal-mechanical Analysis (TMA) testing, and test fixtures design \& manufacturing for the specific mechanical testing.

2) Initial characterization - knowledge of the resin, type of the resin, and ratio of matrixfiber, etc. will also examine specimen design for the specific testing.

3) Performing thermal aging

- Carbon composite core $10 \mathrm{~mm}$ long in TGA apparatus for 100 hours at $100^{\circ} \mathrm{C}$

- Samples $100 \mathrm{~mm}$ long in an oven in the air;

\begin{tabular}{|c|c|}
\hline Temp stability & Temp max \\
\hline 500 hours & 100 hours \\
\hline
\end{tabular}

4) Thermal aging characterization:

From sample aged in TGA apparatus with sample dimension of $10 \mathrm{~mm}$ long

\begin{tabular}{|l|l|l|}
\hline Techniques & \multicolumn{1}{|c|}{ Characteristics } & Number and type of samples \\
\hline TGA & $\begin{array}{l}\text { Loss of weight versus } \\
\text { time at } 100,180,225^{\circ} \mathrm{C}\end{array}$ & 3 samples $(\mathrm{C} 7$ core $10 \mathrm{~mm}$ long) \\
\hline DMA & $\begin{array}{l}\text { Tg (Storage, Loss } \\
\text { modulus, and damping } \\
\text { coefficient) }\end{array}$ & $\begin{array}{l}3 \text { samples: rectangular or circular } \\
\text { rod machined from carbon core }\end{array}$ \\
\hline
\end{tabular}

For samples aged in oven under air is described below.

\begin{tabular}{|l|l|l|}
\hline \multicolumn{1}{|c|}{ Techniques } & \multicolumn{1}{|c|}{ Characteristics } & \multicolumn{1}{c|}{ Number and type of samples } \\
\hline $\begin{array}{l}\text { Microscopy } \\
\text { analysis }\end{array}$ & $\begin{array}{l}\text { Presence of cracks } \\
\text { Homogeneity of the material }\end{array}$ & $\begin{array}{l}\text { 3 samples of } 100 \mathrm{~mm} \text { long coming out } \\
\text { of aging program + new one. } \\
\text { Surface polished and then checked }\end{array}$ \\
\hline $\begin{array}{l}\text { 3-point flexural } \\
\text { ASTM D790 }\end{array}$ & $\begin{array}{l}\text { Maximum load \& sag of the } \\
\text { sample during the test }\end{array}$ & $\begin{array}{l}\text { 3 samples of } 100 \mathrm{~mm} \text { long per time- } \\
\text { temperature }\end{array}$ \\
\hline
\end{tabular}

5) Qualification criteria - Glass Transition Temperature (Tg), mechanical tensile test, 3point bending test, and creep testing. 


\section{Task 3: Establish Acceptance Criteria}

ORNL will establish initial acceptance criteria and final validation of the developed criteria from the developed testing database.

\section{Task 4: Attend Semi-Annual Task Force Meetings and Conference Calls}

ORNL will present the results at various stages of the study to EPRI members at project review meetings and participate in conference calls as required. 



\section{PRELIMINARY CHARACTERIZATION OF C7 CONDUCTOR CARBON COMPOSITE CORE}

The key benefits and characteristics of C7 overhead conductor discussed in Southwire C7 Overhead Conductor Innovation [1] are the followings:

- Minimal thermal expansion - minimal sag increase at high power transfer

- Stranded core - no single point of failure

- Flexible - robust, installs like a traditional conductor

- Less sag - for lines with clearance or structure limitations

- Thermoplastic resins - long usage history in demanding applications with established hightemperature performance $\left(180-225^{\circ} \mathrm{C}\right)$

- Conventional connectors - traditional two-piece compression, crew friendly

- Designs for all loading conditions - light loading to extreme ice loading

- Trapezoidal wire (TW), Zirconium Aluminum ( $\mathrm{Zr}-\mathrm{Al}$ ) and O-temper versions

Those key advantages mentioned above were further examined and validated through the proposed testing protocols. The detailed properties of PPS and PEEK polymer, and C7 carbon composite provided by the vendors are discussed in this section

\subsection{C7 overhead conductor system components technical specifications}

A thermoplastic, such as PPS or PEEK, is a plastic material, a polymer, that becomes pliable or moldable above a specific temperature and solidifies upon cooling. Most thermoplastics have a high molecular weight. The polymer chains associate through intermolecular forces, which weaken rapidly with increased temperature, yielding a viscous liquid. Thus, thermoplastics may be reshaped by heating and are typically used to produce parts by various polymer processing techniques. Thermoplastics differ from thermosetting polymers, such as epoxy, which form irreversible chemical bonds during the curing process. Thermosets do not melt when heated: they decompose and do not reform upon cooling. Table 1 and Figure 6 show thermal key points of thermoplastic of polymer, including PPS and PEEK polymers.

Table 1 Thermoplastic Polymer Characteristics, used in Composite. [6]

\begin{tabular}{|l|c|c|l|}
\hline Polymer & $\mathbf{T g}$ & Process Temperature & \multicolumn{1}{|c|}{ Morphology } \\
\hline PEEK & $143^{\circ} \mathrm{C}$ & $380-395^{\circ} \mathrm{C}$ & Semi-Crystalline \\
\hline PPS & $89^{\circ} \mathrm{C}$ & $290-325^{\circ} \mathrm{C}$ & Semi-Crystalline \\
\hline PEI & $217^{\circ} \mathrm{C}$ & $300-330^{\circ} \mathrm{C}$ & Amorphous \\
\hline PEKK & $156^{\circ} \mathrm{C}$ & $340-365^{\circ} \mathrm{C}$ & Semi-Crystalline \\
\hline Nylon-6 & $47^{\circ} \mathrm{C}$ & $210-230^{\circ} \mathrm{C}$ & Semi-Crystalline \\
\hline Nylon-11 & $42^{\circ} \mathrm{C}$ & $180-205^{\circ} \mathrm{C}$ & Semi-Crystalline \\
\hline
\end{tabular}


Figure 6 shows that the Tg for PPS and PEEK are $89^{\circ} \mathrm{C}$ and $143^{\circ} \mathrm{C}$, respectively; and the melting temperature (Tm) for PPS and PEEK are $275^{\circ} \mathrm{C}$ and $335^{\circ} \mathrm{C}$, respectively. The modulus thermal aging history also indicates that semi-crystalline thermoplastic, such as PPS and PEEK have different aging characteristic compared to amorphous thermoplastic polymers.
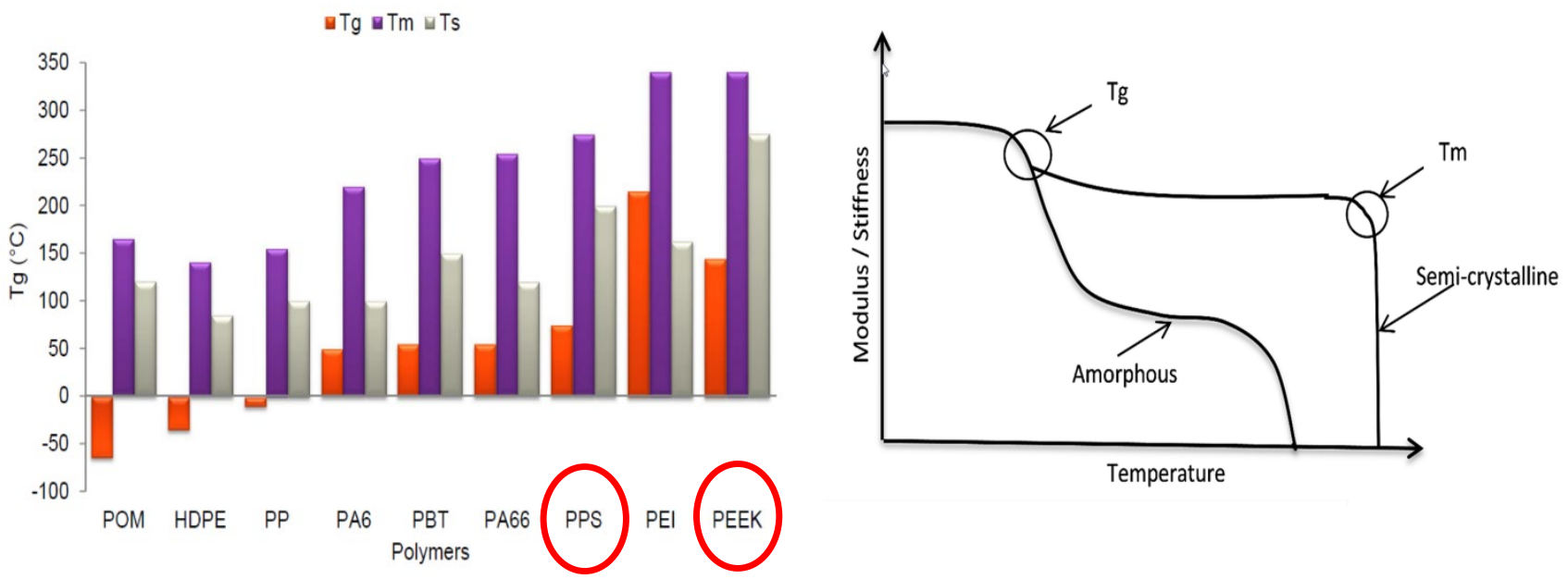

Figure 6 (Left) Thermal key points of different thermoplastic polymers, (Right) the schematic diagram illustrated the determination of $\mathrm{Tg}$ and $\mathrm{Tm}$ from DMA test for semicrystalline materials, such as PPS and PEEK polymers. [6]

Table 2 show thermoplastic polymer composite reinforced with carbon fiber, where PPS-CF45 and PPS-CF5 1 are similar to that of $\mathrm{C} 7$ composite core materials, with $\mathrm{CF}$ volumes at $37 \%$ and $43 \%$, respectively. It is noted that C 7 composite core extension of $2 \%$ total strain was reached before failure. The elevated tensile and thermal aging properties of the uncapped PPS and PEEK polymers carbon composites are shown in Figures 7-8.

Table 2 Celstran® CFR-TPR PPS Property Comparison. [6]

\begin{tabular}{|c|c|c|c|c|c|c|c|c|}
\hline & \multicolumn{2}{|c|}{ PPS-CF50 } & \multicolumn{2}{|c|}{ PPS-CF45 } & \multicolumn{2}{|c|}{ PPS-CF60 } & \multicolumn{2}{|c|}{ PPS-CF51 } \\
\hline $\begin{array}{l}\text { Capping Thickness } \\
(\mathrm{mm})\end{array}$ & \multicolumn{2}{|c|}{0.0} & \multicolumn{2}{|c|}{0.15} & \multicolumn{2}{|c|}{0.0} & \multicolumn{2}{|c|}{0.15} \\
\hline $\begin{array}{l}\text { Diameter } \\
(\mathrm{mm})\end{array}$ & \multicolumn{2}{|c|}{3.18} & \multicolumn{2}{|c|}{3.48} & \multicolumn{2}{|c|}{3.18} & \multicolumn{2}{|c|}{3.48} \\
\hline $\begin{array}{l}\text { CF Volume } \\
\%\end{array}$ & \multicolumn{2}{|c|}{$43 \%$} & \multicolumn{2}{|c|}{$37 \%$} & \multicolumn{2}{|c|}{$51 \%$} & \multicolumn{2}{|c|}{$43 \%$} \\
\hline Tensile Strength & 329 ksi & $2269 \mathrm{MPa}$ & $290 \mathrm{ksi}$ & $2000 \mathrm{MPa}$ & 372 ksi & $2566 \mathrm{MPa}$ & $329 \mathrm{ksi}$ & $2269 \mathrm{MPa}$ \\
\hline Tensile Break Load & $4105 \mathrm{lb}$ & $18670 \mathrm{~N}$ & $4210 \mathrm{lb}$ & $18700 \mathrm{~N}$ & $4490 \mathrm{lb}$ & $19970 \mathrm{~N}$ & $4850 \mathrm{lb}$ & $21570 \mathrm{~N}$ \\
\hline Tensile Modulus & 15.7 Mpsi & $108 \mathrm{GPa}$ & 13.3 Mpsi & $91.7 \mathrm{GPa}$ & 17.1 Mpsi & $118 \mathrm{GPa}$ & 14.4 Mpsi & 99 Gpa \\
\hline Tensile Strain to Fail & \multicolumn{2}{|c|}{$2.07 \%$} & \multicolumn{2}{|c|}{$2.08 \%$} & \multicolumn{2}{|c|}{$2.07 \%$} & \multicolumn{2}{|c|}{$2.19 \%$} \\
\hline Density & $0.055 \mathrm{lb} / \mathrm{in}^{3}$ & $1.53 \mathrm{~g} / \mathrm{cc}$ & $\begin{array}{l}0.0536 \\
\mathrm{lb} / \mathrm{in}^{3}\end{array}$ & $1.48 \mathrm{~g} / \mathrm{cc}$ & $0.0569 \mathrm{lb} / \mathrm{in}^{3}$ & $1.58 \mathrm{~g} / \mathrm{cc}$ & $0.054 \mathrm{lb} / \mathrm{in}^{3}$ & $1.50 \mathrm{~g} / \mathrm{cc}$ \\
\hline Lineal Weight & $123 \mathrm{ft} / \mathrm{lb}$ & 82 m/kg & $108 \mathrm{ft} / \mathrm{lb}$ & $72 \mathrm{~m} / \mathrm{kg}$ & $119 \mathrm{ft} / \mathrm{lb}$ & $80 \mathrm{~m} / \mathrm{kg}$ & $101 \mathrm{ft} / \mathrm{lb}$ & 68 m/kg \\
\hline
\end{tabular}




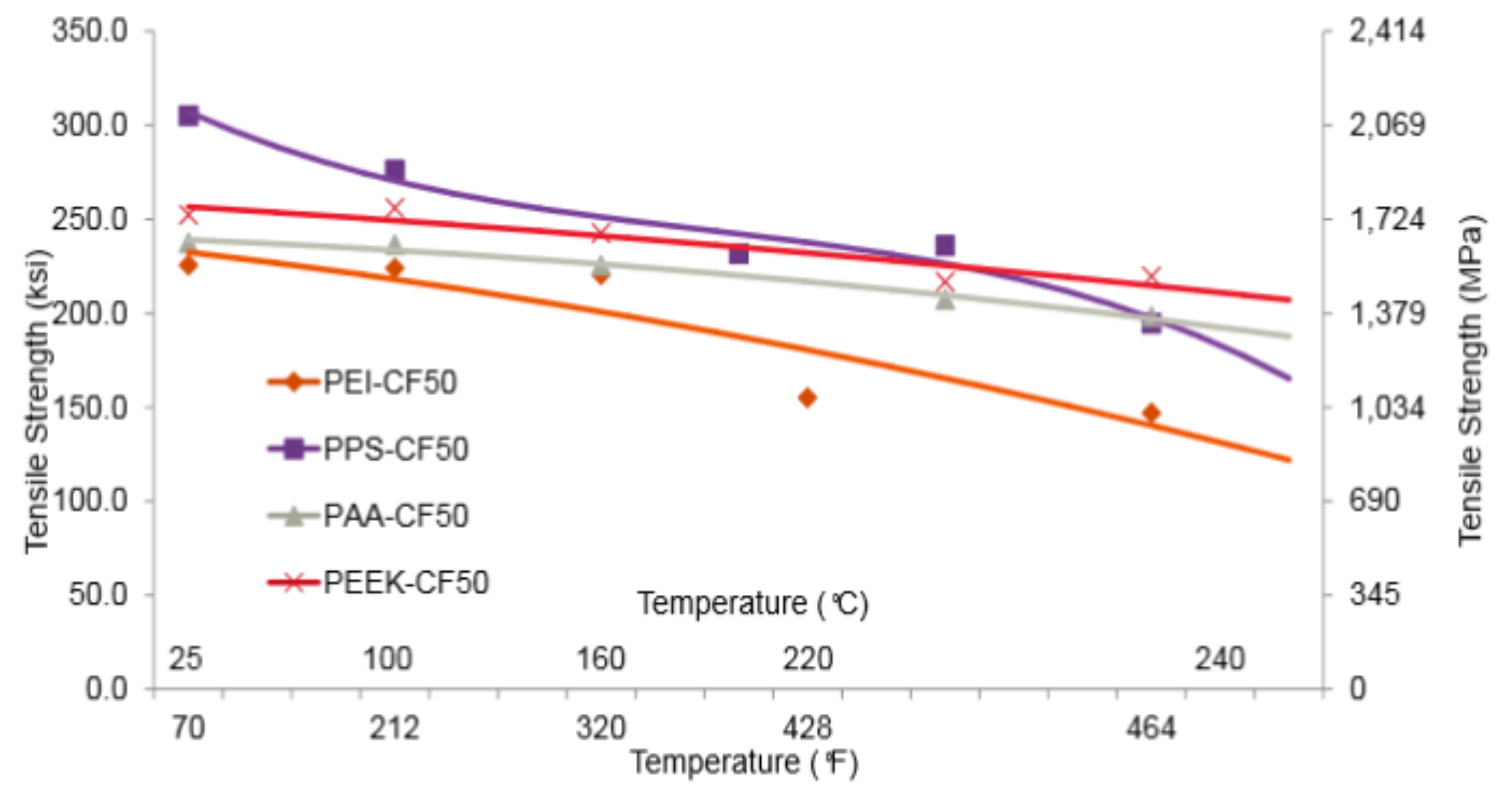

Figure 7 Thermoplastic carbon composite tensile strength at elevated temperature. [6]
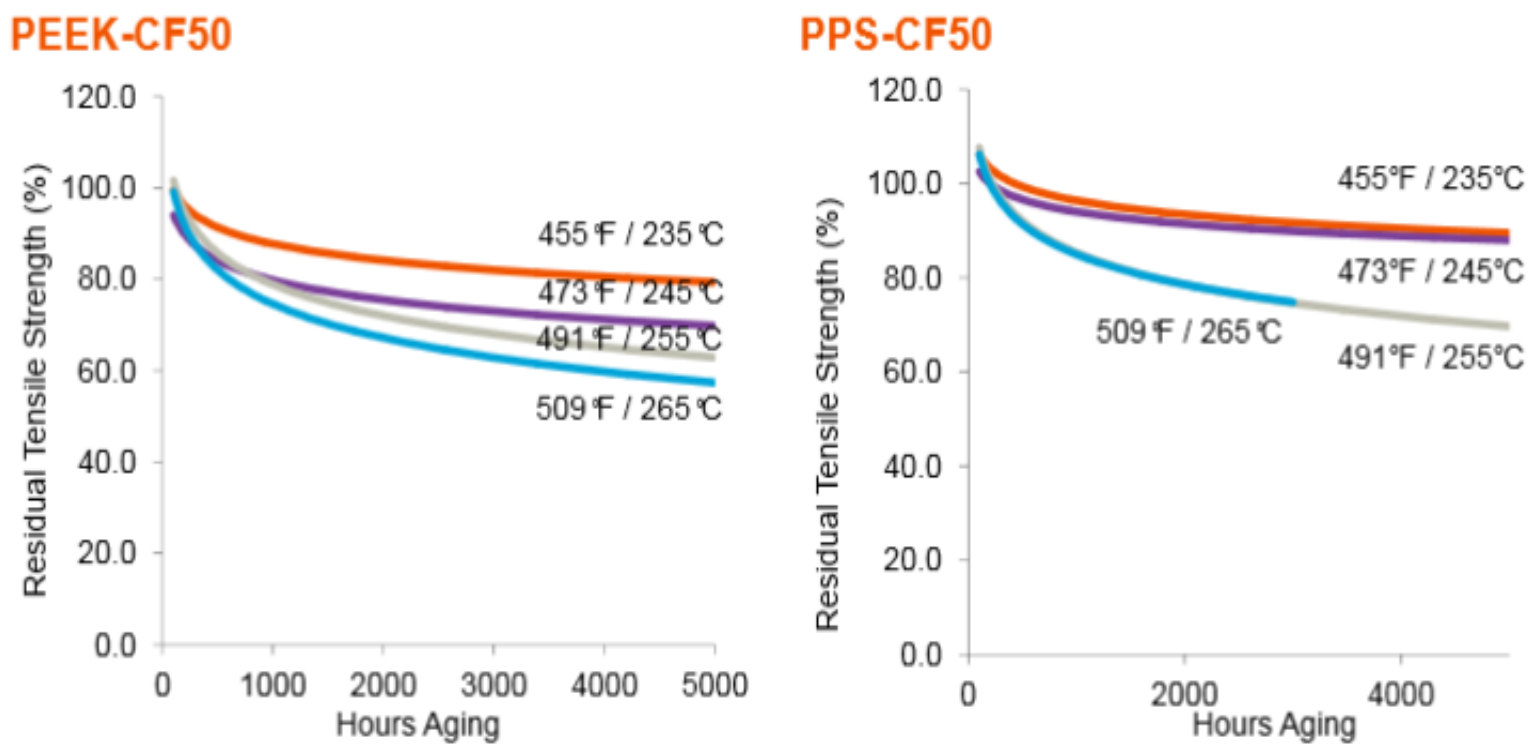

Figure 8 Preconditioned tension strength retention for uncapping PPS and PEEK carbon composites, where the uncapped samples were preconditioned at an elevated temperature for a set period of time and tensile tested to failure. [6]

Figure 8 shows that at operation temperature lower than $255^{\circ} \mathrm{C}$, the uncapped PPS carbon composite has about $10 \%$ reduction in strength due to thermal aging under long-term temperature exposure, up to 4000 hours. 
The thermoplastic composite properties related to Fortron PPC carbon fiber composite are shown in Figs. 9-10, which indicates that high load continuous use temperature for Fortron PPS and PEEK are $85^{\circ}$ and $138^{\circ} \mathrm{C}$, respectively. [7]

Table 3. Thermoplastic composite properties. [7]

\begin{tabular}{|c|c|c|c|c|}
\hline & Tg, ${ }^{\circ} \mathbf{C}$ & $\begin{array}{c}\text { High Load } \\
\text { Continuous use } \\
\text { Temperature, }{ }^{\circ} \mathbf{C}\end{array}$ & $\begin{array}{c}\text { Approx. } \\
\text { Resin Cost, } \\
\mathbf{\$} / \mathbf{l b}\end{array}$ & $\begin{array}{c}\text { Approx. Carbon } \\
\text { Reinforced } \\
\text { prepreg Cost, \$/lb }\end{array}$ \\
\hline Fortron PPS & 90 & 85 & 5.00 & 30.00 \\
\hline PEI & 217 & 115 & 10.00 & 45.00 \\
\hline PEEK & 143 & 138 & 60.00 & 90.00 \\
\hline
\end{tabular}

Table 4. Fortron $®$ PPS carbon fiber composite properties - Thermo-Lite $® 4268$. [7]

\begin{tabular}{|l|l|l|l|}
\hline & \multicolumn{3}{|c|}{ Physical Property Data } \\
\hline Fiber Type & AS-4 & Resin Type & PPS \\
\hline Fiber Weight \% & $66 \pm 3$ & Resin Weight \% & $34 \pm 3$ \\
\hline Fiber Volume \% & $59 \pm 3$ & Resin Volume \% & $41 \pm 3$ \\
\hline Fiber Areal Weight & $150 \mathrm{~g} / \mathrm{m}^{2}$ & Total Areal Weight & $227 \mathrm{~g} / \mathrm{m}^{2}$ \\
\hline Density & $0.58 \mathrm{lb} / \mathrm{in}^{3}\left(1.61 \mathrm{~g} / \mathrm{cm}^{3}\right)$ & & \\
\hline Thickness/Ply & $0.0056(0.14 \mathrm{~mm})$ & Tape Width & $12 "(30.5 \mathrm{~cm})$ \\
\hline
\end{tabular}

\begin{tabular}{|l|c|c|}
\hline \multicolumn{3}{|c|}{ Mechanical Property Data } \\
\hline Laminate Property & Fiber Orientation $^{1}$ & Test Data \\
\hline Tensile Strength - Ksi (MPa) & $0^{\circ}$ & $297(2,045)$ \\
\hline Tensile Modulus - Msi (GPa) & $90^{\circ}$ & $7.2(50)$ \\
\hline Compression Strength - Ksi (MPa) & $0^{\circ}$ & $18.5(127)$ \\
\hline Compression Modulus - Msi (GPa) & $90^{\circ}$ & $1.3(8.8)$ \\
\hline Flexural Strength - Ksi (MPa) & $0^{\circ}$ & $162(1,117)$ \\
\hline Flexural Modulus - Msi (GPa) & $0^{\circ}$ & $17.2(118)$ \\
\hline Shear Strength (4 Point) - Ksi (MPa) & $0^{\circ}$ & $243(1,672)$ \\
\hline
\end{tabular}

The detailed technical specification for C7 Overhead Conductor provided by Southwire are outlined in Table 5, including C7 conductor composite system physical dimensions and the associated mechanical properties. Table 3 shows the continuous and contingency ratings of $\mathrm{C} 7$ 
composite core conductor with full annealed conductor strands are 1666 amps @ $180^{\circ} \mathrm{C}$ and

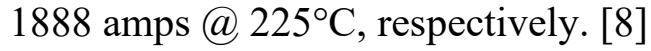

Table 5. C7 Overhead Conductor Technical Specifications. [8]

\begin{tabular}{|c|c|c|c|}
\hline & 795 kcmil 26/7 ACSR/Drake & 995 kcmil T13 ACCR/TW/C7 & 995 kcmil T13 ACCS/TW/C7 \\
\hline \multicolumn{4}{|l|}{ Construction Information } \\
\hline Size & 795 kcmil [402.9 mm2] & 995 kcmil [504.2 mm2] & 995 kcmil [504.2 mm2] \\
\hline Overall Diameter & 1.108 in. [28.14 mm] & 1.108 in. [28.14 mm] & 1.108 in. [28.14 mm] \\
\hline Equivalent Type Number & 16 & 13 & 13 \\
\hline Weight & 1.093 lb./ft. [1.627 kg/m] & 0.996 lb./ft. [1.482 kg/m] & 1.000 lb./ft. $[1.488 \mathrm{~kg} / \mathrm{m}]$ \\
\hline Rated Breaking Strength & $31,500 \mathrm{lb} .[140.1 \mathrm{kN}]$ & 46,000 lb. [204.6 kN] & $35,700 \mathrm{lb} .[158.8 \mathrm{kN}]$ \\
\hline \multicolumn{4}{|l|}{ Outer Strand Information } \\
\hline Material & 1350-H19 Aluminum & Aluminum-Zirconium Alloy & 1350-O Aluminum \\
\hline Conductivity & $61.2 \%$ IACS & $60 \%$ IACS & $63 \%$ IACS \\
\hline Number of Strands & 26 & 20 & 20 \\
\hline \multicolumn{4}{|l|}{ Core Information } \\
\hline Material & GA2 Zinc-Galvanized Steel & Celstran ${ }^{\circledR}$ CFR-TPR & Celstran ${ }^{\circledR}$ CFR-TPR \\
\hline Conductivity & $8 \%$ IACS & $0 \%$ IACS & $0 \%$ IACS \\
\hline Number of Strands & 7 & 7 & 7 \\
\hline Strand Diameter & 0.136 in. [3.45 mm] & 0.136 in. [3.45 mm] & 0.136 in. [3.45 mm] \\
\hline Core Diameter & $0.408 \mathrm{in} .[10.36 \mathrm{~mm}]$ & 0.408 in. $[10.36 \mathrm{~mm}]$ & 0.408 in. $[10.36 \mathrm{~mm}]$ \\
\hline \multicolumn{4}{|l|}{ Electrical Information } \\
\hline DC Resistance @ 20ㄷ & $0.1129 \Omega / \mathrm{mi} .[0.0702 \Omega / \mathrm{km}]$ & $0.0937 \Omega / \mathrm{mi} .[0.0582 \Omega / \mathrm{km}]$ & $0.0892 \Omega / \mathrm{mi} .[0.0554 \Omega / \mathrm{km}]$ \\
\hline Continuous Rating* & 731 amps @75C & 1672 amps @ $180^{\circ} \mathrm{C}$ & 1666 amps @ $180^{\circ} \mathrm{C}$ \\
\hline Contingency Rating* & 993 amps @ 100C & 1903 amps @ 225 ${ }^{\circ} \mathrm{C}$ & 1888 amps @ $225^{\circ} \mathrm{C}$ \\
\hline
\end{tabular}

*Ampacity estimates are for comparison only, and are based on $40^{\circ} \mathrm{C}$ ambient, $2 \mathrm{ft} . / \mathrm{sec}$. wind speed, $90^{\circ}$ wind angle, 95.97 watts $/ \mathrm{ft}^{2}$ 


\subsection{Initial C7 carbon composite core physical examinations}

The microscopy, scanning electron microscope (SEM), and energy dispersive spectroscopy (EDS) examinations of the received C7 carbon composite core samples from EPRI are shown in Figs 9-15. Large variation of carbon fiber distribution with PPS was observed, which shows the inhomogeneous characteristic of $\mathrm{C} 7$ composite core, where the carbon fiber $(\mathrm{CF})$ volume ratio ranges are from $28 \%$ to $51 \%$ from different sections of the $\mathrm{C} 7$ composite core sample.

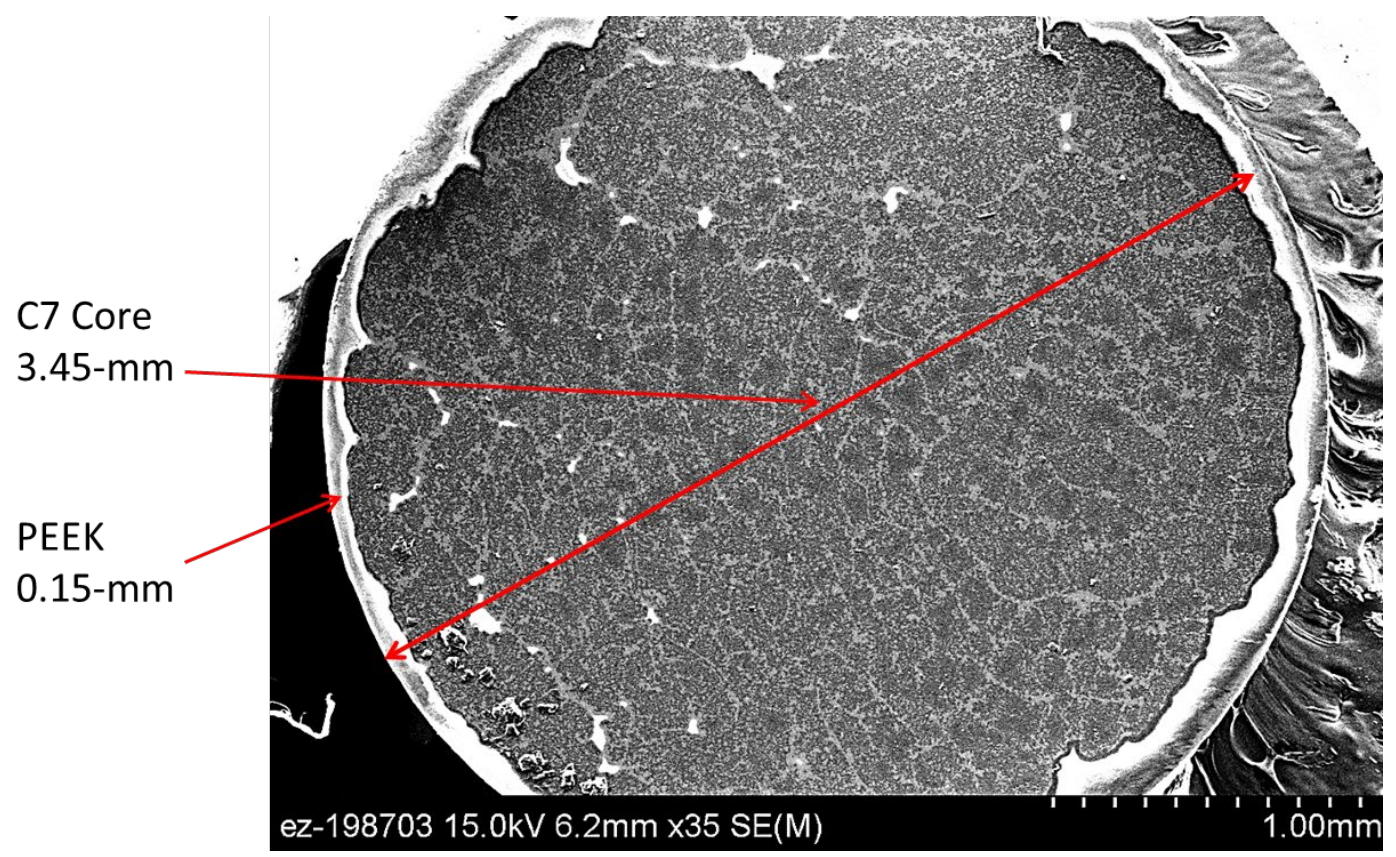

Figure 9 Microscopy image of the cross-section of the received $\mathrm{C} 7$ composite core samples.
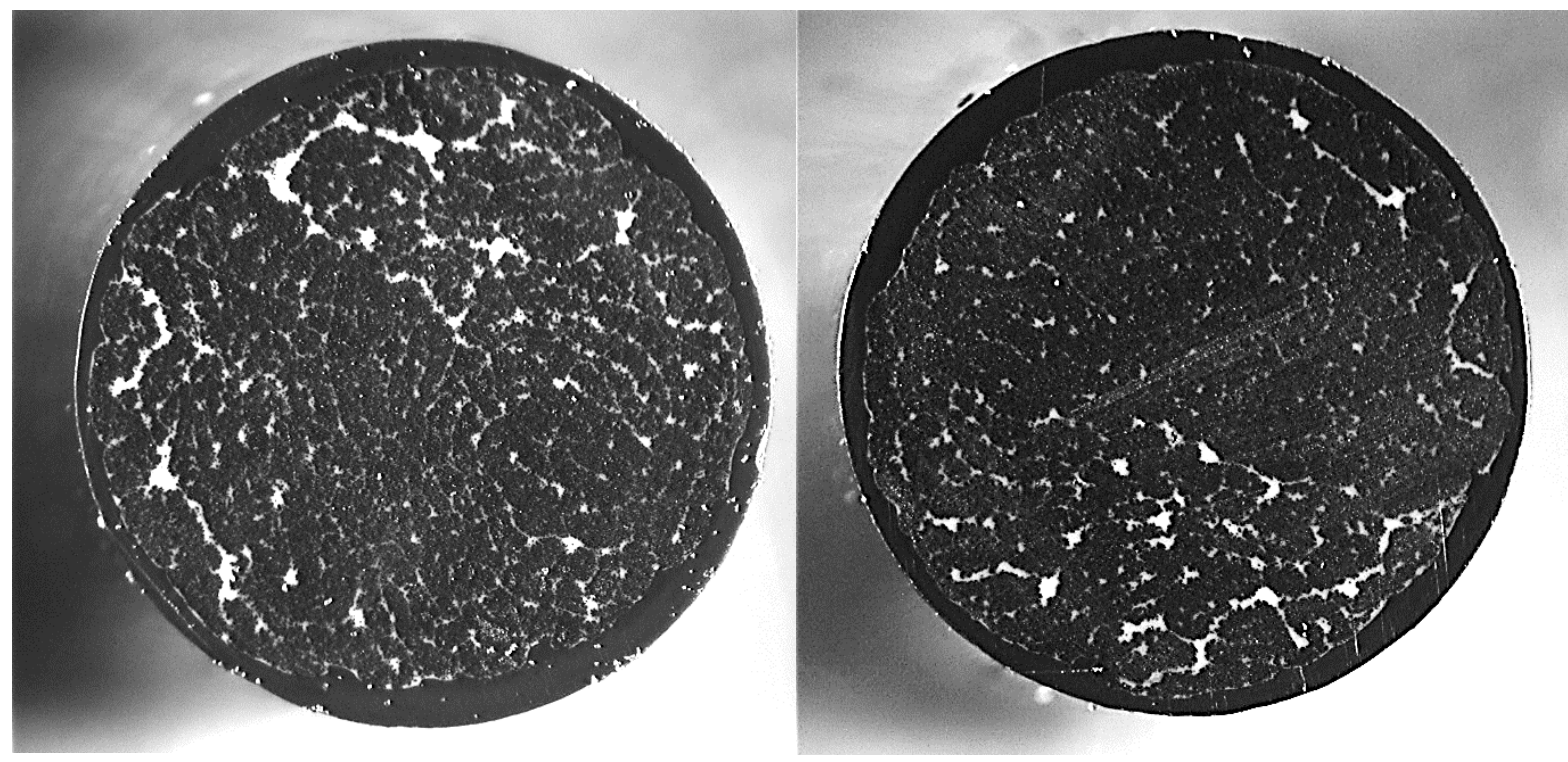

Figure 10 Typical cross-section images of the received $\mathrm{C} 7$ composite core samples. 

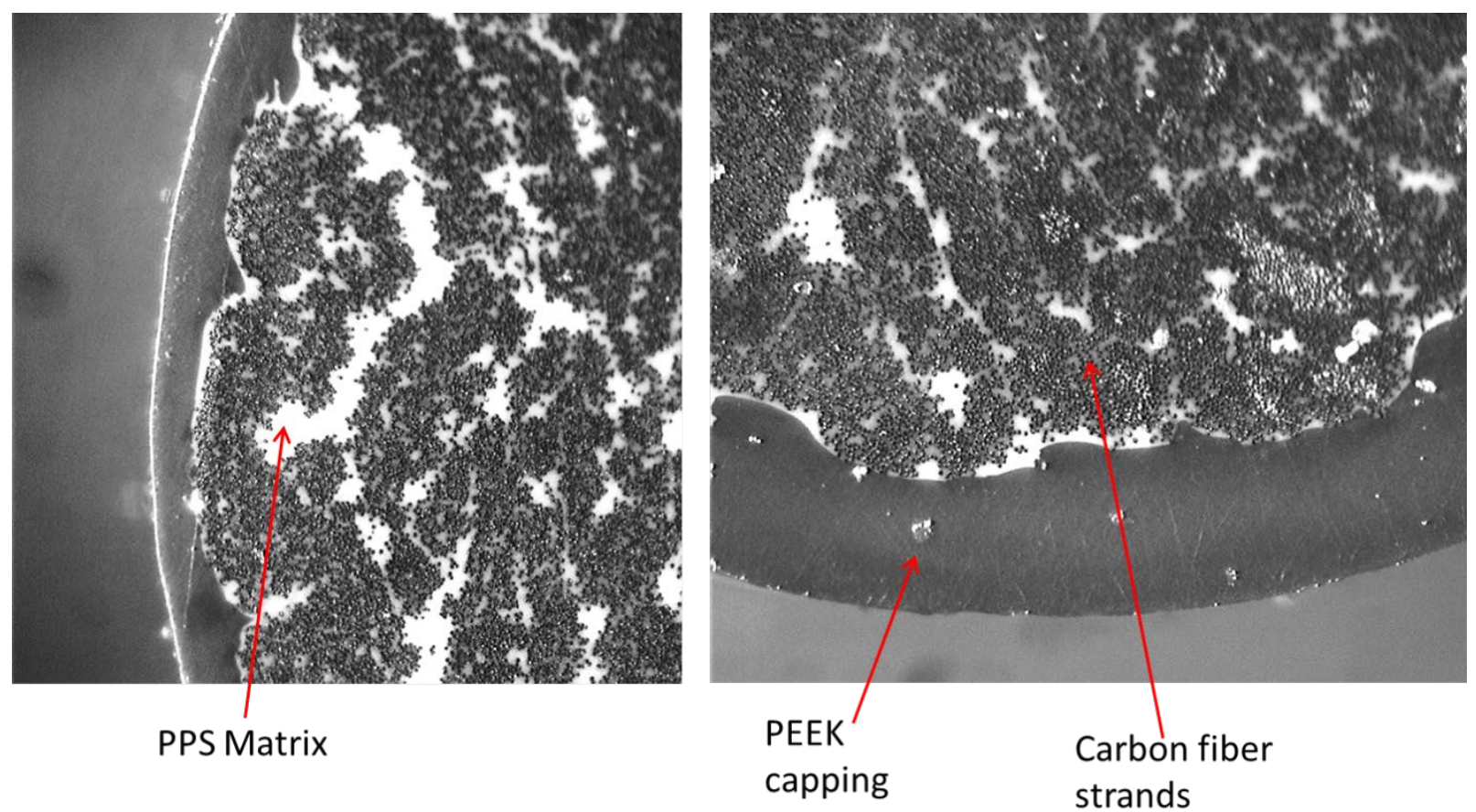

Figure 11 The detailed microscopy images of $\mathrm{C} 7$ carbon composite core samples.
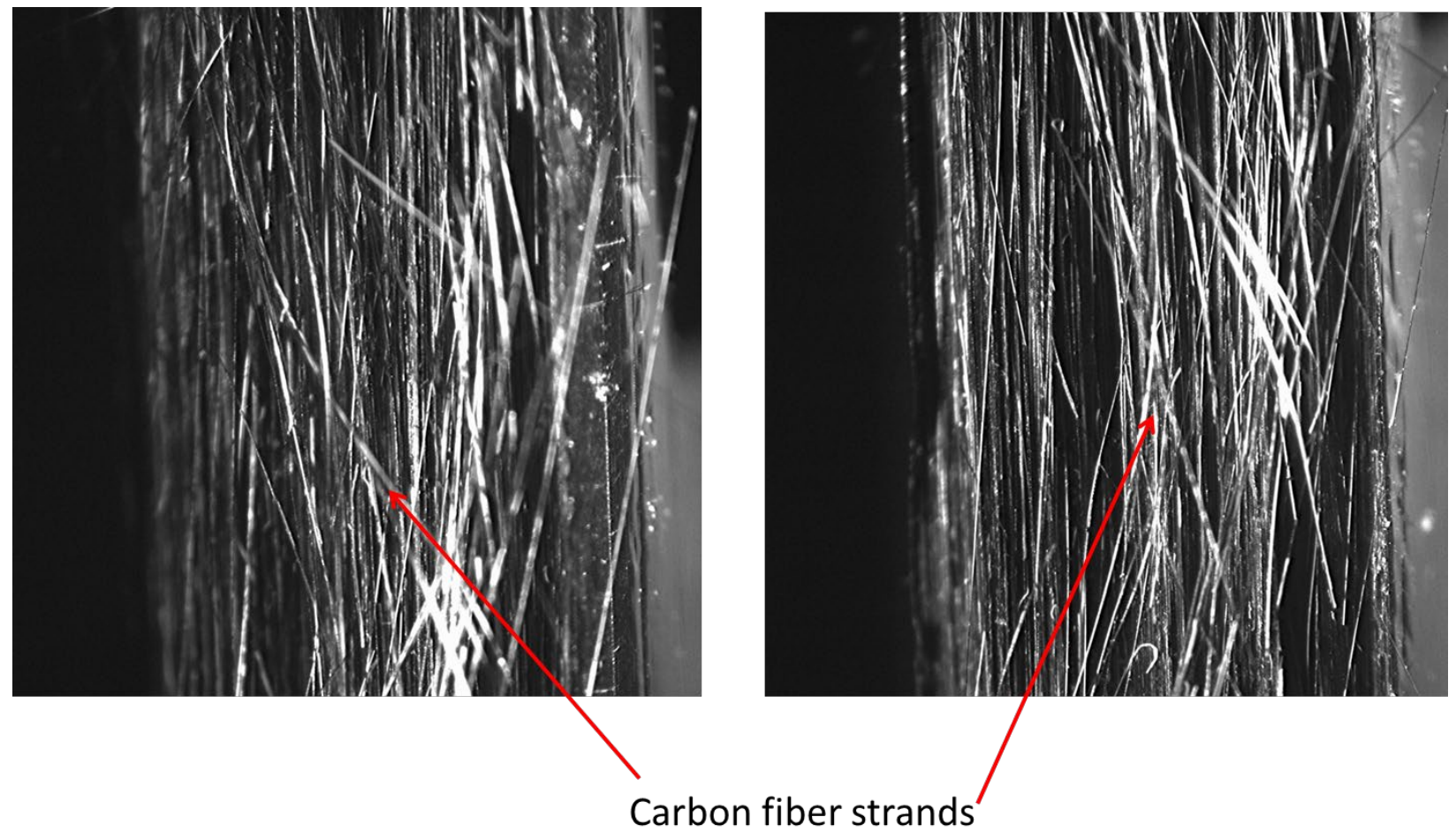

Figure 12 The detailed images of the $\mathrm{C} 7$ carbon fibers observed from fracture PPS regions. 

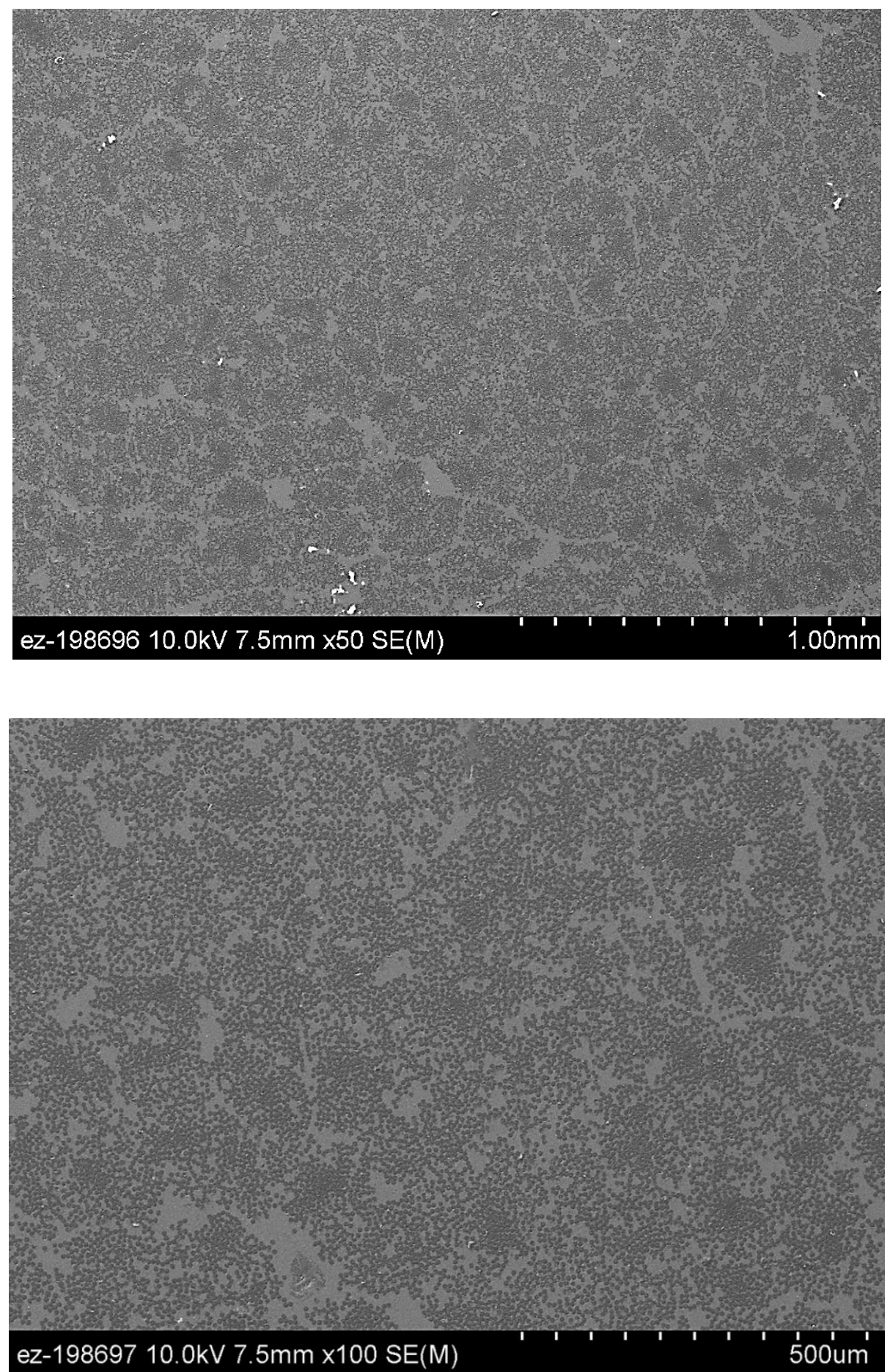

Figure 13 SEM images of PPS matrix of the received C7 carbon composite core sample, light color portions are the PPS matrix and the dark color portions are carbon fibers. 

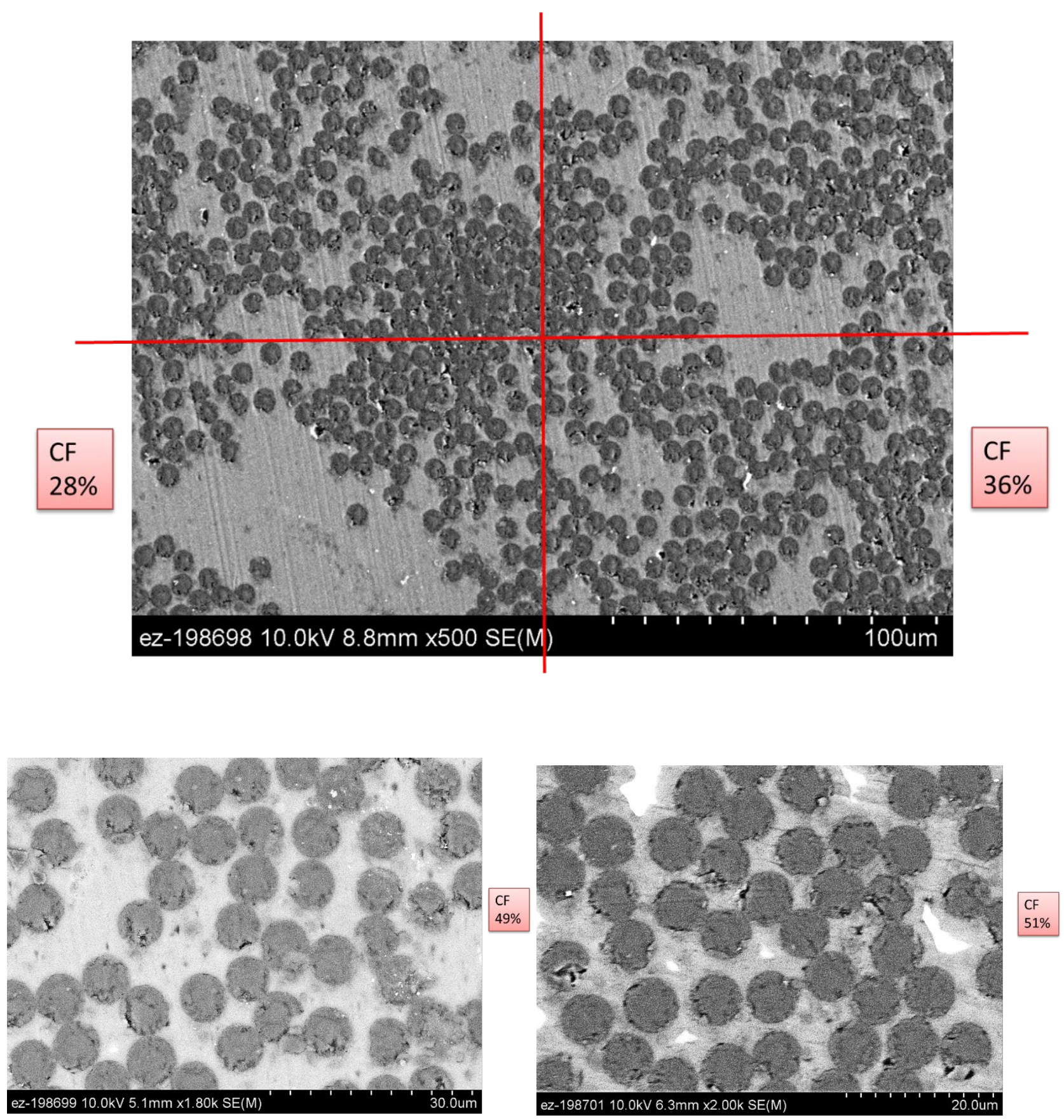

Figure 14 Carbon fiber strands distribution in PPS matrix, which shows the inhomogeneous characteristic of $\mathrm{C} 7$ composite core, where the carbon fiber (CF) volume ratio ranges are from $28 \%$ to $51 \%$ from different sections of $\mathrm{C} 7$ composite core sample. 


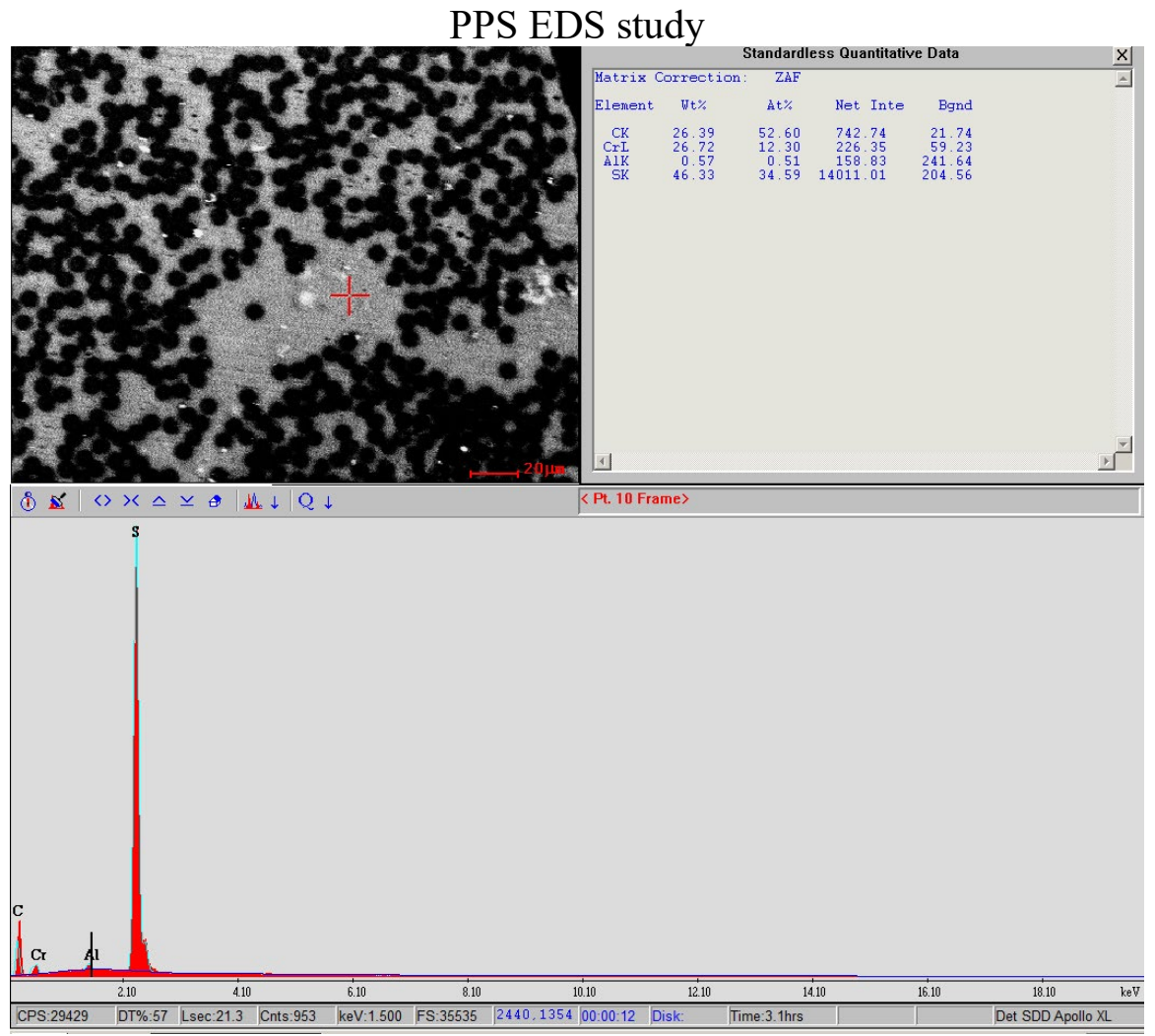

Carbon fiber region EDS study

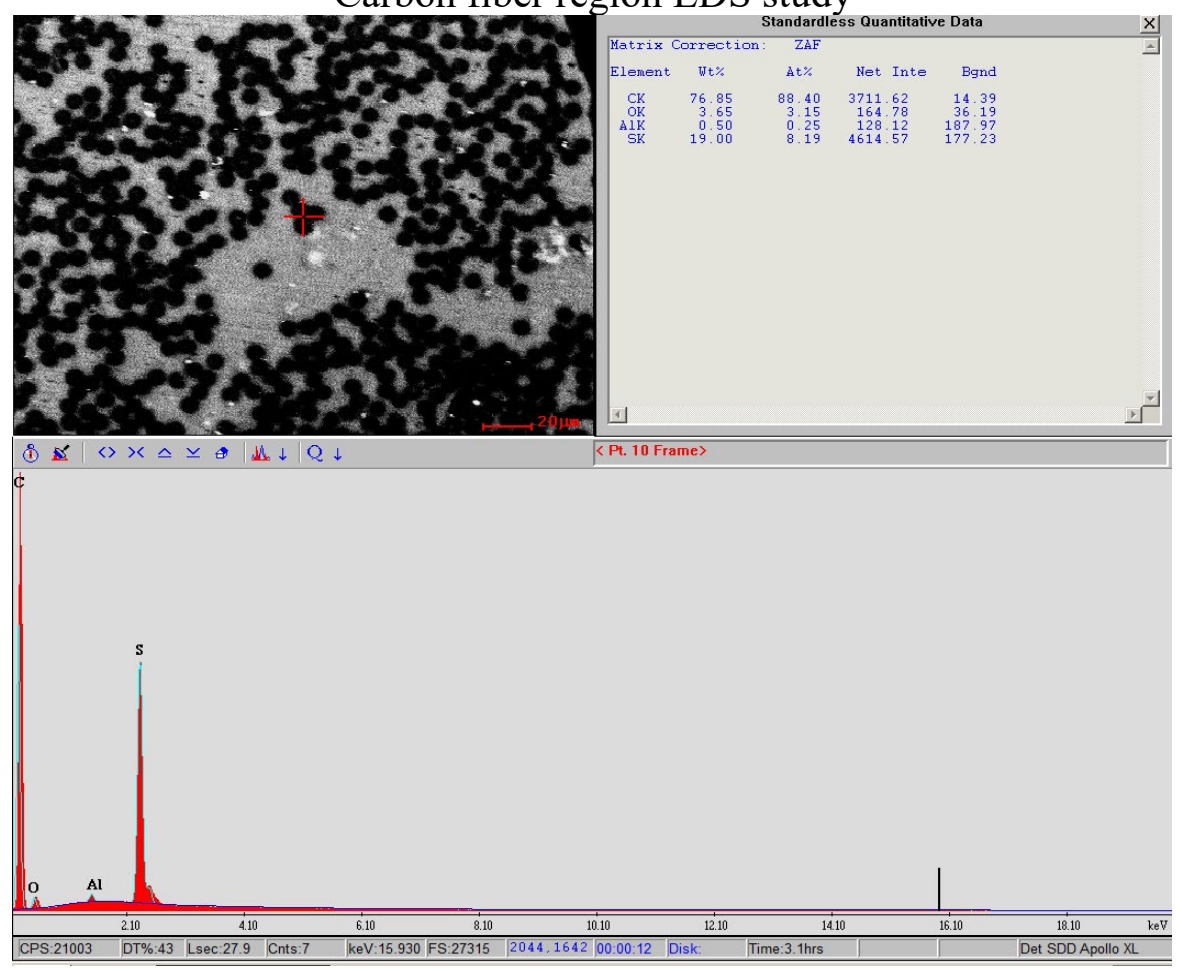



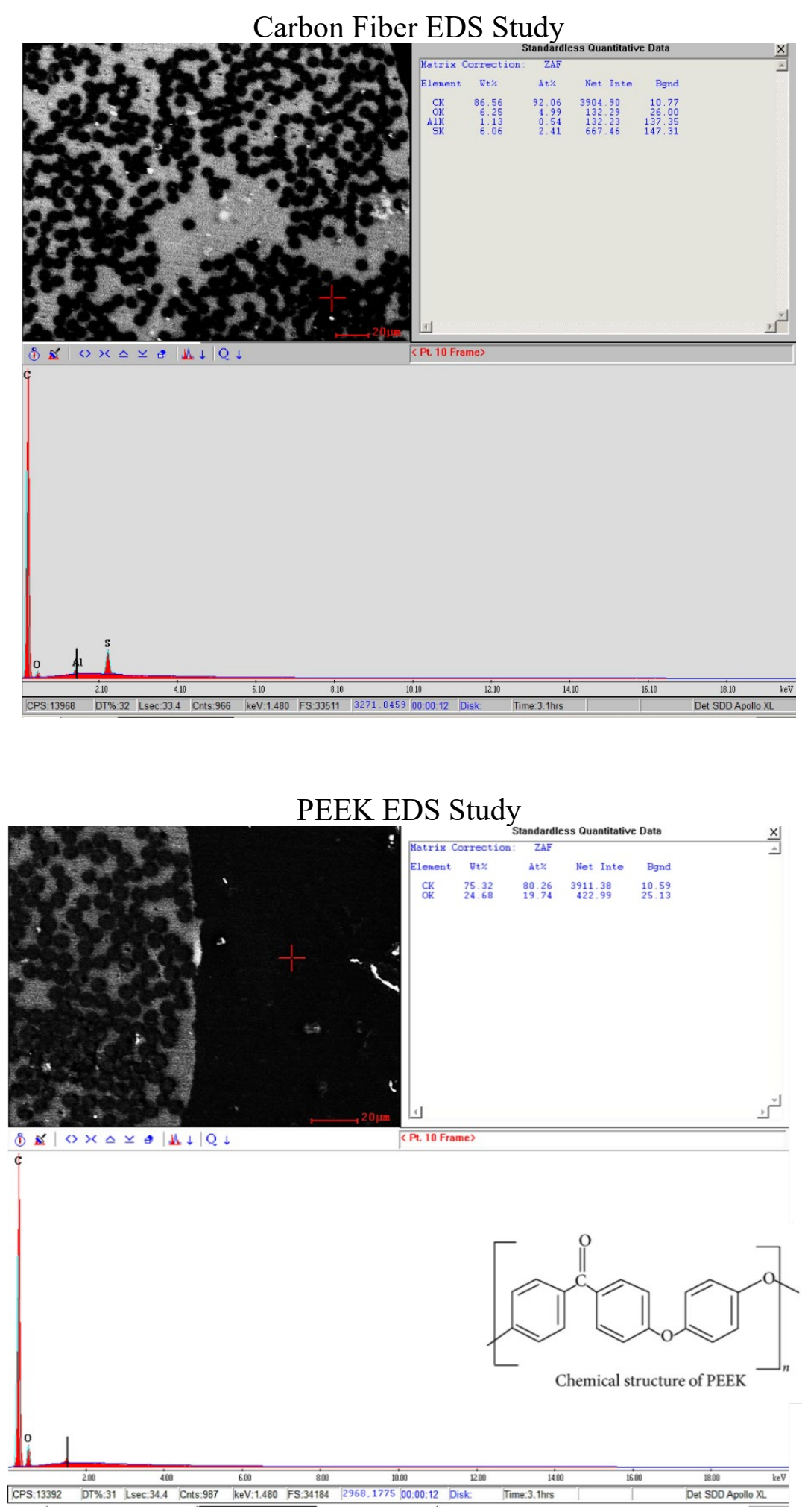

Figure 15 EDS studies on PPS, PEEK, and carbon fiber portions of $\mathrm{C} 7$ carbon composite core. 



\section{THERMAL AGING EXPERIMENTS AND THERMAL AGING CHARACTERIZATIONS USING TGA, DMA, AND TMA TECHNIQUES}

The thermal aging experiments were carried out on $\mathrm{C} 7$ carbon composite core in TGA apparatus heating up to $700^{\circ} \mathrm{C}$; in TGA apparatus for 100 hours at $100^{\circ} \mathrm{C}, 180^{\circ} \mathrm{C}$ and $225^{\circ} \mathrm{C}$ under nitrogen and under air, respectively. The thermal aging characterizations were performed on $\mathrm{C} 7 \mathrm{carbon}$ composite core samples aged in TGA, DMA, TMA apparatuses, the test results and the associated aging techniques characteristics are discussed in this section.

\begin{tabular}{|l|l|l|}
\hline Techniques & \multicolumn{1}{|c|}{ Characteristics } & Planed Number of samples \\
\hline TGA & Loss of weight versus temperatures & 3 samples (carbon core wire) \\
\hline DMA & $\begin{array}{l}\text { Tg (Storage, Loss modulus, and Damping } \\
\text { factor- Tan } \delta)\end{array}$ & 3 samples: (carbon core wire) \\
\hline TMA & Tg (Thermal expansion) & 3 samples: (carbon core wire) \\
\hline
\end{tabular}

\subsection{TGA test results}

TGA determines the change in weight relation to change in temperature or time; typically used to determine characteristics of polymer materials to determine degradation temperatures. Samples of each constituent present in the C7 composite core, such as PEEK, PPS, and C7 carbon core were prepared. The samples were continually weighed in the oven of a thermobalance, and the resulting masses were recorded on a computer.

Figure 16 is a TGA thermogram of the $\mathrm{C} 7$ composite core, PPS, and PEEK, obtained between $25^{\circ} \mathrm{C}$ and $700^{\circ} \mathrm{C}$, with a rate of warming of $20^{\circ} \mathrm{C} \mathrm{min}^{-1}$, under nitrogen. The main mass loss processes can be distinguished, centered around $500^{\circ} \mathrm{C}$. Above $600^{\circ} \mathrm{C}$, the mass of the sample had limited changes for PPS and C7 carbon core samples. It can reasonably be assumed that the whole of the polymer matrix has been pyrolyzed. The fraction of charge mass in the PPS composite was estimated at $78 \%$, which corresponds to a fraction of polymer matrix in the total mass of $22 \%$. The body of tests carried out on the $\mathrm{C} 7$ carbon composite core sample led to fractions of polymer matrix in the total mass at about $26 \%$. The experimental error was estimated at $\pm 3 \%$.

Figure 17 is a TGA thermogram of $\mathrm{C} 7$ composite core samples obtained between $25^{\circ} \mathrm{C}$ and $700^{\circ} \mathrm{C}$, with a rate of warming of $20^{\circ} \mathrm{C} \mathrm{min}^{-1}$, under air. The main mass loss processes can be distinguished, centered around $550^{\circ} \mathrm{C}$. Above $600^{\circ} \mathrm{C}$, the mass of the PEEK sample was 
completely combusted, and the C7 carbon composite core and the PPS were not completely combusted after 2 hours at $700 \mathrm{C}$.

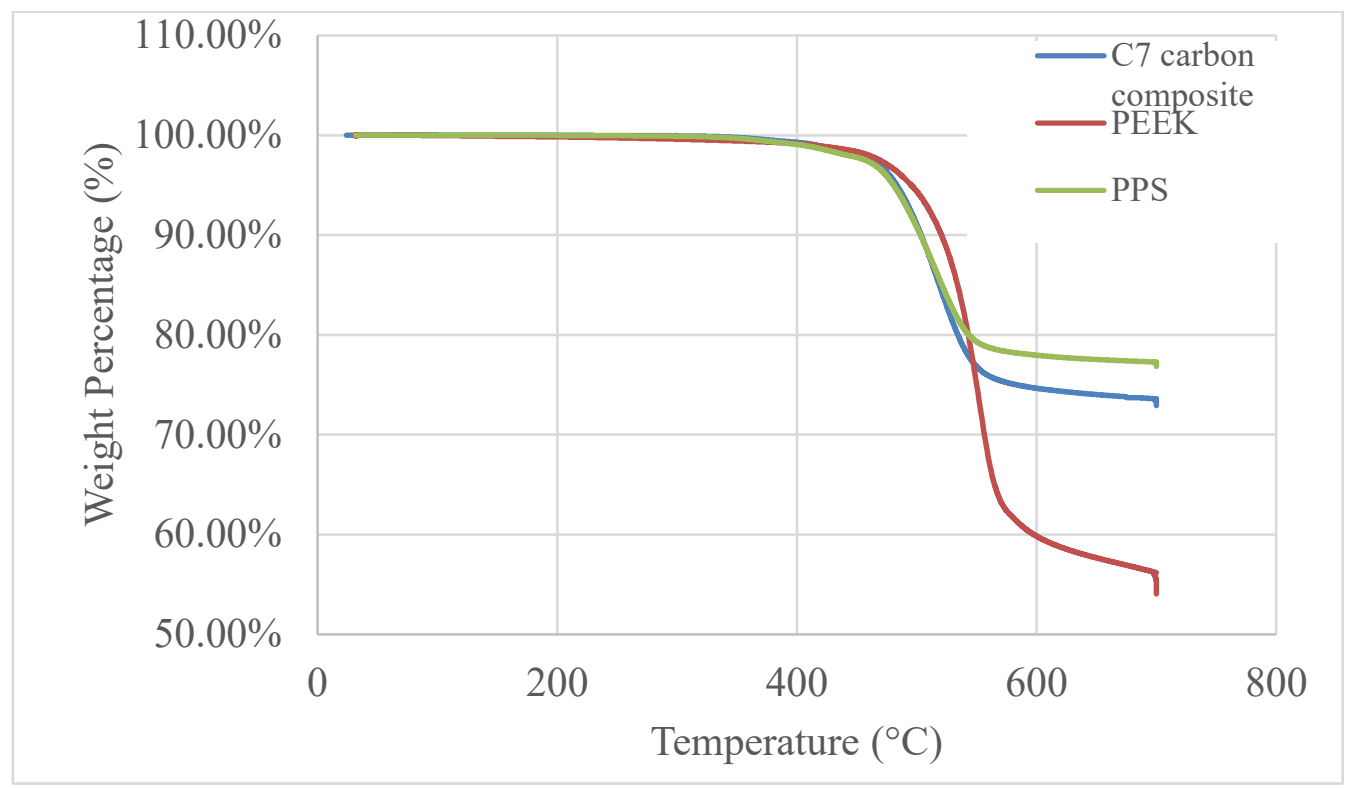

TGA test results Weight Loss-Temperature profile in nitrogen.

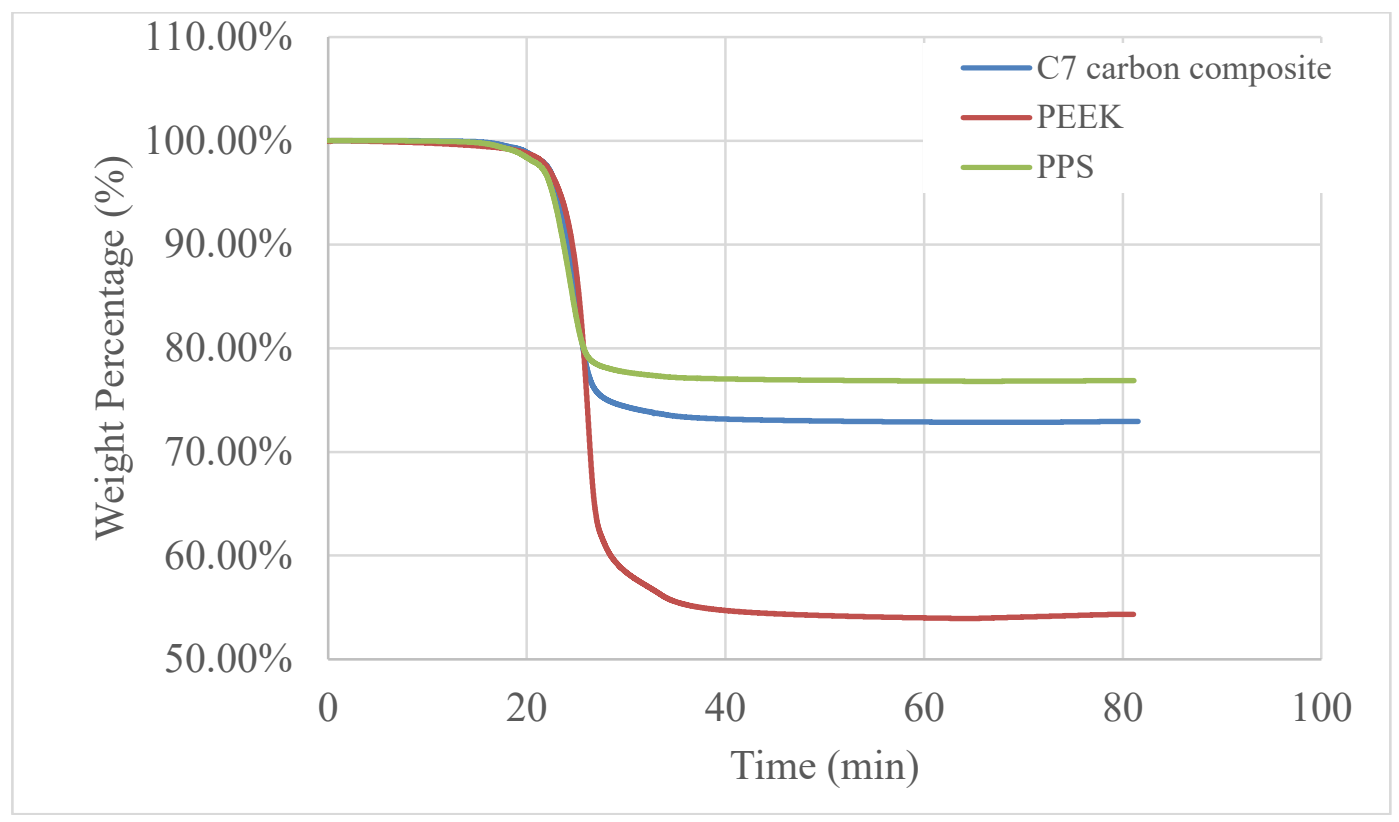

TGA test results Weight loss-Time history in nitrogen. 


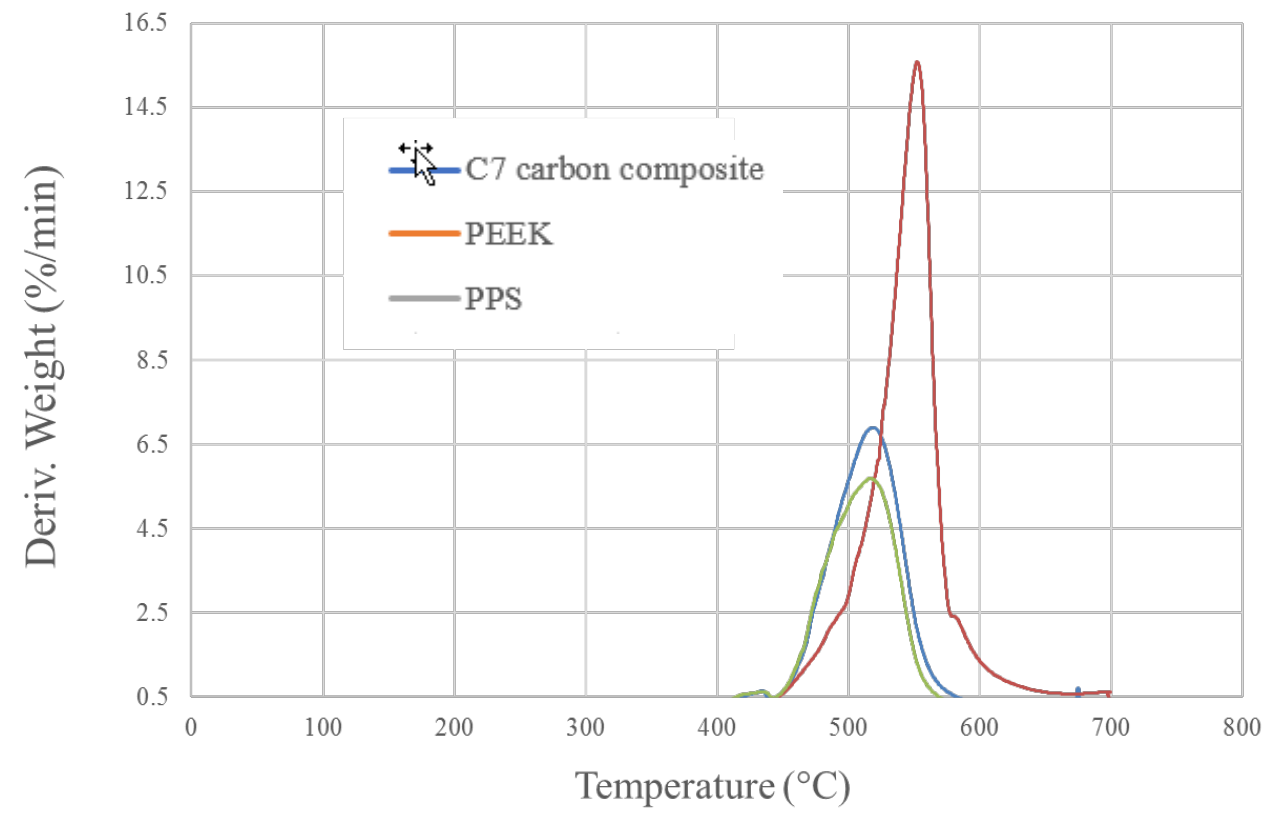

First derivative of TGA test results in nitrogen.

Figure 16 TGA test results in nitrogen for data up to $700 \mathrm{C}$. The PEEK loses $\sim 45 \%$ of its weight and the PPS loses $\sim 22 \%$ with the $\mathrm{C} 7$ carbon core in between at $\sim 26 \%$. The PEEK loses its volatiles at $555^{\circ} \mathrm{C}$ and the PPS at $525^{\circ} \mathrm{C}$.

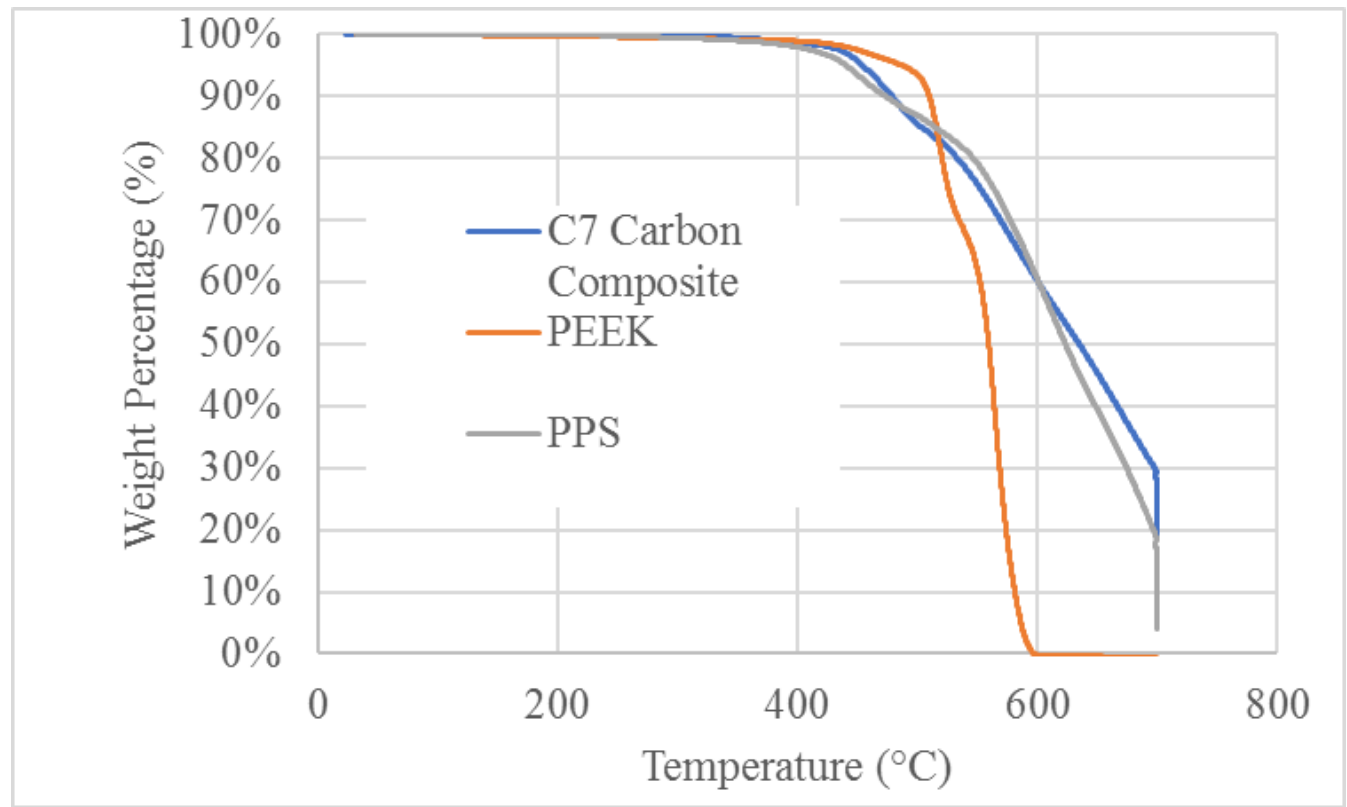

TGA test results Weight Loss-Temperature profile in air 


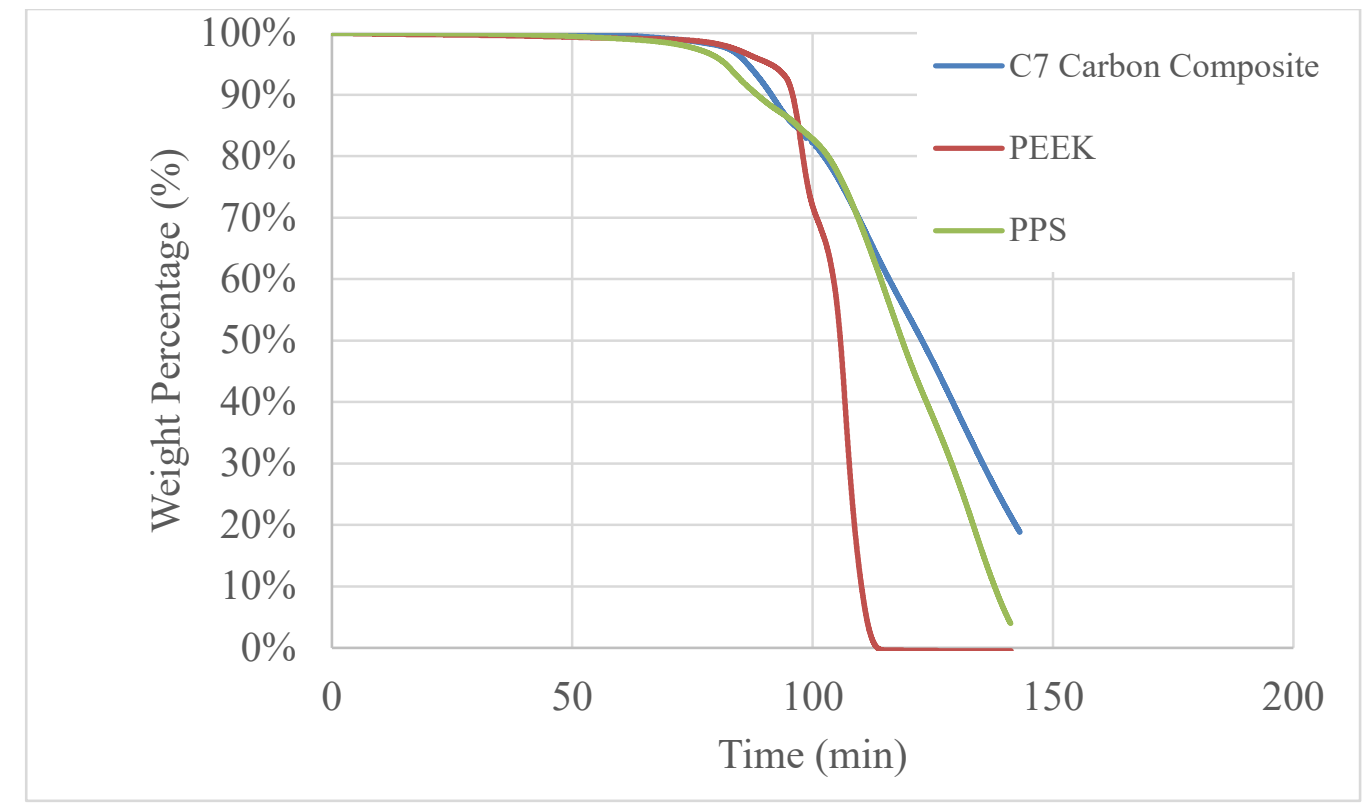

TGA test results Weight loss-Time history in air

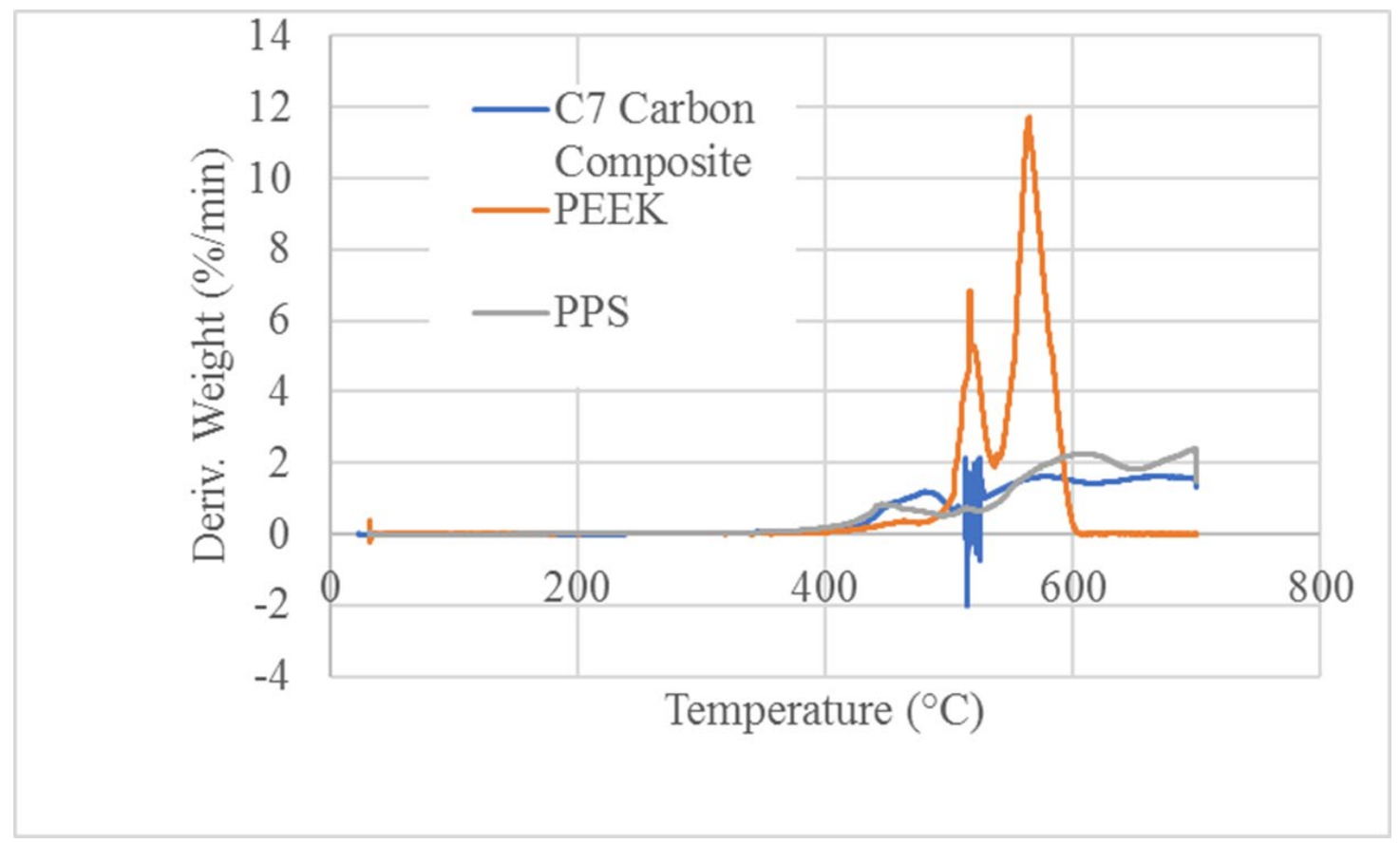

First derivative of TGA test results in air

Figure 17 TGA test results in air, where the $\mathrm{C} 7$ carbon and the PPS were not completely combusted after 2 hours at $700 \mathrm{C}$. The noisiness of the $\mathrm{C} 7$ carbon composite derivative curve might be due to the cylindrical fiber rolling a little bit during combustion. 
The TGA thermal aging study of $\mathrm{C} 7$ carbon core sample under 100 hours thermal aging in nitrogen is shown in Figure 18, which shows the changes between $100^{\circ} \mathrm{C}, 180^{\circ} \mathrm{C}$ and $210^{\circ} \mathrm{C}$ under nitrogen of the masses of test samples made up from the $\mathrm{C} 7$ carbon core. In this case, the whole volume of the $\mathrm{C} 7$ composite core samples is subject to the effects of thermolysis alone. Figure 18 shows good thermal stability of the $\mathrm{C} 7$ carbon composite core aging under $100^{\circ} \mathrm{C}$, and minor change in $180^{\circ} \mathrm{C}$ up to $0.2 \%$ weight loss in contrast to the $225^{\circ} \mathrm{C}$ thermal aging with $0.5 \%$ weight loss at the end of 100 hours thermal aging.

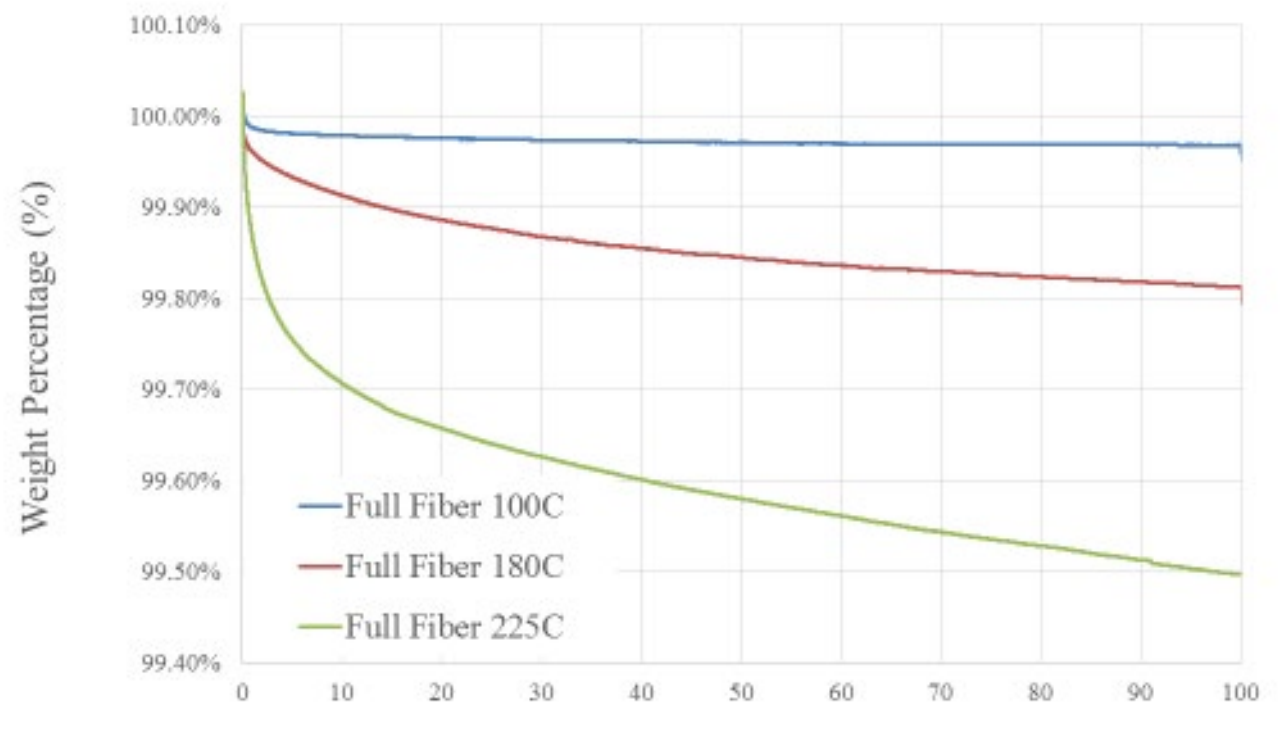

Time (h)

Figure 18 TGA thermal aging test results in nitrogen, which shows the variations in the mass of $\mathrm{C} 7$ carbon core samples among $100^{\circ} \mathrm{C}, 180^{\circ} \mathrm{C}$, and $210^{\circ} \mathrm{C}$ under nitrogen. 


\subsection{DMA testing results}

\section{Principle of DMA}

Dynamic mechanical properties refer to the response of a material as it is subjected to a periodic force. These properties may be expressed in terms of a dynamic modulus, a dynamic loss modulus, and a mechanical damping term. Typical values of dynamic moduli for polymers range from $10^{6}$ $10^{12}$ dyne $/ \mathrm{cm}^{2}\left(0.1-10^{5} \mathrm{MPa}\right)$ depending upon the type of polymer, temperature, and frequency.

For an applied stress varying sinusoidally with time, a viscoelastic material will also respond with a

\section{DMA Q800 Tester Set-up}

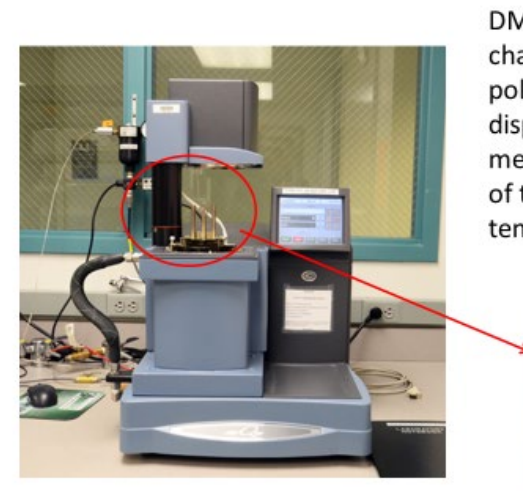

DMA is a technique used to characterize materials, specifically polymers, such as Tg. It applies a displacement to a sample and measures the mechanical response of the bulk material in a controlled temperature environment.

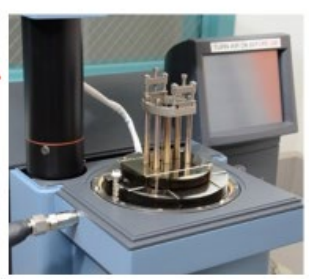
sinusoidal strain for low amplitudes of stress. The sinusoidal variation in time is usually described as a rate specified by the frequency $(\mathrm{f}=\mathrm{Hz} ; \omega=\mathrm{rad} / \mathrm{sec})$. The strain of a viscoelastic body is out of phase with the stress applied, by the phase angle, $\delta$. This phase lag is due to the excess time necessary for molecular motions and relaxations to occur. Dynamic stress, $\sigma$, and strain, $\varepsilon$, given as:
(1) $\sigma=\sigma_{o} \sin (\omega t+\delta)$
(2) $\varepsilon=\varepsilon_{o} \sin (\varpi t)$

where $\omega$ is the angular frequency. Using this notation, stress can be divided into an "in- phase" component $\left(\sigma_{o} \cos \delta\right)$ and an "out-of-phase" component $\left(\sigma_{o} \sin \delta\right)$ and rewritten as,

(3) $\sigma=\sigma_{\mathrm{o}} \sin (\omega \mathrm{t}) \cos \delta+\sigma_{\mathrm{o}} \cos (\omega \mathrm{t}) \sin \delta$.

Dividing stress by strain to yield a modulus and using the symbols E' and E" for the inphase (real) and out-of-phase (imaginary) moduli yields:

(4) $\sigma=\varepsilon_{o} E^{\prime} \sin (\varpi t)+\varepsilon_{o} E^{\prime \prime} \cos (\omega t)$

$$
E^{\prime}=\frac{\sigma_{o}}{\varepsilon_{o}} \cos \delta \quad E^{\prime \prime}=\frac{\sigma_{o}}{\varepsilon_{o}} \sin \delta
$$

(6) $\varepsilon=\varepsilon_{o} \exp (i \omega t), \quad \sigma=\sigma_{o} \exp (\omega t+\delta) i$

$$
E^{*}=\frac{\sigma}{\varepsilon}=\frac{\sigma_{o}}{\varepsilon_{o}} e^{i \delta}=\frac{\sigma_{o}}{\varepsilon_{o}}(\cos \delta+i \sin \delta)=E^{\prime}+i E^{\prime \prime}
$$


Equation (7) shows that the complex modulus obtained from a dynamic mechanical test consists of "real" and "imaginary" parts. The real (storage) part describes the ability of the material to store potential energy and release it upon deformation. The imaginary (loss) portion is associated with energy dissipation in the form of heat upon deformation. The above equation is rewritten for shear modulus as,

(8) $G^{*}=G^{\prime}+i G^{\prime \prime}$

where $\mathrm{G}^{\prime}$ is the storage modulus and $\mathrm{G}^{\prime \prime}$ is the loss modulus. The phase angle $\delta$ is given by

$$
\tan \delta=\frac{G^{\prime \prime}}{G^{\prime}}
$$

The storage modulus is often associated with "stiffness" of a material and is related to the Young's modulus, E. The dynamic loss modulus is often associated with "internal friction" and is sensitive to different kinds of molecular motions, relaxation processes, transitions, morphology and other structural heterogeneities. Thus, the dynamic properties provide information at the molecular level to understanding the polymer mechanical behavior.

The $\mathrm{Tg}$ is seen as a large drop (a decade or more) in the storage modulus when viewed on a log scale against a linear temperature scale, shown in Figures 2-3. A concurrent peak in the $\tan \delta$ is also seen. The value reported as the Tg varies with industry with the onset of the E' drop, the peak of the $\tan \delta$, and the peak of the E" curve being the most commonly used.

The performed DMA test results on the baseline C7 carbon core samples and the associated Tg values are provided in Figures 19-28. The storage modulus G', loss modulus G', and tan $\delta$ were measured at a frequency of $1 \mathrm{~Hz}$, where the DMA test parameters are provided in the associated figures per each DMA test. DMA trace on thermal cycles aging C7 carbon core sample received from EPRI is shown on Figures 29-30.

There are two Tg of C7 carbon composite core samples observed from DMA technique, at $90^{\circ} \mathrm{C}$ and $170^{\circ} \mathrm{C}$ regions; and the melting temperature is around $290^{\circ} \mathrm{C}$. Which seems to be consistent to Tg of $89^{\circ} \mathrm{C}$ and $150^{\circ} \mathrm{C}$ for PPS and PEEK, respectively, shown in Table 1. Apparently these $\mathrm{Tg}$ of $90^{\circ} \mathrm{C}$ are lower than $180^{\circ} \mathrm{C}$ of $\mathrm{C} 7$ conductor operation temperature. And the $\mathrm{C} 7$ carbon composite core melting temperature is consistent with that of PPS at $275^{\circ} \mathrm{C}$ shown in Figure 6 . Nevertheless, based on Table 3, the recommended heavy and long-term operation for PPS and PEEK are $85^{\circ} \mathrm{C}$ and $138^{\circ} \mathrm{C}$, respectively.

Comparison of EPRI thermal cycle aging C7 carbon core samples DMA test results and baseline C7 carbon core sample DMA test results was shown in Figure 30. Which shows decrease in storage and loss modulus from aging $\mathrm{C} 7$ carbon core sample compared to that of baseline $\mathrm{C} 7$ carbon core sample; and thermal cycling aging sample also shows lower damping than that of the baseline sample. The aging sample DMA test result shows increase in Tg compared to that of baseline sample.

The details of C7 core samples DMA test results are provided below. 


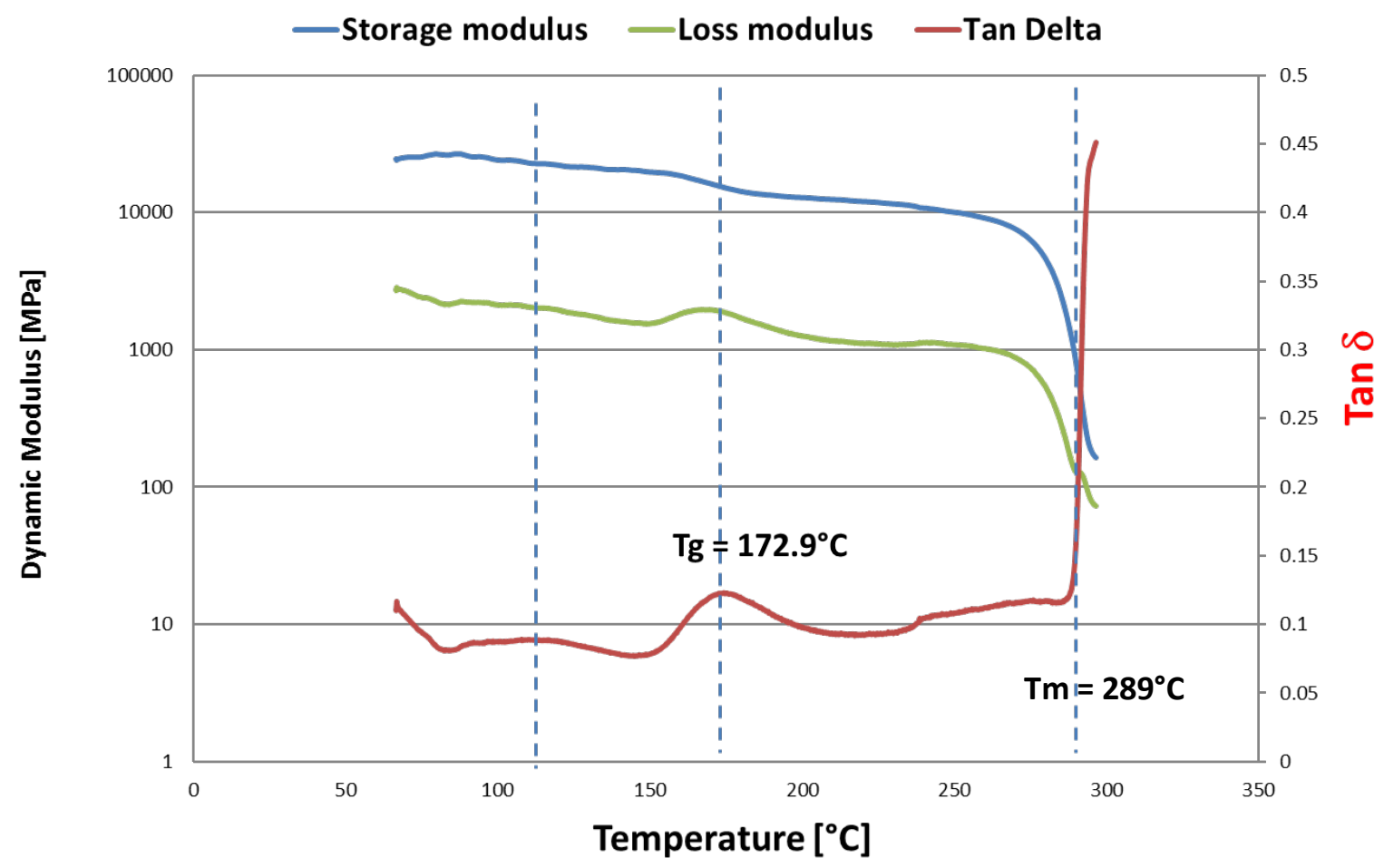

C7 Carbon Core DMA Testing \#1

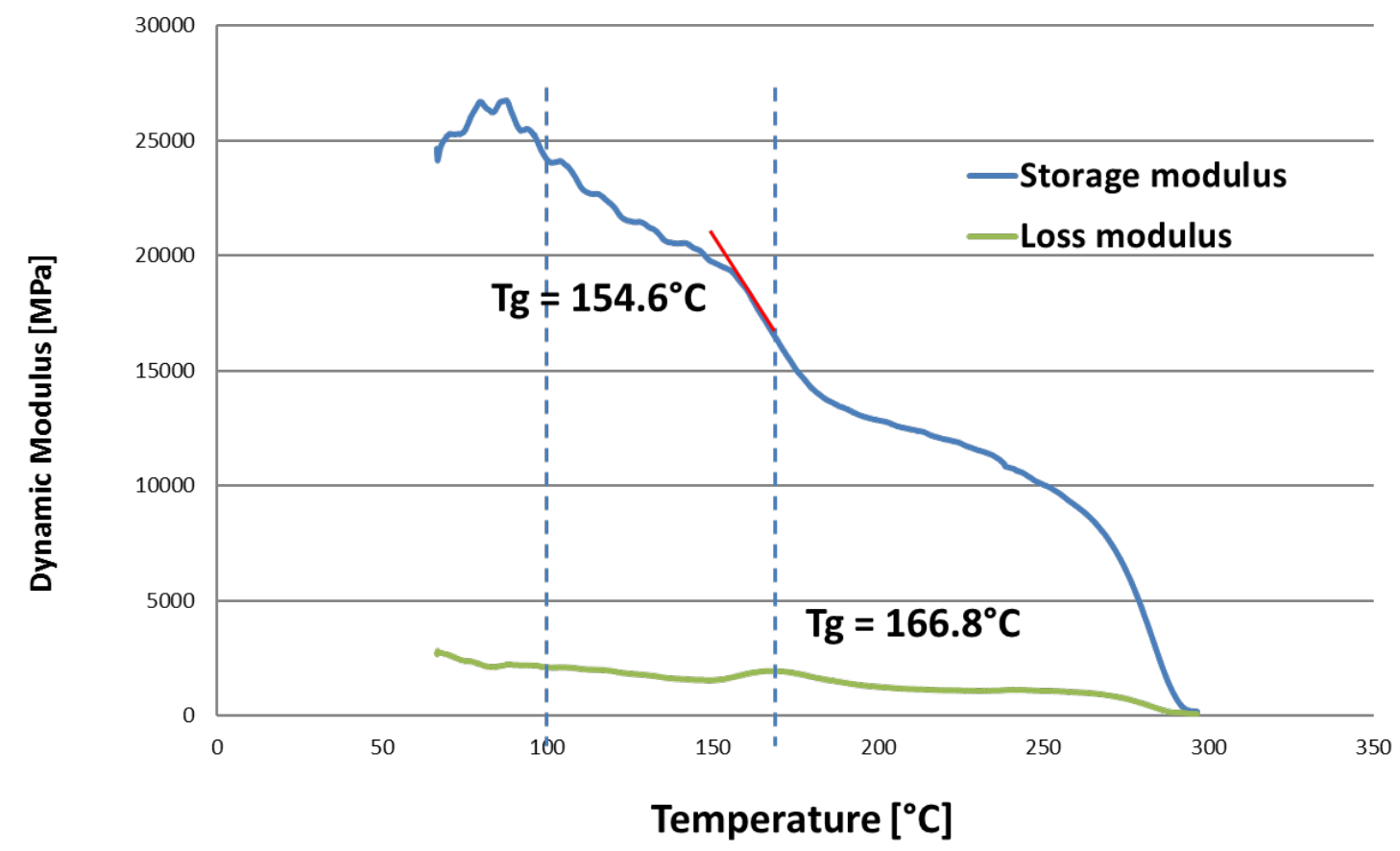

Figure $19 \mathrm{C} 7$ composite core material DMA Testing, sample \#1; Test temperature ramp at $3^{\circ} \mathrm{C} / \mathrm{min}$ from room temperature to $300^{\circ} \mathrm{C}$, with the following parameters: driving force is at $0.1 \mathrm{~N}$, amplitude of $1.4 \mu \mathrm{m}$, and static force of $0.11 \mathrm{~N}$. 


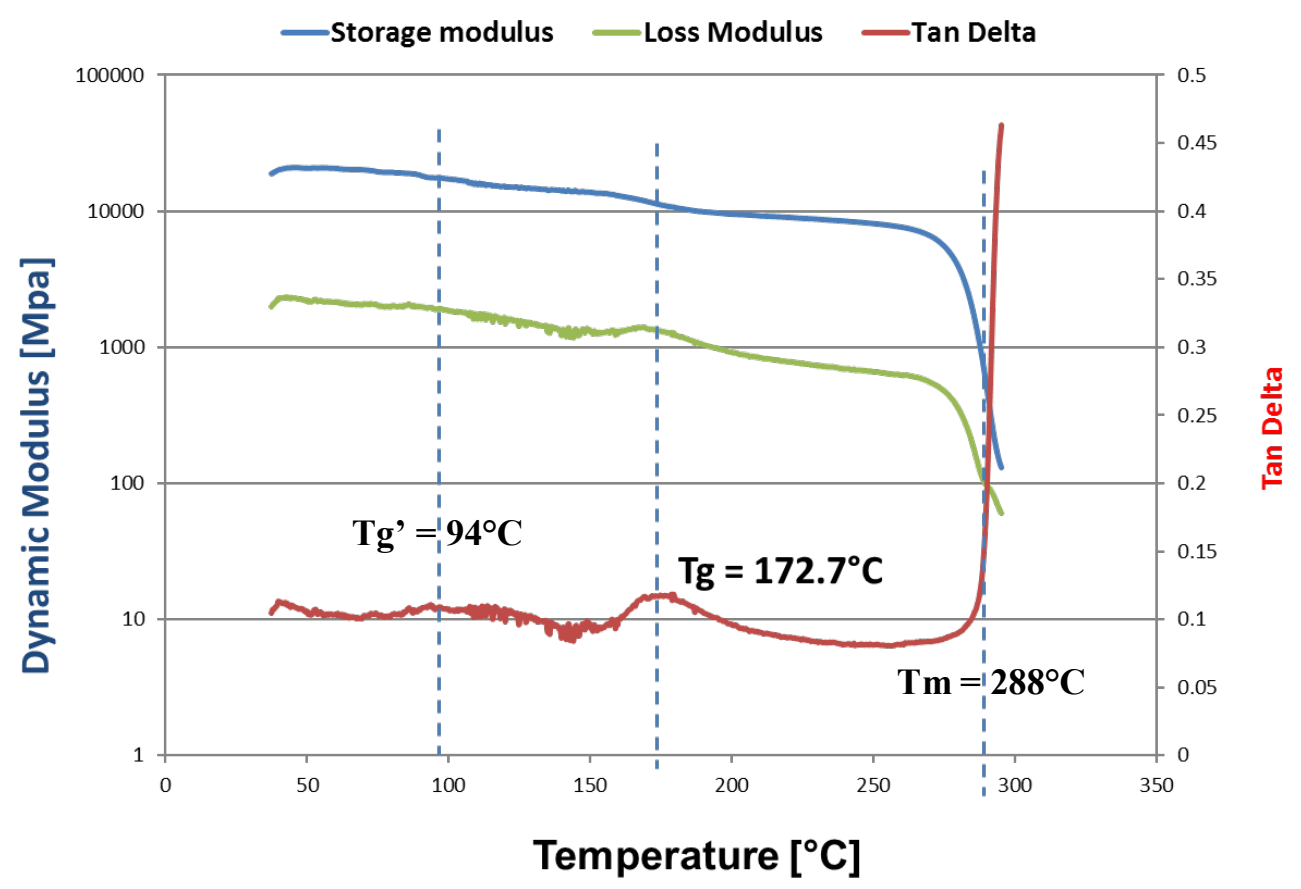

C7 Carbon Core DMA Testing \#2,

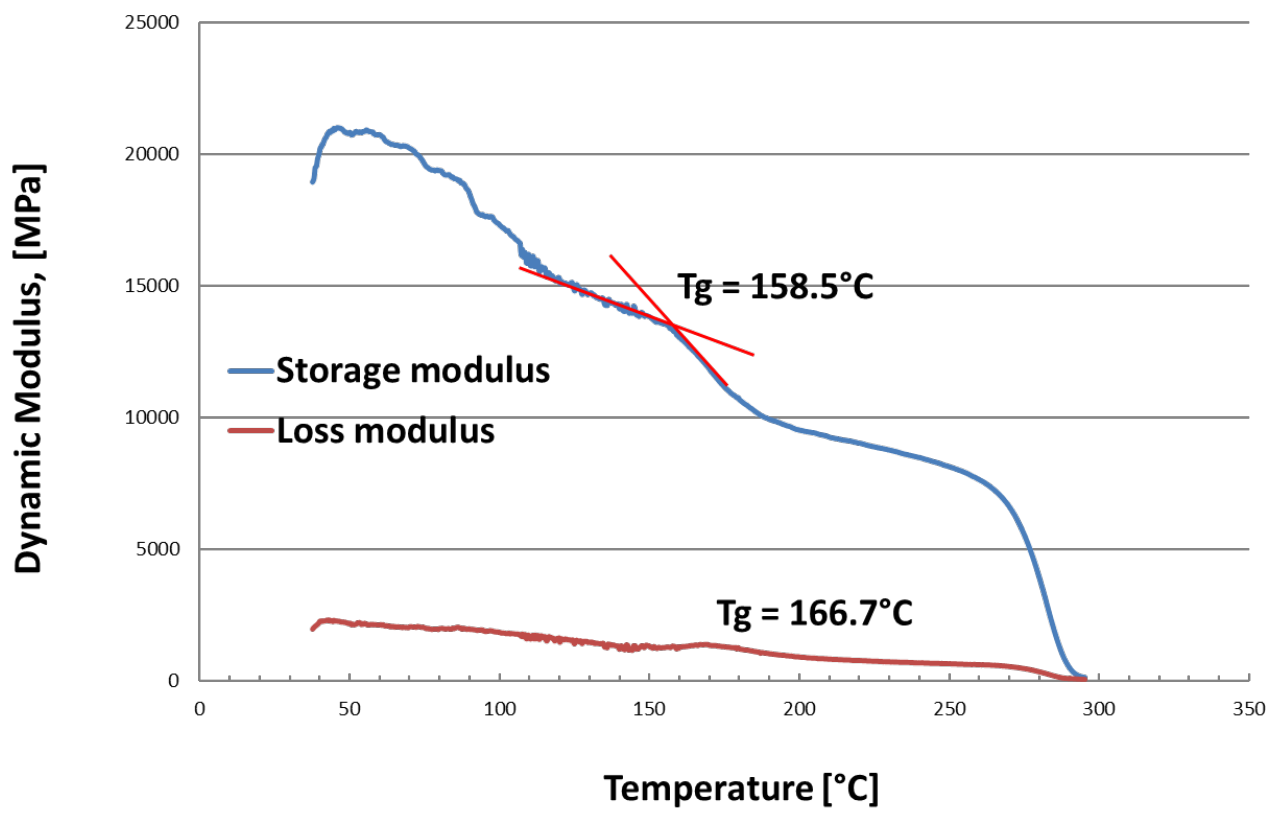

Figure $20 \mathrm{C7}$ composite core material DMA Testing, sample \#2; Test temperature ramp at $5^{\circ} \mathrm{C} / \mathrm{min}$ from room temperature to $300^{\circ} \mathrm{C}$, with the following parameters: driving force is at $0.1 \mathrm{~N}$, amplitude of $1.7 \mu \mathrm{m}$, and static force of $0.14 \mathrm{~N}$. 


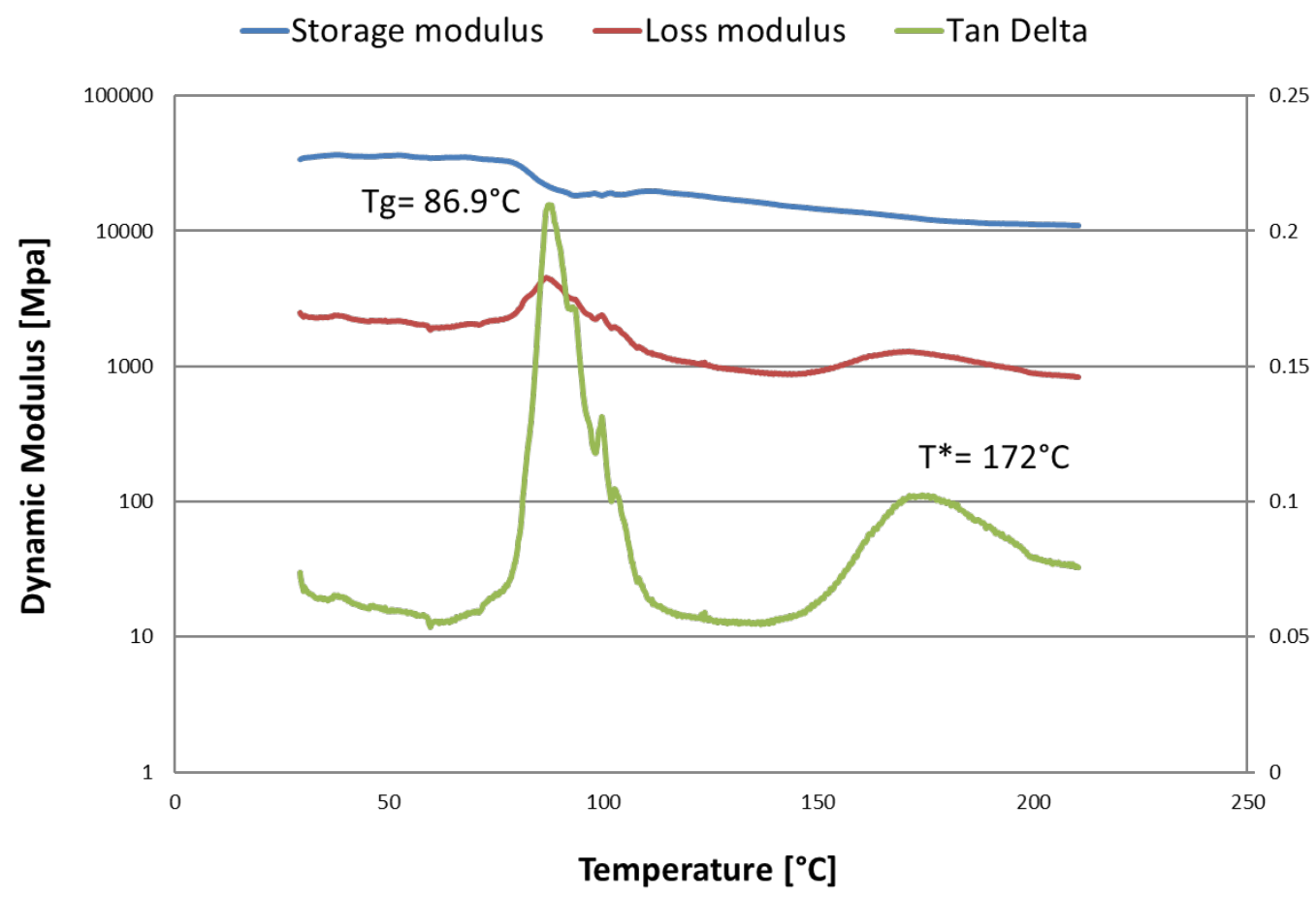

C7 Carbon Core DMA Testing \#3

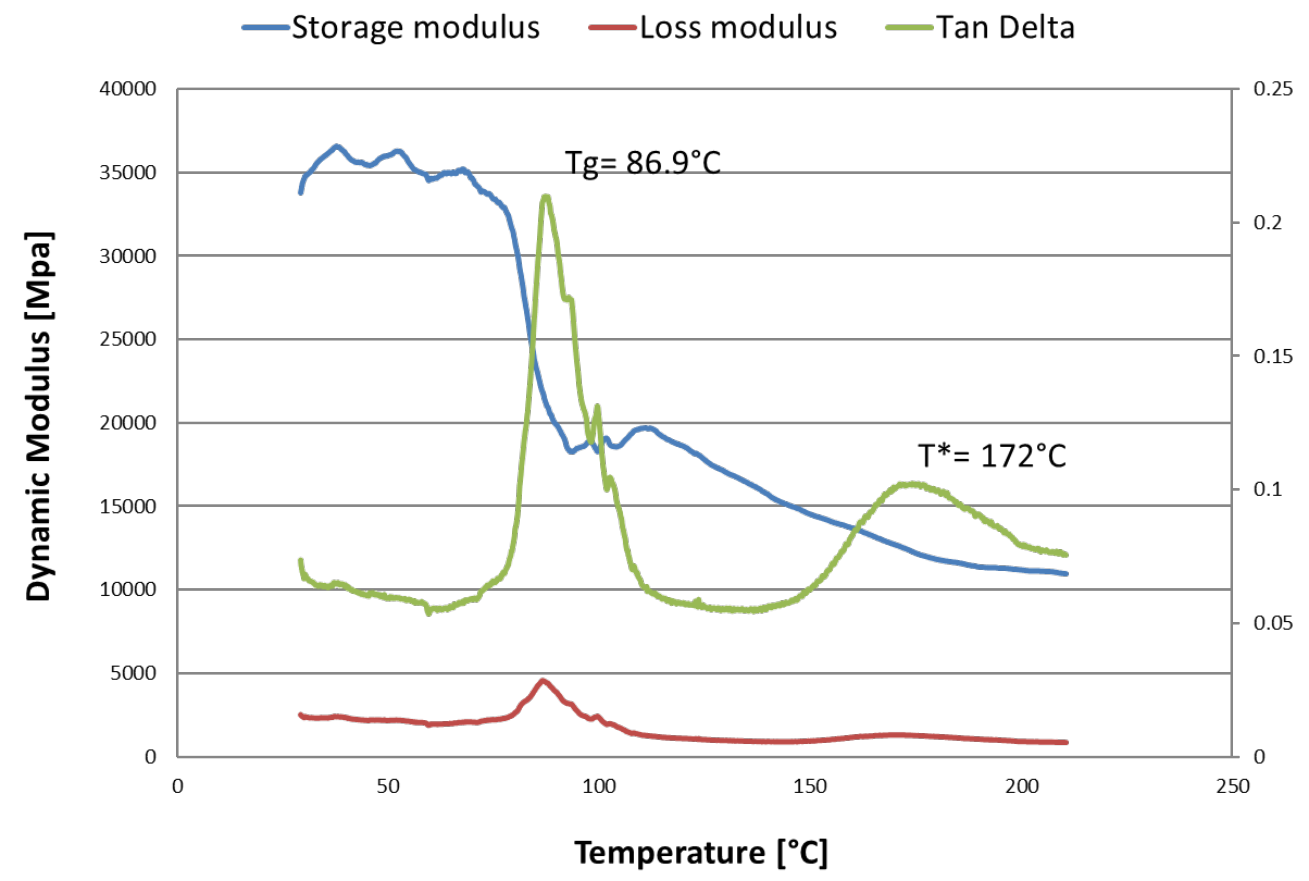

Figure $21 \mathrm{C} 7$ core material DMA Testing, sample \#3; Test temperature ramp at $3^{\circ} \mathrm{C} / \mathrm{min}$ from room temperature to $250^{\circ} \mathrm{C}$, with the following parameters: driving force is at $0.089 \mathrm{~N}$, amplitude of 1.0 micron, and static force of $0.134 \mathrm{~N}$. 


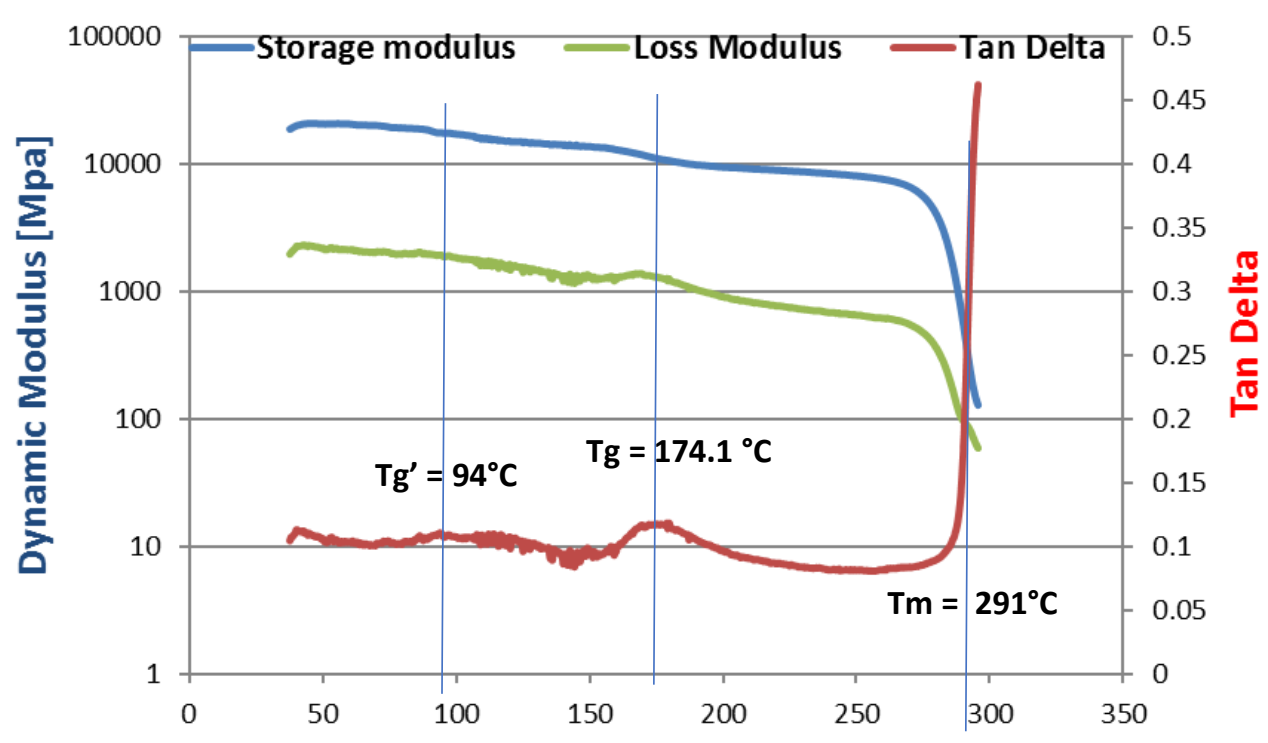

Figure $22 \mathrm{C} 7$ core material DMA Testing, sample \#4; Test temperature ramp at $5^{\circ} \mathrm{C} / \mathrm{min}$ from room temperature to $300^{\circ} \mathrm{C}$, with the following parameters: driving force is at $0.1 \mathrm{~N}$, amplitude of $1.8 \mu \mathrm{m}$, and static force of $0.14 \mathrm{~N}$.

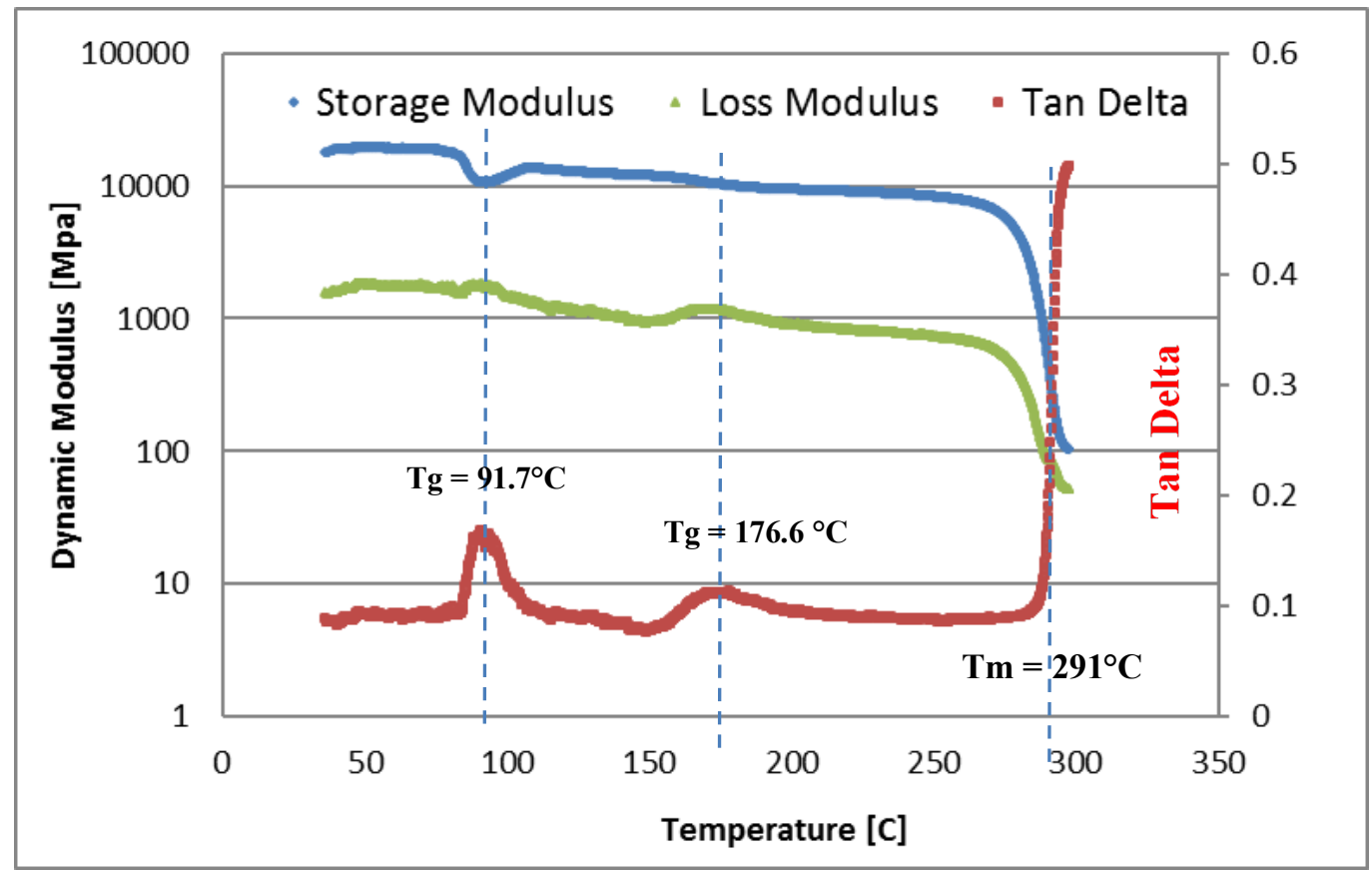

Figure $23 \mathrm{C} 7$ core material DMA Testing, sample \#5; Test temperature ramp at $3^{\circ} \mathrm{C} / \mathrm{min}$ from room temperature to $300^{\circ} \mathrm{C}$, with the following parameters: driving force is at $0.1 \mathrm{~N}$, amplitude of $1.85 \mu \mathrm{m}$, and static force of $0.14 \mathrm{~N}$. 


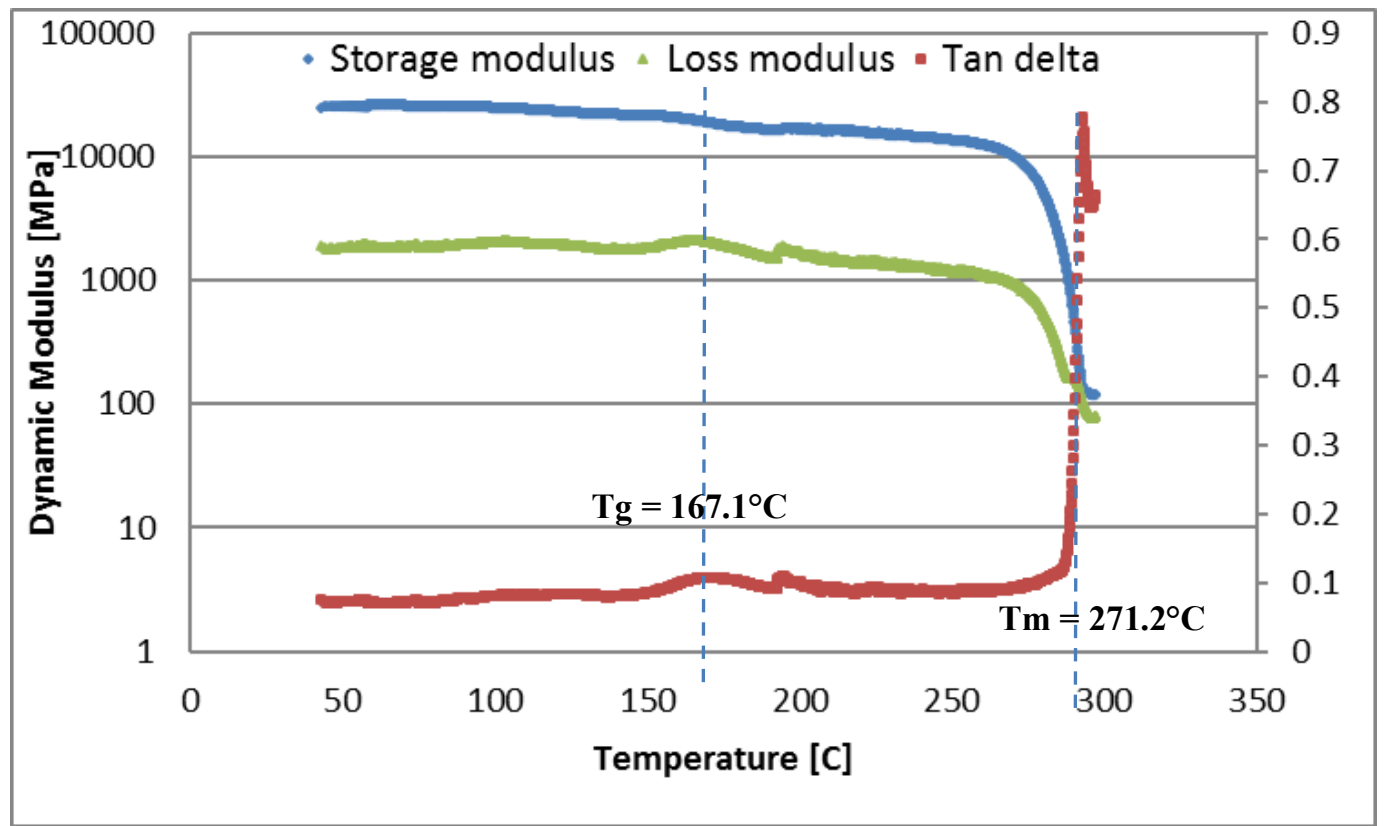

Figure $24 \mathrm{C} 7$ core material DMA Testing, sample \#6; Test temperature ramp at $3^{\circ} \mathrm{C} / \mathrm{min}$ from room temperature to $300^{\circ} \mathrm{C}$, with the following parameters: driving force is at $0.18 \mathrm{~N}$, amplitude of $2.78 \mu \mathrm{m}$, and static force of $0.27 \mathrm{~N}$.

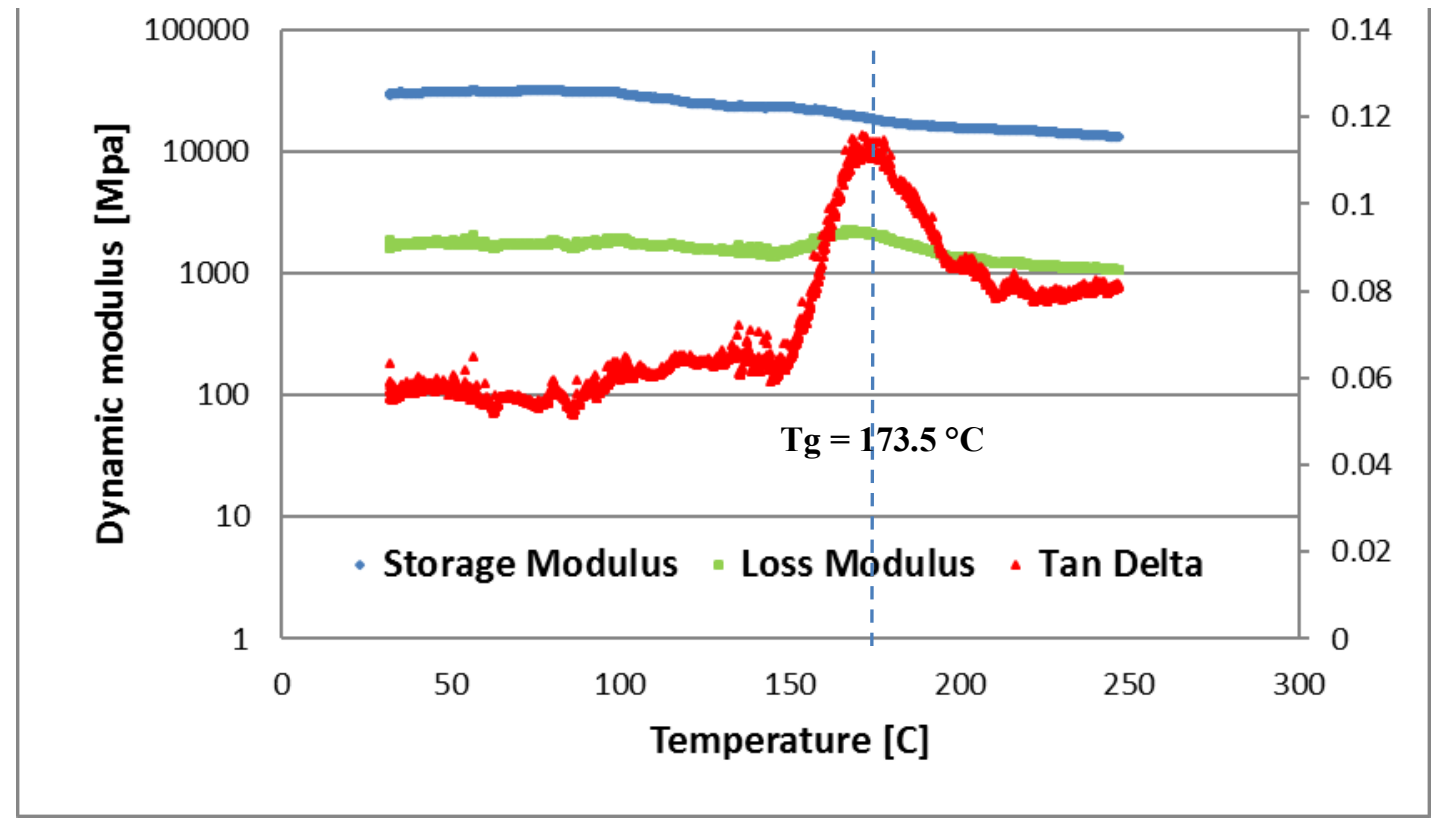

Figure 25 C7 composite core material DMA Testing, sample \#7; Test temperature ramp at $3^{\circ} \mathrm{C} / \mathrm{min}$ from room temperature to $250^{\circ} \mathrm{C}$, with the following parameters: driving force is at $0.1 \mathrm{~N}$, amplitude of $1.1 \mu \mathrm{m}$, and static force of $0.136 \mathrm{~N}$. 


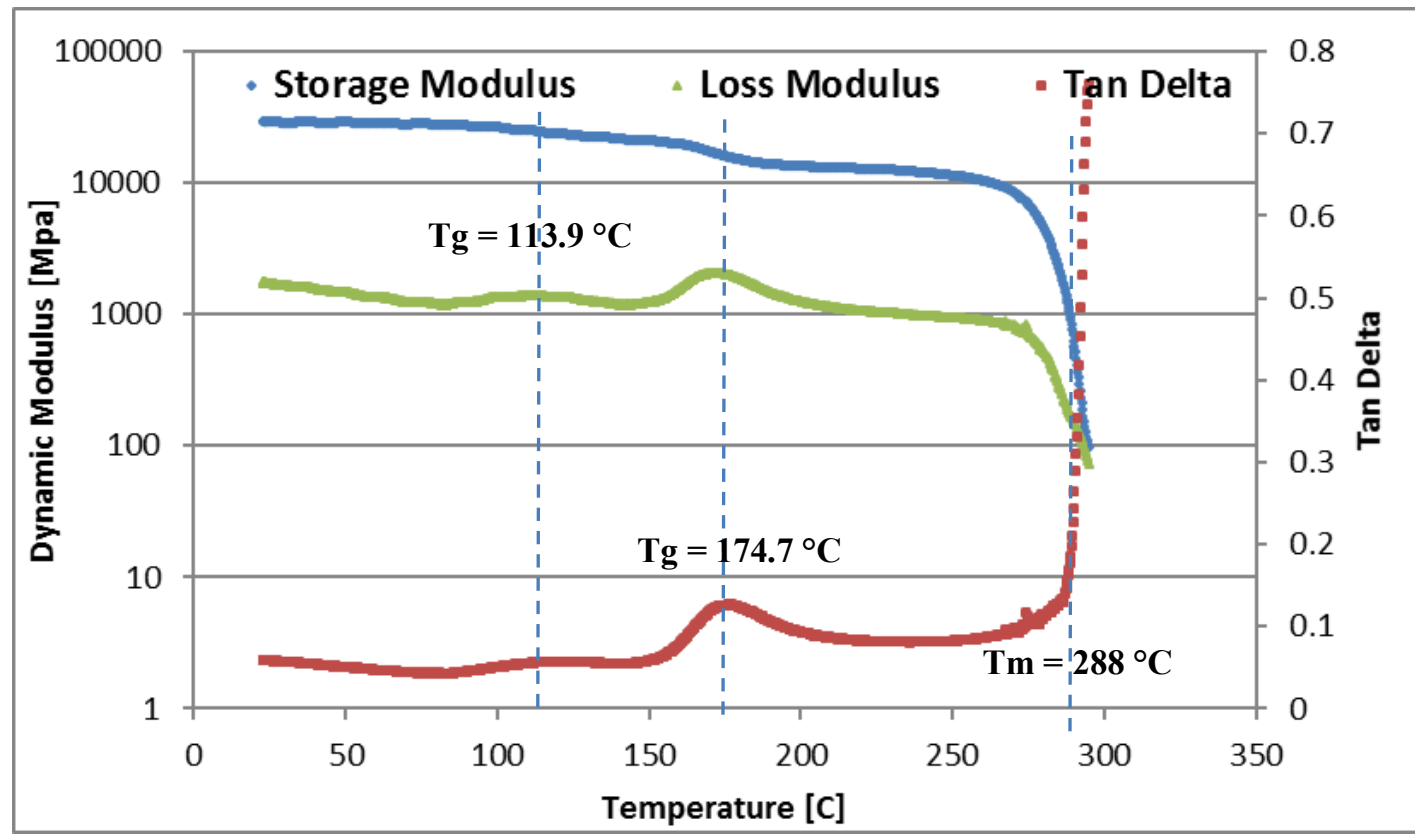

Figure $26 \mathrm{C} 7$ core material DMA Testing, sample \#8; Test temperature ramp at $5^{\circ} \mathrm{C} / \mathrm{min}$ from room temperature to $300^{\circ} \mathrm{C}$, with the following parameters: driving force is at $0.1 \mathrm{~N}$, amplitude of $1.2 \mu \mathrm{m}$, and static force of $0.136 \mathrm{~N}$.

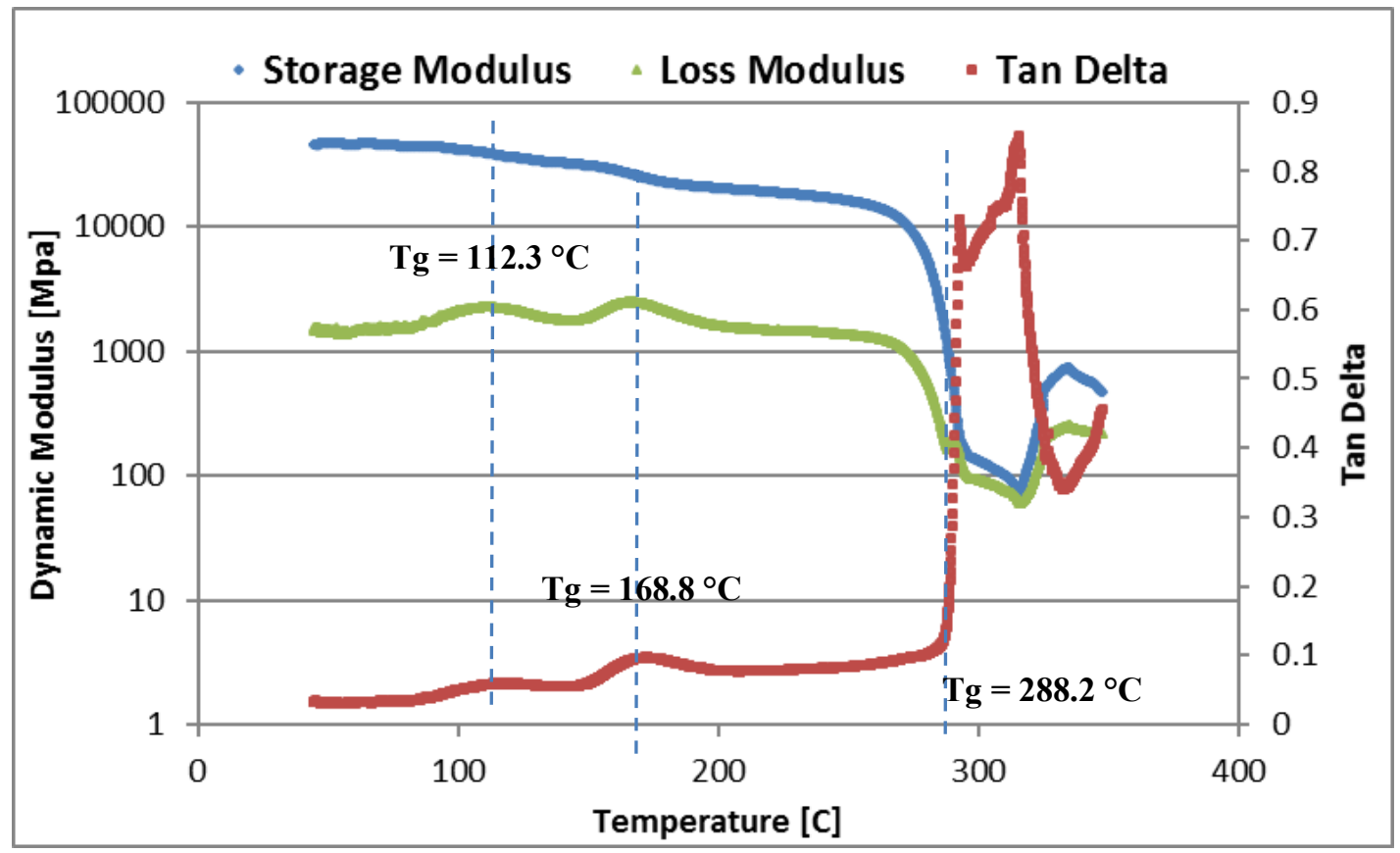

Figure $27 \mathrm{C} 7$ core material DMA Testing, sample \#9; Test temperature ramp at $3^{\circ} \mathrm{C} / \mathrm{min}$ from room temperature to $350^{\circ} \mathrm{C}$, with the following parameters: driving force is at $0.175 \mathrm{~N}$, amplitude of $1.55 \mu \mathrm{m}$, and static force of $0.258 \mathrm{~N}$. 


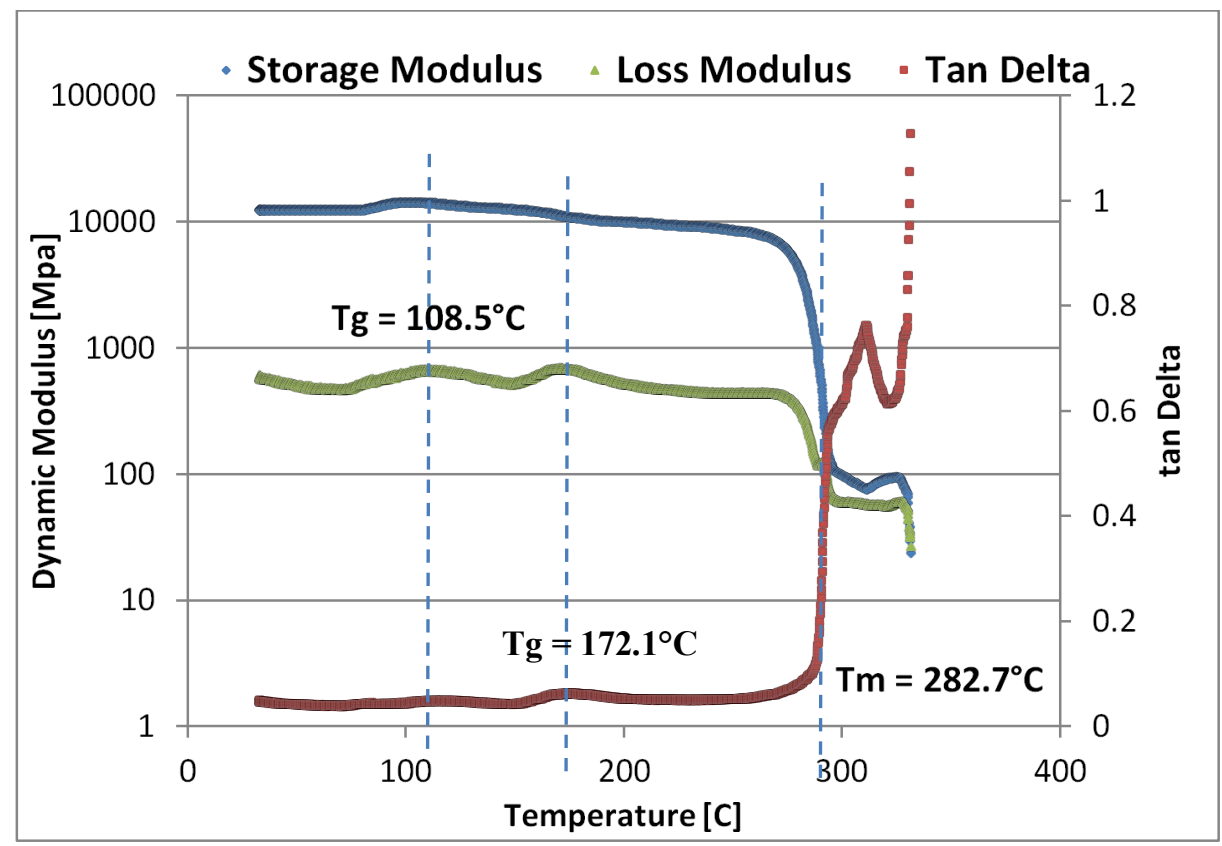

Figure $28 \mathrm{C} 7$ core material DMA Testing, sample \#10; Test temperature ramp at $3^{\circ} \mathrm{C} / \mathrm{min}$ from room temperature to $350^{\circ} \mathrm{C}$, with the following parameters: driving force is at $0.1 \mathrm{~N}$, amplitude of $2.85 \mu \mathrm{m}$, and static force of $0.14 \mathrm{~N}$.

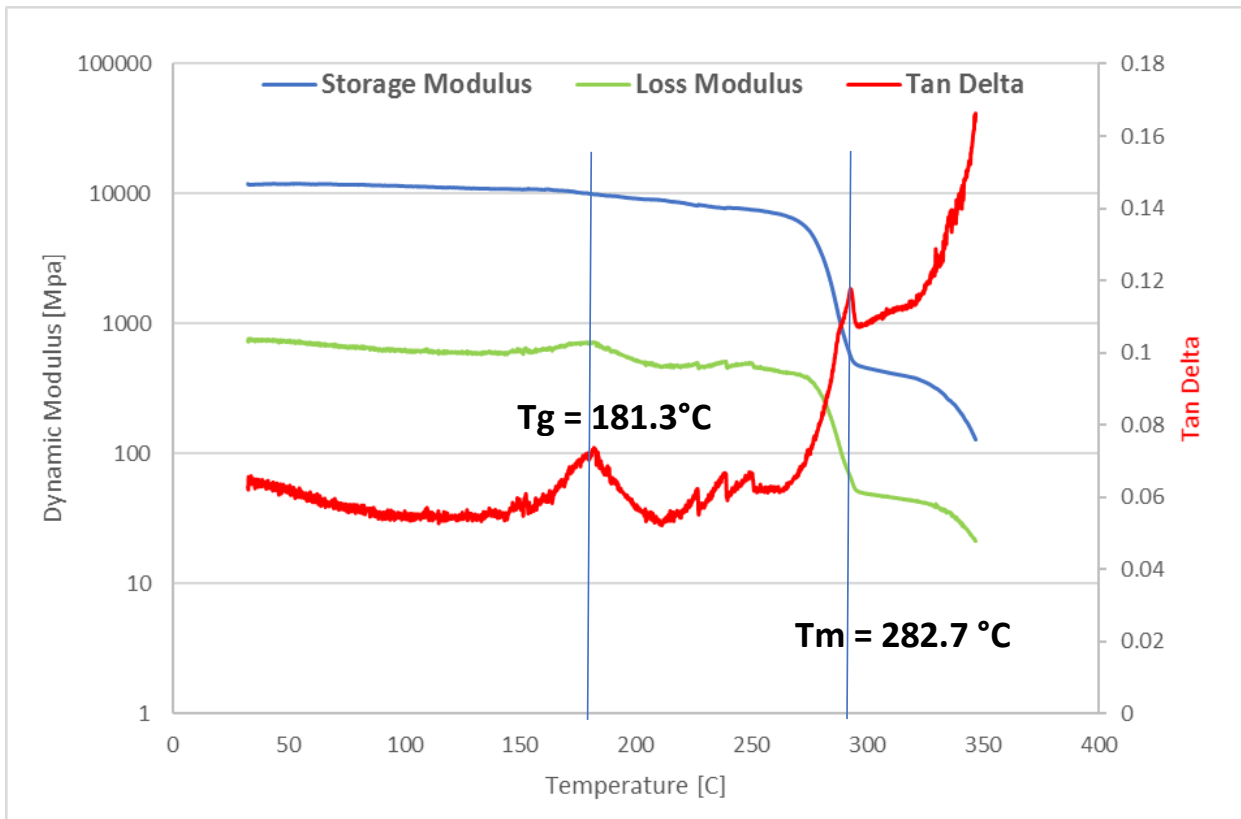

Figure 29 C7 core material DMA Testing, sample \#11 of received EPRI thermal cycling Otemp carbon core aging sample; Test temperature ramp at $5^{\circ} \mathrm{C} / \mathrm{min}$ from room temperature to $350^{\circ} \mathrm{C}$, with the following parameters: driving force is at $0.1 \mathrm{~N}$, amplitude of $3.0 \mu \mathrm{m}$, and static force of $0.12 \mathrm{~N}$. 


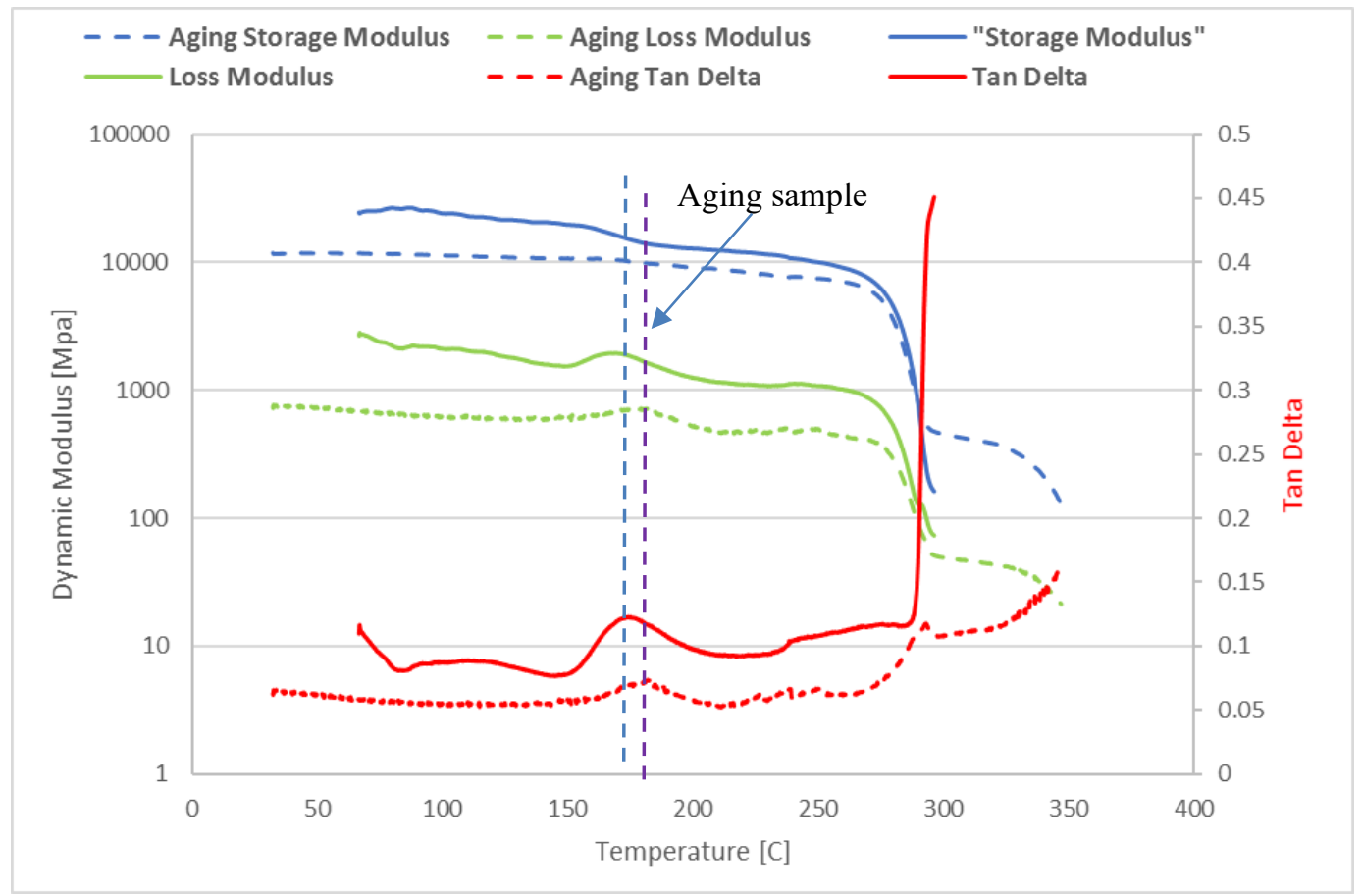

Figure 30 Comparison of EPRI aging C7 composite core sample DMA test results and baseline $\mathrm{C} 7$ carbon core sample DMA test results. Which shows decrease in storage and loss modulus from aging $\mathrm{C} 7$ carbon core sample compared to that of baseline $\mathrm{C} 7$ carbon core sample; and thermal cycling aging sample also shows lower damping than that of the baseline sample. The aging sample DMA test result shows increase in $\mathrm{Tg}$ compared to that of baseline sample. 


\subsection{TMA testing results}

\section{Principles of TMA}

A dilatometer is used to determine the linear thermal expansion of a solid as a function of temperature. Unlike the classical methods in which the experimental setup is kept as free of forces as possible, in the thermomechanical analysis, a constant, usually small load acts on the specimen. The measured expansion of the specimen can be used to determine the coefficient of linear thermal expansion $\alpha$.

\section{TMA Q400 Tester Set-up}

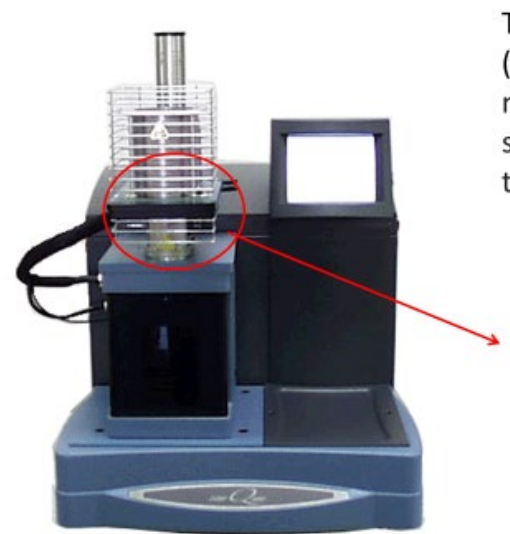

Thermomechanical Analysis (TMA), is a technique that measures changes in sample size as a function of temperature, time and load.

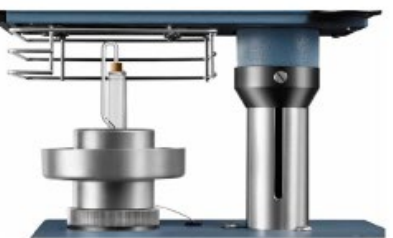

The 1st heating phase yields information about the actual state of the specimen, including its thermal and mechanical history. When thermoplastics soften, especially above the glass transition, orientations and stresses may relax, as a result of which post-crystallization and recrystallization processes may occur. On the other hand, the specimen may deform under the applied test load. To determine the coefficient of expansion as a material characteristic, the material must not undergo irreversible changes, such as post-crystallization, postpolymerization, relaxation of orientation or internal stress and so forth during a 2 nd heating phase that has followed controlled cooling. Also, the anisotropy of the sample part must be taken into account.

The coefficient of linear thermal expansion can serve as a material characteristic only where material behavior is reversible. The coefficient of thermal expansion $\left(1 \times 10^{-6} /{ }^{\circ} \mathrm{C}\right)$ comparison of different materials is shown to the right.
- 1350 Aluminum (all tempers)

- Aluminum Alloys (all)

- Copper

- Steel

- Metal Matrix Composite (3M)

- Polymer Composite
23.0

23.0

16.0

11.5

6.3

1.7

The temperature-dependent change of length is the progressive change of length expressed regarding the initial length/reference length 10 . It is a relative measure of the linear expansion, which always has a value of 0 at the start of the trial at the reference temperature $T_{0}$. The differential (or local) coefficient of linear thermal expansion $\alpha(T)$ is derived as follows:

$$
\alpha(\mathrm{T})=\frac{1}{1_{0}} \cdot \frac{\mathrm{dl}_{\mathrm{th}}}{\mathrm{dT}} \quad\left[\frac{\mu \mathrm{m}}{\mathrm{m}^{\circ} \mathrm{C}}\right]
$$

The values may assume the dimensions $\left[10^{-6}{ }^{\circ} \mathrm{C}^{-1}\right]$.

The Tg evaluated from TMA technique is around $157^{\circ} \mathrm{C}$ to $170^{\circ} \mathrm{C}$ for the baseline $\mathrm{C} 7$ core and about $193^{\circ} \mathrm{C}$ for the thermal cycle aged $\mathrm{C} 7$ core sample. However, the linear thermal expansion coefficient for the post-Tg region is around $3.23 \mathrm{E}-6$ to $6.49 \mathrm{E}-6 /{ }^{\circ} \mathrm{C}$, which is about $2-4$ times higher than $1.7 \mathrm{E}-6 /{ }^{\circ} \mathrm{C}$ for the typical polymer composite. 


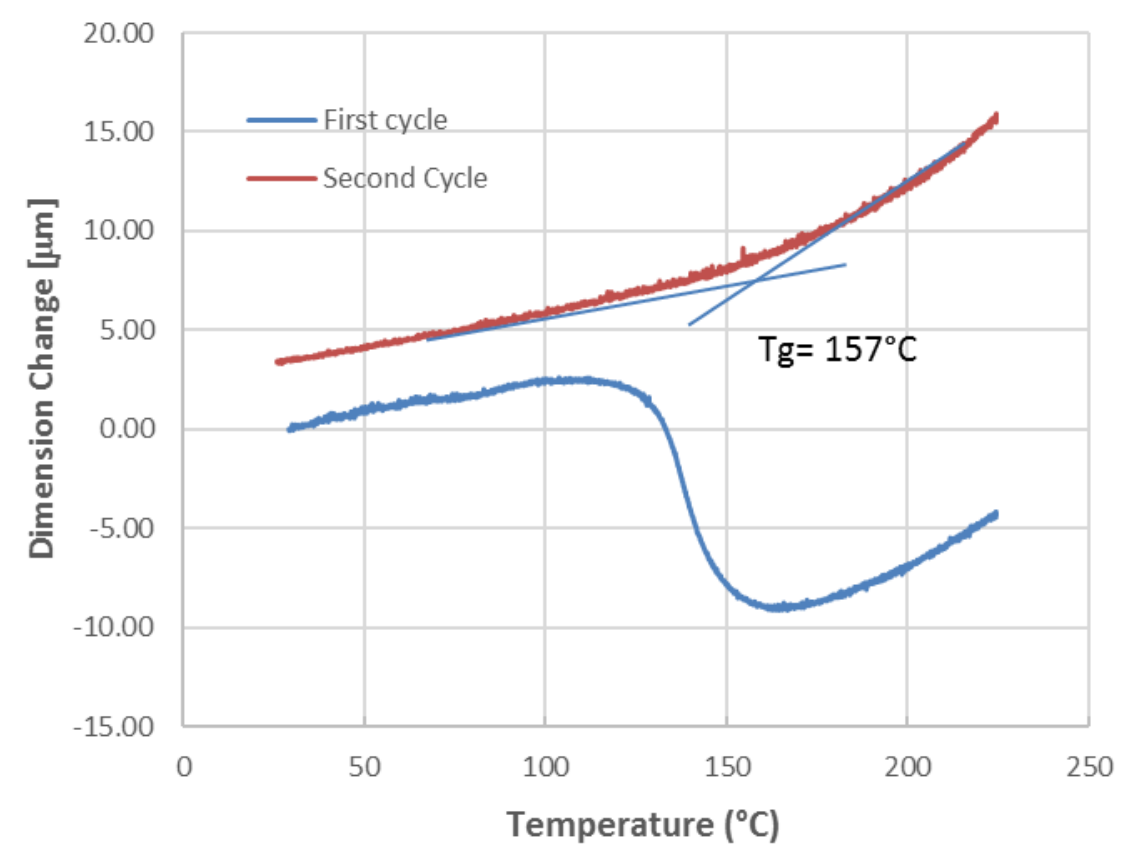

C7 carbon core TMA testing 1

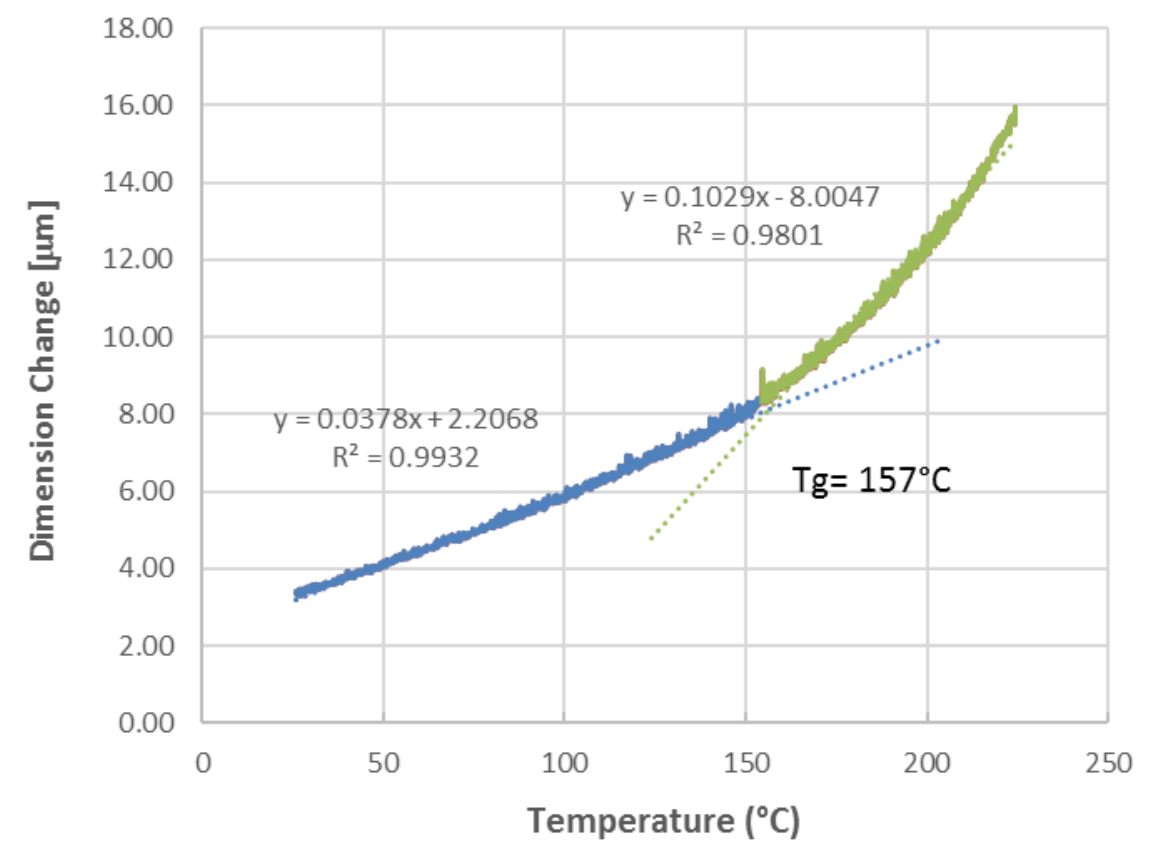

Figure $31 \mathrm{C} 7$ carbon core TMA testing 1 , first cycle ramp at $5^{\circ} \mathrm{C} / \mathrm{min}$ to $225 \mathrm{C}$, force $0.1 \mathrm{~N}$; second cycle: ramp at $5^{\circ} \mathrm{C} / \mathrm{min}$ to $225 \mathrm{C}$, load $0.05 \mathrm{~N}$, sample length $21.21 \mathrm{~mm}$. 

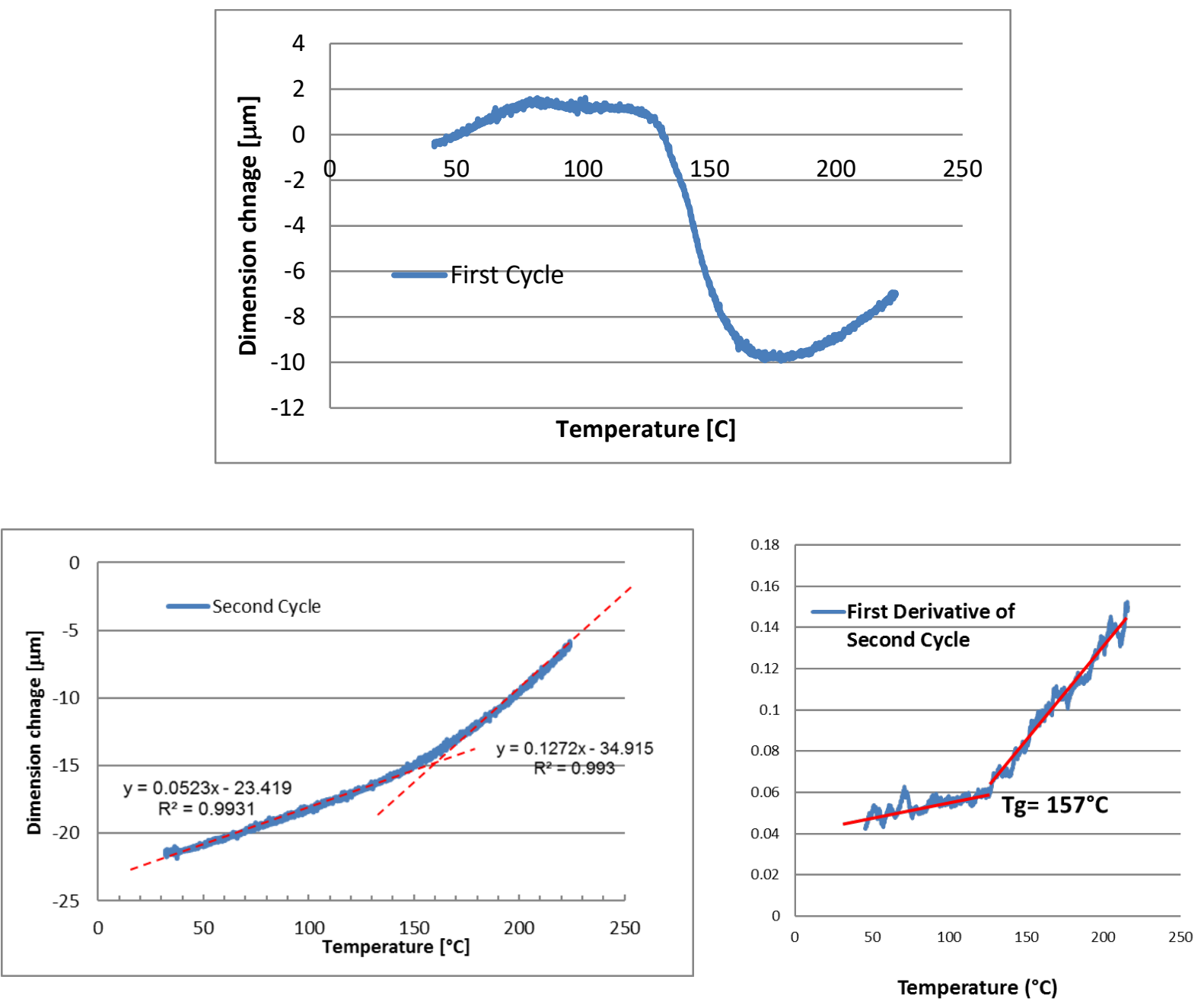

Figure $32 \mathrm{C} 7$ Core TMA Testing \#2; first cycle: ramp $10^{\circ} \mathrm{C} / \mathrm{min}$ to $225 \mathrm{C}$, load force $0.05 \mathrm{~N}$; second cycle ramp down $5^{\circ} \mathrm{C} / \mathrm{min}$ to $20 \mathrm{C}$, ramp up $5^{\circ} \mathrm{C} / \mathrm{min}$ to $225 \mathrm{C}$, load $0.02 \mathrm{~N}$, ramp down $5 \mathrm{C} / \mathrm{min}$ to 20C. Sample length $19.59-\mathrm{mm}$. 

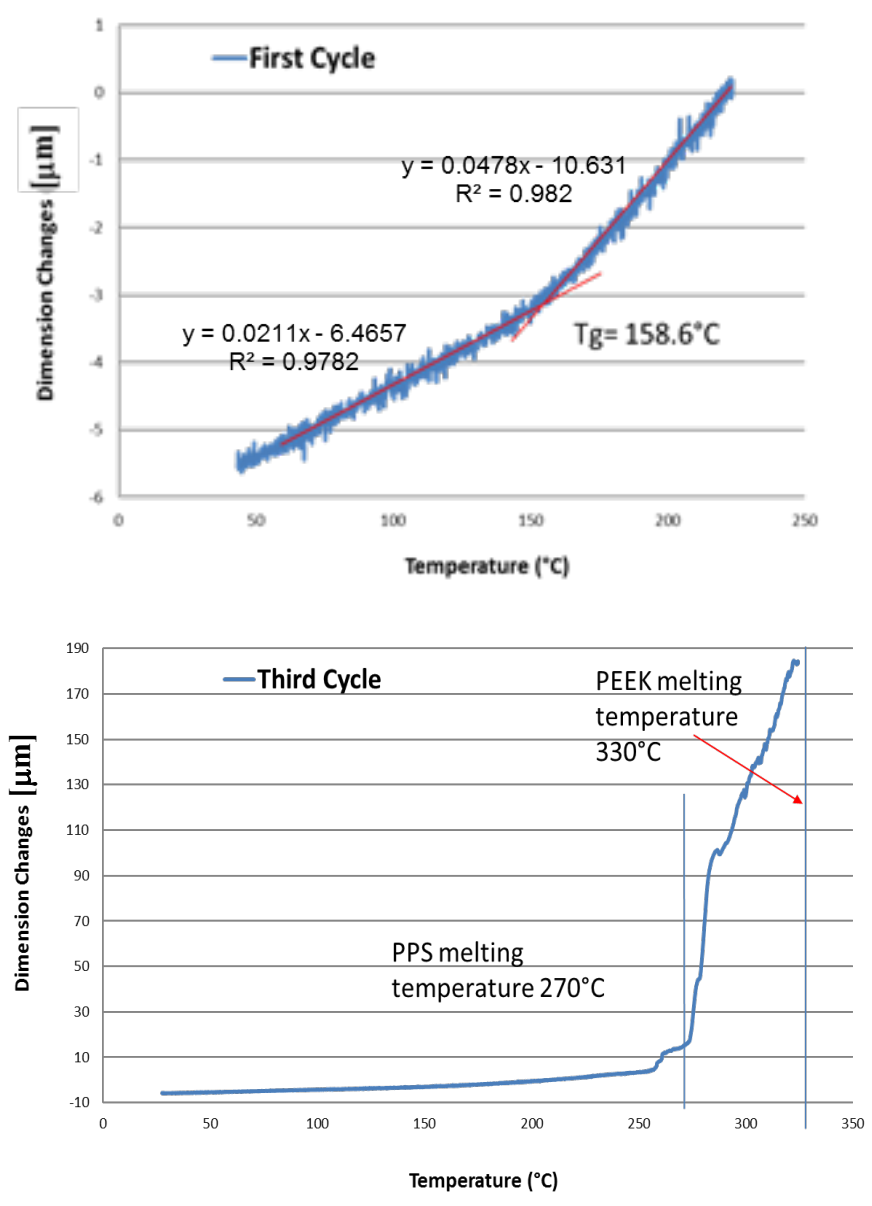
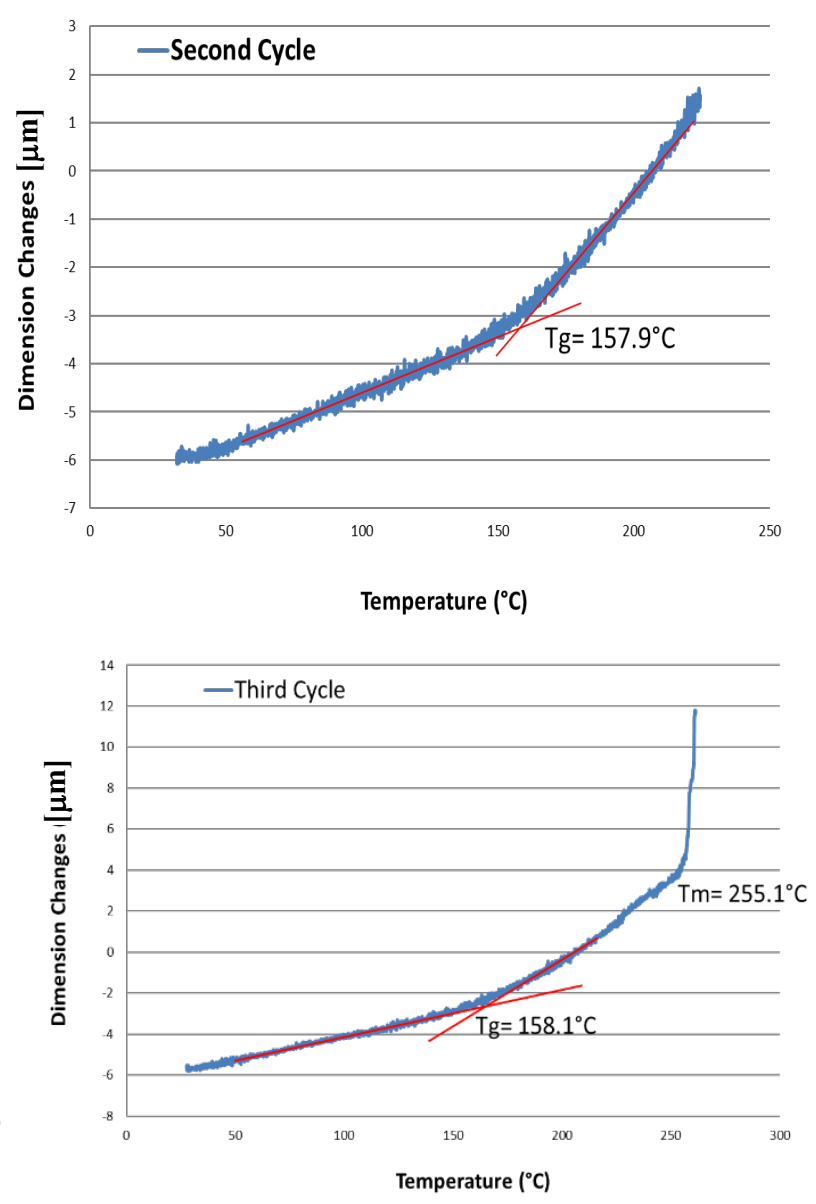

Figure 33 TMA C7 carbon Core Testing \#3; first cycle: ramp $10^{\circ} \mathrm{C} / \mathrm{min}$ to $225 \mathrm{C}$, load force $0.05 \mathrm{~N}$; second cycle ramp down $5^{\circ} \mathrm{C} / \mathrm{min}$ to $20 \mathrm{C}$, ramp up $5^{\circ} \mathrm{C} / \mathrm{min}$ to $225 \mathrm{C}$, load $0.02 \mathrm{~N}$, ramp down $5 \mathrm{C} / \mathrm{min}$ to $20 \mathrm{C}$, ramp up $5 \mathrm{C} / \mathrm{min}$ to $325 \mathrm{C}$, load $0.02 \mathrm{~N}$. sample length $8.4-\mathrm{mm}$. 


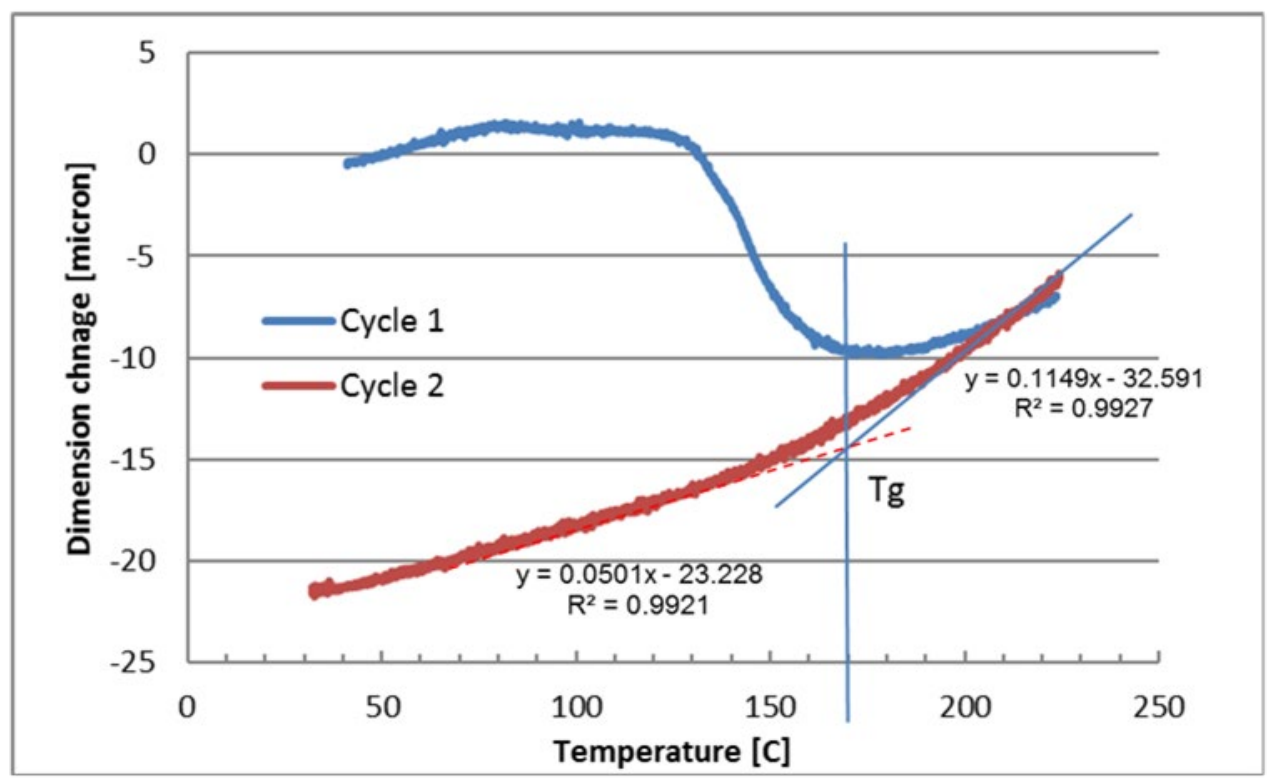

Figure 34 Cycle 1: Ramp $10^{\circ} \mathrm{C} / \mathrm{min}$ to $225 \mathrm{C}$, force $0.05 \mathrm{~N}$; Cycle 2: Ramp $5^{\circ} \mathrm{C} / \mathrm{min}$ to $225^{\circ} \mathrm{C}$, load force $0.02 \mathrm{~N}$, sample length $19.6-\mathrm{mm}$.

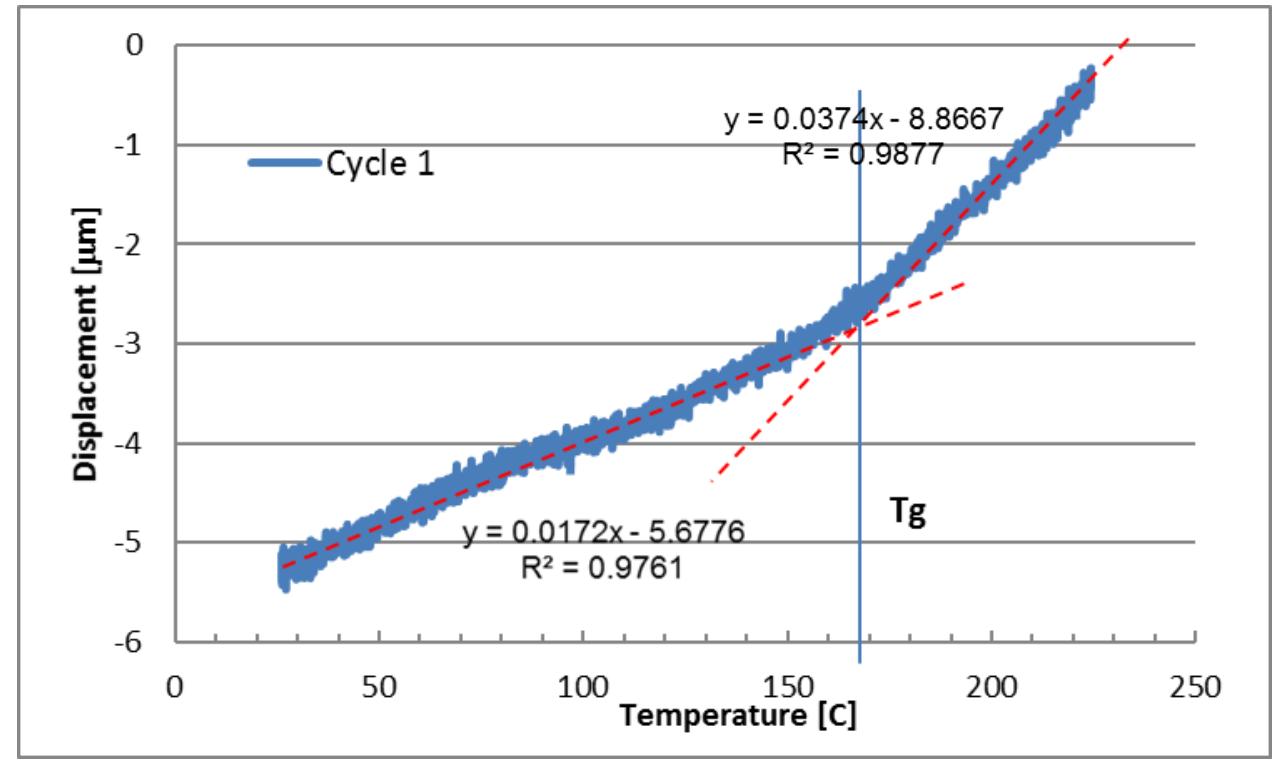

Figure 35 Cycle 1: Ramp 5C/min to 225C, load 0.05N; Cycle 2: 5C/min to 225C, load 0.02N. sample length $2.7-\mathrm{mm}$. 


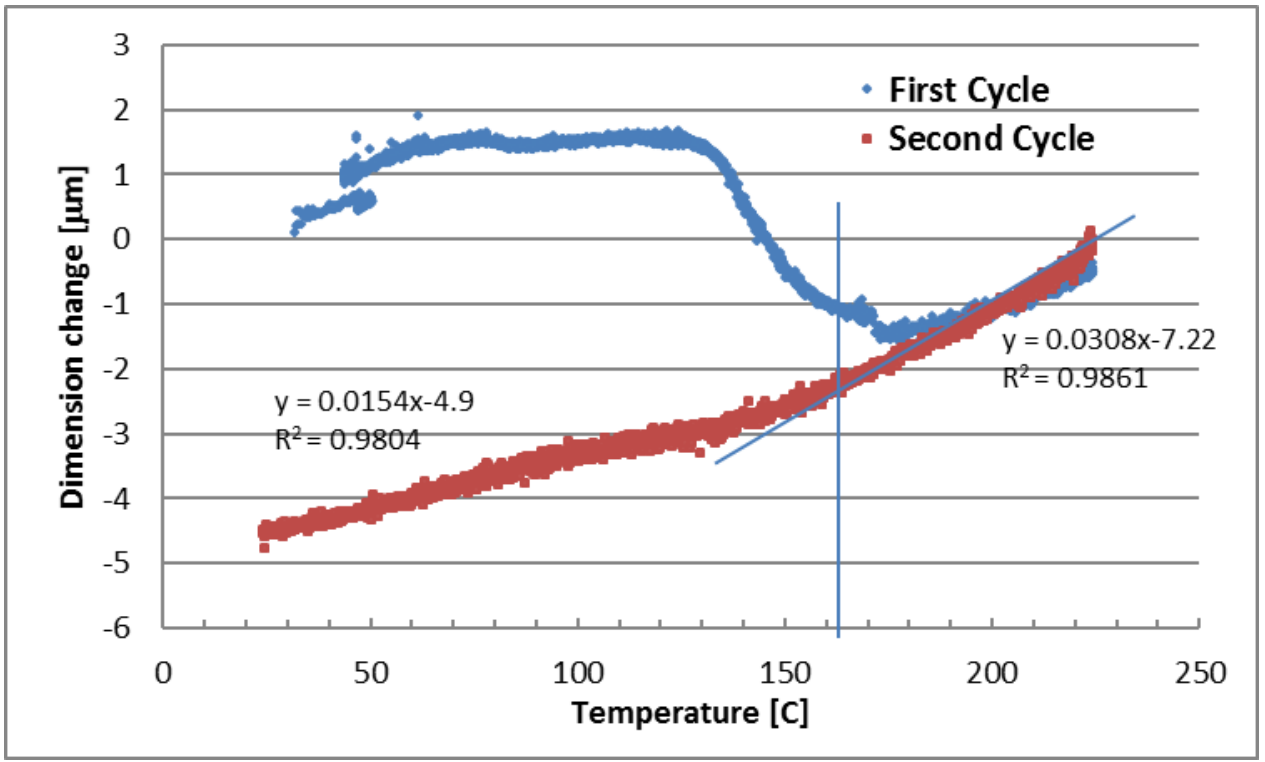

Figure 36 Sample length $9.509 \mathrm{~mm}$, Cycle 1: Ramp 5C/min to 225C, load 0.1N; Cycle 2: Ramp $5 \mathrm{C} / \mathrm{min}$ to 225 , load $0.05 \mathrm{~N}$. 

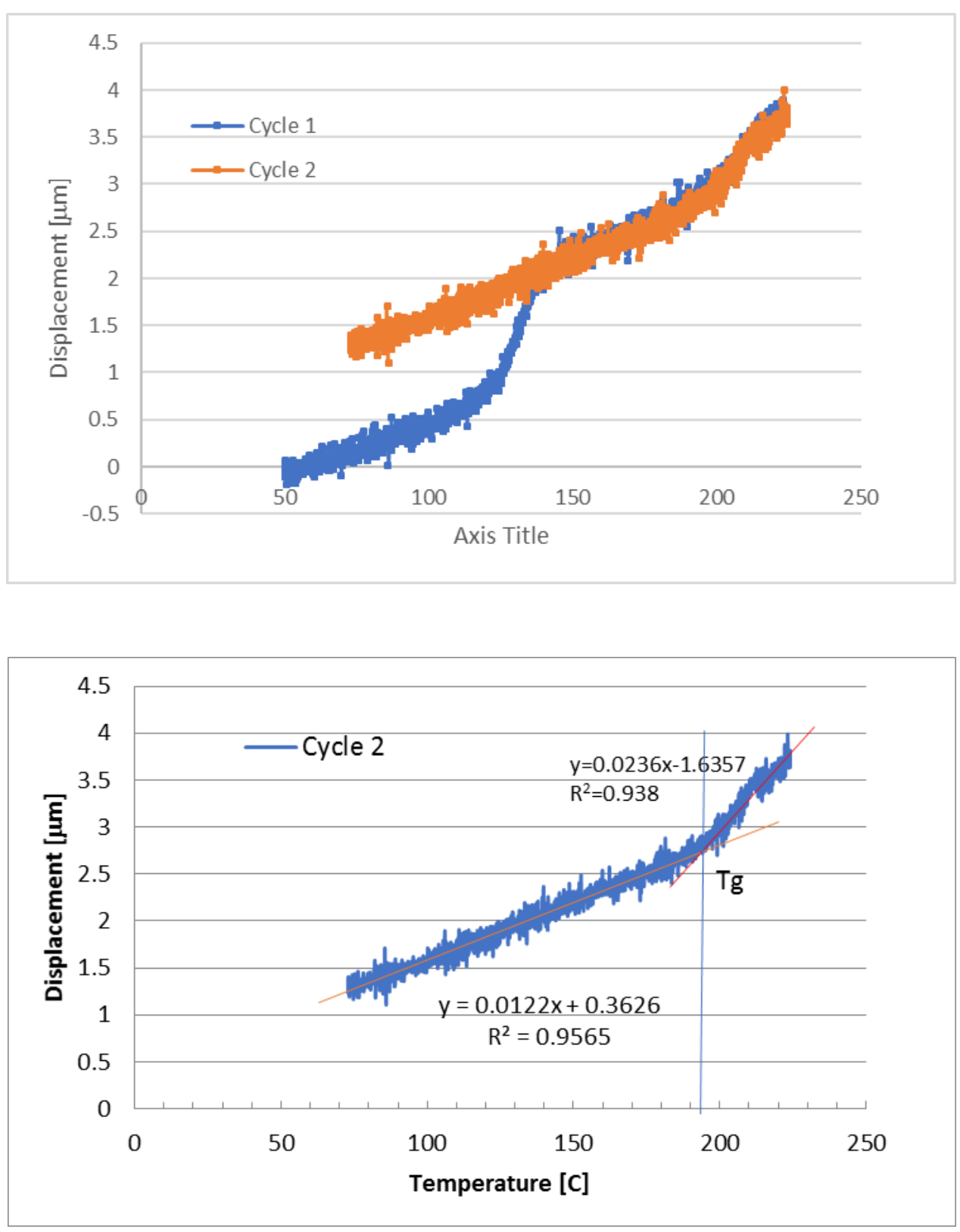

Figure 37 Aging C7 core Cycle 1: Ramp 10C/min to 225C, load force $0.05 \mathrm{~N}$; Cycle $25 \mathrm{C} / \mathrm{min}$ to 225C, load 02N. length 6.96-mm. 


\section{THERMAL AGING CHARACTERIZATION USING 3- POINT BENDING TEST}

The thermal aging experiments were carried out on $\mathrm{C} 7$ carbon composite core sample with dimension of $\phi 3.45 \mathrm{~mm} \times 100 \mathrm{~mm}$ in an oven the air, at $180^{\circ} \mathrm{C}$ for 100,500 , and 1000 hours; and at $225^{\circ} \mathrm{C}$ for 100 hours. The thermal aging characterizations were performed on baseline and thermally aged $\mathrm{C} 7$ composite core samples using 3-point bending test; the test results and the associated aging characteristics are discussion in this section.

\begin{tabular}{|l|l|l|}
\hline Techniques & Characteristics & Planned number of samples \\
\hline $\begin{array}{l}\text { Microscopy } \\
\text { analysis }\end{array}$ & $\begin{array}{l}\text { Presence of cracks } \\
\text { Homogeneity of the material }\end{array}$ & $\begin{array}{l}\text { 3 samples, rods } \phi 3.45 \times 100 \mathrm{~mm} \\
\text { coming out of ageing program }+ \\
\text { new one. }\end{array}$ \\
\hline $\begin{array}{l}\text { 3-point flexural } \\
\text { ASTM D790 }\end{array}$ & $\begin{array}{l}\text { Maximum deflection and failure } \\
\text { load of the sample during the test }\end{array}$ & $\begin{array}{l}\text { 3 samples per (time-temperature) } \\
\text { rods } \phi 3.45 \times 100 \mathrm{~mm}\end{array}$ \\
\hline
\end{tabular}

The aging C7 core samples were compared to baseline C7 core samples, shown in Figure 38; no apparent surface crack or damage were observed.
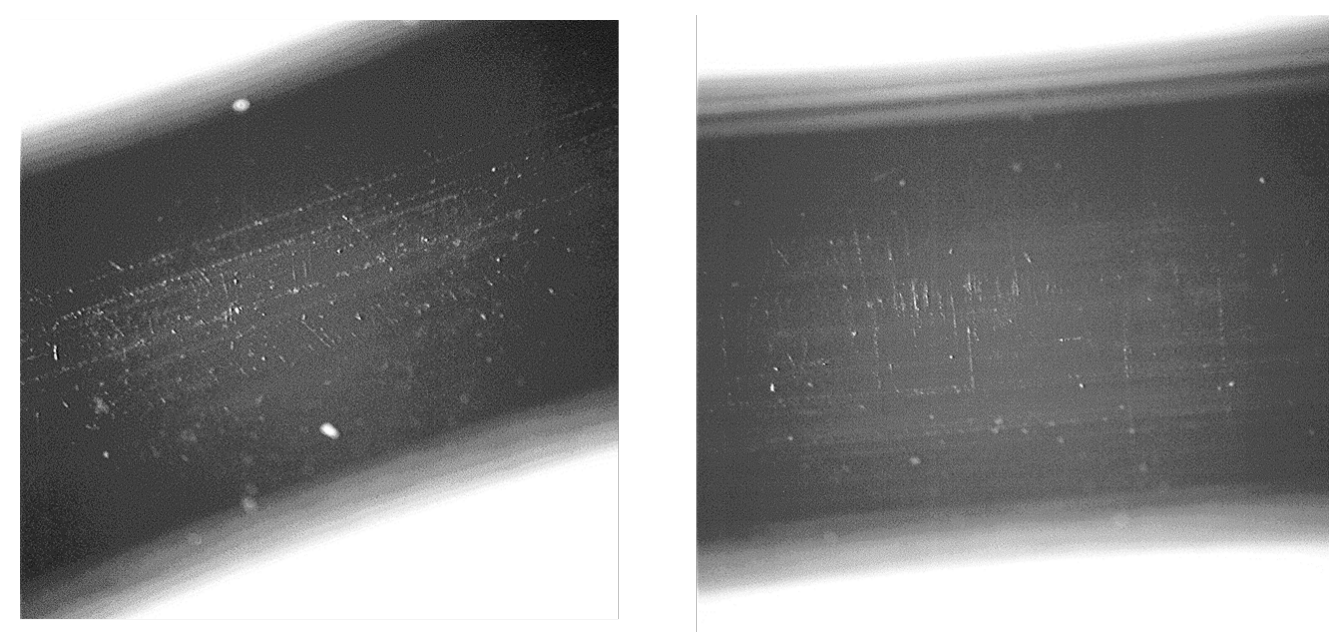

Baseline C7 Composite Core Samples 


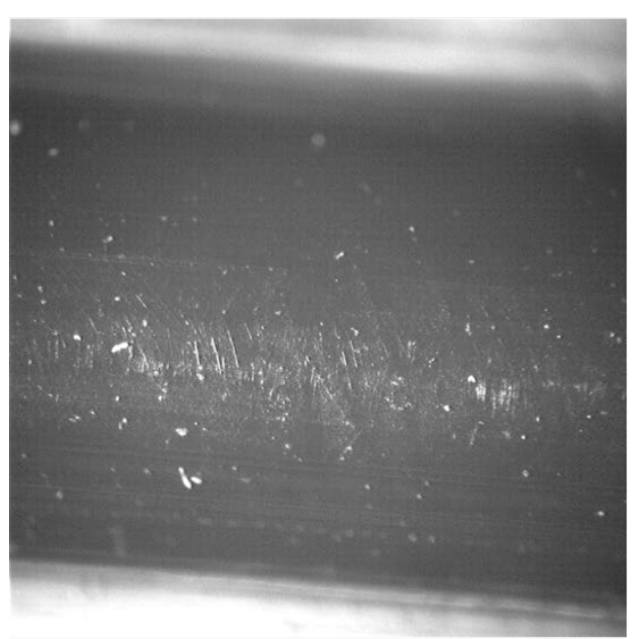

Baseline sample

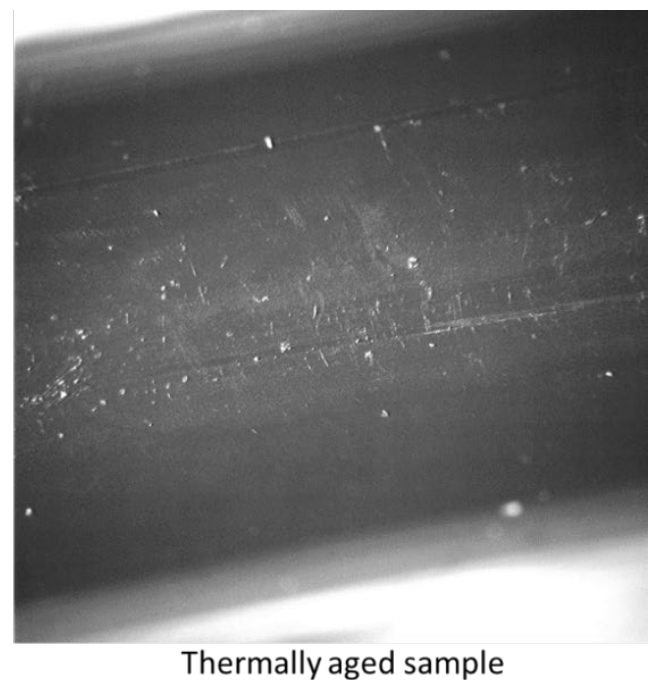

Thermally aged sample at $180^{\circ} \mathrm{C}, 500$ hours

Baseline \& $180^{\circ} \mathrm{C}$ Thermally Aged C7 Composite Core Samples

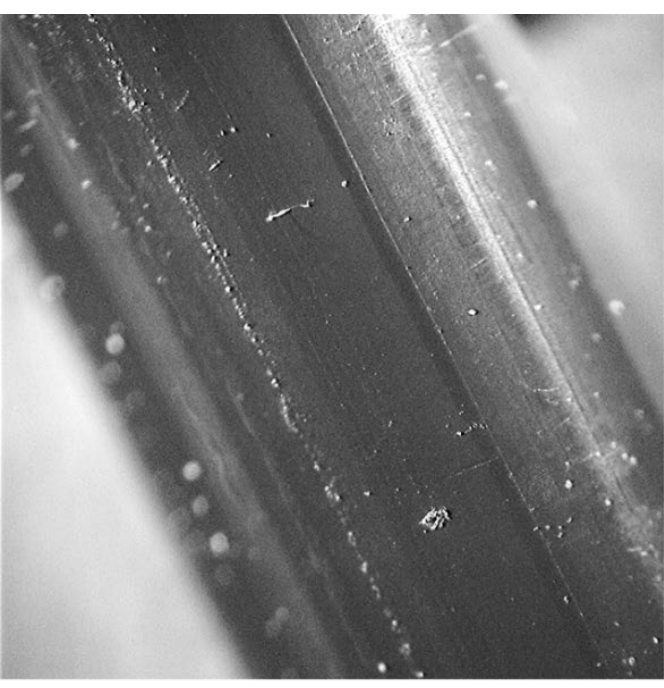

Baseline sample

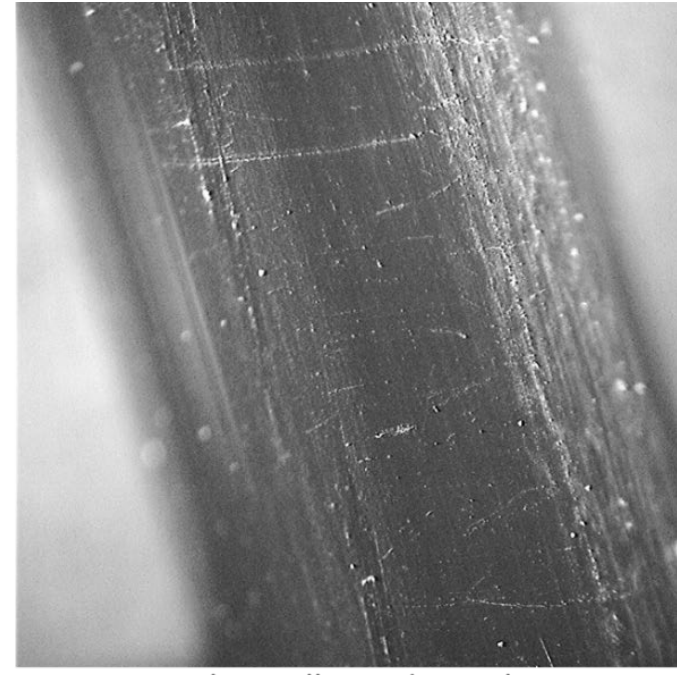

Thermally aged sample at $225^{\circ} \mathrm{C}, 100$ hours

Baseline \& $225^{\circ} \mathrm{C}$ Thermally Aged C7 Composite Core Samples

Figure 38 Comparison of microscopy images for $\mathrm{C} 7$ carbon composite core baseline sample and thermally aged samples at $180^{\circ} \mathrm{C}$ and $225^{\circ} \mathrm{C}$, respectively. 


\subsection{3-point Bending Test Results}

General observations from C7 core sample 3-point test results are stated below.

- Baseline $\mathrm{C} 7$ carbon core samples failed within loading ranges of $30-35 \mathrm{lb}$. and deflection ranges of $0.24-0.38$ inch. The pop-in occurred around $15 \mathrm{lb}$. and $27.5 \mathrm{lb}$.

- Thermally aged sample of $180^{\circ} \mathrm{C}-500$ hours failed at $33.9 \mathrm{lb}$. at 0.297 -inch deflection.

- Thermally aged sample of $180^{\circ} \mathrm{C}-1000$ hours failed at $46.4 \mathrm{lb}$. at 0.455 -inch deflection.

- Thermally aged sample of $225^{\circ} \mathrm{C}-100$ hours failed at $40.2 \mathrm{lb}$. at 0.406 -inch deflection.

- Baseline maximum stress is around $119 \mathrm{ksi}$ to $139 \mathrm{ksi}$, the corresponding maximum strain range is around $0.83 \%$ to $1.31 \%$.

- Maximum stress range of the thermal aging samples is around $133 \mathrm{ksi}$ to $184 \mathrm{ksi}$, and the corresponding maximum strain at failure is around $1.01 \%$ to $1.52 \%$ strain ranges.

- For EPRI thermal cycling aged samples, the maximum stress range is around $131 \mathrm{ksi}$ to $153 \mathrm{ksi}$, and the corresponding maximum strain at failure is around $1.062 \%$ to $1.256 \%$.

- The Young's modulus appeared to be reduced for thermal aging $\mathrm{C} 7$ core samples compared to that of baseline $\mathrm{C} 7$ core samples.

- The average Young's modulus of tested C7 core materials is around $8.5 \mathrm{msi}$, which is about $1 / 3$ value compared to that of steel.

- C7 core tested data of O-temp conductor has higher deflection than that of Zr-Al conductor.

The details of the 3-point bending test results are shown in Figures 39-57.

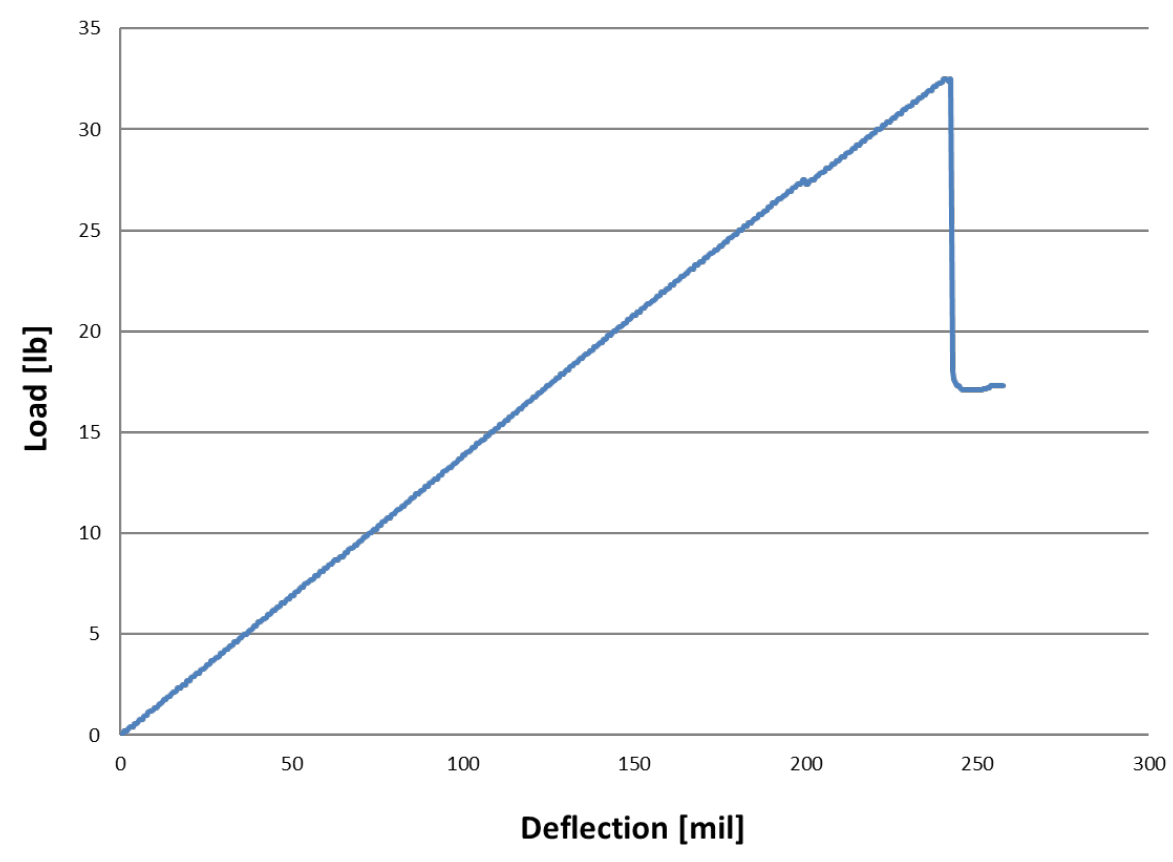



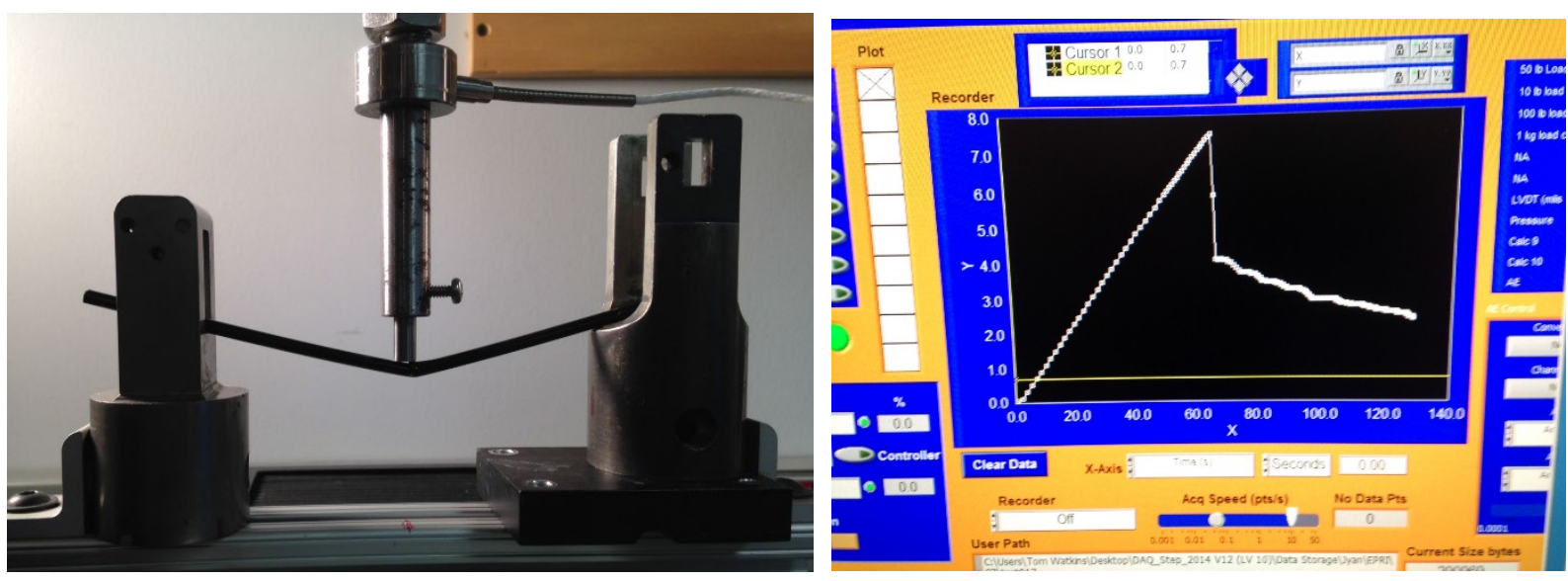

Figure 39 C7 Carbon Core 3-point Bending Test Sample \#1.

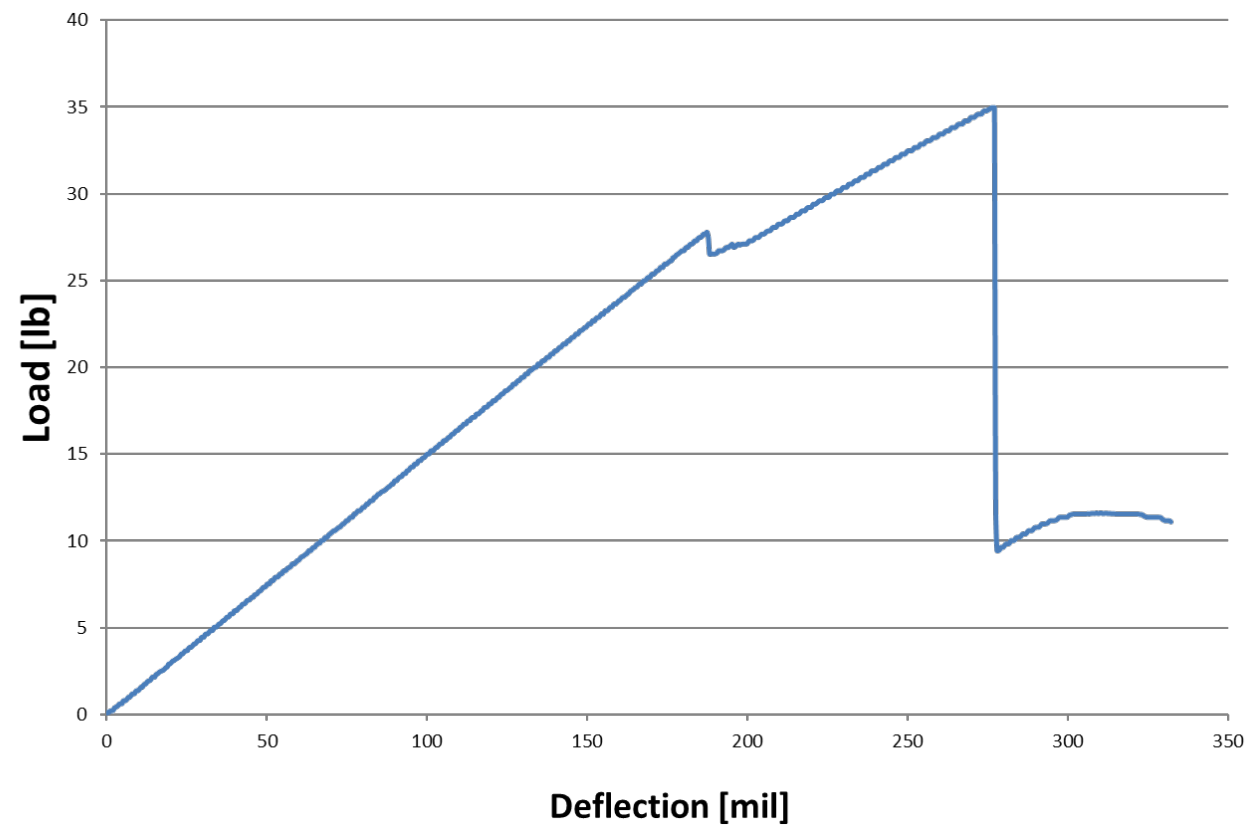

Figure 40 C7 Carbon Core 3-point Bending Test Sample \#2. 


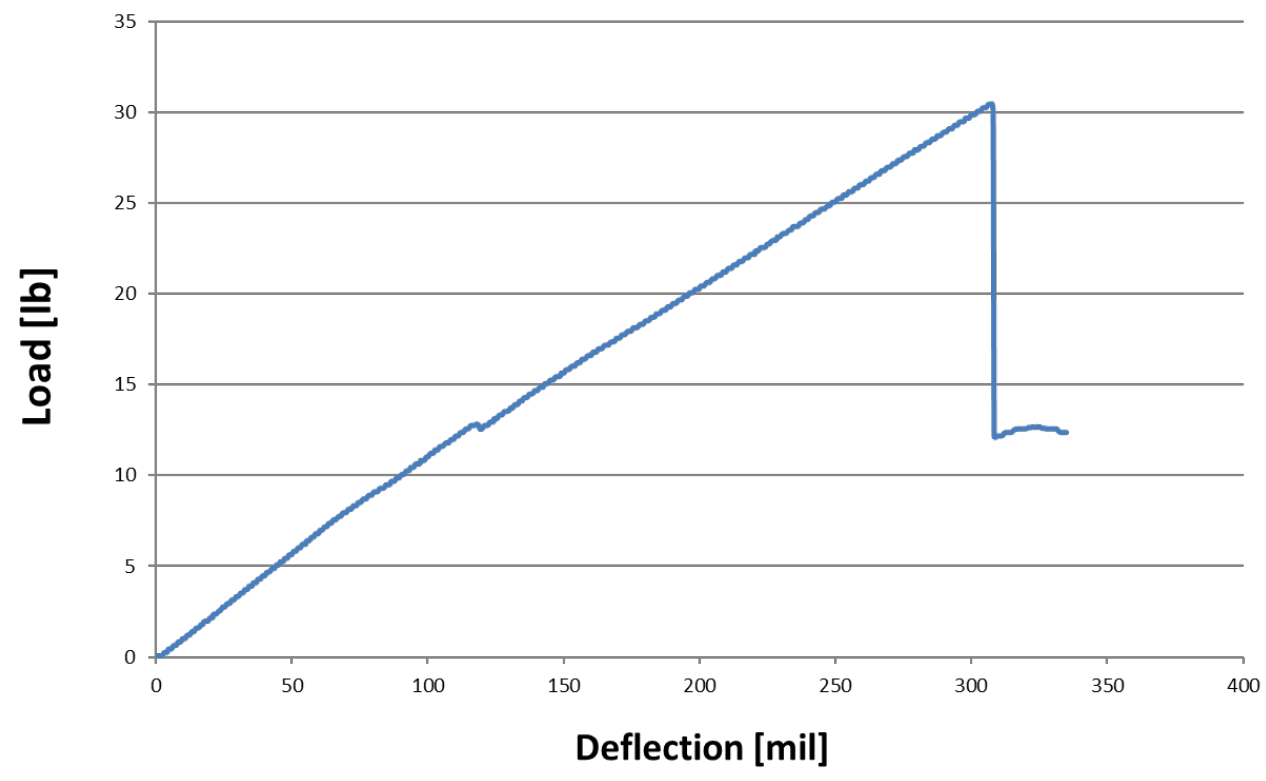

Figure 41 C7 Carbon Core 3-point Bending Test Sample \#3.

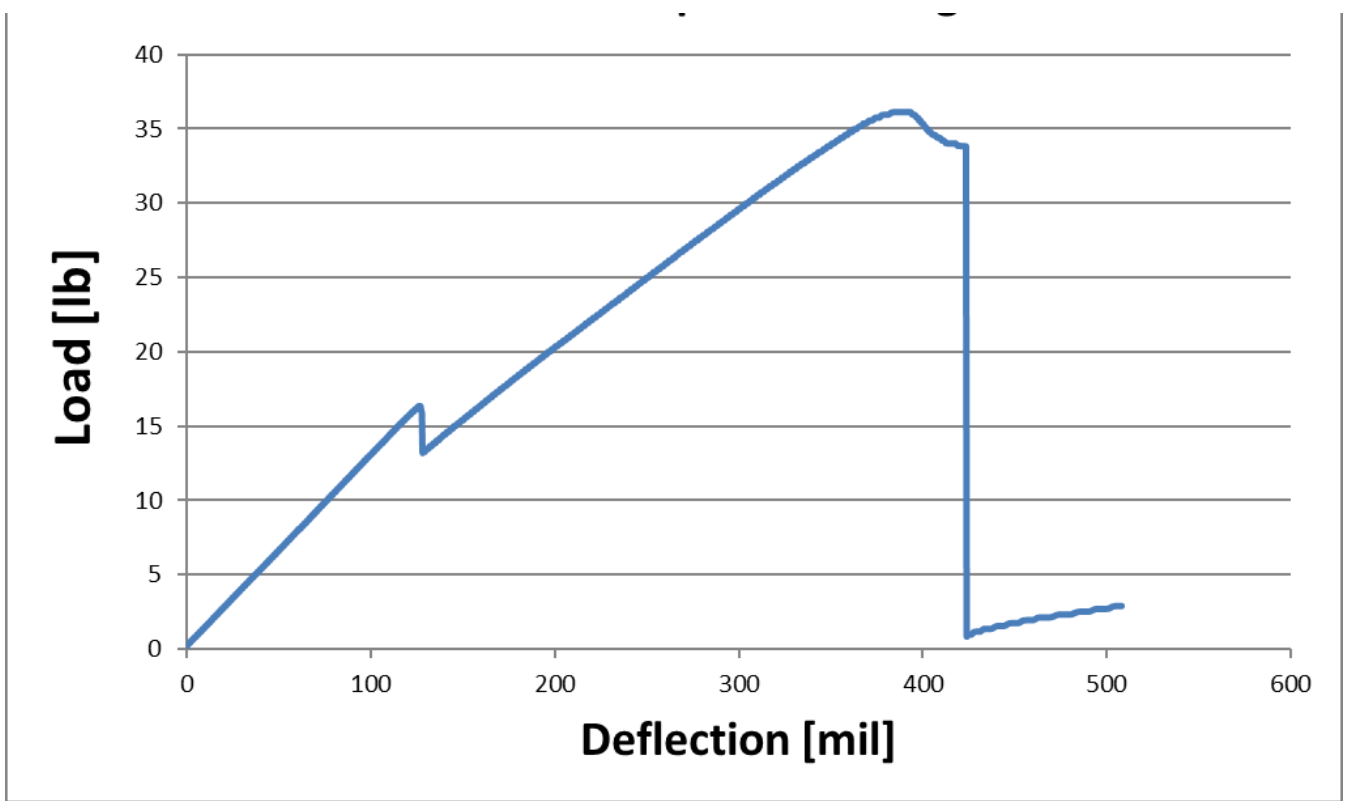

Figure 42 C7 Carbon Core 3-point Bending Test Sample \#4. 


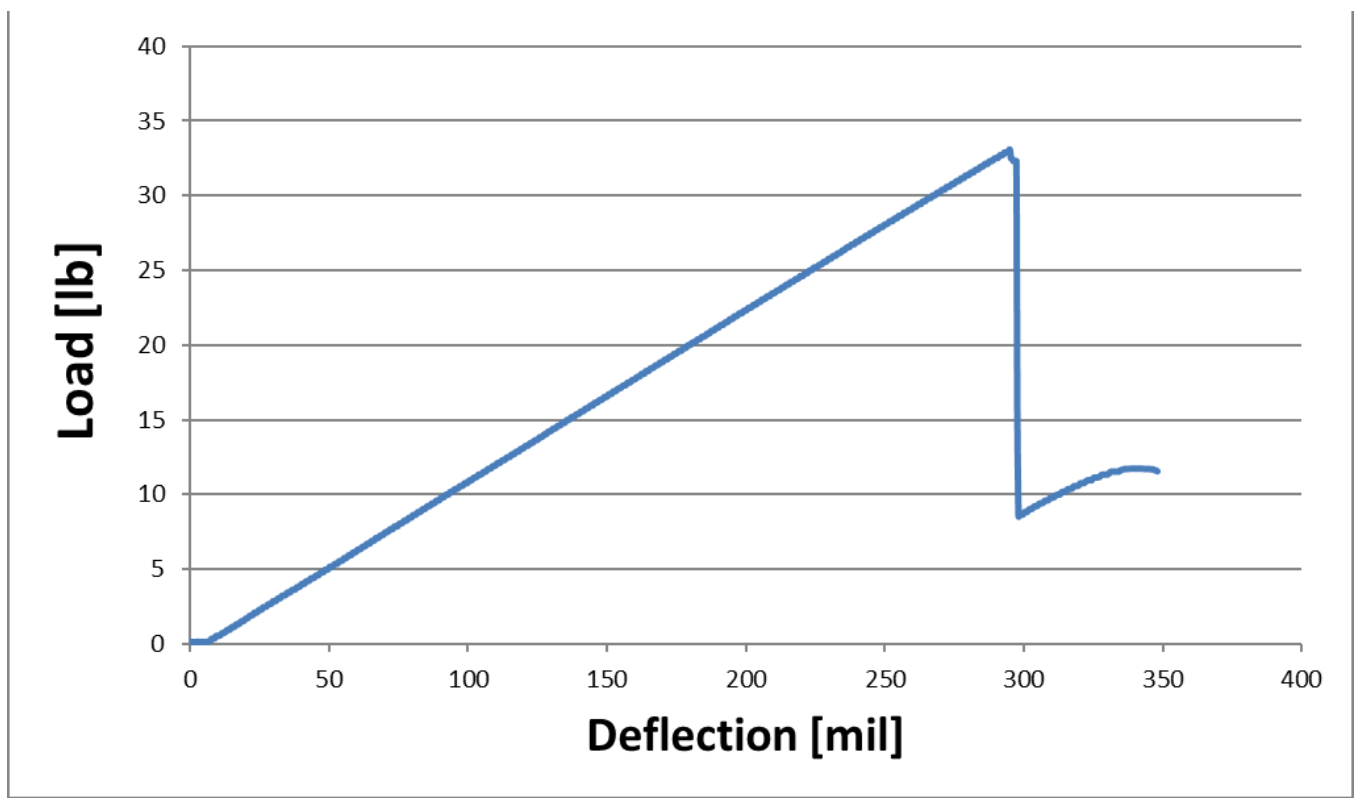

Figure 43 C7 Carbon Core 3-point Bending Test Sample \#5.

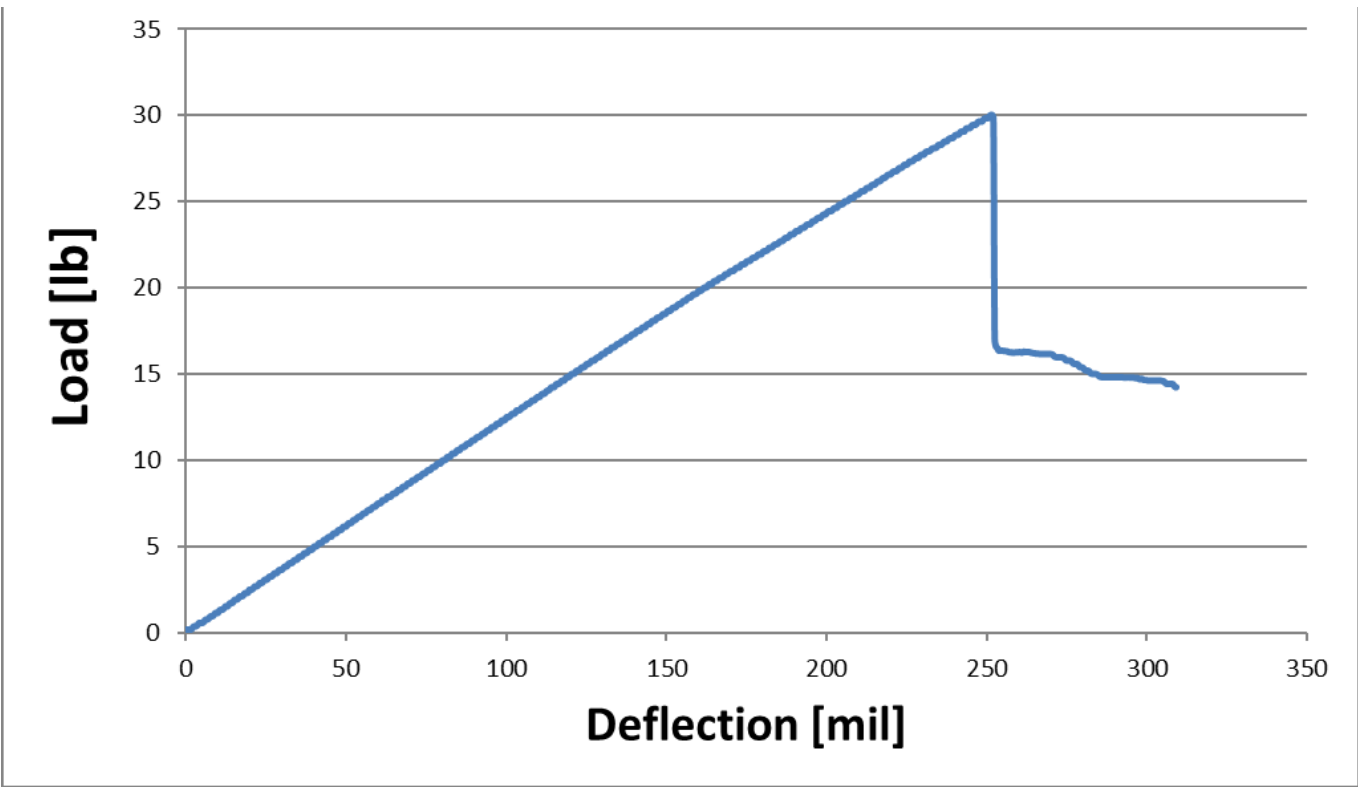

Figure 44 C7 Carbon Core 3-point Bending Sample \#6. 


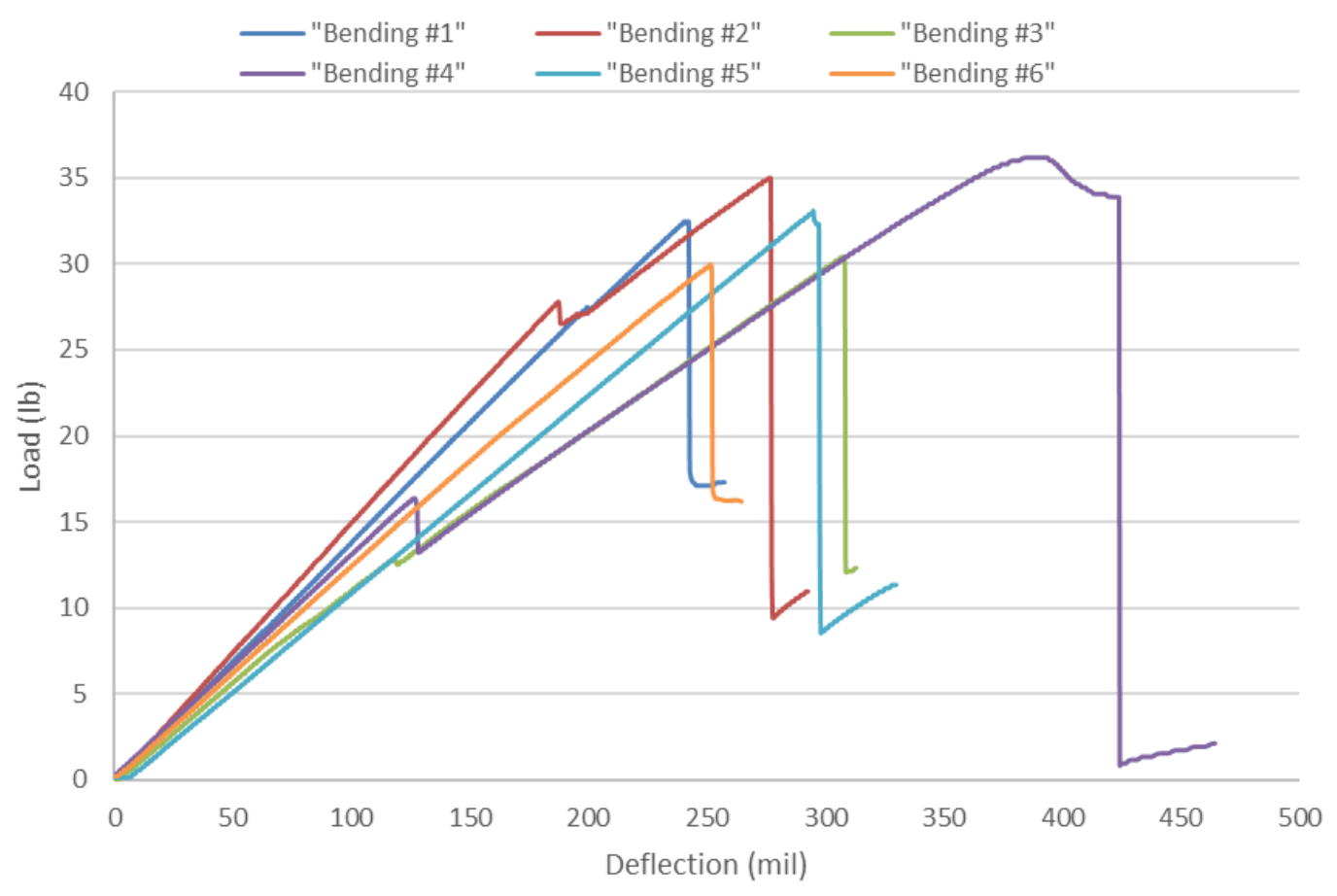

Figure 45 Baseline C7 Carbon Core 3-point Bending Test Results.

\section{Thermal aging test data}

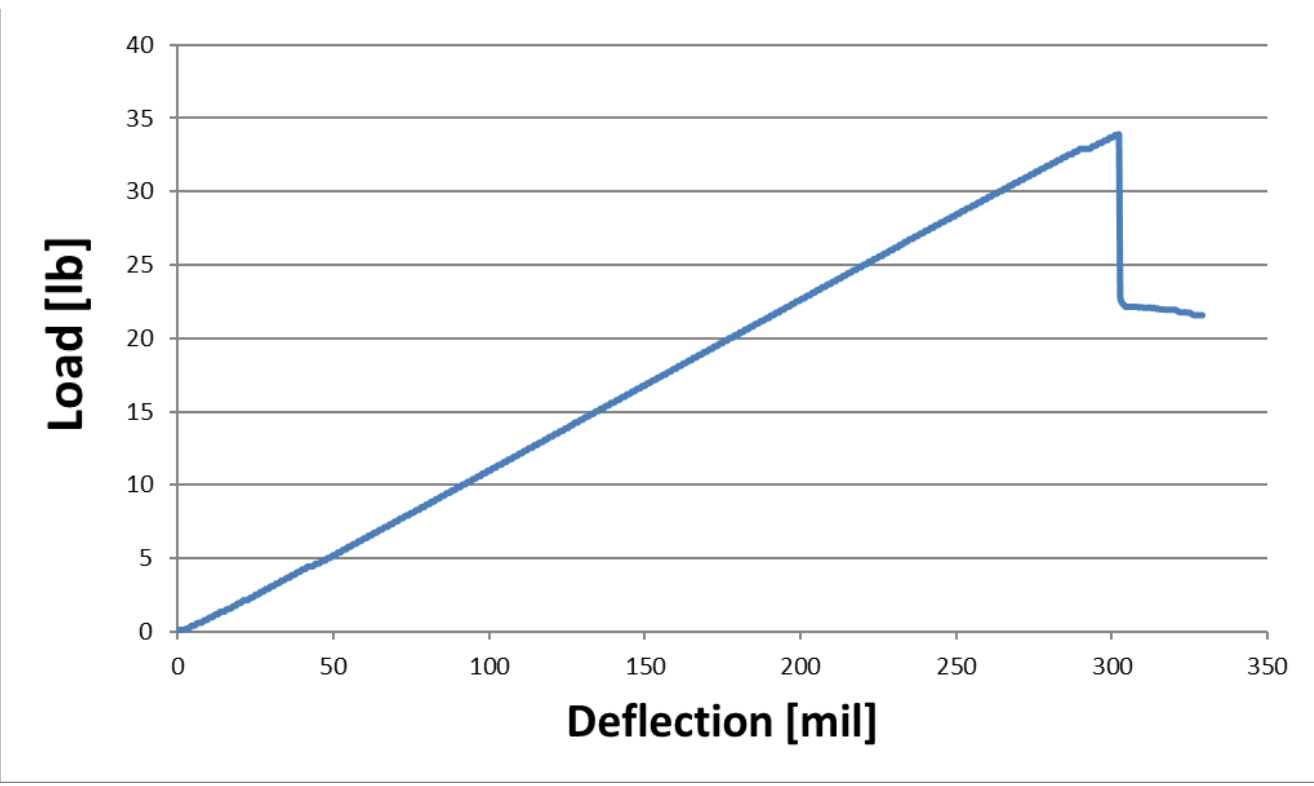

Figure 46 C7 Carbon Core 3-point Bending Test, aging sample with 180C for 100 hours. 


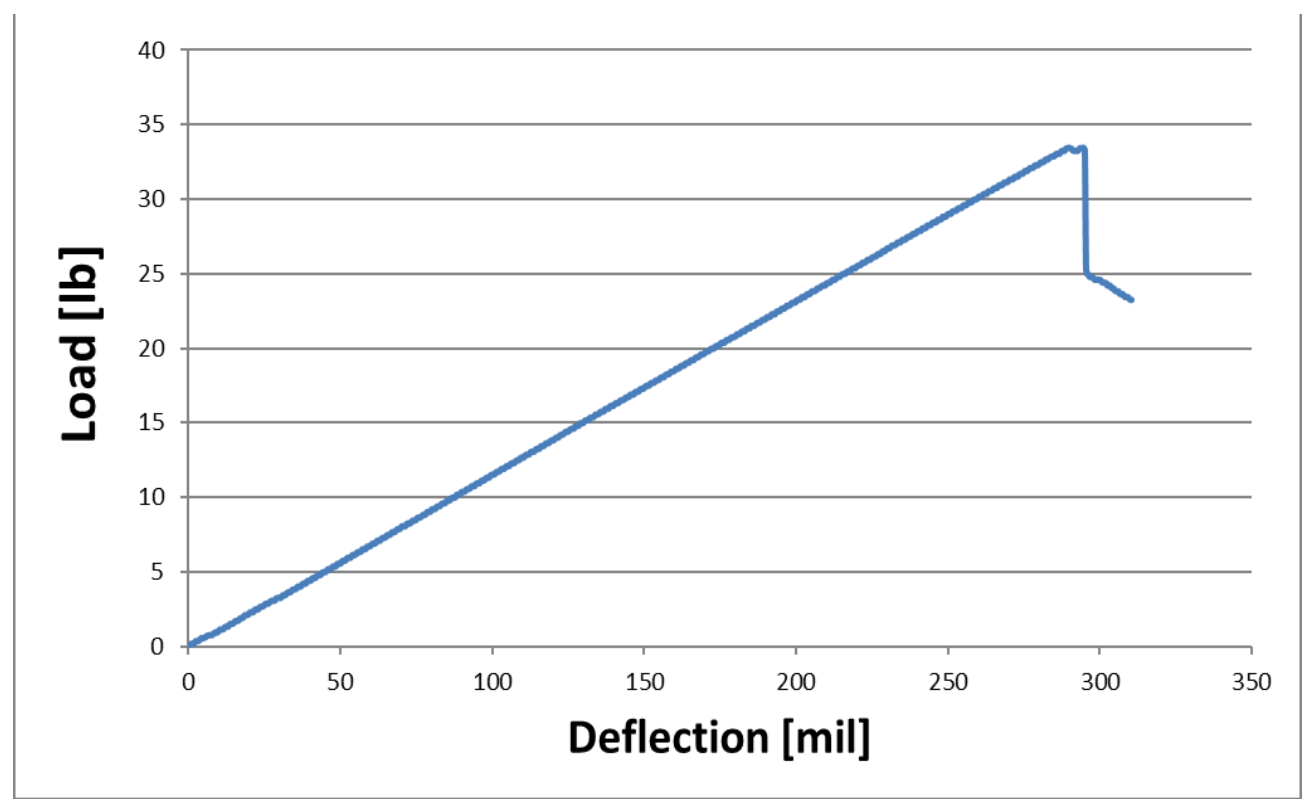

Figure $47 \mathrm{C} 7$ Carbon Core 3-point Bending test, sample aged at $180^{\circ} \mathrm{C}$ for 500 hours.

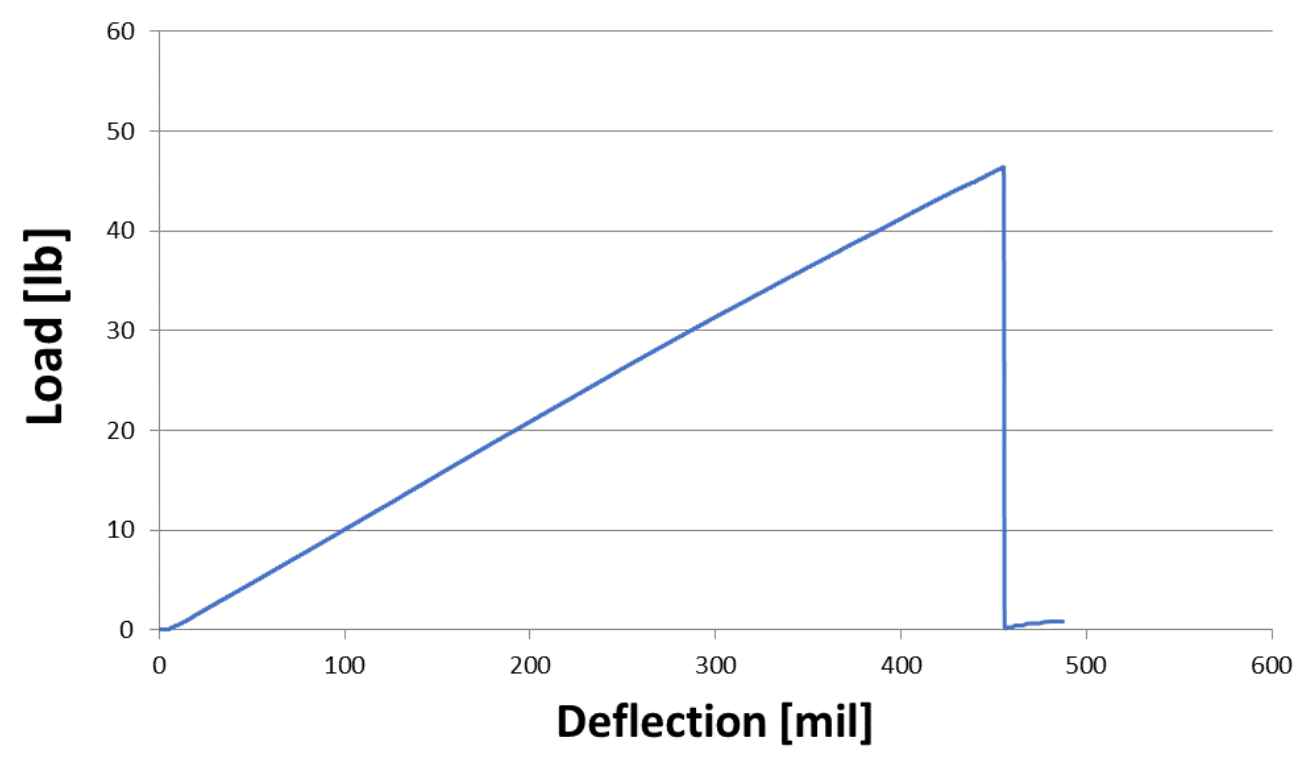

Figure 48 C7 Carbon Core 3-point Bending Test, sample aged at 180C for 1000 hours. 


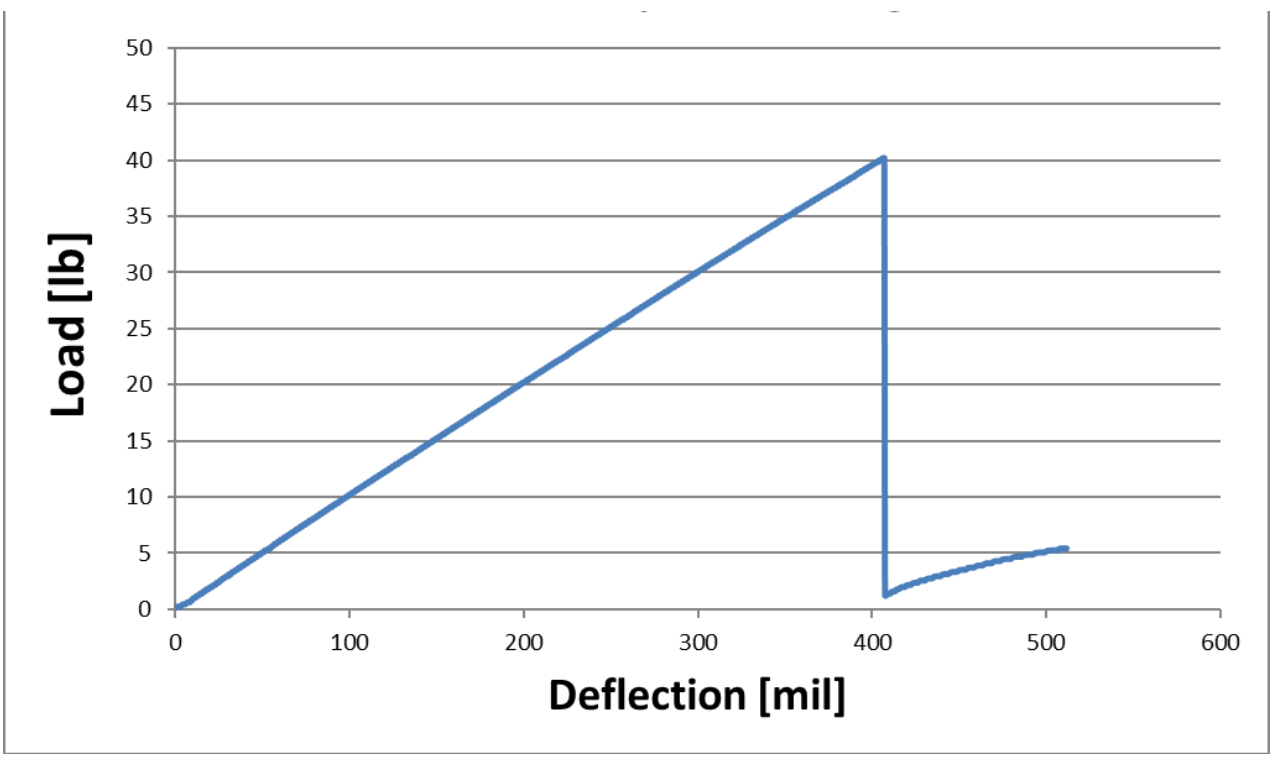

Figure $49 \mathrm{C} 7$ Carbon Core 3-point Bending Test, sample aged at $225^{\circ} \mathrm{C}-$ for 100 hours.

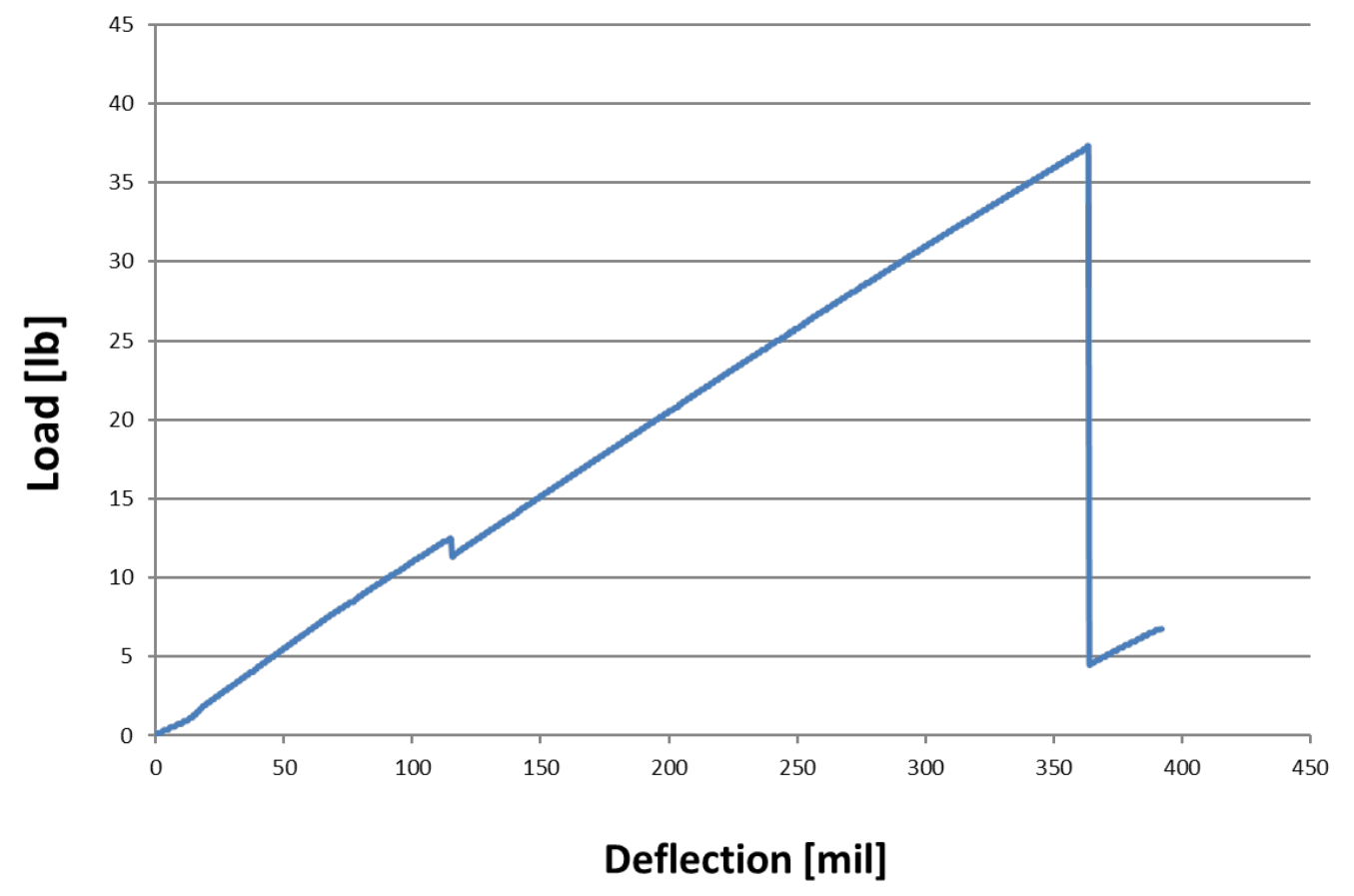

Figure $50 \mathrm{C} 7$ Carbon Core 3-point Bending Test, sample aged at $225^{\circ} \mathrm{C}$ for 100 hours. 


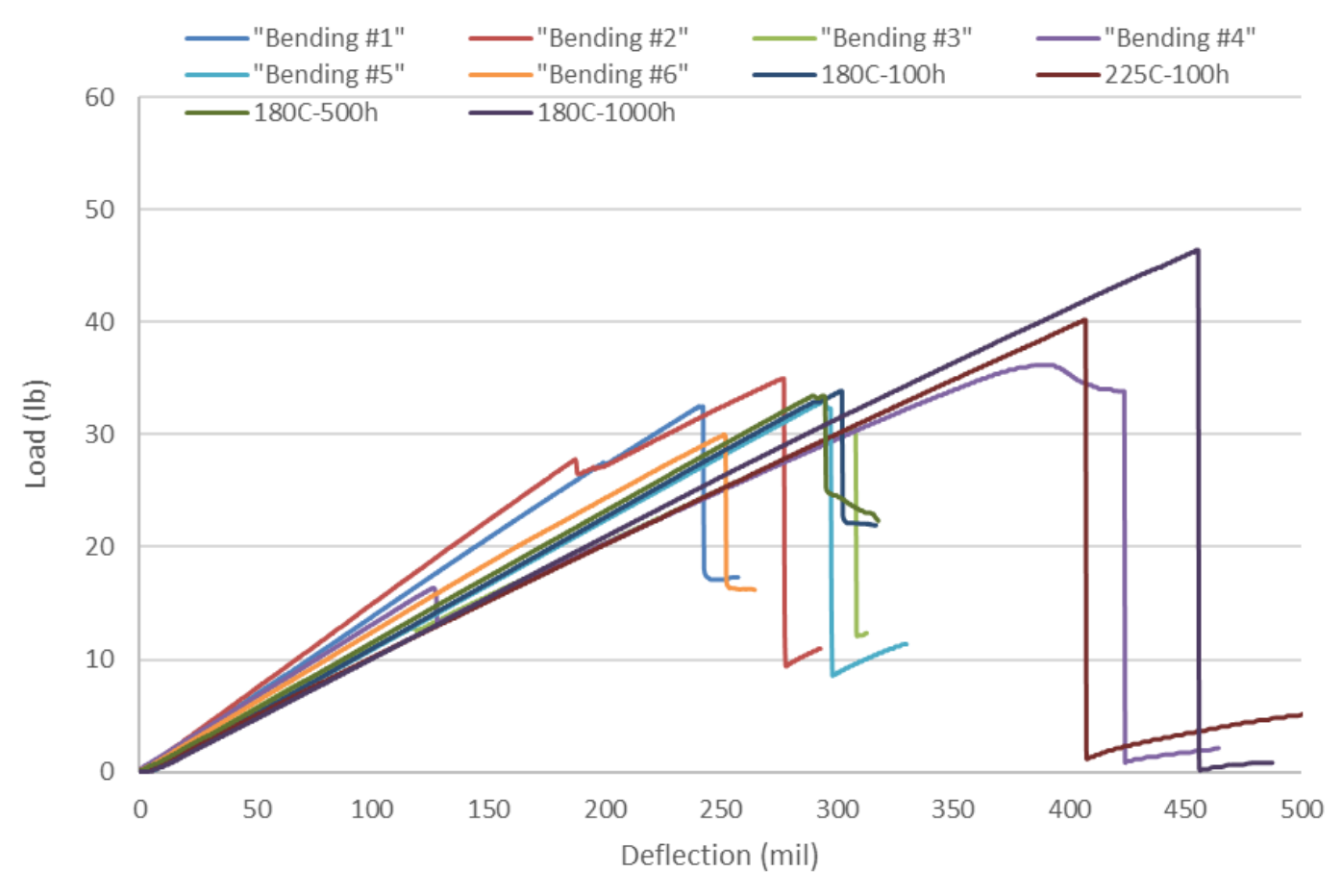

Figure 51 C7 Carbon Core 3-point Bending Tests, including baseline and aging samples.

\section{$\underline{E P R I}$ thermal cycling aging $C 7$ core samples}

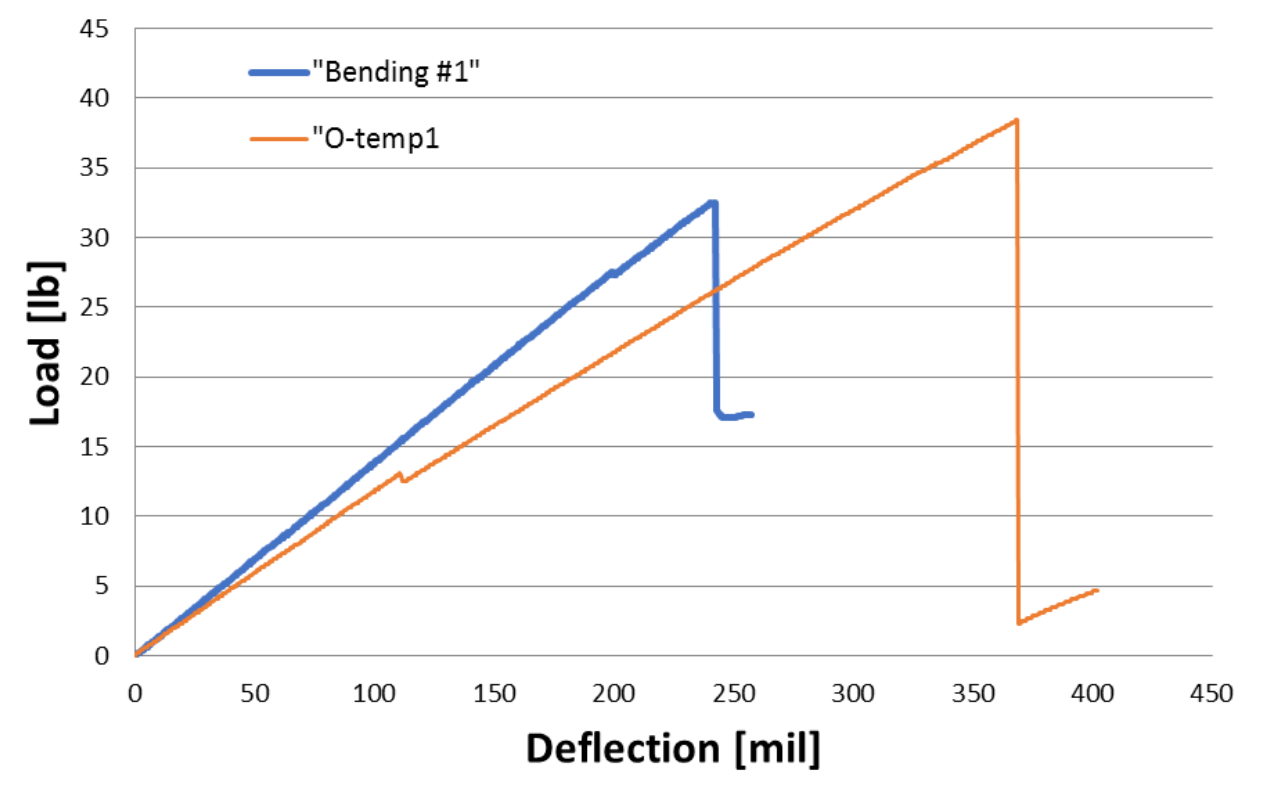

Figure $52 \mathrm{C} 7$ core 3P bending testing with EPRI thermal cycling aged O-temp-1 sample. 


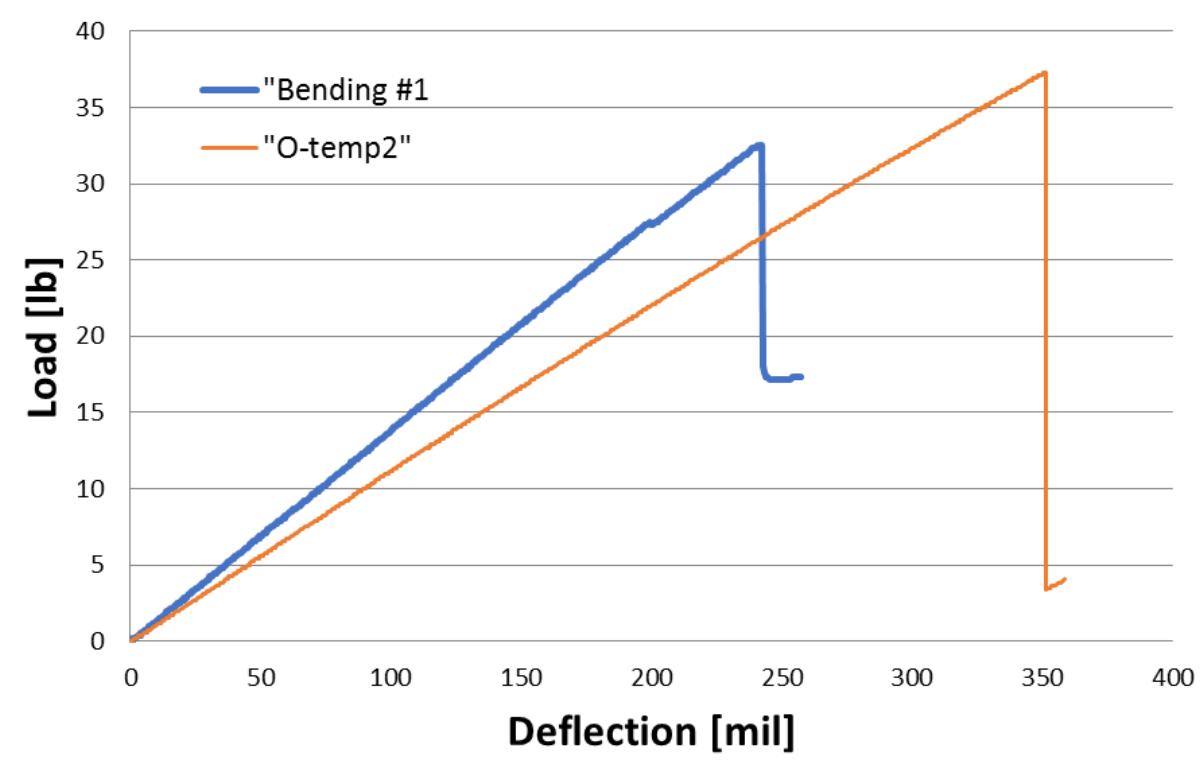

Figure $53 \mathrm{C} 7$ core 3P bending tests with EPRI thermal cycling aged O-temp-2 sample.

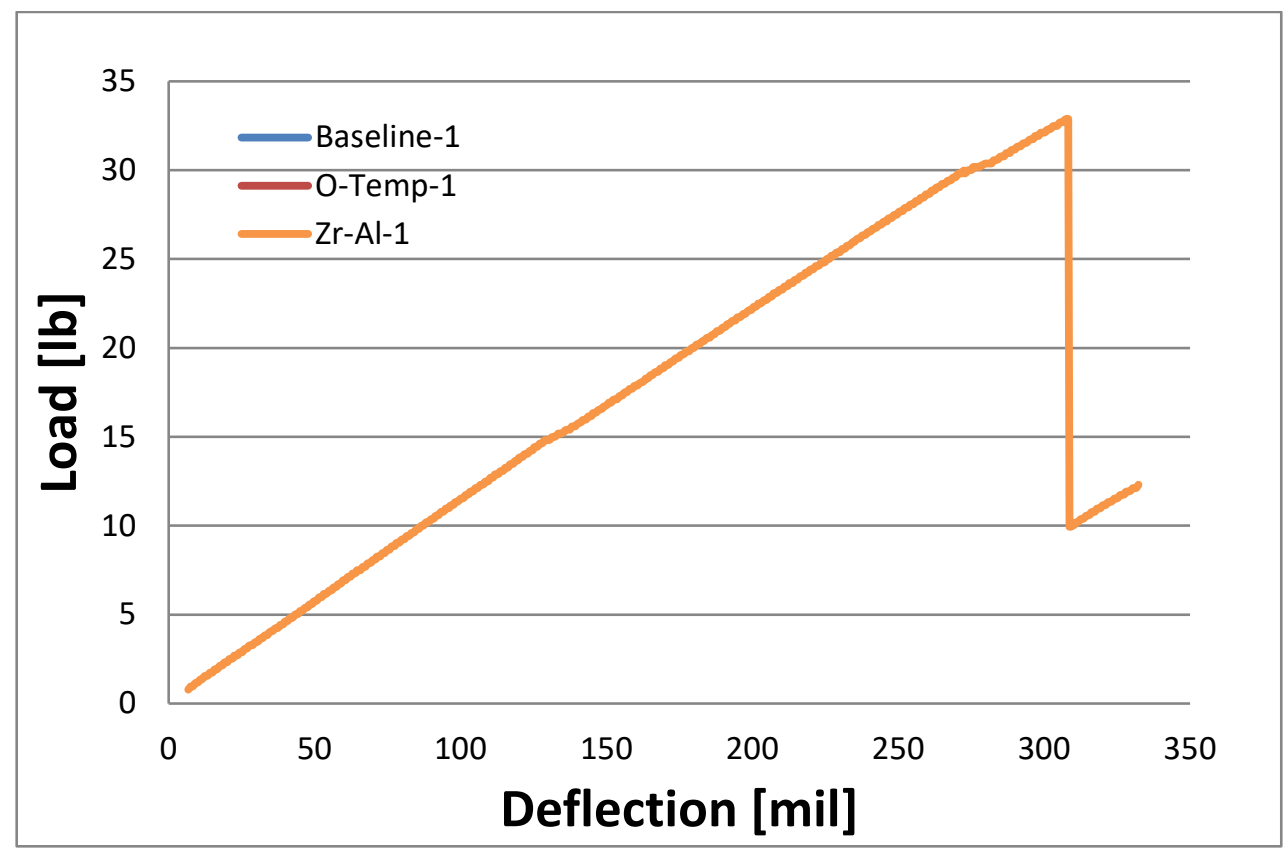




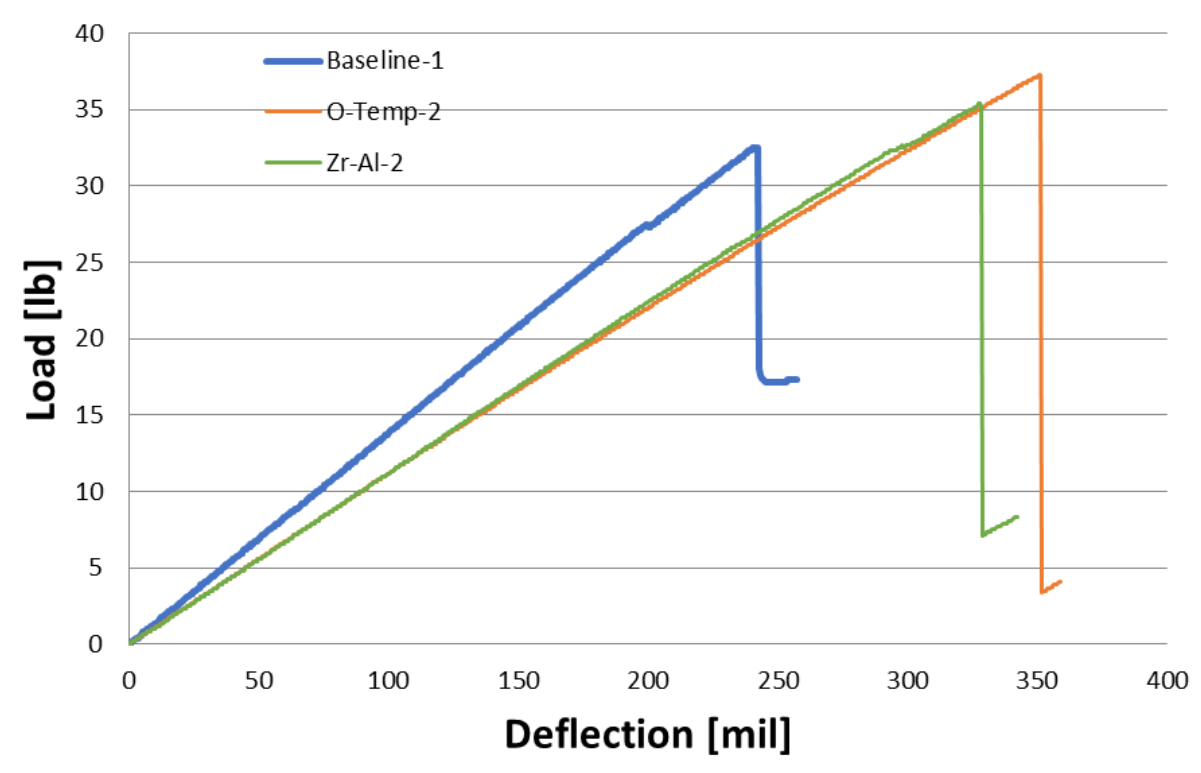

Figure 54 C7 Carbon Core 3 Point-bending Tests with EPRI thermal cycling aged O-temp and $\mathrm{Zr}$-Al conductor samples.

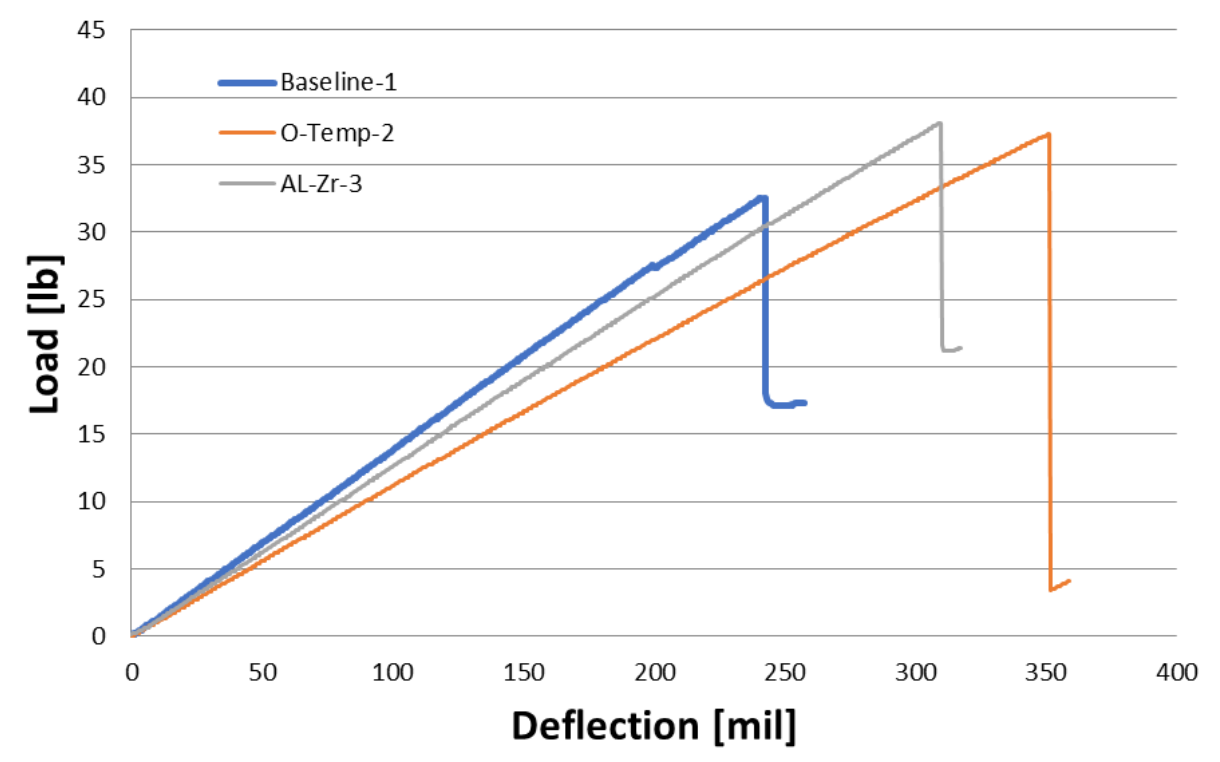

Figure 55 C7 Carbon Core 3 Point-bending Tests with EPRI thermal cycling aged 0-temp and $\mathrm{Zr}$-Al conductor samples. 


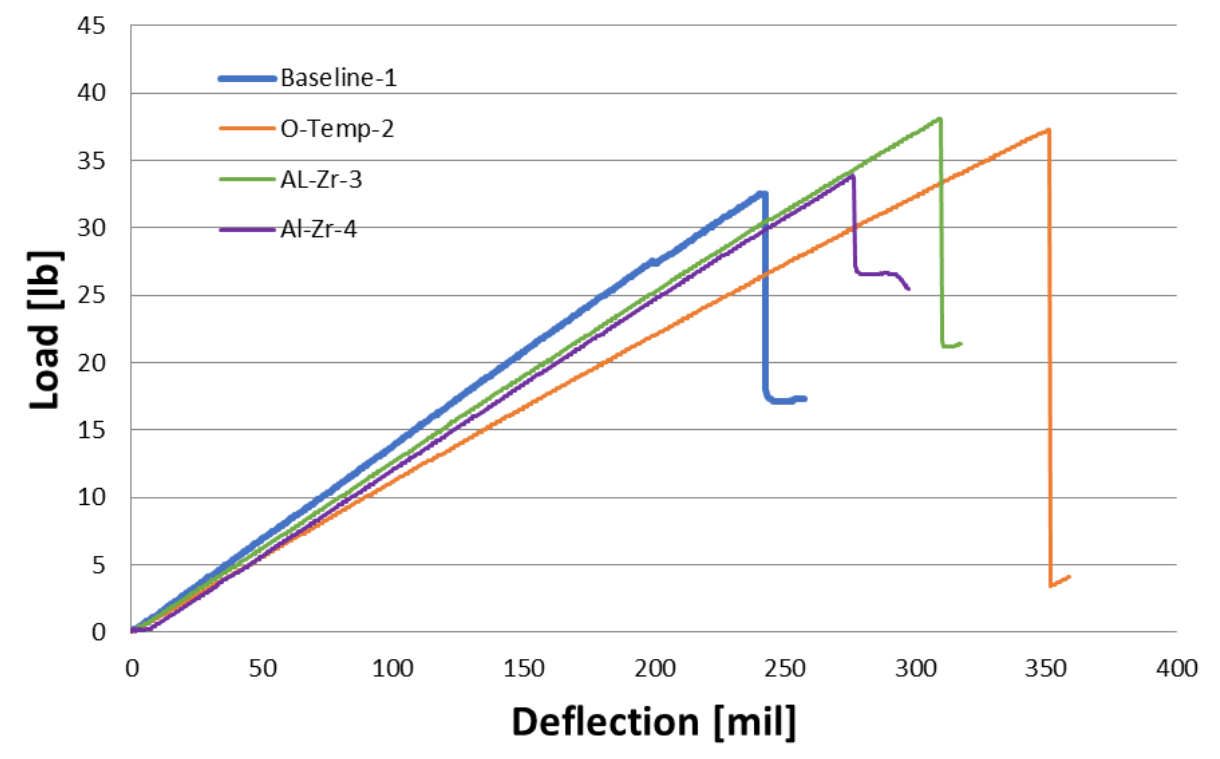

Figure 56 C7 Carbon Core 3 Point-bending Tests with EPRI thermal cycling aged O-temp and $\mathrm{Zr}-\mathrm{Al}$ conductor samples.

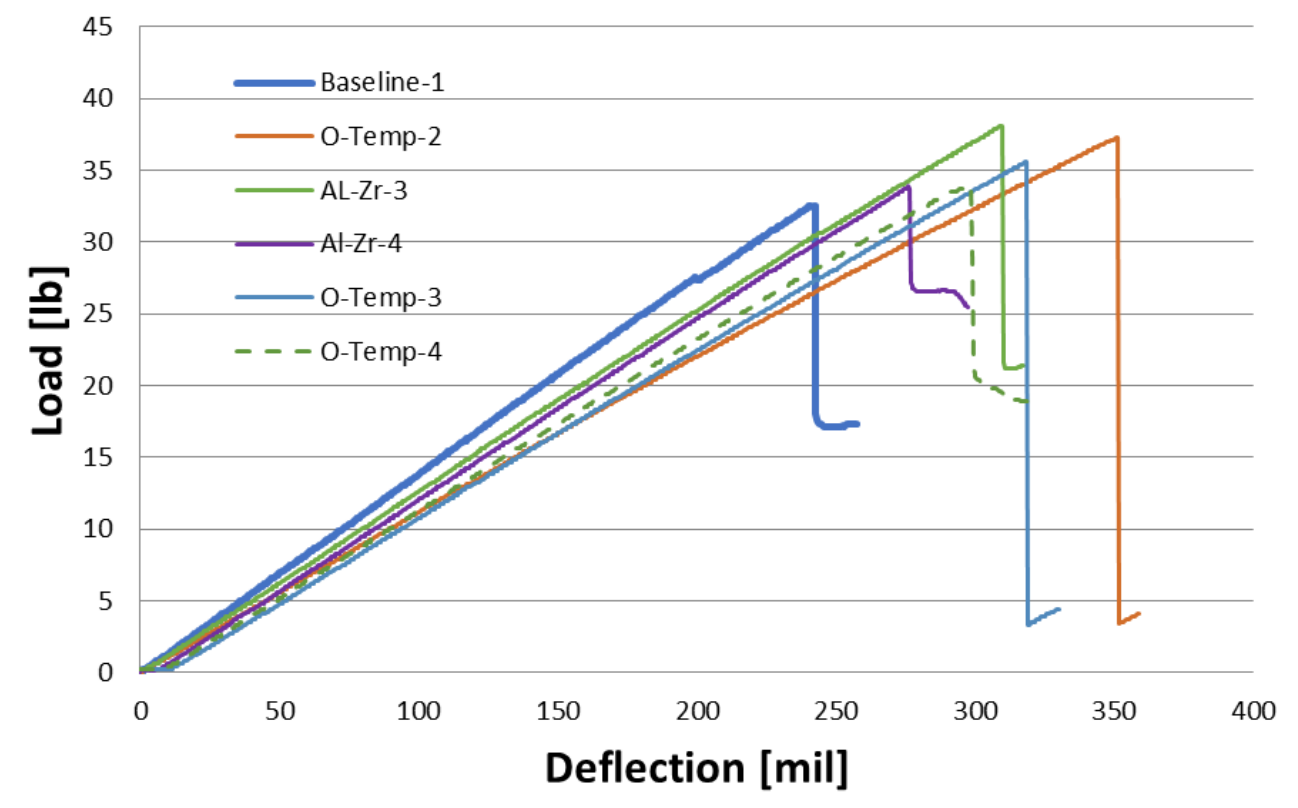

Figure 57 C7 Carbon Core 3 Point-bending Tests with EPRI thermal cycling aged O-temp and $\mathrm{Zr}$-Al conductor samples; where O-temp shows more thermal softening than $\mathrm{Zr}-\mathrm{Al} \mathrm{C7}$ samples with lower stiffness and longer sag deflection. 



\section{THERMAL AGING CHARACTERIZATION USING TENSILE TEST}

\subsection{Pilot tensile test and sample grip design}

The C7 sample with 4-inch gage section and 2-inch hydraulic grip section was designed and used for pilot tensile testing. The maximum tensile load reached upon failure is around $2000 \mathrm{lb}$. The C7 composite core sample was failed at grip section, as shown in Figure 58; and apparently PEEK layer fracture and delamination are the root cause.

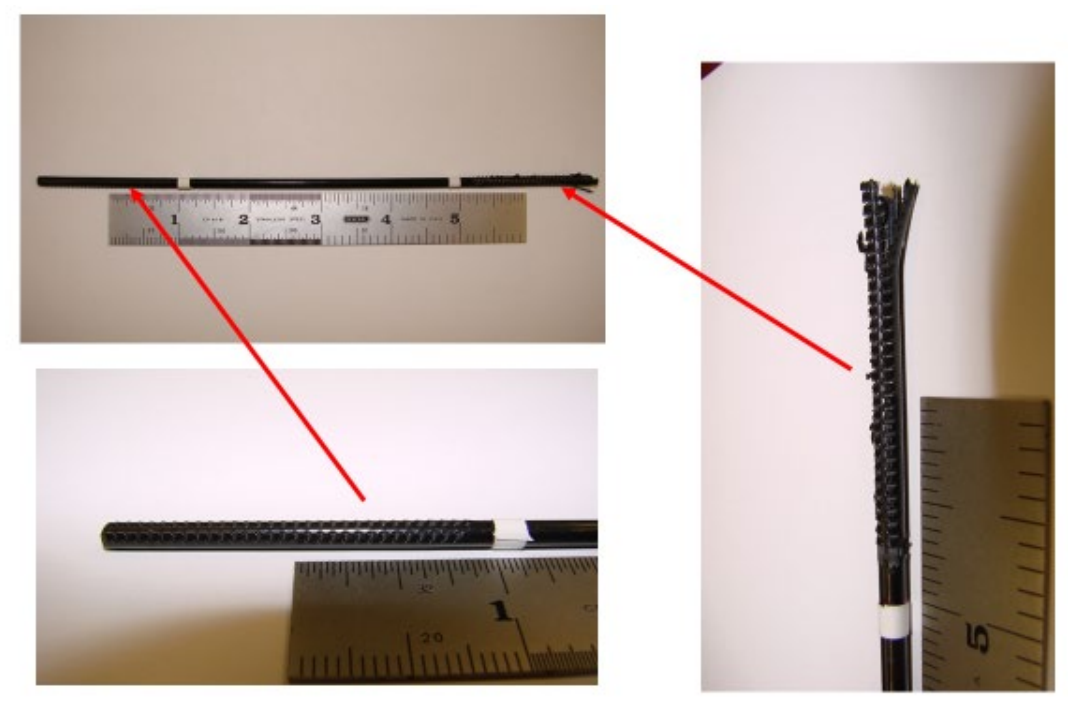

Figure $58 \mathrm{C} 7$ core tensile testing using hydraulic grip clamps of 2-inch in length.

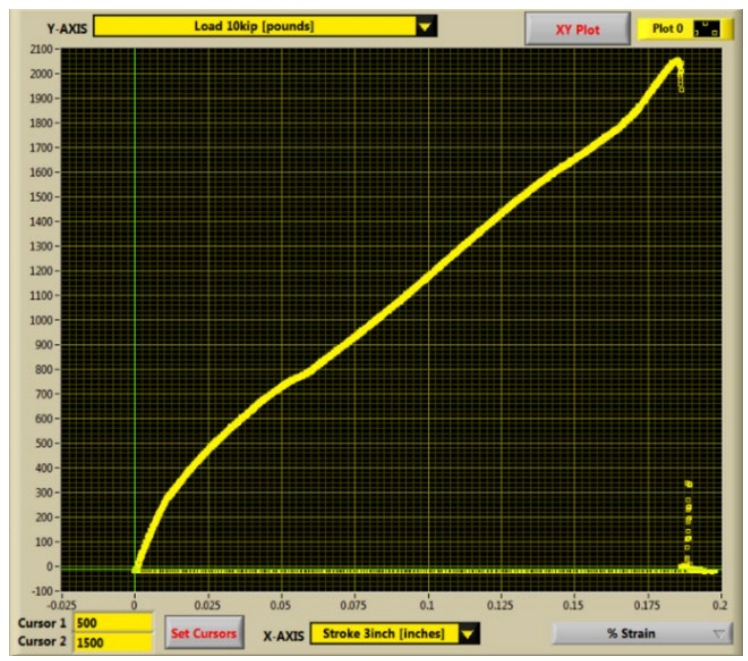

Figure $59 \mathrm{C} 7$ core pilot tensile test load-stroke history. 
A series of grip modifications and pilot testing, demonstrated in Figures 61-63, were designed and performed to improve the C7 core sample's grip capacity under tensile test; and to ensure C7 core sample will fail at gage section instead of at grip region, as outlined below.

- Special grip design to ensure sufficient friction strength during tensile testing

- Grip plate dimension, and grove depth

- Copper bushing insert dimension to provide sufficient protection to the $\mathrm{C} 7$ rods

- Bolt sizes to ensure sufficient compressive stress on grip plates

- Interface bonding adhesive to increase interface shear resistance

- Tensile testing under different loading rates;

- $0.0003 \mathrm{in} / \mathrm{sec}, 0.003 \mathrm{in} / \mathrm{sec}, 0.03 \mathrm{in} / \mathrm{see}$, and $0.3 \mathrm{in} / \mathrm{sec}$

- $\quad$ C7 fracture initiation site

- C7 failure profile considerations

- Catastrophic damage mechanism, C7 rod upon failure completed disintegrated into fibrous form under medium or low loading rate; while at very high loading rate $\mathrm{C} 7$ fail at much lower load compared to that of low or medium loading rate and $\mathrm{C} 7$ rod failed in a brittle failure mode with $\mathrm{C} 7$ core sample cross-section nearly intact.

- C7 Young's Modulus and its comparison to steel

- In general, C7 has much lower E, (8-10 msi), it's about 30\% of that of steel (29 msi) shown in Figure 60; which means large deformation/displacement under load would be experienced by $\mathrm{C} 7$ core wire compared to that of steel deformation.

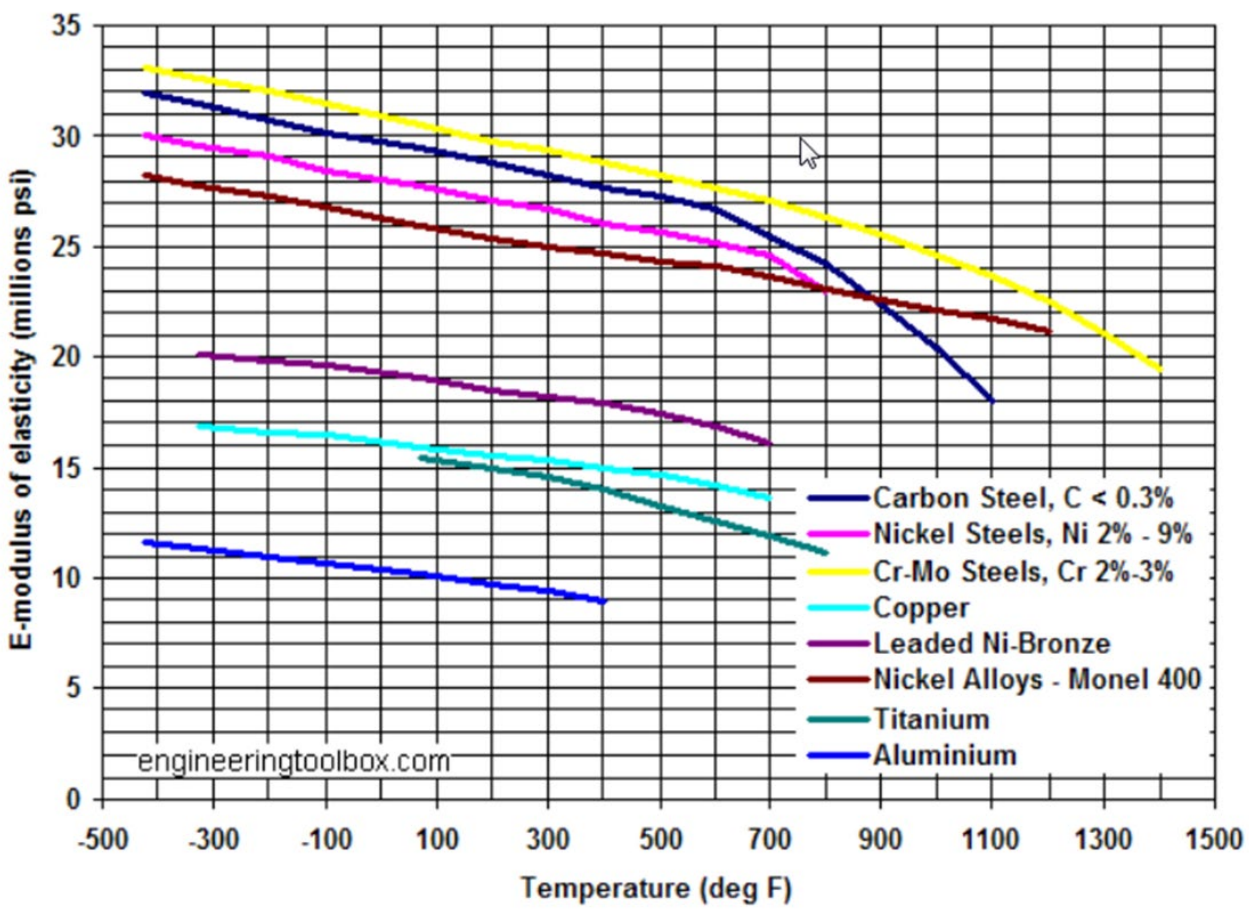

Figure 60 Metallic Materials Tensile Testing General Trends. 
$\mathrm{C} 7$ tensile testing at $0.003 \mathrm{in} / \mathrm{sec}$ loading rate

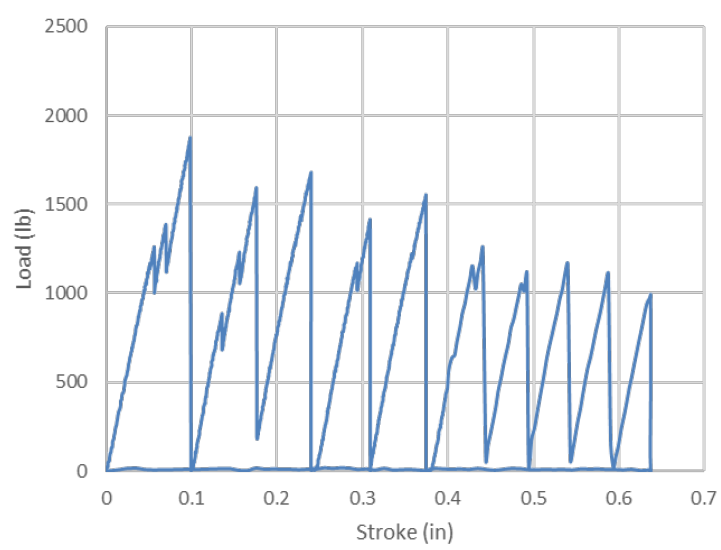

$\mathrm{C} 7$ tensile testing at $0.003 \mathrm{in} / \mathrm{sec}$ loading rate

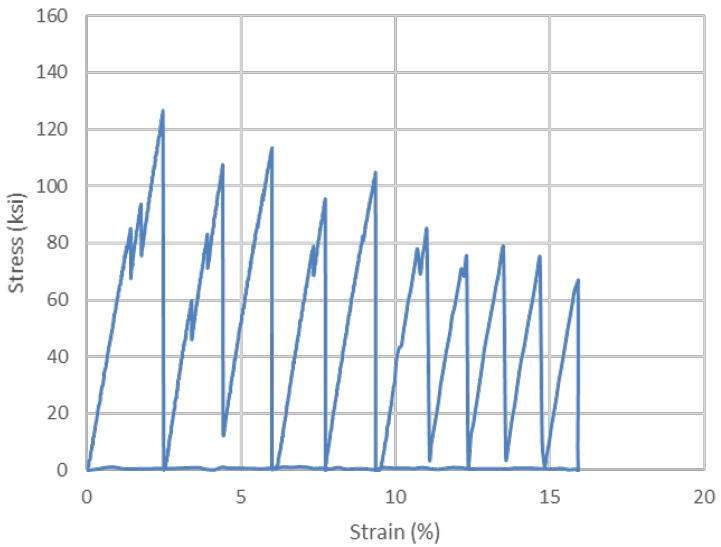

Figure $61 \mathrm{C} 7$ core tensile test using new grip design with brass insert shows grip slip.

C7 tensile tetsing w/ copper insert + epoxy

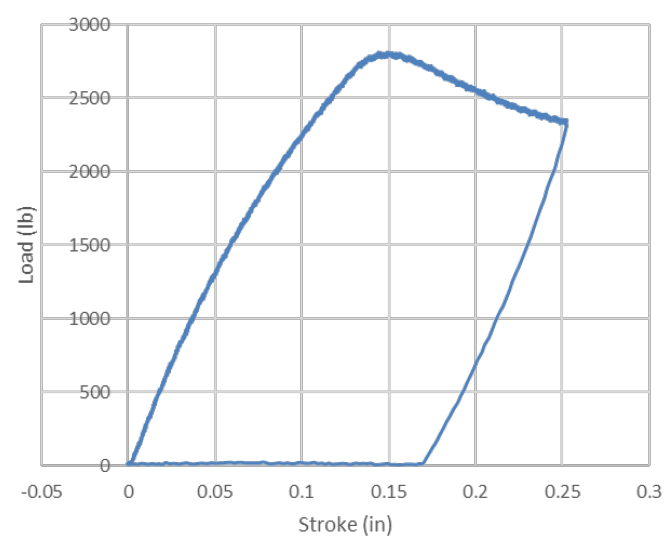

C7 tensile testing $\mathrm{w} /$ copper insert + epoxy

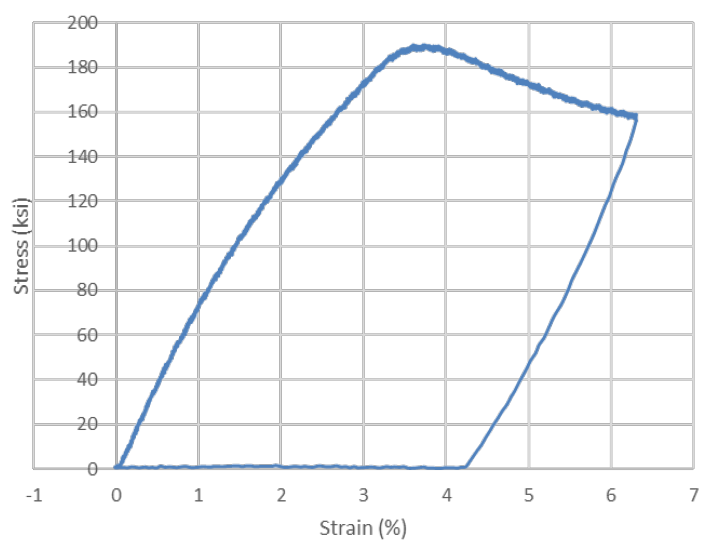

Figure 62 Tensile testing using grip w/ thin hard copper insert + epoxy shows grip slip.

C7 tesnile testing new grip with soft copper insert + epoxy

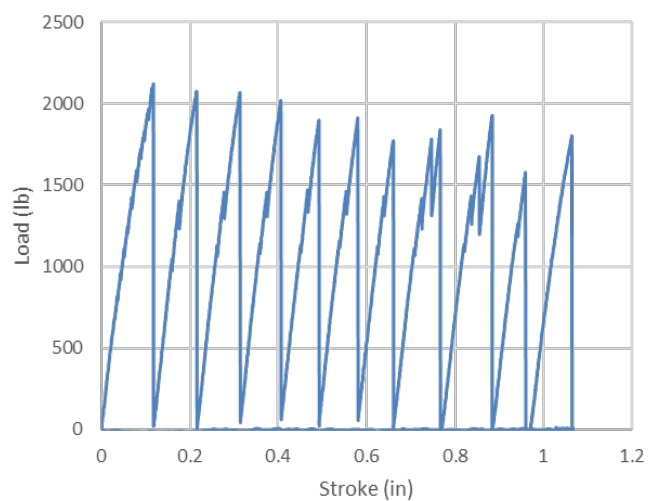

C7 tesnile testing new grip with soft copper insert + epoxy

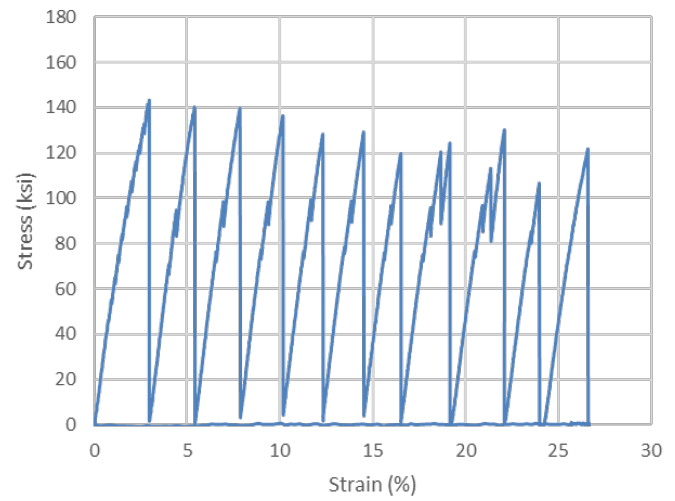

Figure 63 Tensile testing using new grip with thick soft copper insert + epoxy shows slip. 
After a series of pilot testing on the grip designs; the soft copper insert with sufficient grip length of 5.75-inch was adopted for the sample grip. The detail of the final grip design is shown in Figure 64. The C7 composite core samples tensile test results are detailed in Figures 64-89.
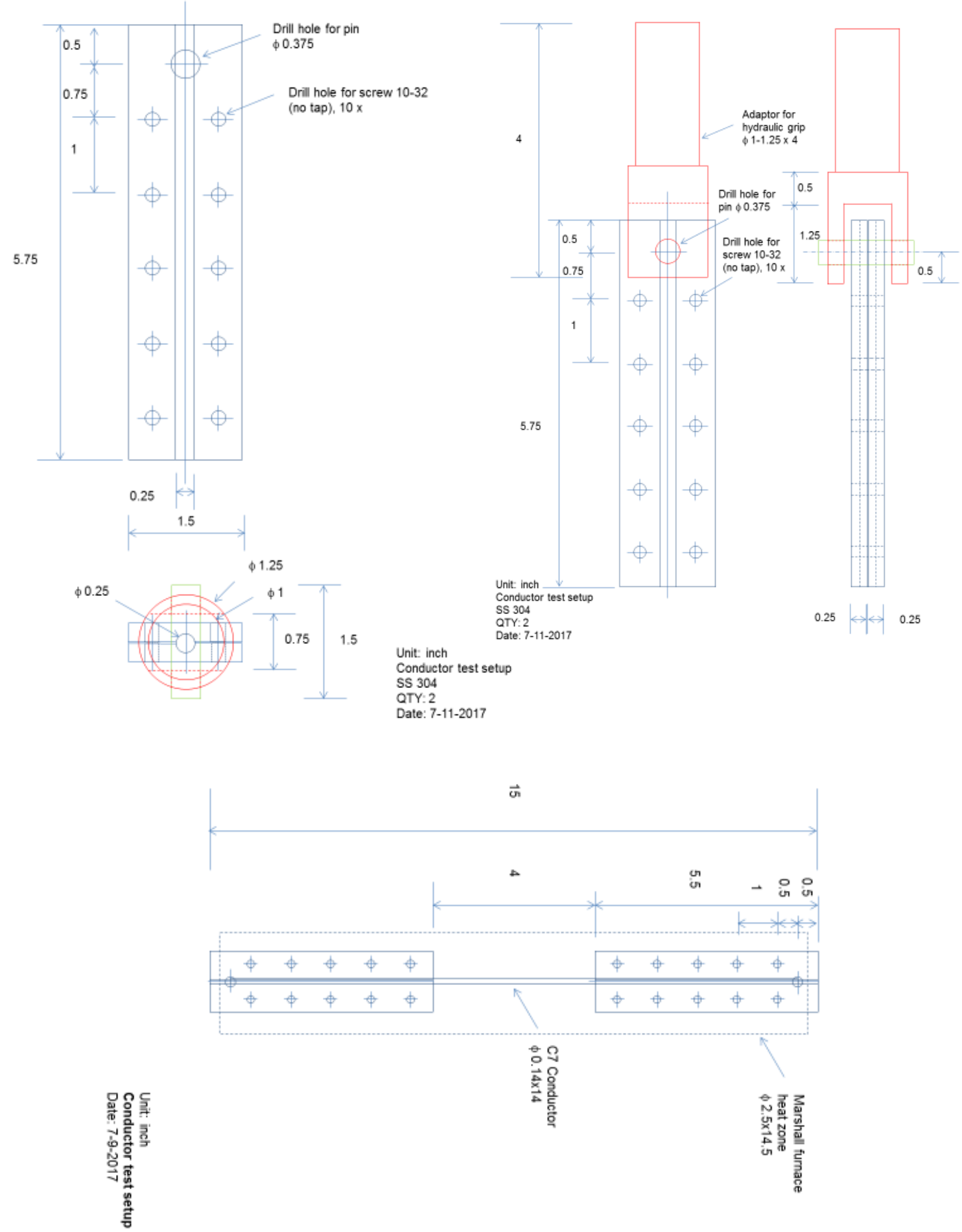

Figure 64 Final grip design for $\mathrm{C} 7$ core sample tensile testing. 


\subsection{C7 composite core sample tensile test results at room temperature}

Based on the new grip design a series of loading rate dependent tensile tests were performed as detailed below.
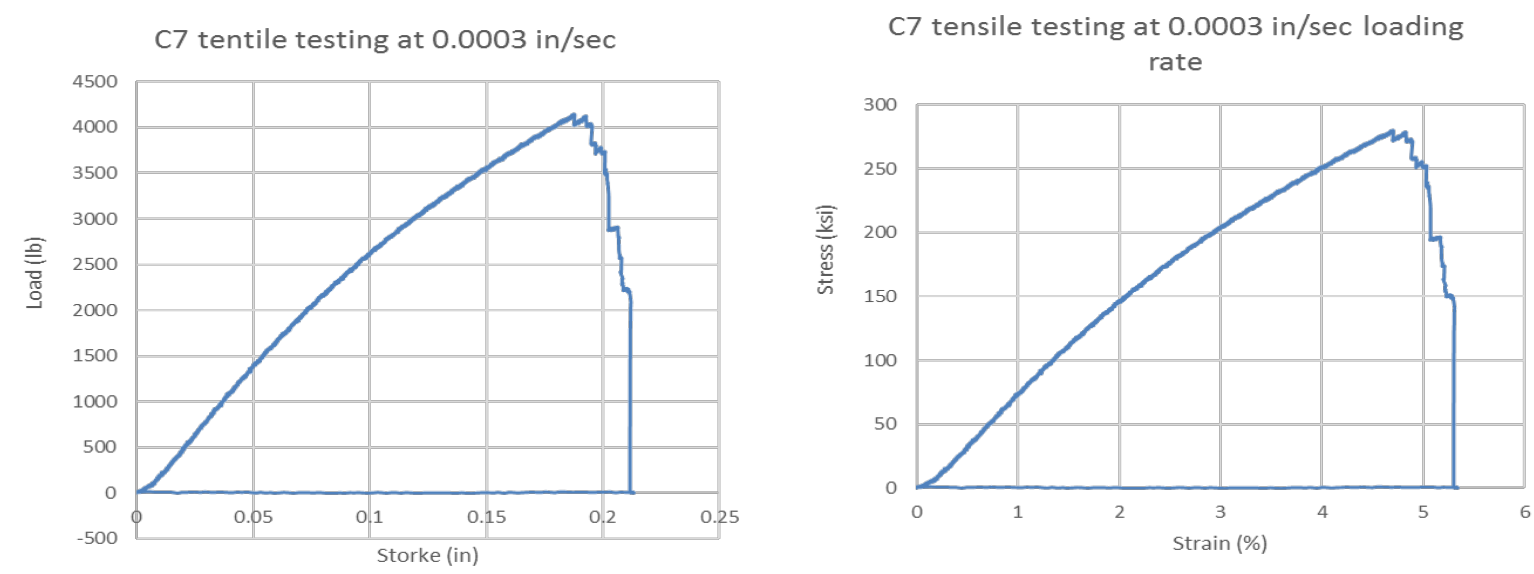

Figure $65 \mathrm{C} 7$ core tensile testing at $0.0003 \mathrm{in} / \mathrm{sec}$ loading rate.

$\mathrm{C} 7$ tensile tetsing $\mathrm{w} /$ new grip at 0.0003 in/see loading rate

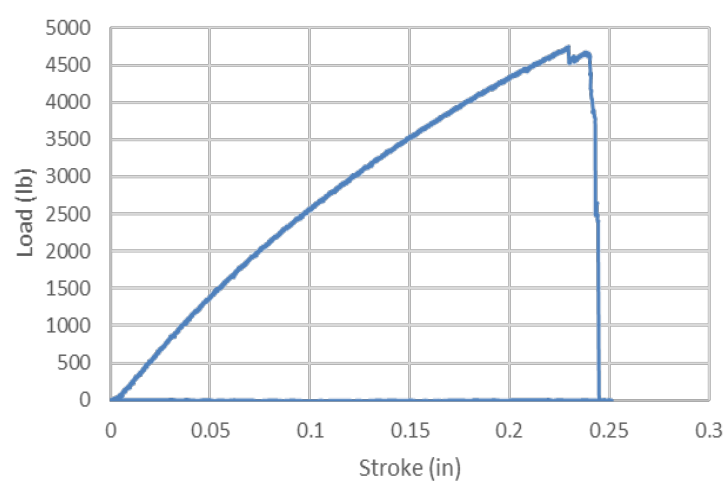

C7 tensile tetsing $\mathrm{w} /$ new grip at 0.0003 in/see loading rate

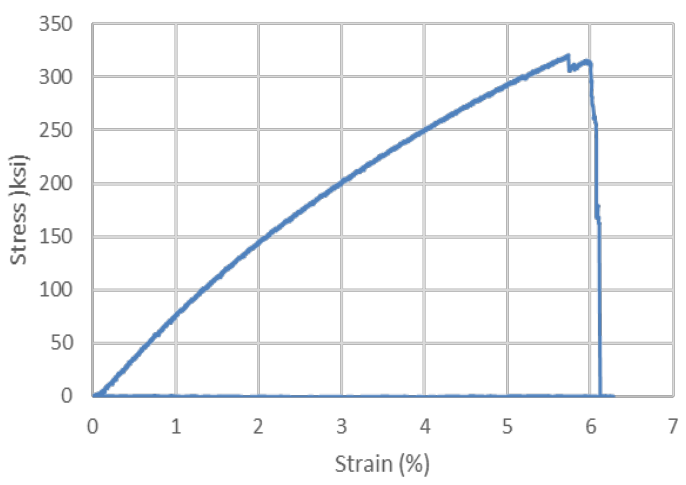

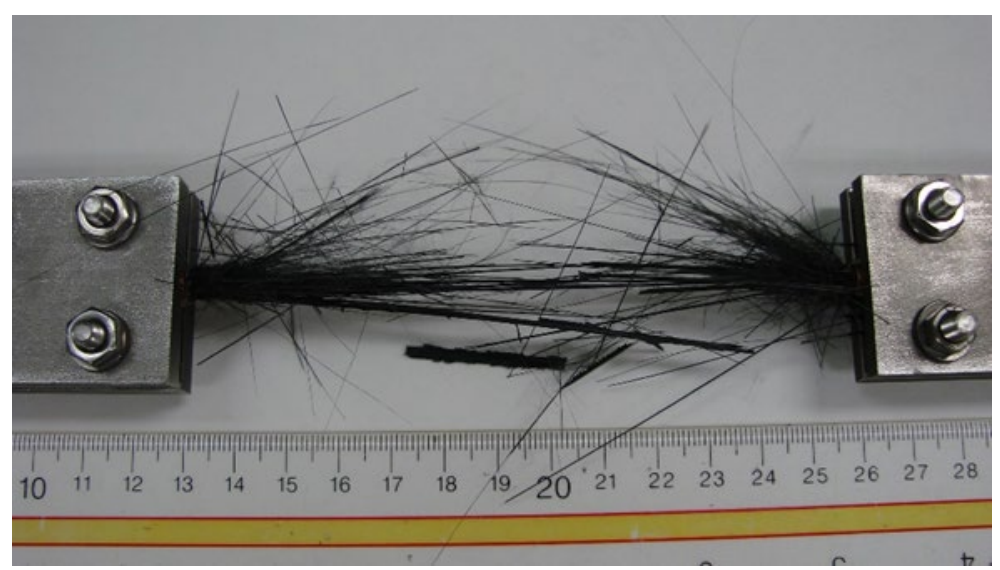



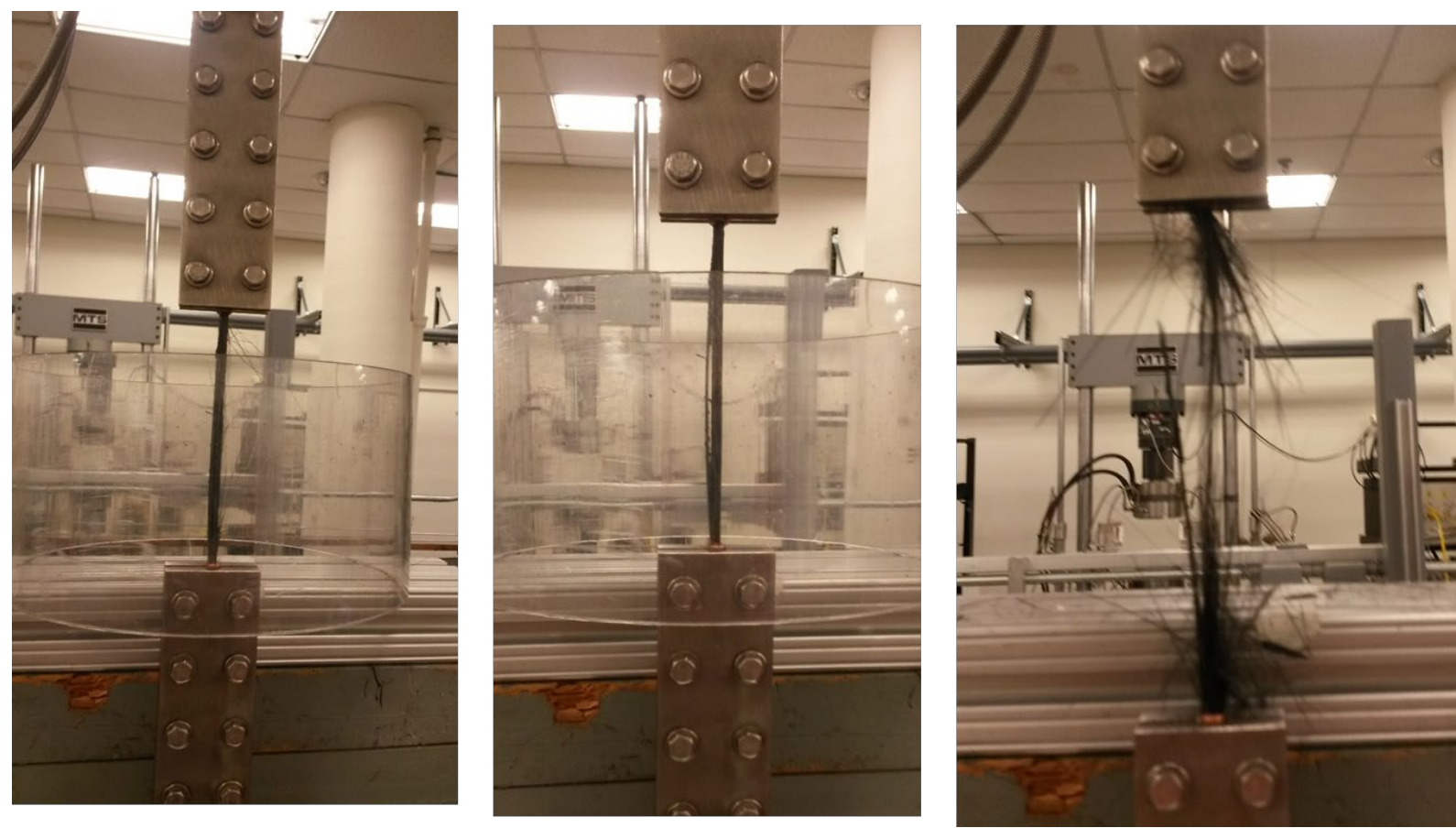

Figure $66 \mathrm{C} 7$ core tensile testing failure evolutions, from left to right, at $0.0003 \mathrm{in} / \mathrm{sec}$ loading rate.

$\mathrm{C} 7$ tensile testing at $0.003 \mathrm{in} / \mathrm{sec}$ loading rate

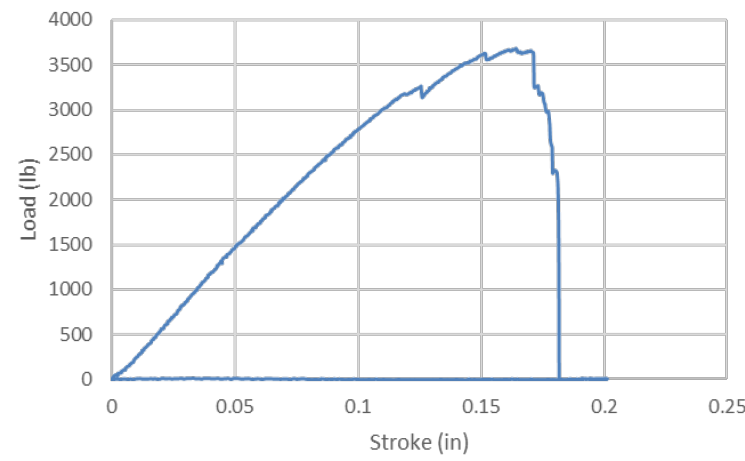

$\mathrm{C} 7$ tensile testing at $0.003 \mathrm{in} / \mathrm{sec}$ loading rate

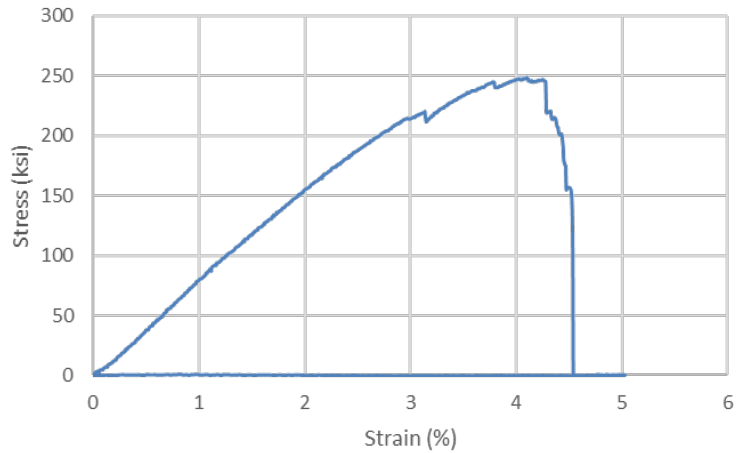

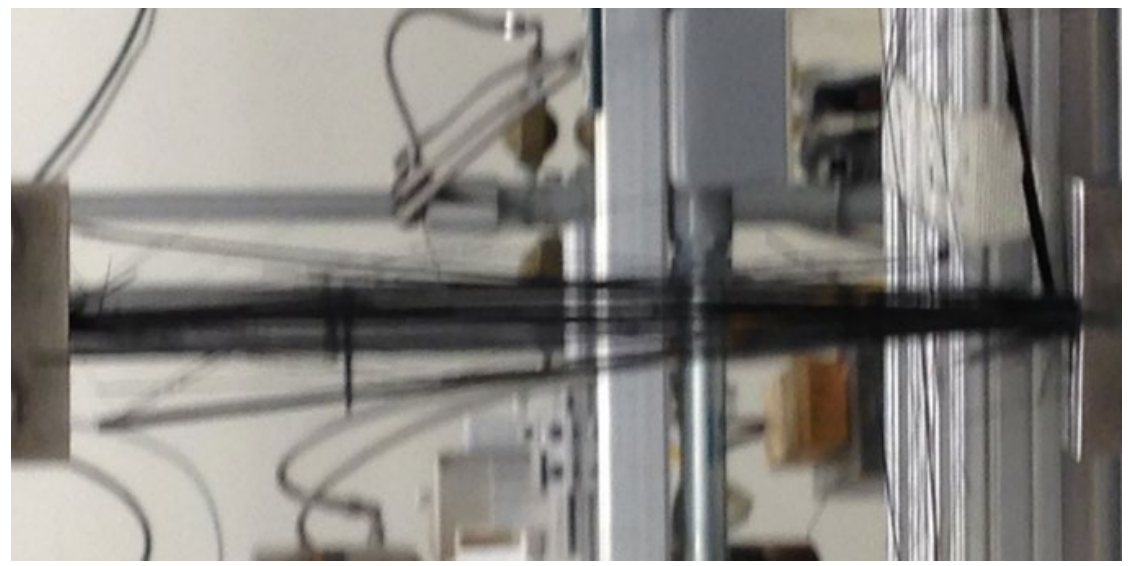

Figure $67 \mathrm{C} 7$ core tensile testing at $0.003 \mathrm{in} / \mathrm{sec}$ loading rate. 
$\mathrm{C} 7$ tensile testing at $0.003 \mathrm{in} / \mathrm{sec}$ loading rate

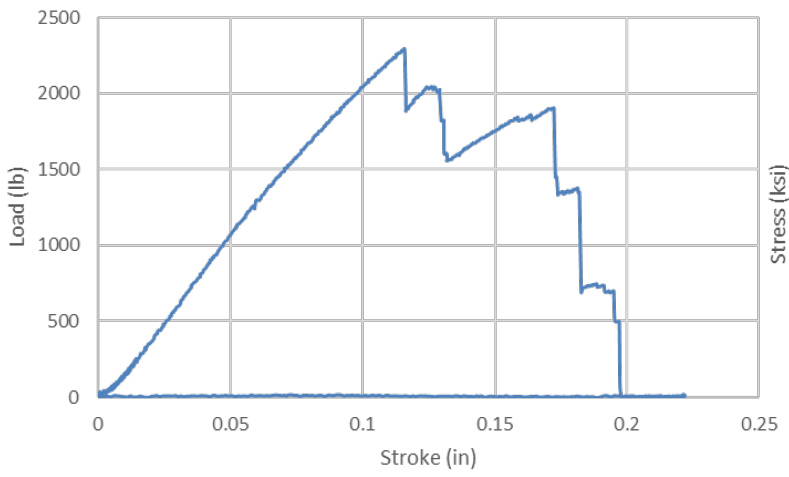

$\mathrm{C} 7$ tensile testing at $0.003 \mathrm{in} / \mathrm{sec}$ loading rate

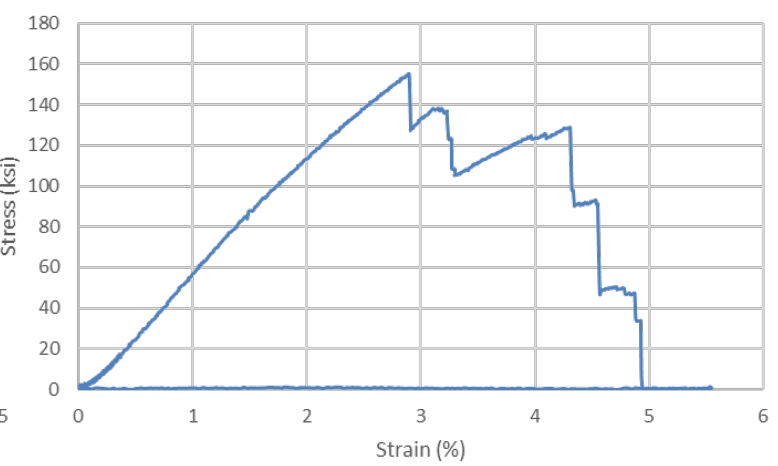

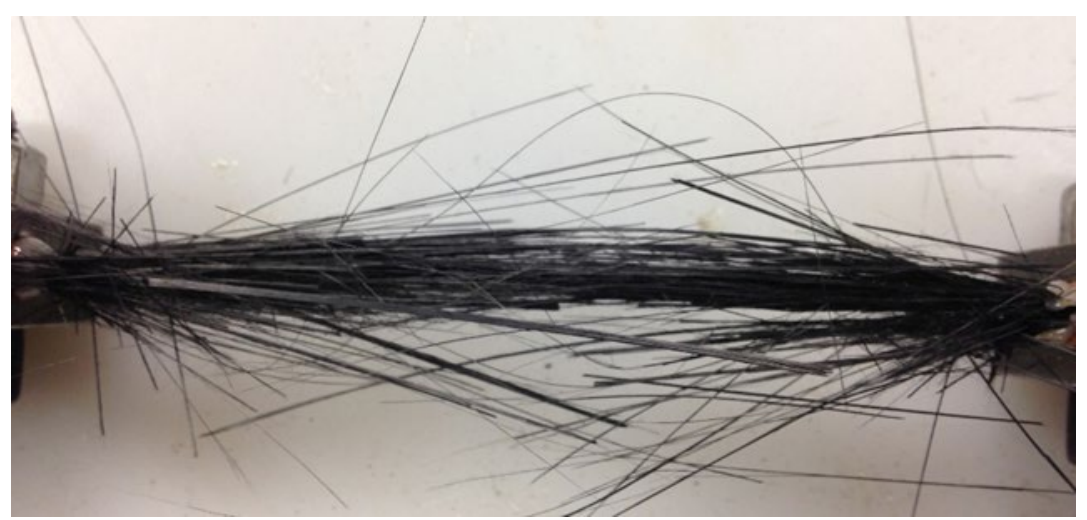

Figure $68 \mathrm{C} 7$ core tensile testing at $0.003 \mathrm{in} / \mathrm{sec}$ loading rate.

$\mathrm{C} 7(\mathrm{Zr})$ tensile test at $0.003 \mathrm{in} / \mathrm{sec}$ loading rate

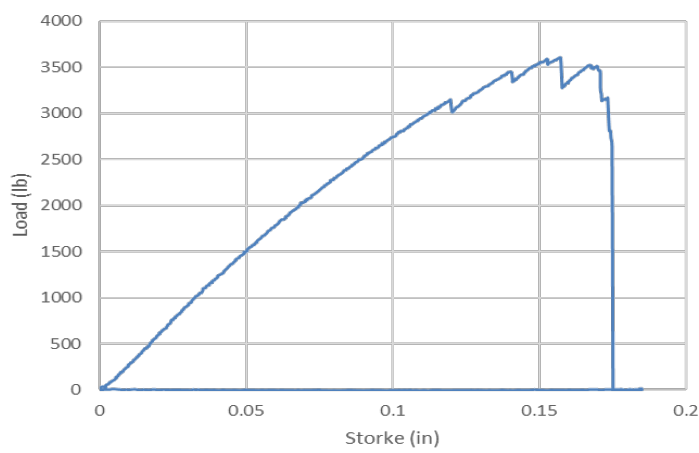

$\mathrm{C} 7(\mathrm{Zr})$ tensile test at $0.003 \mathrm{in} / \mathrm{sec}$ loading rate

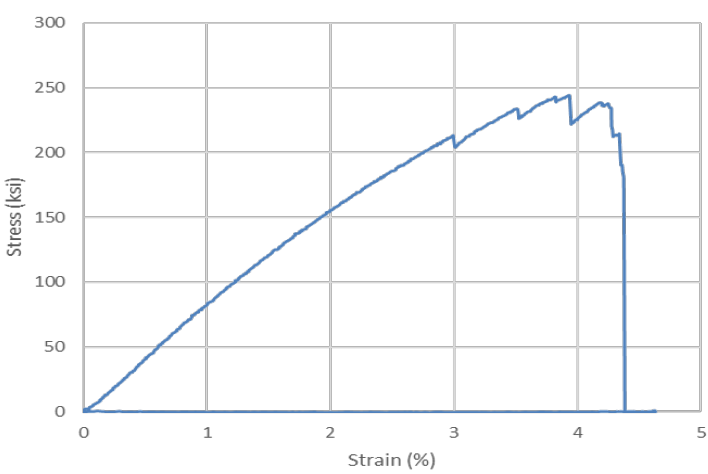




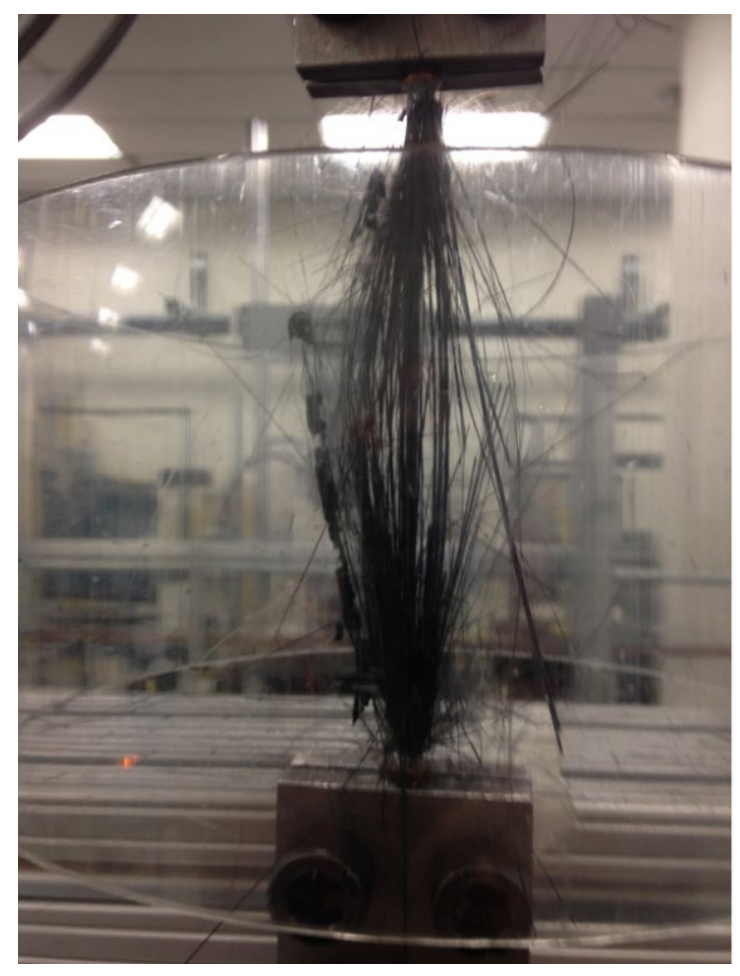

Figure 69 EPRI C7 (Zr-Al) core tensile testing aged under $180^{\circ} \mathrm{C}$ thermal cycling, 0.003 in/sec loading rate.

C7 (O) tensile testing at $0.003 \mathrm{in} / \mathrm{sec}$ loading rate

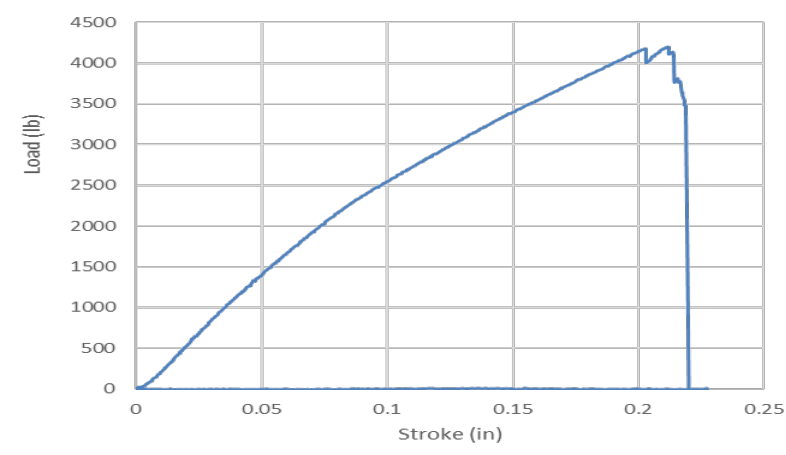

$\mathrm{C7}(\mathrm{O})$ tensile testing at $0.003 \mathrm{in} / \mathrm{sec}$ loading rate

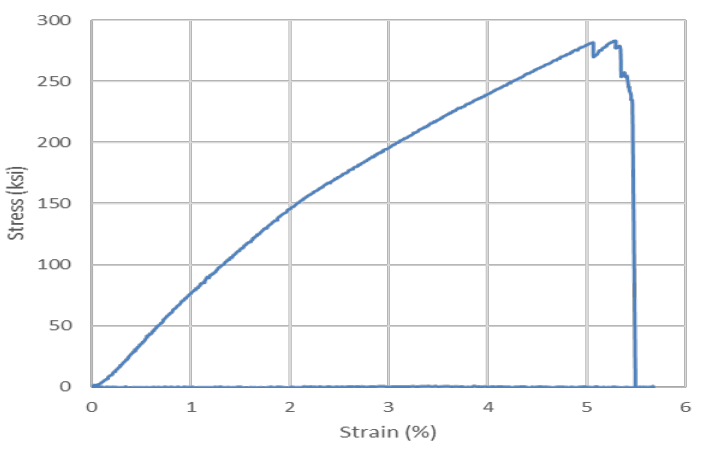




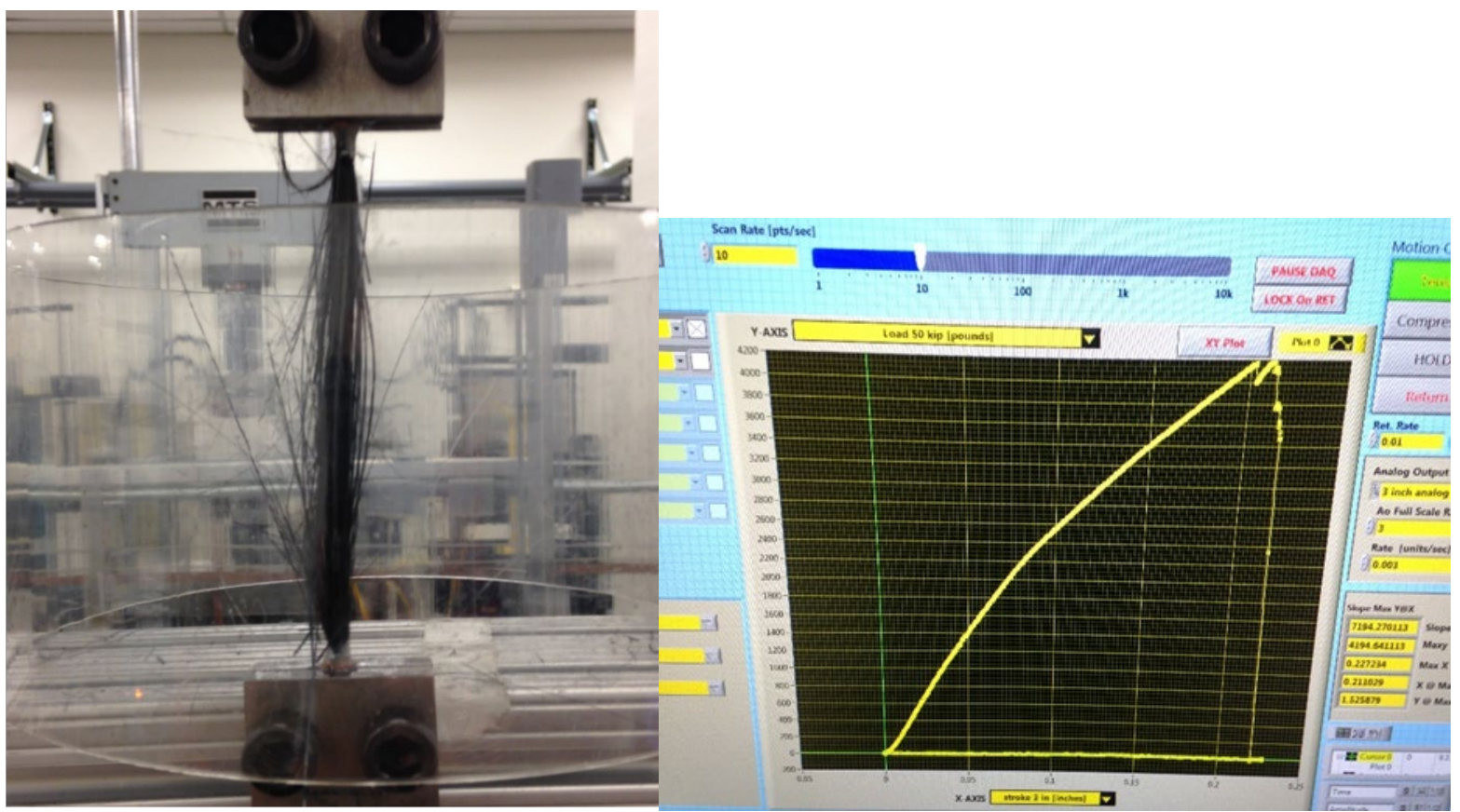

Figure 70 EPRI C7 (O-Temp) core tensile testing aged under $180^{\circ} \mathrm{C}$ thermal cycling, $0.003 \mathrm{in} / \mathrm{sec}$ loading rate.
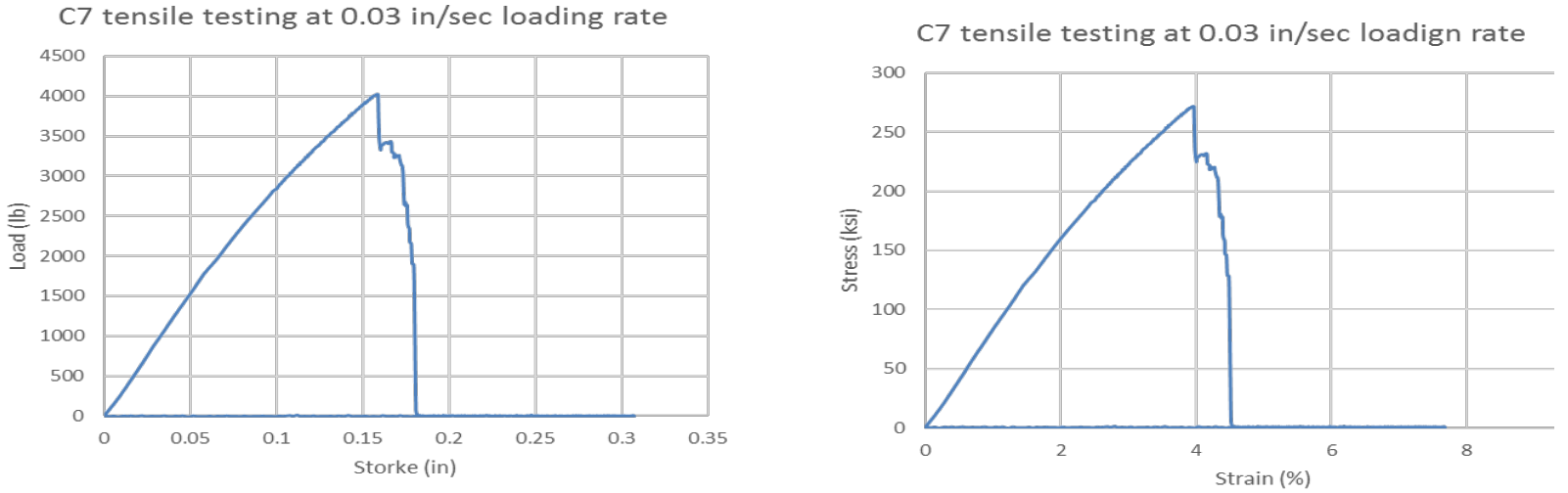


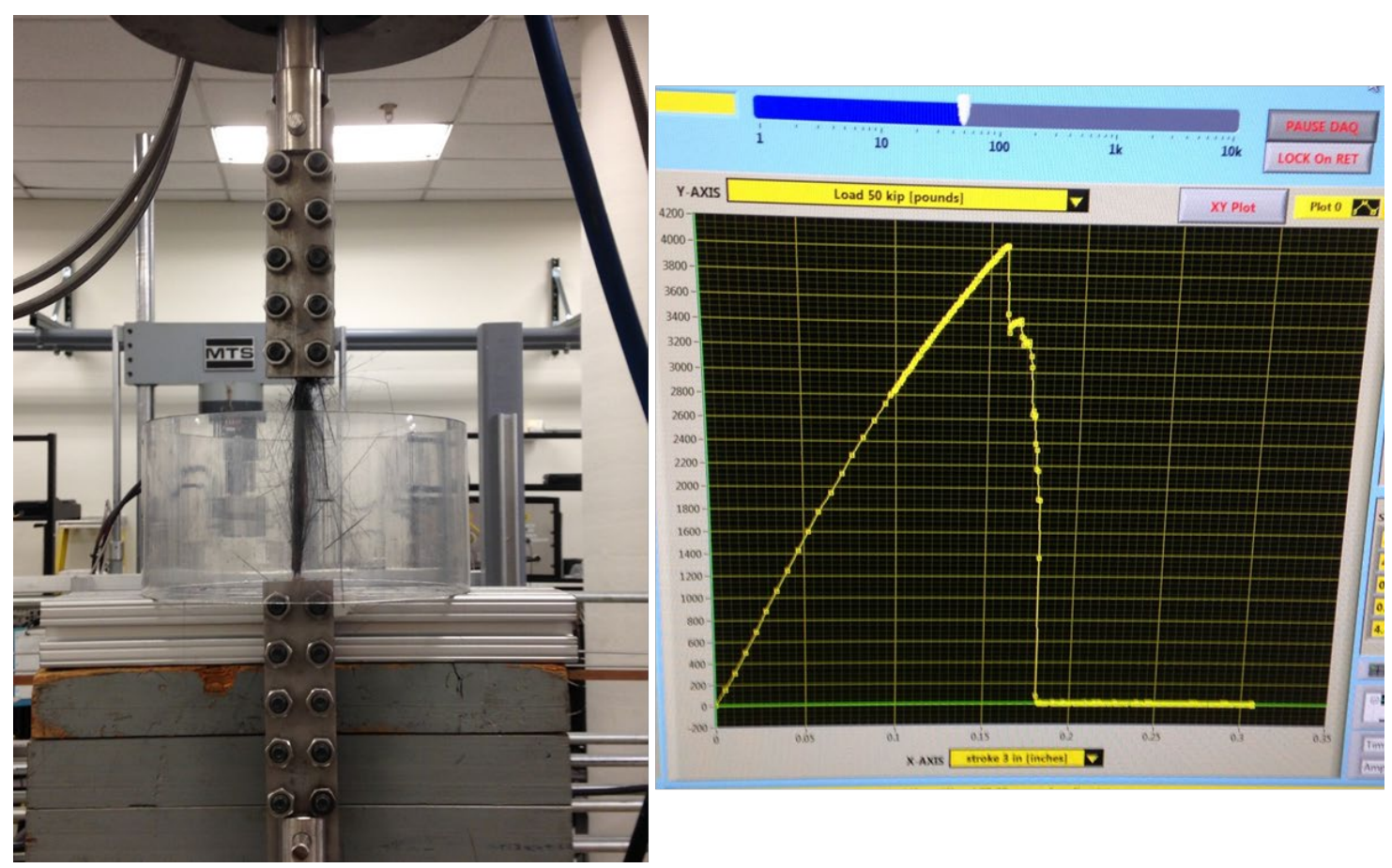

Figure $71 \mathrm{C} 7$ core tensile testing at $0.03 \mathrm{in} / \mathrm{sec}$ loading rate.

$\mathrm{C} 7$ tensile testing at $0.3 \mathrm{in} / \mathrm{sec}$ loading rate

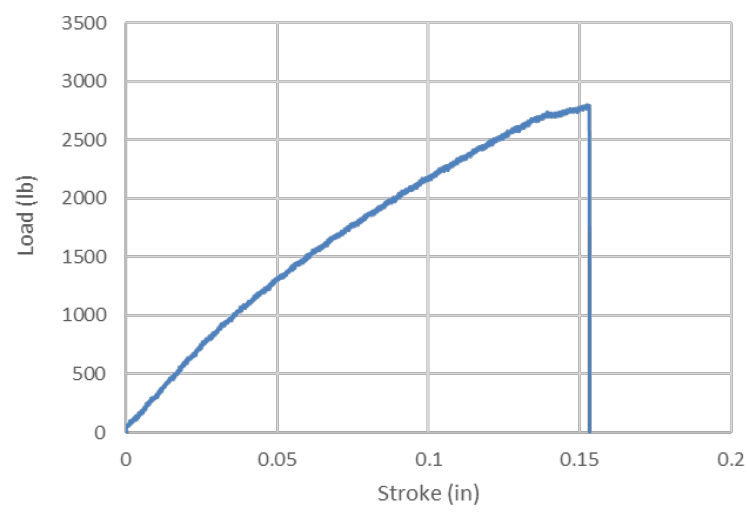

C7 tensile testing $0.3 \mathrm{in} / \mathrm{sec}$ loading rate

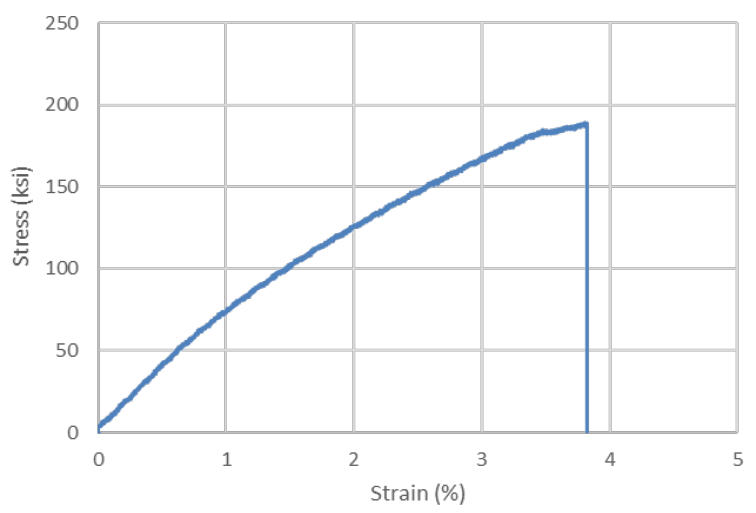




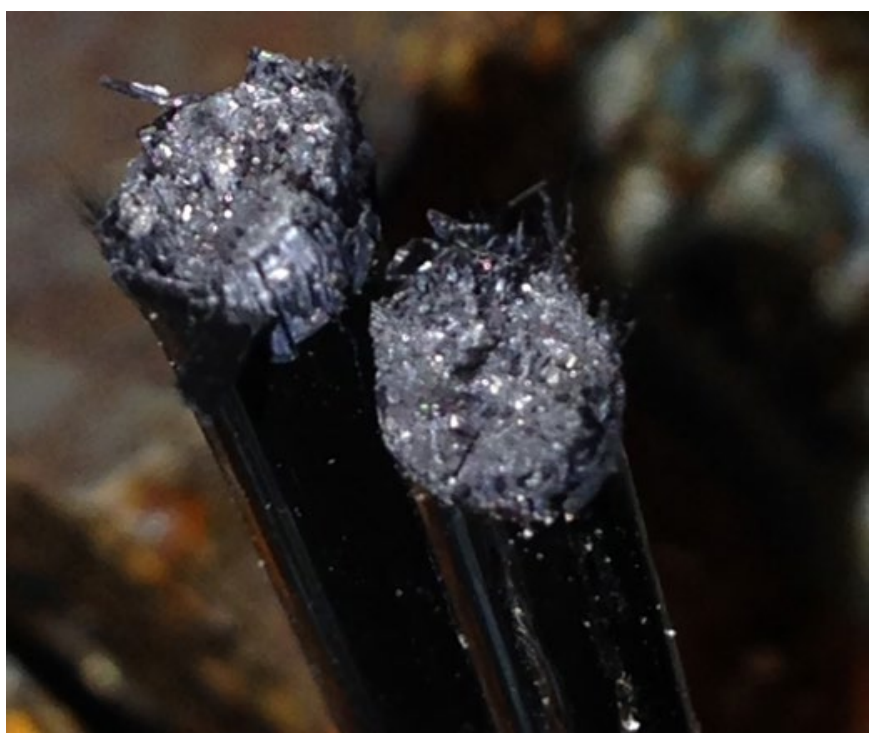

Figure $72 \mathrm{C} 7$ core tensile testing at $0.3 \mathrm{in} / \mathrm{sec}$ loading rate, where fast brittle fracture at failure site was observed w/o carbon fibers and PPS matrix disintegration in contrast to significant $\mathrm{C} 7$ core carbon fibers/PPS matrix disintegration revealed from other lower loading rate tensile tests.

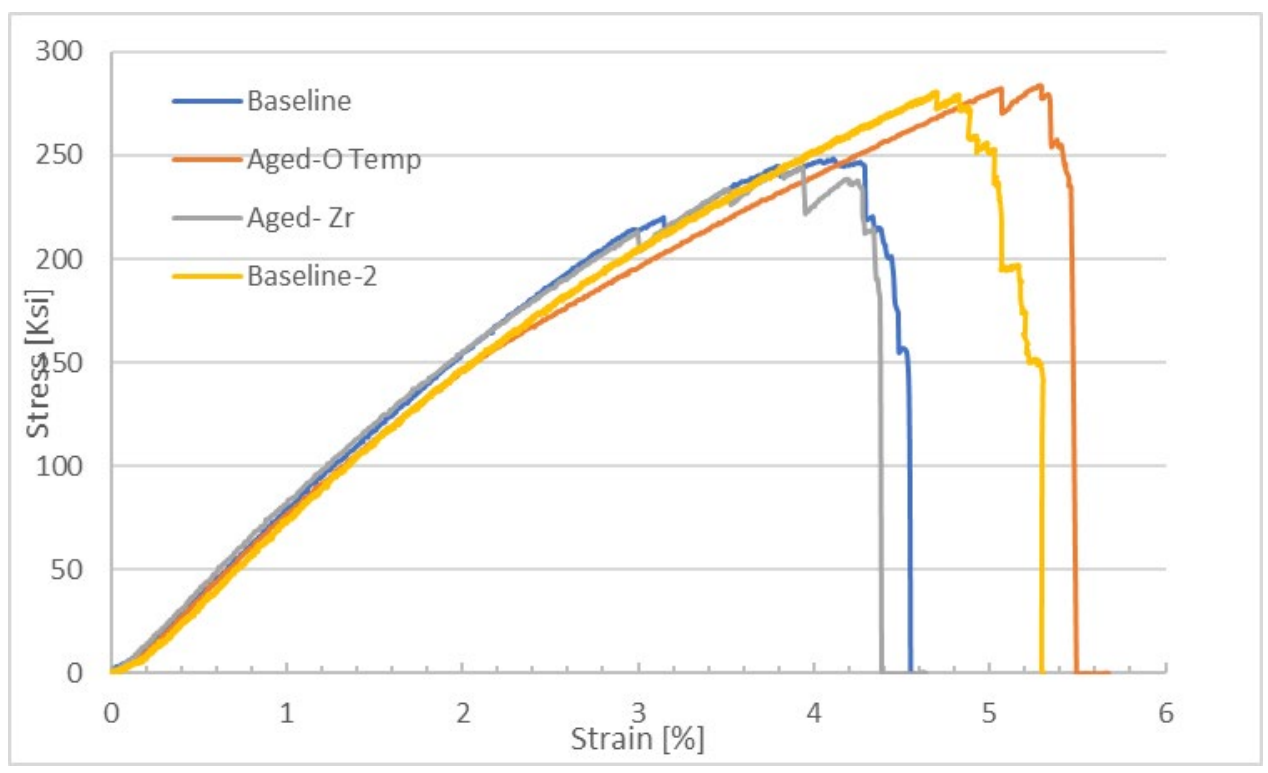

Figure $73 \mathrm{C} 7$ core tensile testing at $0.003 \mathrm{in} / \mathrm{s}$ loading rate, for baseline and EPRI thermal cycle aged samples. Aged EPRI C7 core from Zr-Al conductor has lower ductility compared to aged EPRI C7 core from O-temp conductor. 


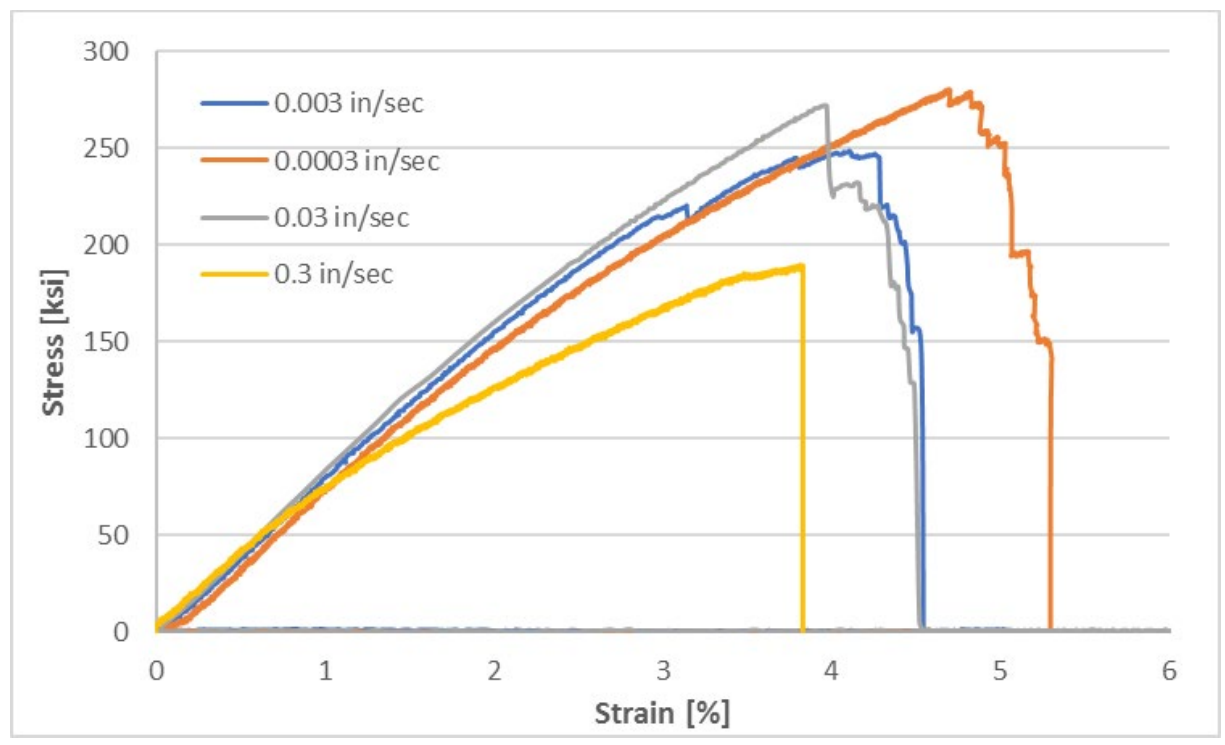

Figure 74 Comparison of baseline $\mathrm{C} 7$ core tensile testing at different loading rates, which show significant ductility reduction at higher loading rate.

\section{Southwire tensile testing on Drake C7 Overhead Conductor}

The Southwire tensile test of Drake C7 overhead conductor with O-temp aluminum conductor has a failure capacity of $40 \mathrm{~K} \mathrm{lb}$, shown in the red trace in Figure 75 . Where, the initial residual strength is at $10 \mathrm{~K} \mathrm{lb}$ from the aluminum conductor upon $\mathrm{C} 7$ core failure. Thus, the net force capacity carried by $7 \mathrm{C} 7$ core wires is $40 \mathrm{~K}-10 \mathrm{~K}=30 \mathrm{~K} \mathrm{lb}$; each $\mathrm{C} 7$ wire strength $=30 \mathrm{~K} / 7$ $=4250 \mathrm{lb}$, which is consistent with that from ORNL C7 core tensile test result.

The Southwire tensile test of Drake C7 overhead conductor with Zr-Al conductor has a failure capacity of $45 \mathrm{~K} \mathrm{lb}$. Where, the initial residual strength is at $15 \mathrm{~K} \mathrm{lb}$ from the $\mathrm{Zr}-\mathrm{Al}$ conductor upon $\mathrm{C} 7$ core failure. Thus, the net force capacity carried by $7 \mathrm{C} 7$ core wires is $45 \mathrm{~K}-15 \mathrm{~K}=30 \mathrm{~K}$ $\mathrm{lb}$; each C7 wire strength is $30 / 7=4280 \mathrm{lb}$.

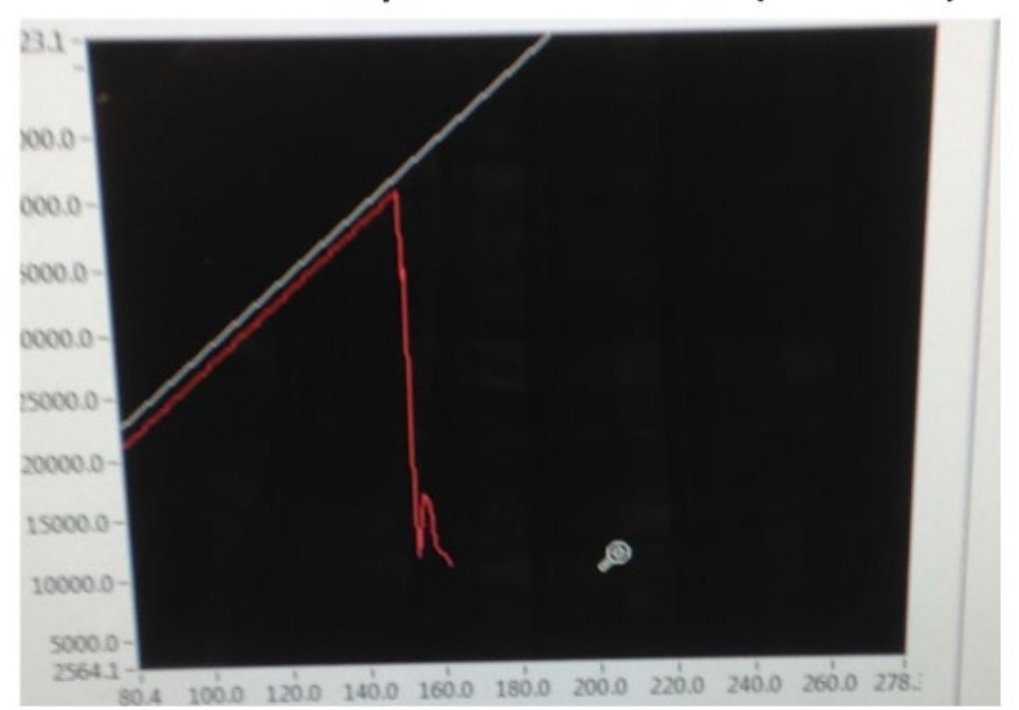

Figure $75 \mathrm{C}$-0-temp conductor splice testing, and $\mathrm{C7}$ conductor failed at $40 \mathrm{~K} \mathrm{Ib}$. 
Southwire tensile test performed on $\mathrm{C} 7$ overhead conductor with O-temp aluminum conductor and with a dead-end connector served a C7 conductor grip end, shows about $32 \mathrm{~K} 1 \mathrm{~b}$. tensile capacity with $5.8 \mathrm{~K}$ lb. residual strength, shown in Figure 76 . Which is about $8 \mathrm{~K} 1 \mathrm{~b}$. load reduction in $\mathrm{C} 7$ conductor tensile capacity compared to that shown in Figure 75 . The estimate $\mathrm{C} 7$ core wire strength is about $3700 \mathrm{lb}$ each. Which is about $600 \mathrm{lb}$ lower than that of $\mathrm{C} 7$ conductor test w/o dead-end connector. This could be interrelated as $\mathrm{C} 7$ core wire damage through deadend connector crimp forming mechanism. Furthermore, postmortem examination also confirmed that the $\mathrm{C} 7$ overhead conductor failure site is within the dead-end connector region.

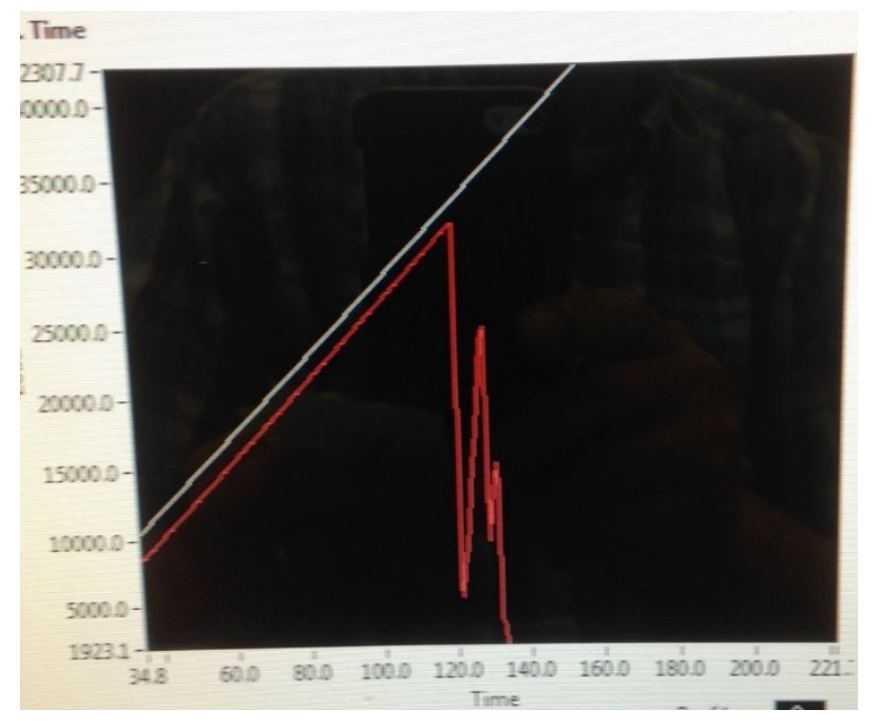

Figure 76 C7-O-temp Drake conductor tensile testing, end grip equipped with the Deadend splice, conductor failed at $32 \mathrm{~K} \mathrm{lb}$. and located inside the Dead-end splice.

Southwire tensile test performed on $\mathrm{C} 7$ overhead conductor with $\mathrm{Zr}-\mathrm{Al}$ conductor and with a dead-end connector, shows $40 \mathrm{~K} \mathrm{lb}$. tensile capacity shown in Figure 77, about $5 \mathrm{~K}$ lb. load reduction compared to that of test sample w/o dead-end type grip; and the test trace showed a $10.8 \mathrm{~K} \mathrm{lb}$. residual strength. The estimated tensile strength for $\mathrm{C} 7 \mathrm{core}$ wire is $4,170 \mathrm{lb}$. each.

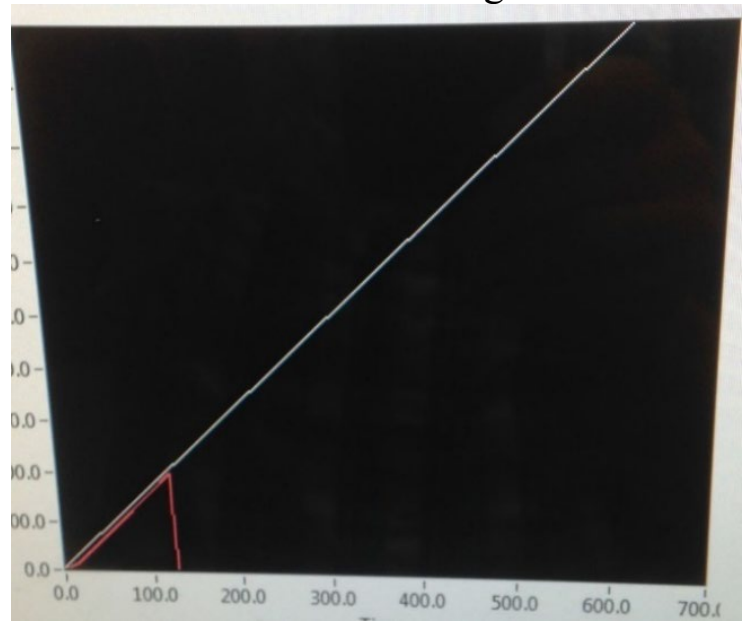

Figure 77 C7 Zr-Al Drake conductor tensile testing, with Dead-end grip; conductor failed at $40 \mathrm{~K} \mathrm{Ib}$. and located inside the Dead-end splice. 


\subsection{High temperature $\mathrm{C} 7$ carbon composite core tensile tests}

The high temperature $\mathrm{C} 7$ core sample tensile test set-up is shown Figure 78. There are two $\mathrm{C} 7$ core sample sizes used in the high temperature tensile testing, which are 15-inch and 27-inch in length, where the corresponding sample grips are located within the furnace and out of furnace, respectively.

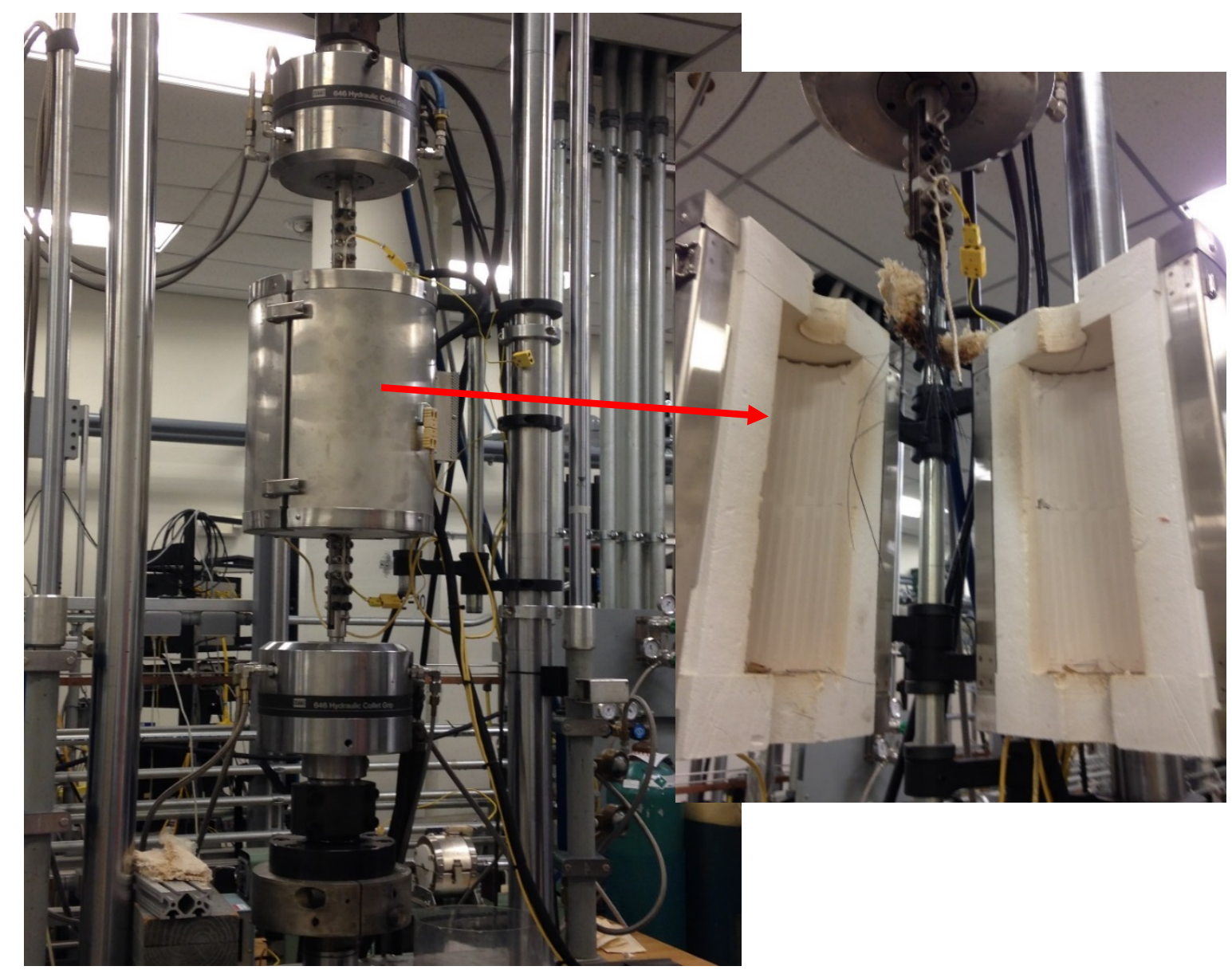

Figure 78 (Left) High temperature tensile testing set-up, (Right) environmental chamber.

\subsubsection{Tested sample grips located outside the environmental chamber}

The first set of tensile testing on $\mathrm{C} 7$ core samples were performed with grip located outside the furnace and with gage section of 17 -inch. The test results carried out at $100^{\circ} \mathrm{C}, 180^{\circ} \mathrm{C}$, and $225^{\circ} \mathrm{C}$ are shown in Figure 79 and Figure 81, respectively. 

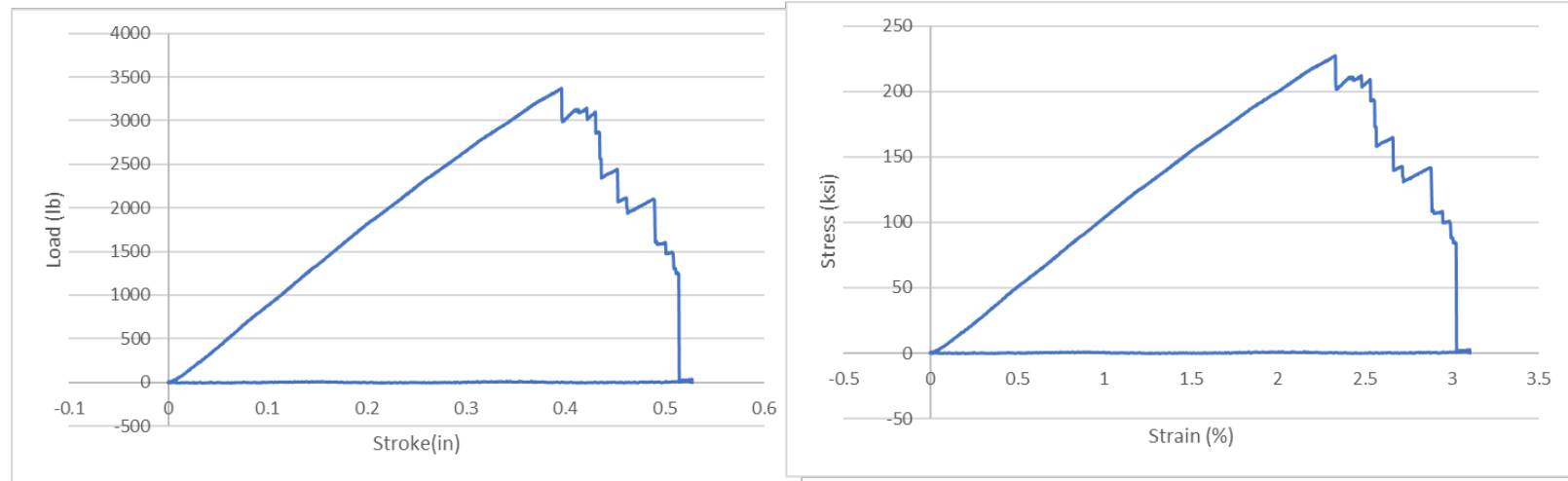

Figure $79 \mathrm{C} 7$ core sample tensile test $\# 3$ at $100^{\circ} \mathrm{C}$
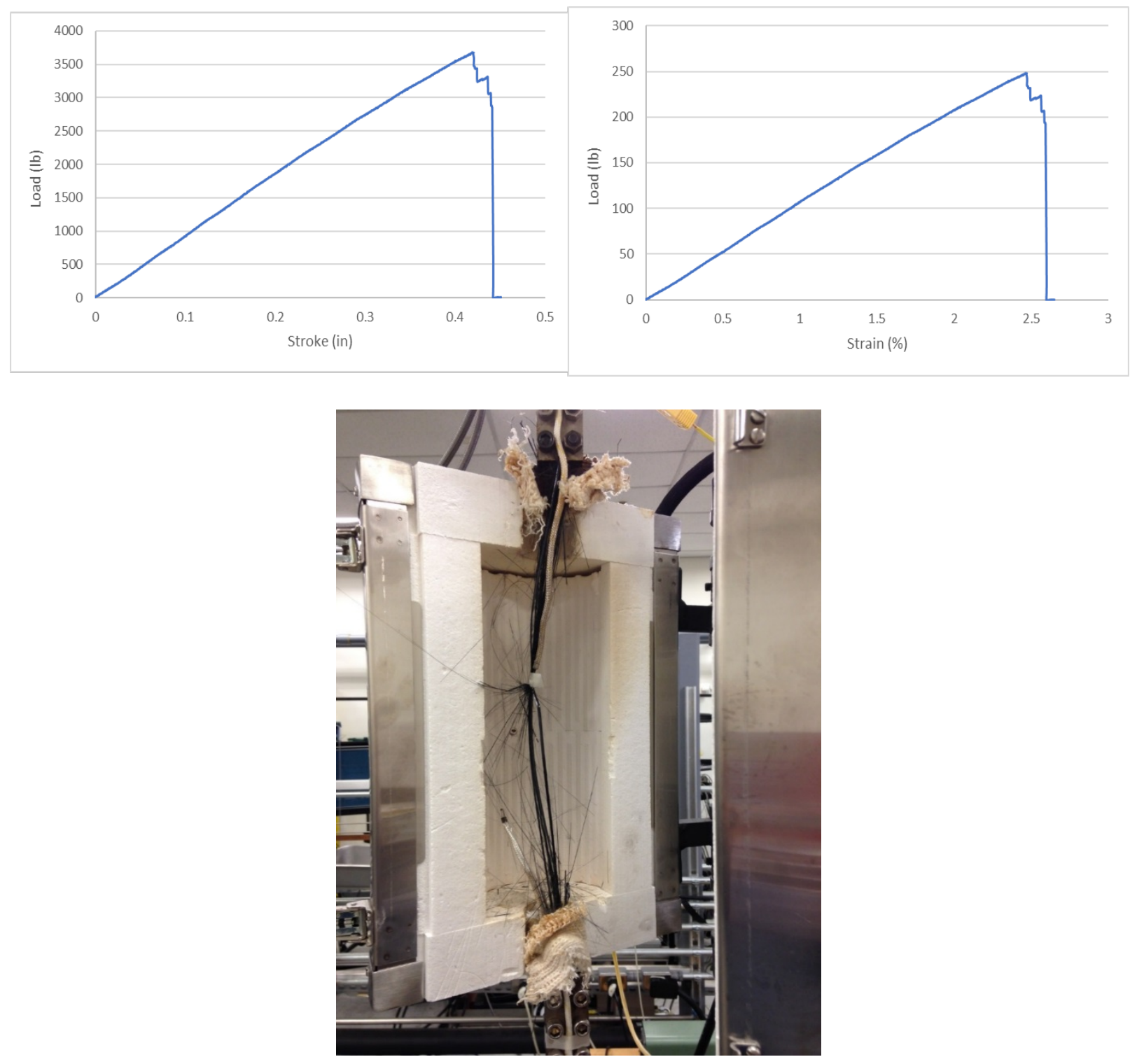

Figure $80 \mathrm{C} 7$ core sample tensile fractured at $180^{\circ} \mathrm{C}$. 

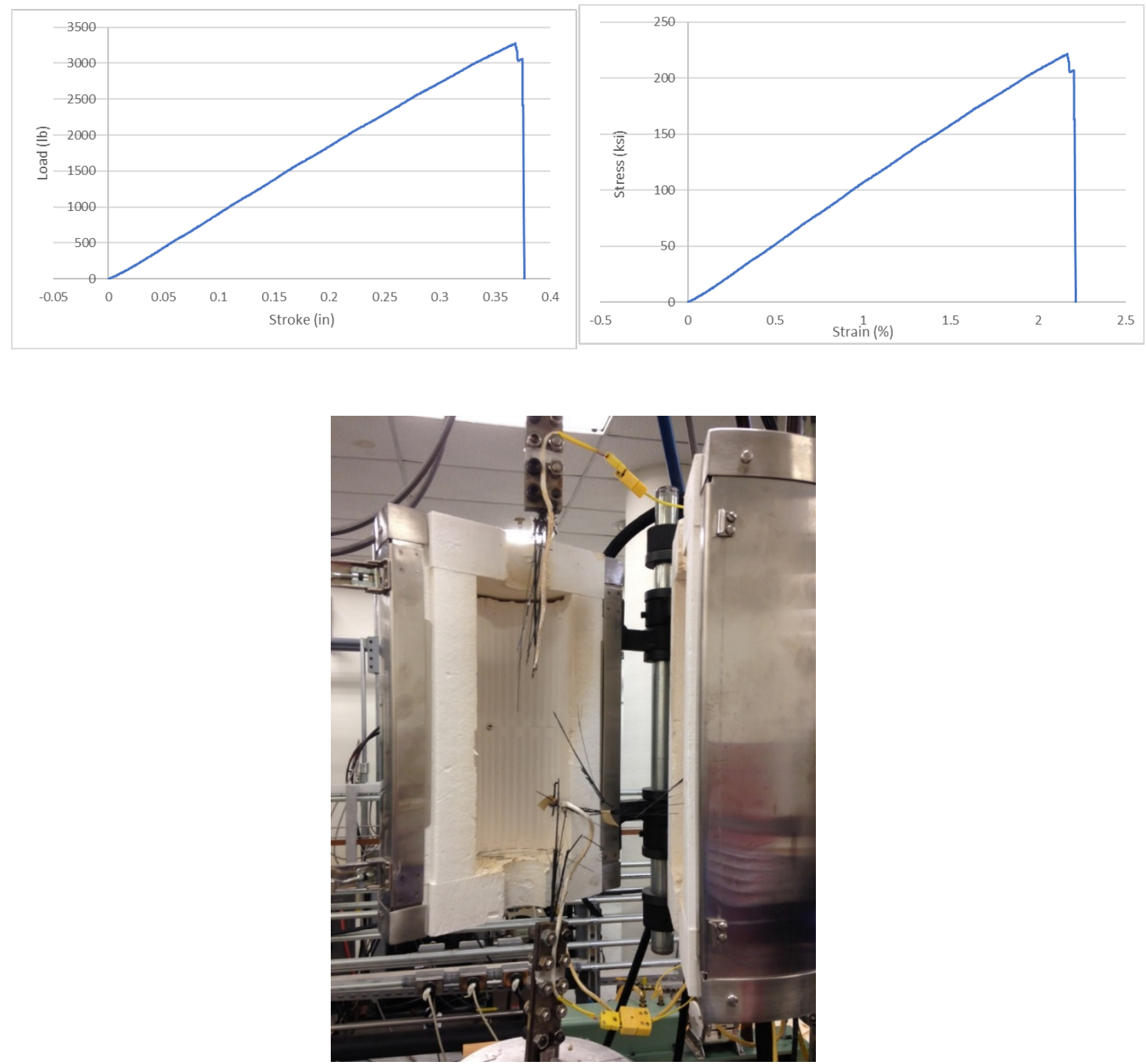

Figure $81 \mathrm{C} 7$ core sample tensile fractured at $225^{\circ} \mathrm{C}$.

\subsubsection{Sample grips located inside the environmental chamber}

The second group of the $\mathrm{C} 7$ core sample tensile test were performed with the grip located inside the furnace. This scenario is more closed to that of $\mathrm{C} 7$ overhead conductor service environment, which was learned from EPRI HTLS thermal cycling experiment that showed higher temperature at conductor and grip interface within the splice connector at higher operating temperature. The temperature profiles obtained from thermal couples located at $\mathrm{C} 7$ core sample and grip are provided in Table 6 , where the grip temperature is about $20^{\circ} \mathrm{C}$ lower than the $\mathrm{C} 7$ core sample temperature. The tensile test results are provided in Figures 82-89, which showed a significant drop in tensile strength at a temperature at or above $180^{\circ} \mathrm{C}$ compared to that of sample grips located outside the furnace. This phenomenon is primary due to $\mathrm{C} 7$ core sample softening above 
$\mathrm{Tg}$ induced grip slip during tensile testing. This lack of sufficient grip strength for $\mathrm{C} 7$ core samples may also indicate the potential weakness of applying the conventional crimping type core grip connector to the $\mathrm{C} 7$ carbon composite core wires designed for the high operating temperature. The Tg of PPS matrix is about $90^{\circ} \mathrm{C}$ for a C7 core sample, thus at $180^{\circ} \mathrm{C}$ operation temperature induced PPS matrix softening can cause PPS matrix flow out of high pressure crimping grip region. The consequence is the significant reduction in the grip or connector crimping strength.

Table 6 Temperature profile of $\mathrm{C} 7$ core sample tensile testing

\begin{tabular}{|c|c|}
\hline \multicolumn{2}{|c|}{ Temperature, ${ }^{\circ} \mathrm{C}$} \\
\hline C7 core sample & Grip \\
\hline 99 & 86 \\
\hline 125 & 104 \\
\hline 180 & 161 \\
\hline 225 & 202 \\
\hline
\end{tabular}
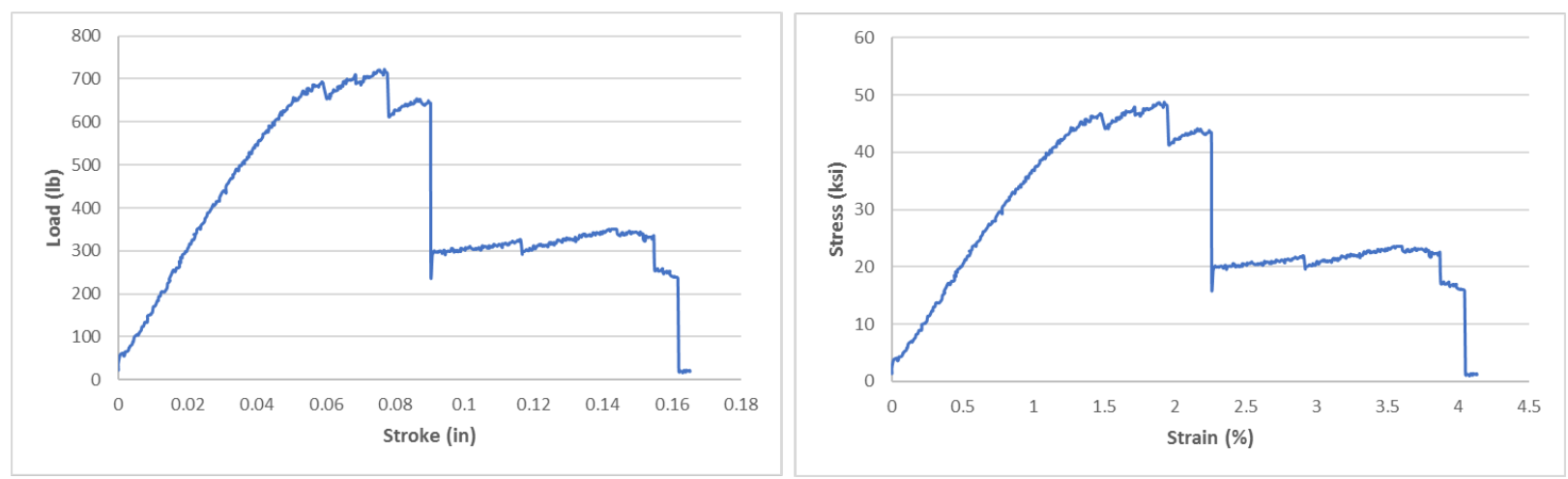

Figure $82 \mathrm{C} 7$ core sample tensile test \#1 at $100 \mathrm{C}$.
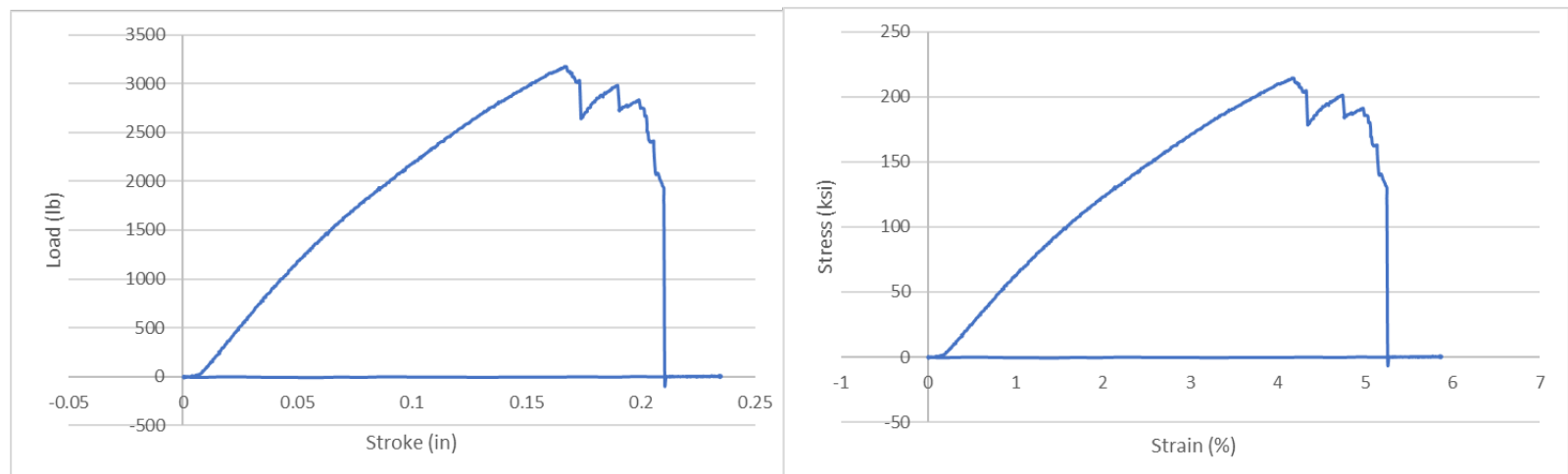


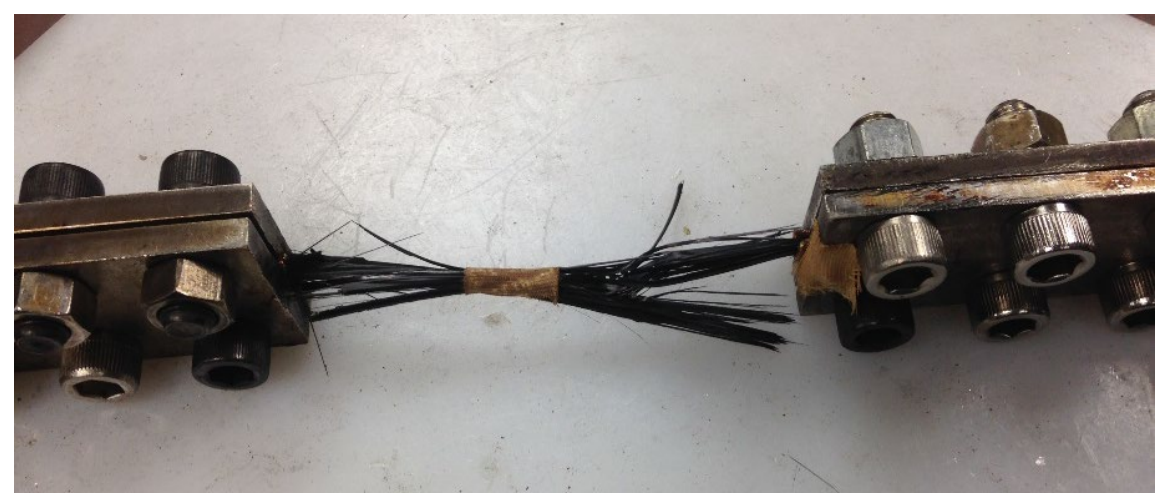

Figure $83 \mathrm{C} 7$ core sample tensile test $\# 2$ at $100^{\circ} \mathrm{C}$.
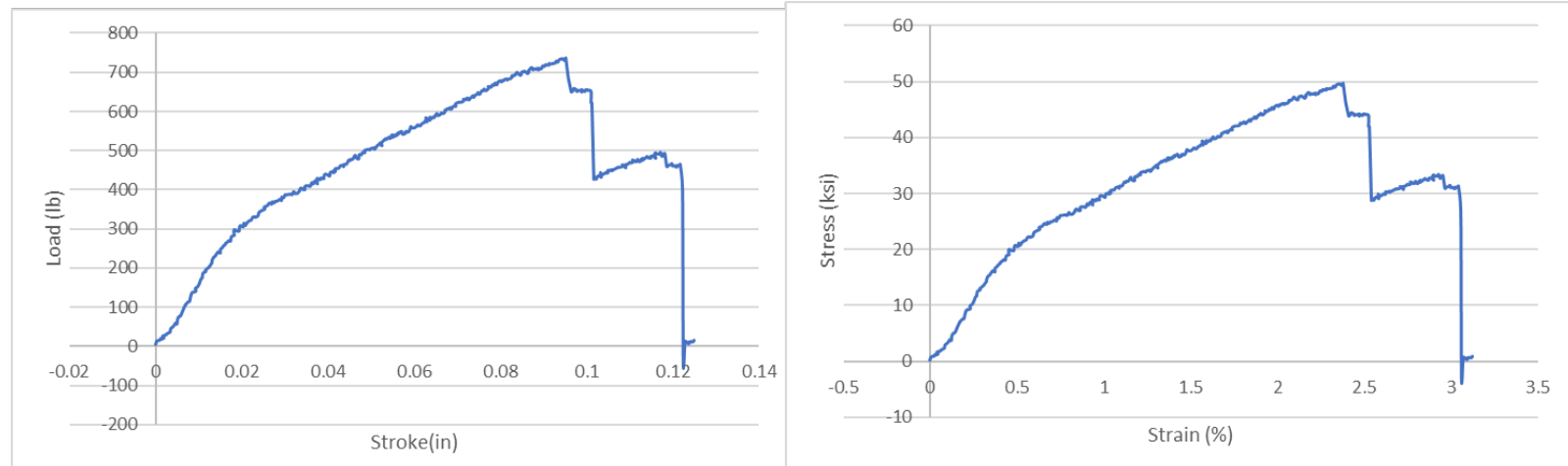

C7 core sample tested at $180^{\circ} \mathrm{C}$

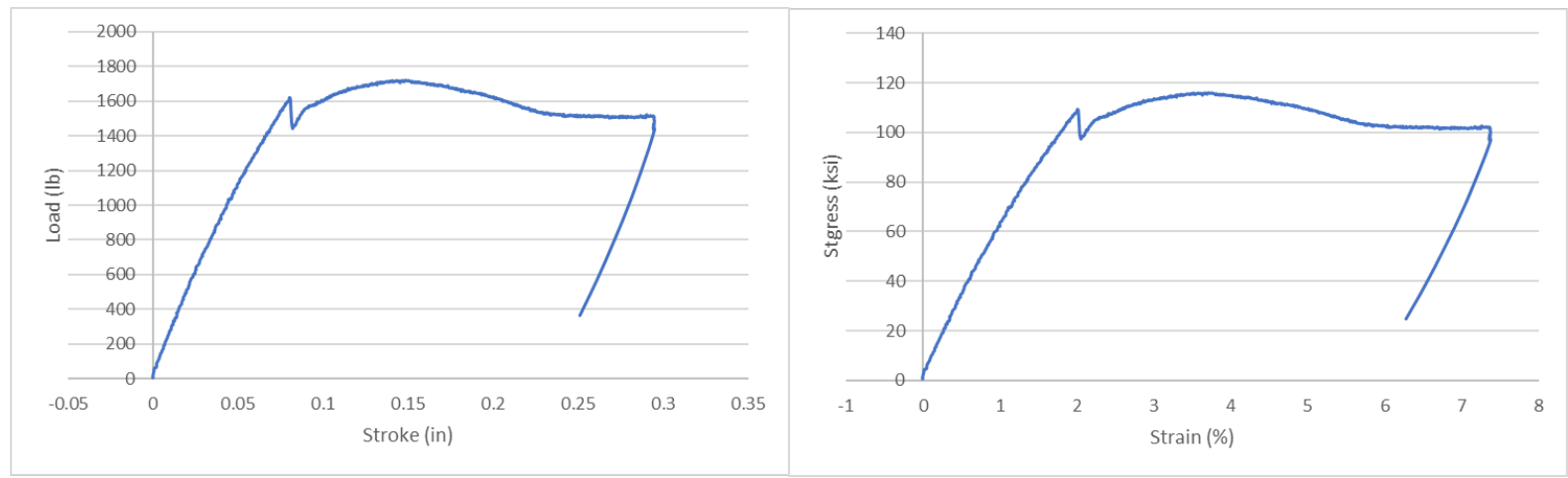

C7 core sample tested at $125^{\circ} \mathrm{C}\left(\operatorname{cool}\right.$ down from $\left.180^{\circ} \mathrm{C}\right)$

Figure $84 \mathrm{C} 7$ core sample tensile test \#4 at $180^{\circ} \mathrm{C}$; Upon completion of $180 \mathrm{C}$ tensile testing, the $\mathrm{C} 7$ core sample was cooled down to RT, followed with tensile test performed at $125^{\circ} \mathrm{C}$, where significant increase in tensile strength at $125^{\circ} \mathrm{C}$ was observed compared to that of $180^{\circ} \mathrm{C}$ testing. 

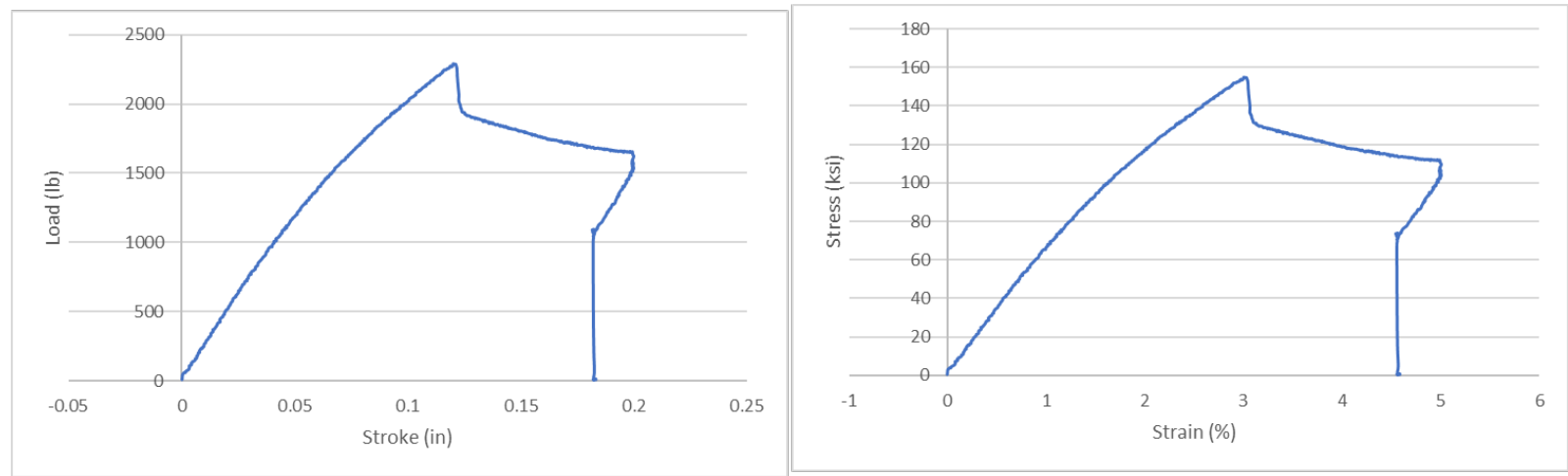

Figure $85 \mathrm{C} 7$ core sample tensile test $\# 5$ at $180^{\circ} \mathrm{C}$.
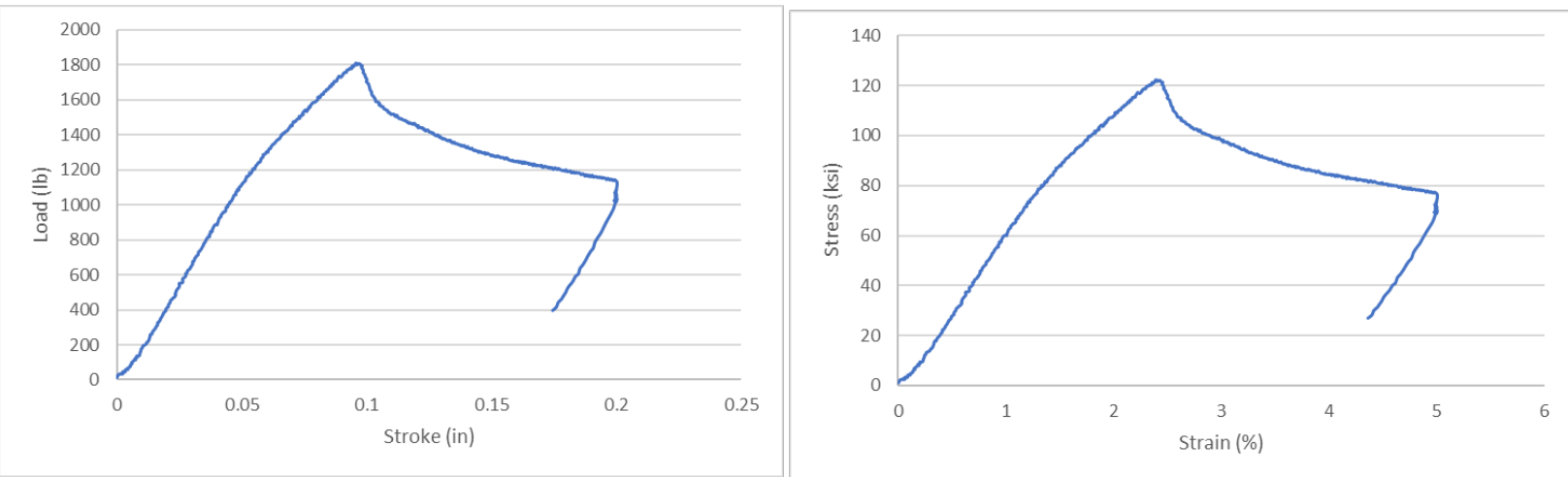

Figure $86 \mathrm{C} 7$ core sample tensile test $\# 6$ at $180^{\circ} \mathrm{C}$.
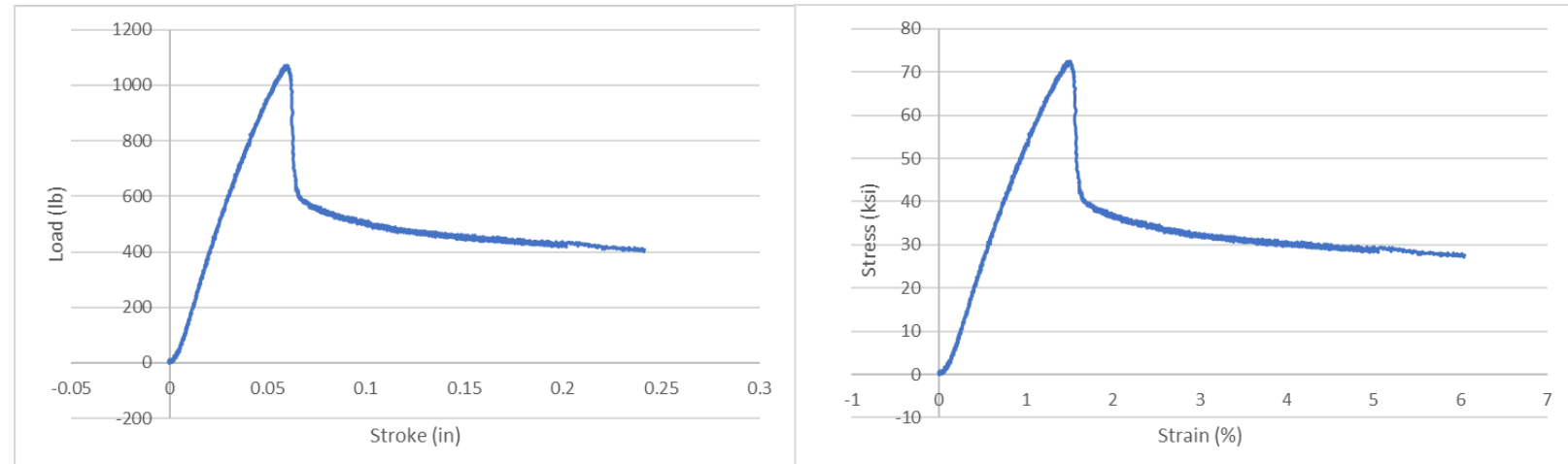

Figure $87 \mathrm{C} 7$ core sample tensile test $\# 7$ at $225^{\circ} \mathrm{C}$. 

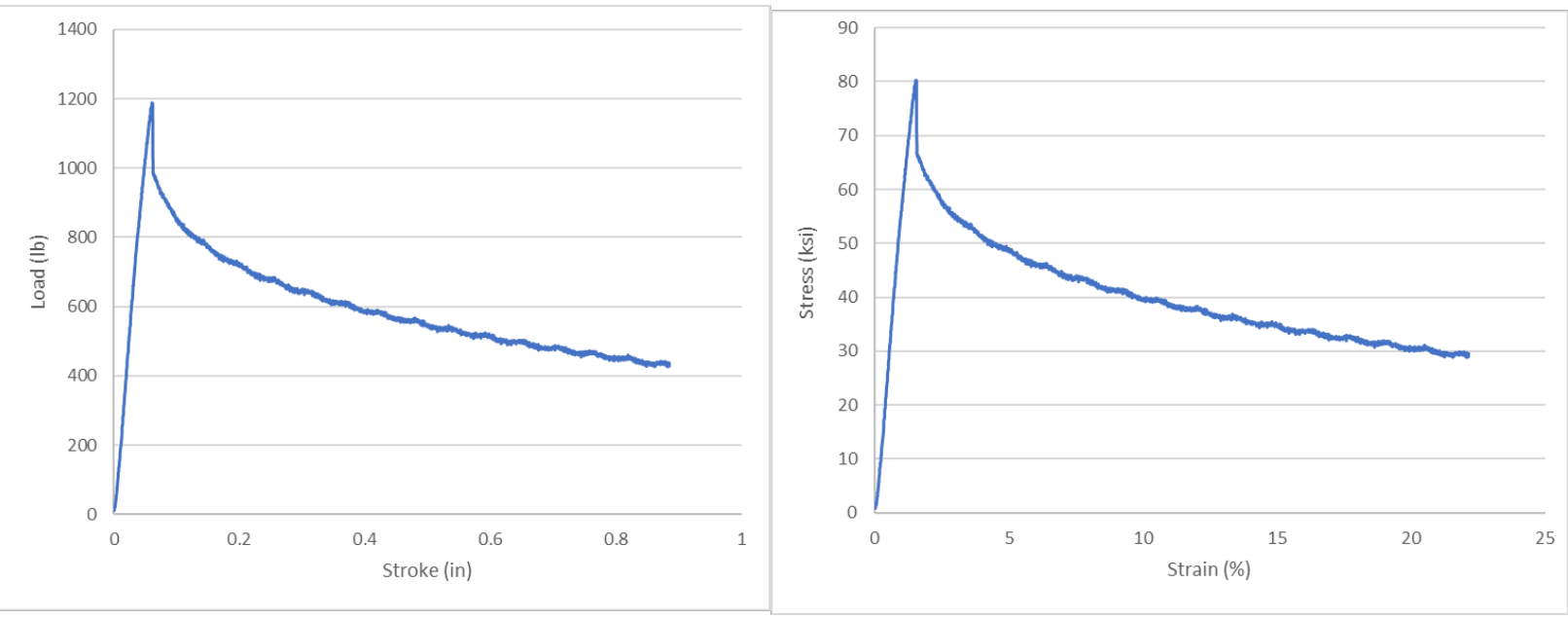

Figure $88 \mathrm{C} 7$ core sample tensile test $\# 8$ at $225^{\circ} \mathrm{C}$.

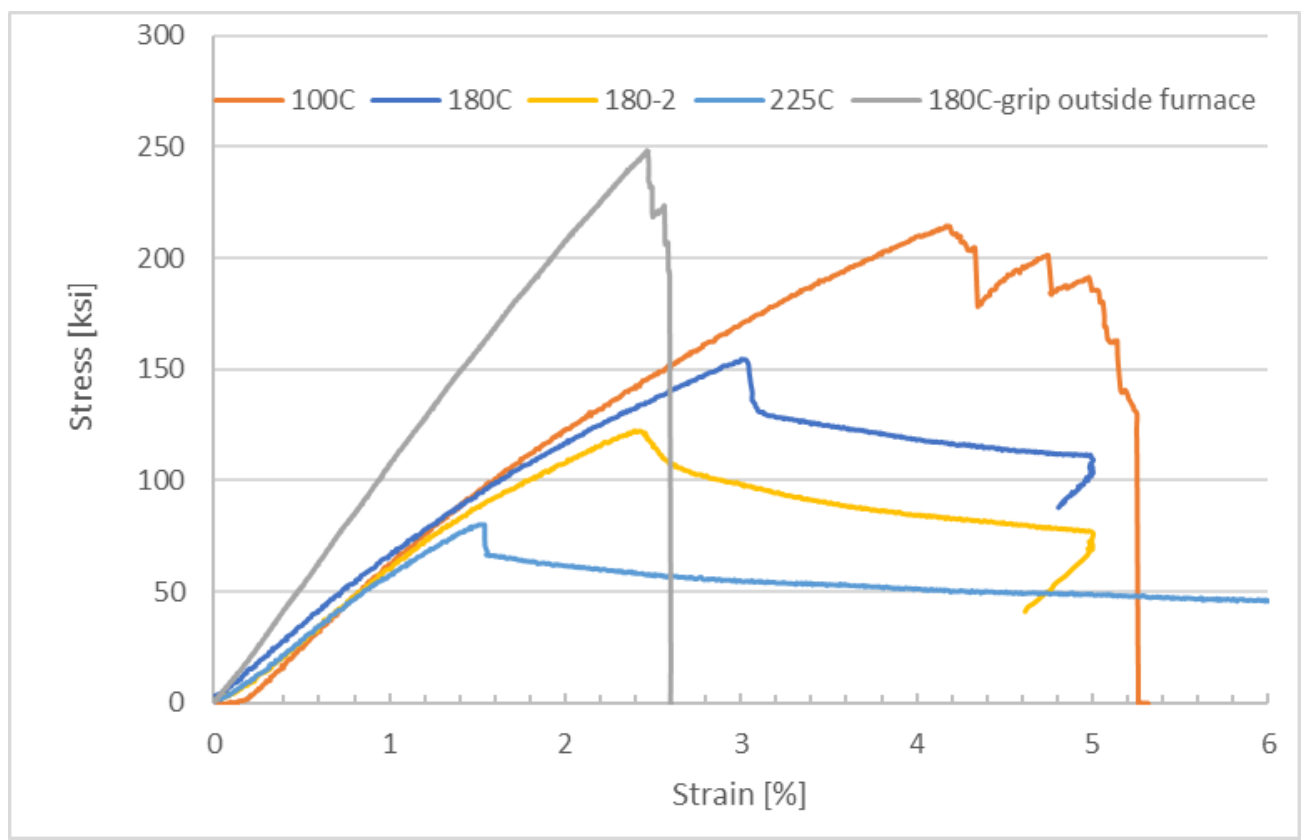

Figure $89 \mathrm{C} 7$ core sample grip temperature effect on $\mathrm{C} 7$ core tensile testing results. Significant tensile strength and stiffness reductions were observed for testing temperature above $100^{\circ} \mathrm{C}$. 


\section{OTHER APPROACHES USED FOR C7 COMPOSITE CORE THERMAL AGING CHARACTERIZATIONS}

\subsection{C7 carbon composite core sample creep testing}

C7 composite core wire long-term creep response is another important high temperature material behavior that needs to be understood. The C7 core sample creep test setup is shown in Figure 90.

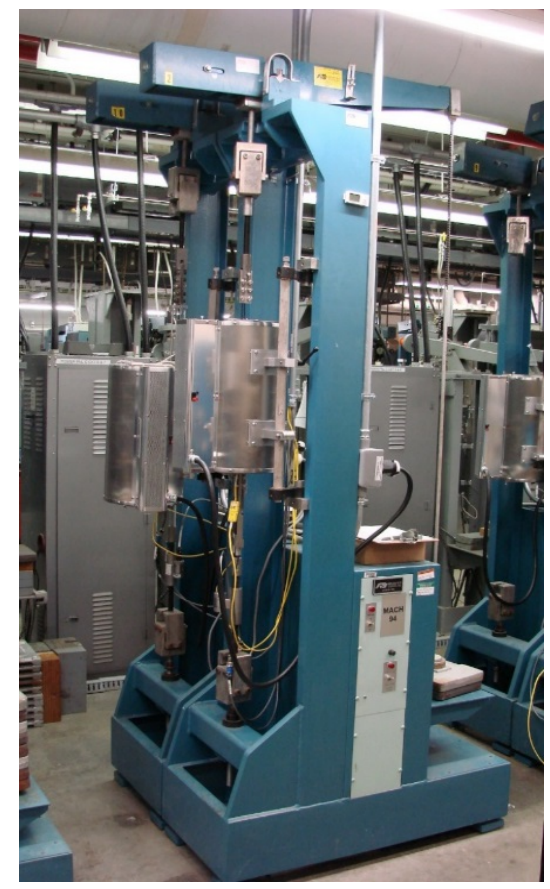

(a)

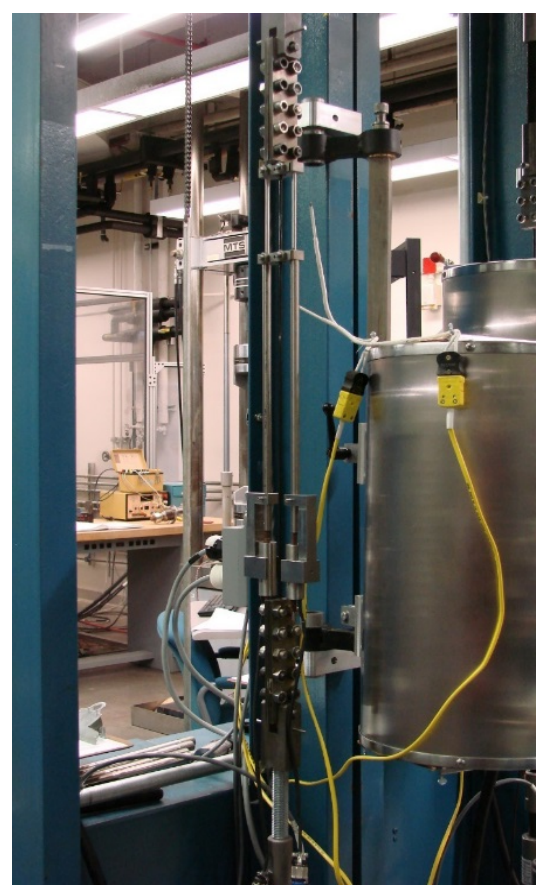

(b)

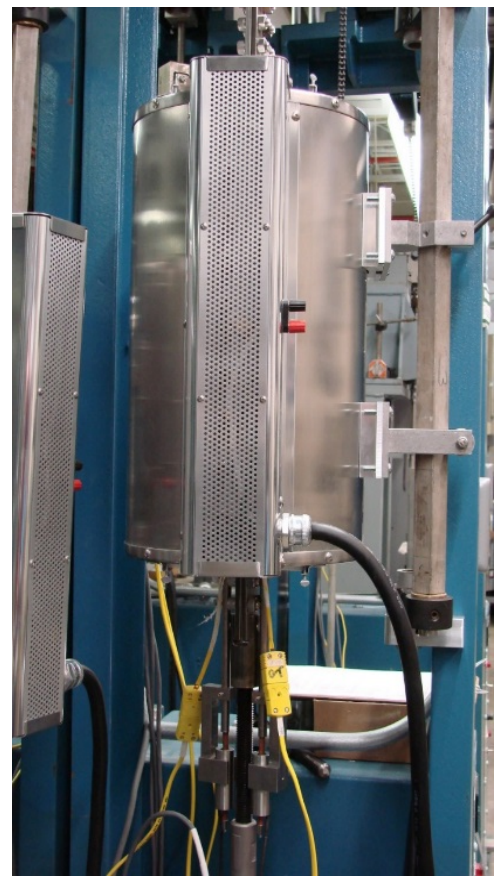

(c)

Figure 90 (a) Creep test frame including environmental chamber, (b) $\mathrm{C7}$ core creep test sample in the loading train with grip, thermal couples, and LVDTs, (c) Close look of the environmental chamber, where grip is located outside the chamber.

The creep test was performed with a load of $1200 \mathrm{lb}$. at $180^{\circ} \mathrm{C}$ for 819 hours and then started with the second creep test with a load of $1200 \mathrm{lb}$. at $225^{\circ} \mathrm{C}$ for another 1534 hours. The details of creep test time histories are provided in Figures 91-93. The associated creep strains at $180^{\circ} \mathrm{C}$ and $225^{\circ} \mathrm{C}$ are provided in Figure 94 and Figure 95, respectively. The estimate creep strain at the performed period is quite small, and the creep variation is mostly due to testing laboratory ambient temperature variability during the winter period. 


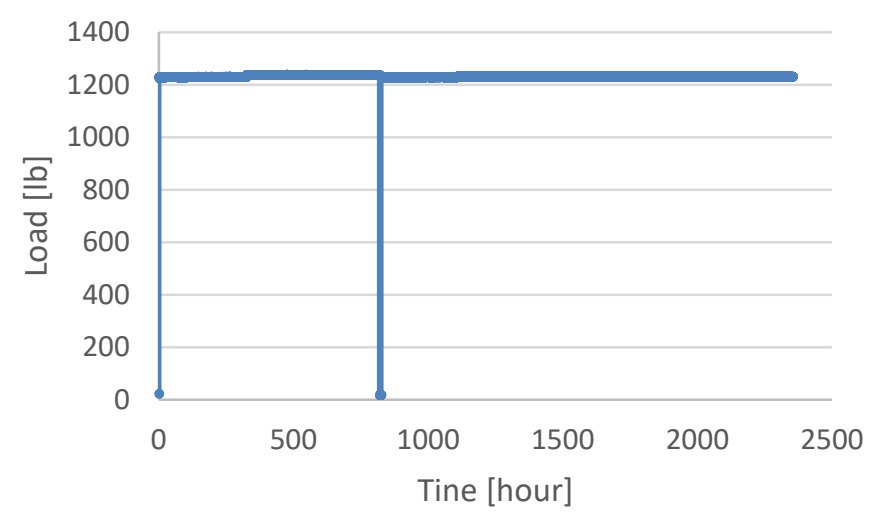

Figure 91 Creep test load-time history.

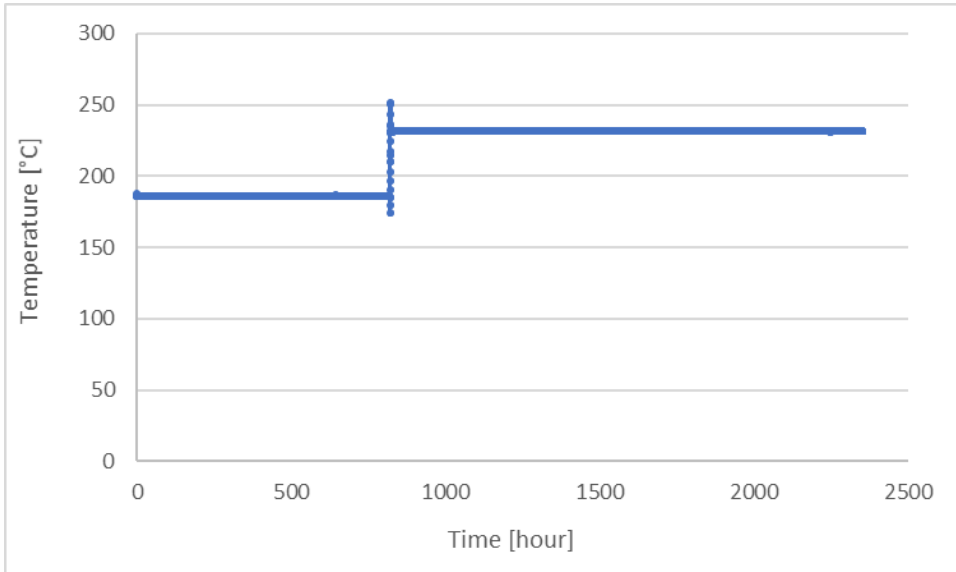

Figure 92 Creep test temperature-time history.

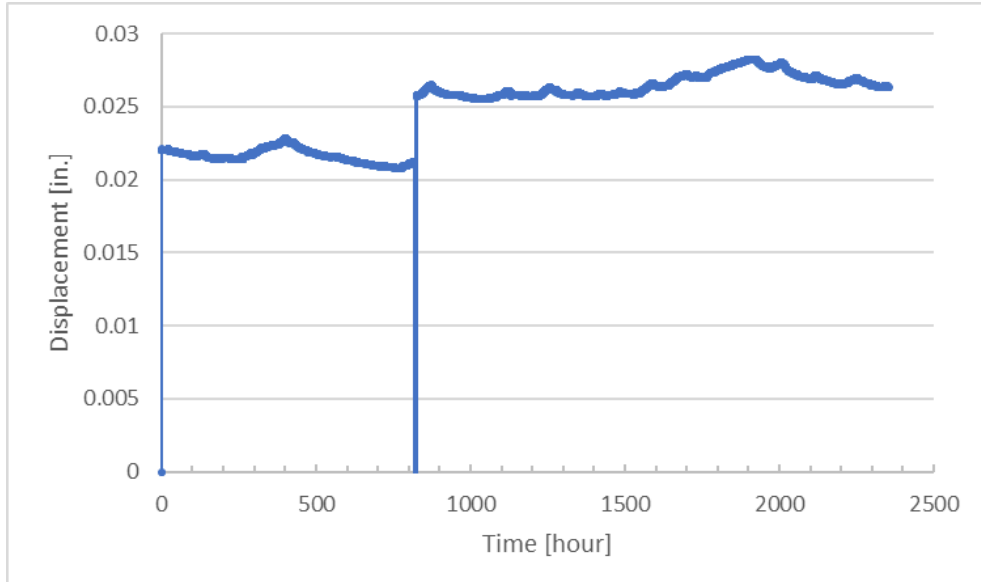

Figure 93 Creep test displacement-time history. 


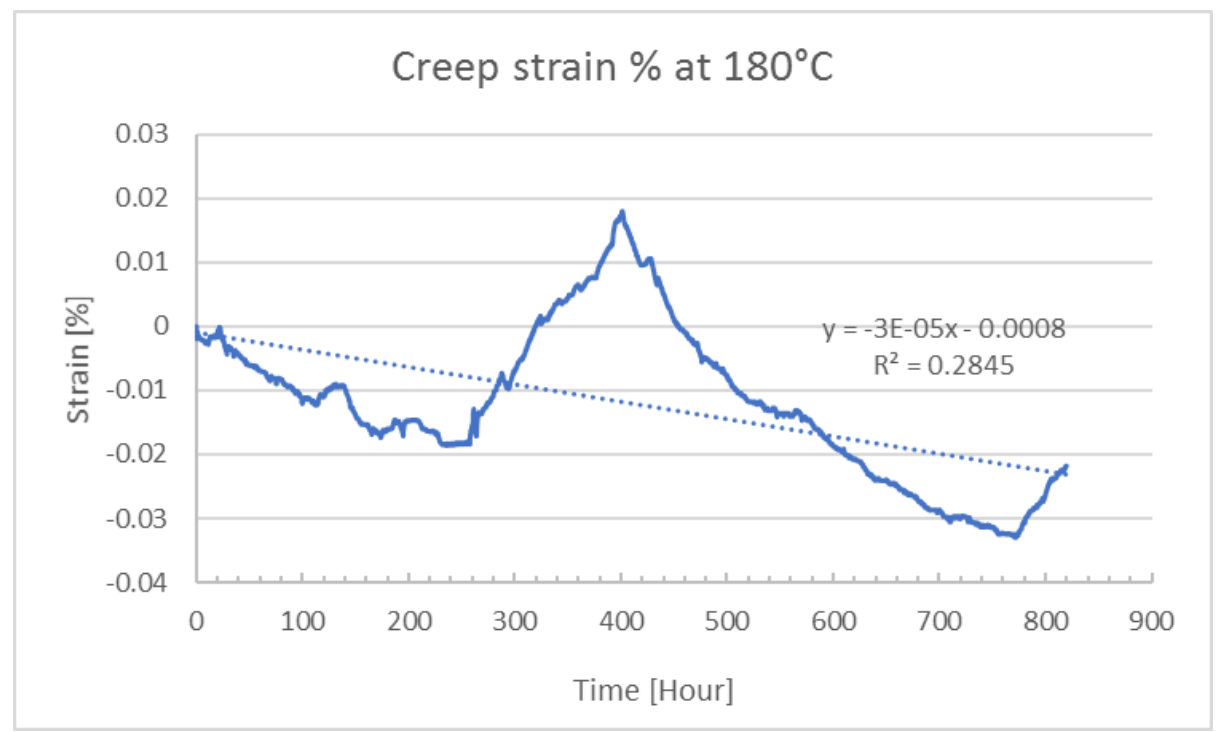

Figure 94 Creep test strain-time history at $180^{\circ} \mathrm{C}, 26$-inch long $\mathrm{C} 7$ core sample with 4-inch gage length. The estimated creep strain rate is $-3 \mathrm{E}-05 \% / \mathrm{hour}$.

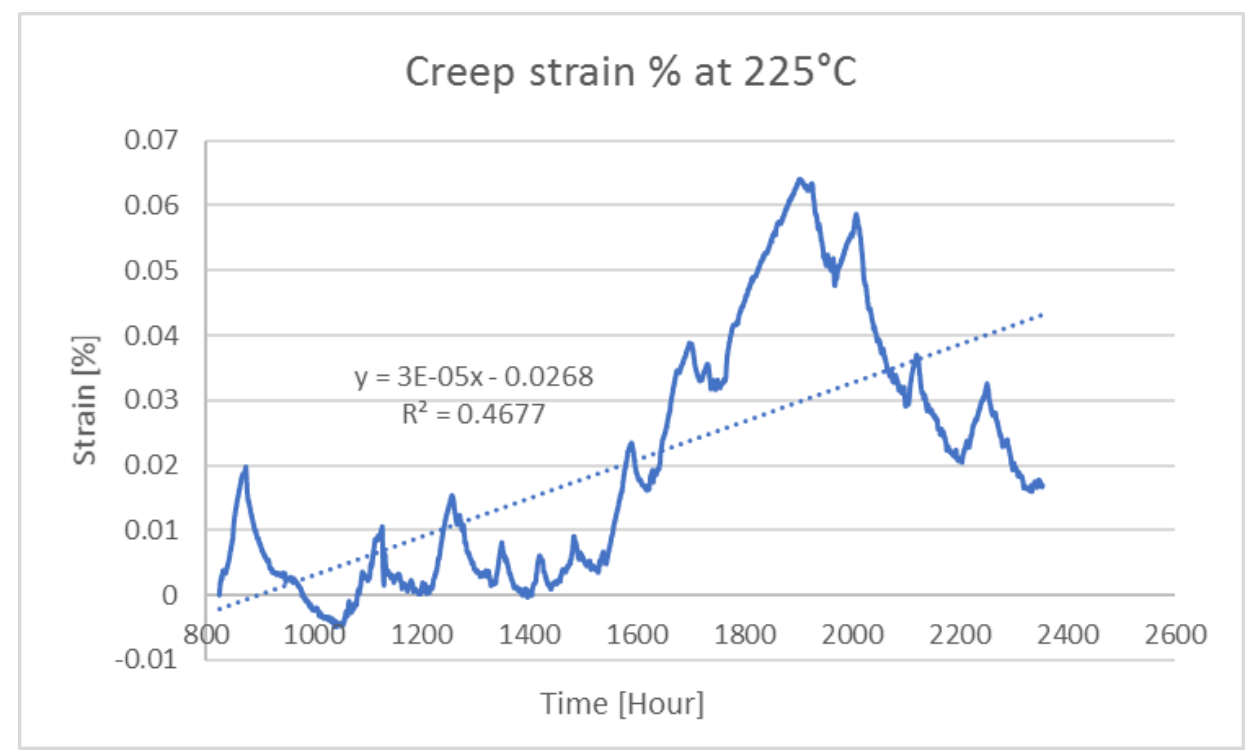

Figure 95 Creep test strain-time history at $225^{\circ} \mathrm{C}$, 26-inch long $\mathrm{C} 7$ core sample with 4-inch gage length. The estimated creep strain rate is $3 E-05 \% / h o u r$. 


\subsection{C7 carbon composite core dynamic stability evaluation}

C7 composite core wire long-term vibration fatigue response is another important thermal-plastic composite material behavior that needs to be understood. C7 carbon composite core dynamic behaviors will be evaluated for both Aeolian and Galloping related vibrations simulation to estimate $\mathrm{C} 7$ composite core effective lifetime under vibration fatigue loading. The ORNL patented cyclic integrated reversible-bending fatigue tester (CIRFT) testing method will be used for C7 composite core dynamic reliability and stability study $[9,10]$. The C7 core sample creep test setup is shown in Figure 96. The real-time CIRFT fatigue test results of 12\% RB bending moment loading under 1.6 million cycles are shown in Figures 97. Large noise observed from the test data is primary due to severe contact interaction among the $7 \mathrm{C} 7$ core wires during reversible dynamic bending loading of $\pm 5 \mathrm{~N}$-m range. From figure 97, no significant increase in mean curvature increases or reduction in the mean flexural rigidity under bending fatigue testing were observed after $1.6 \mathrm{M}$ cycles. There, $\mathrm{C} 7$ core wires dynamic fatigue response was considered intact after $1.6 \mathrm{M}$ cycles bending fatigue test.

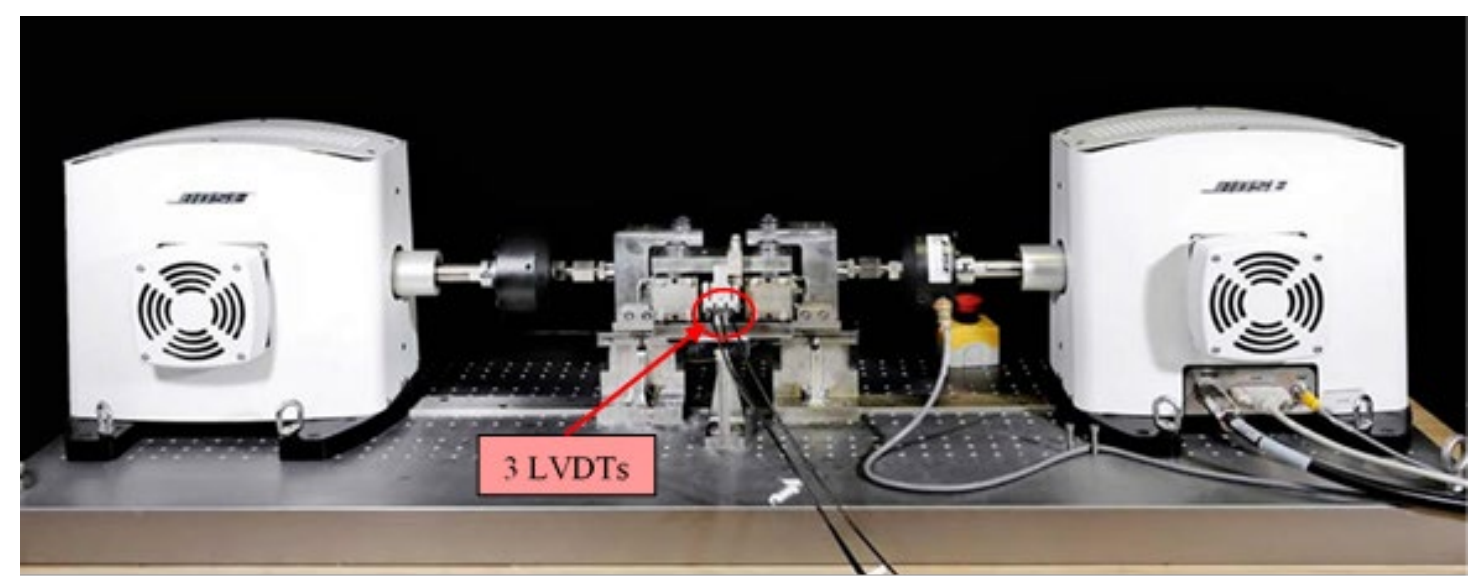

CIRFT Tester overall layout with Bose dual linear actuators and U-frame bending fixture.

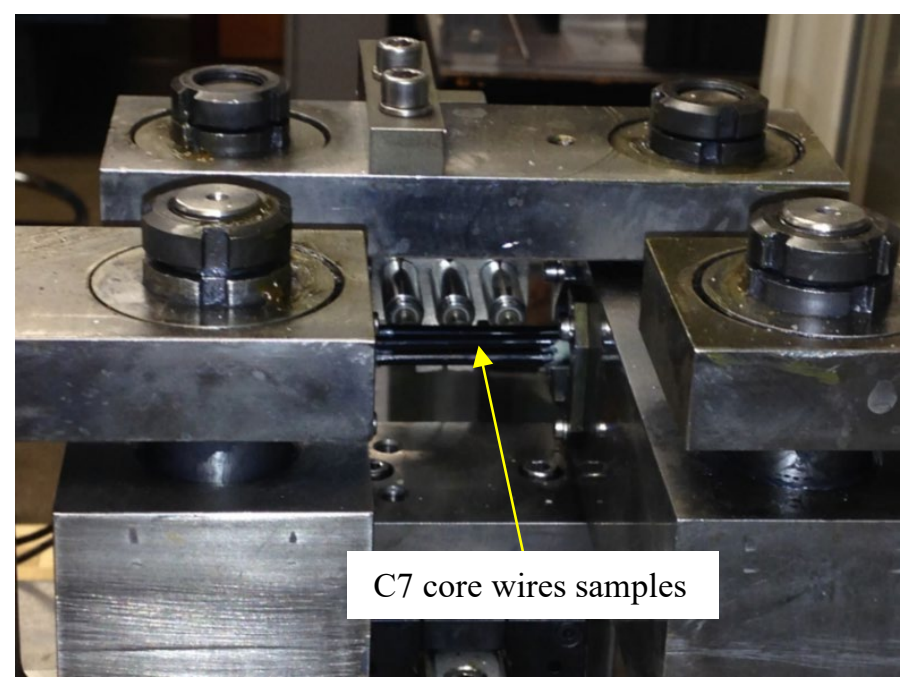

U-frame bending fixture back view 


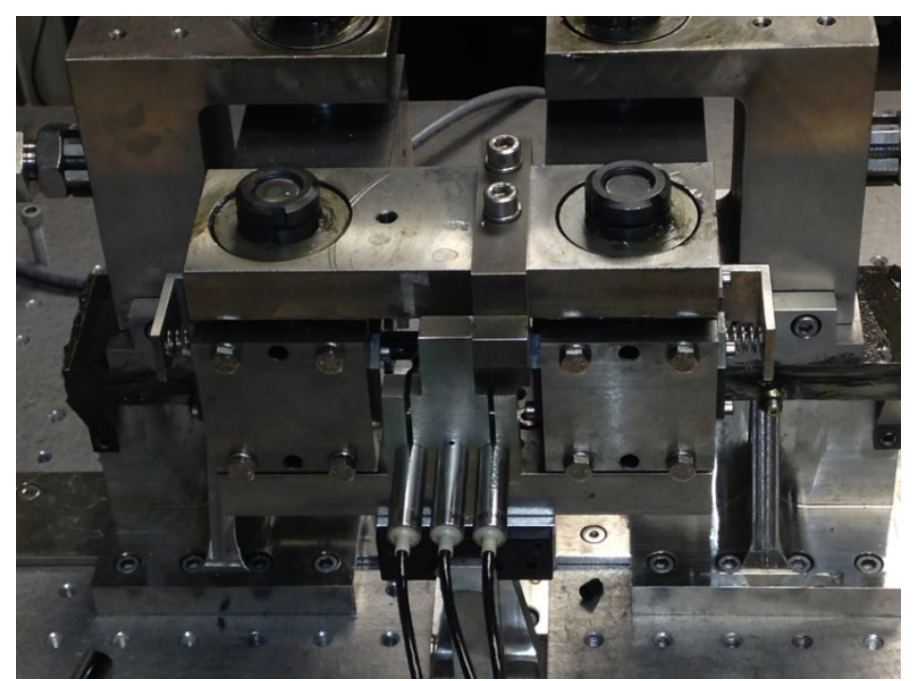

U-frame bending fixture back view, with 3 LVDTs.

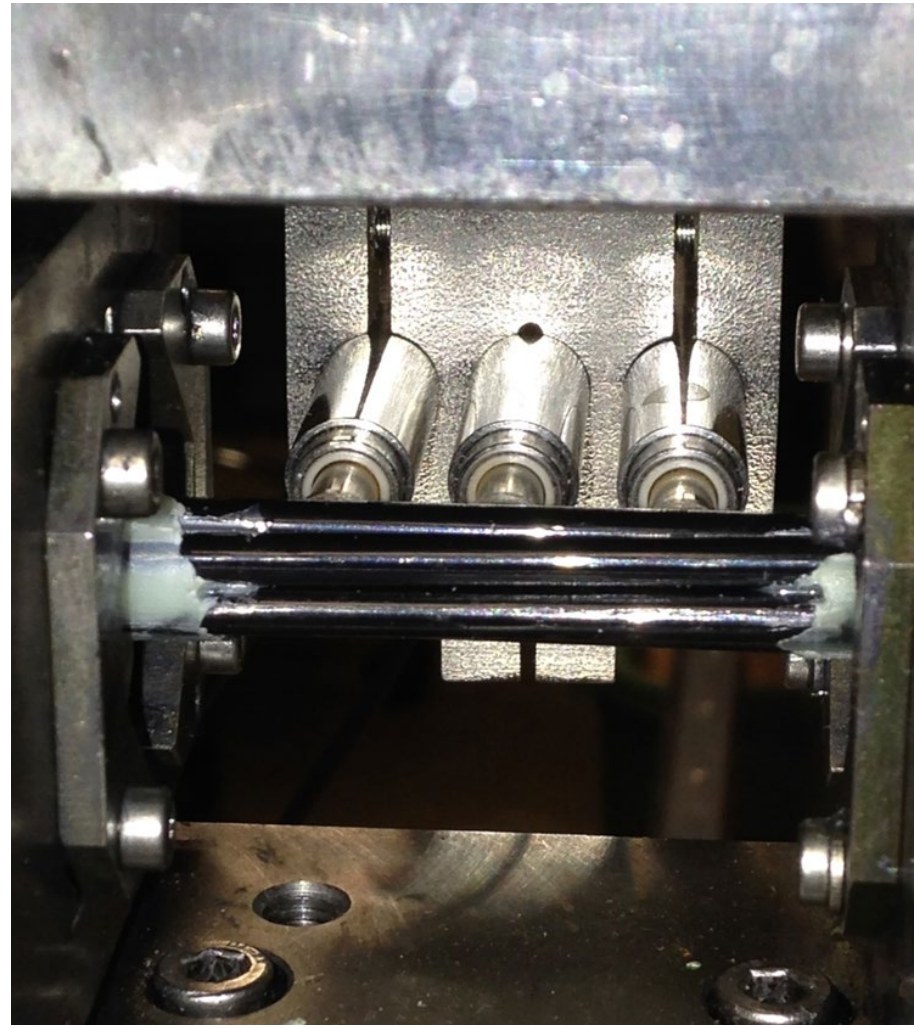

Close view of 7 C7 core wires, U-frame bending fixture, and 3 LVDTs for in-situ deformation/curvature measurement.

Figure 96 General layout of CIRFT tester used for $\mathrm{C7}$ core wires vibration fatigue testing. 


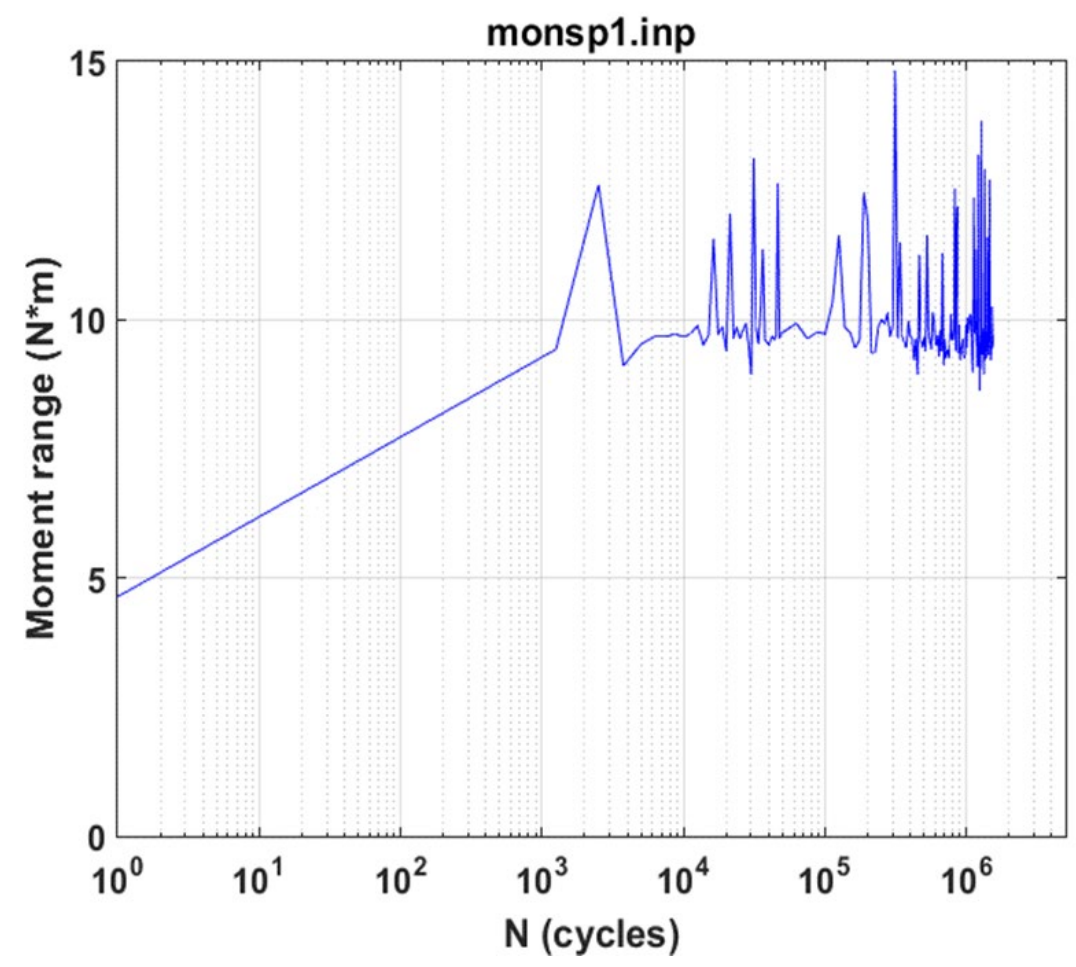

Real-time bending loading range-cycle frequency history

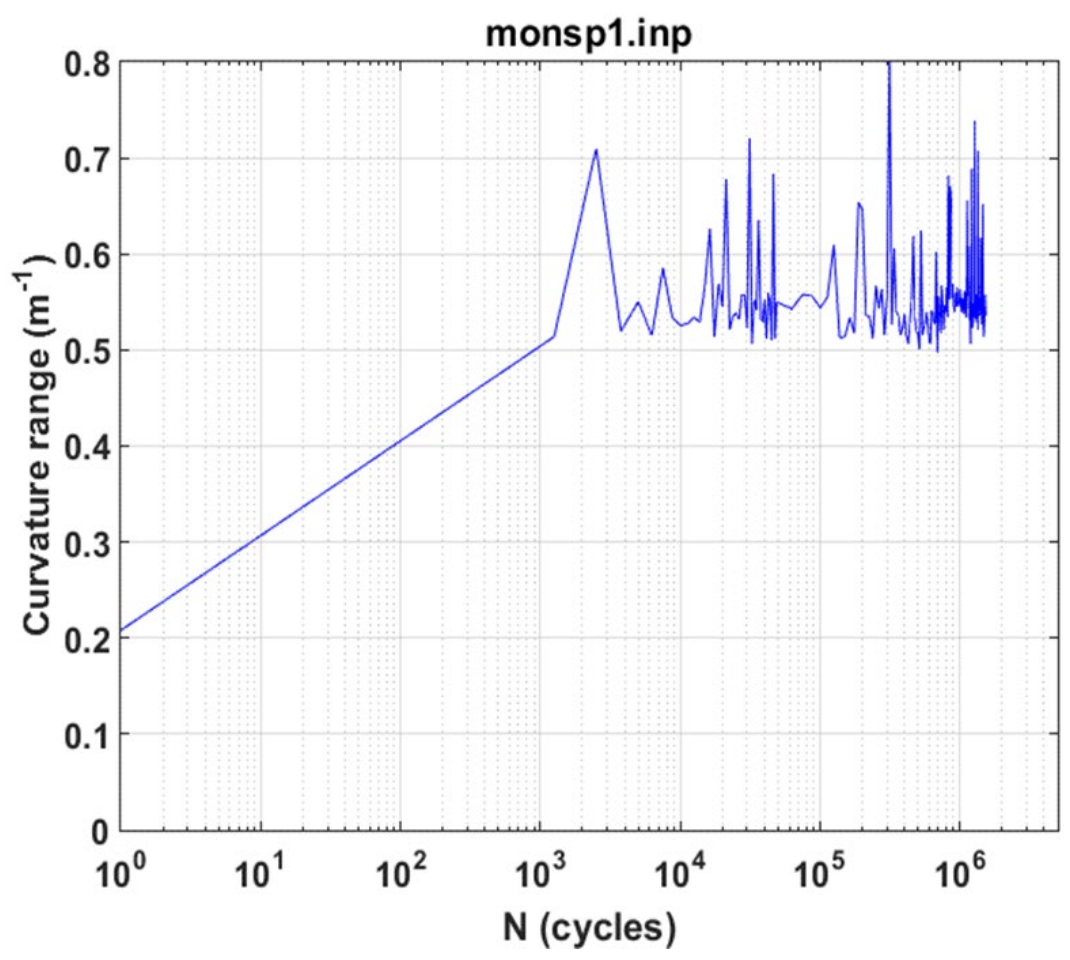

Real-time curvature range-cycle frequency history 


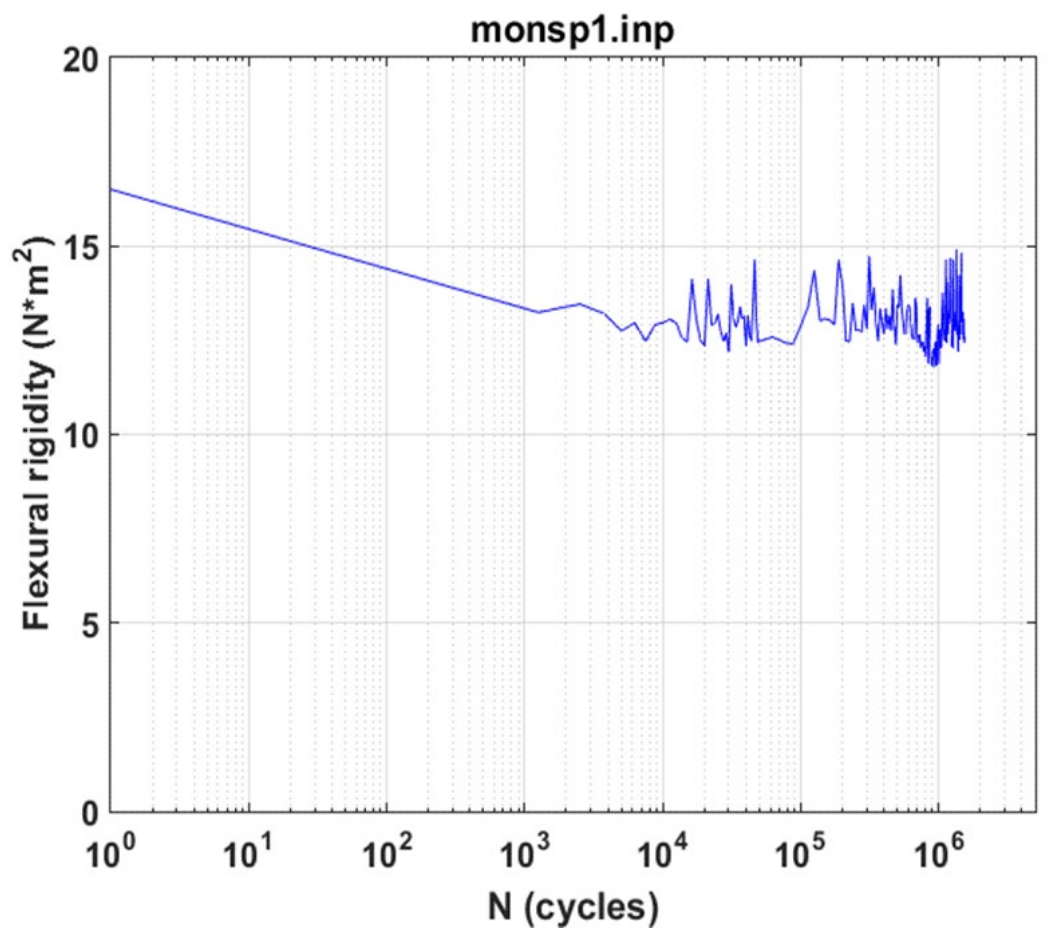

Real-time flexural rigidity-cycle frequency history

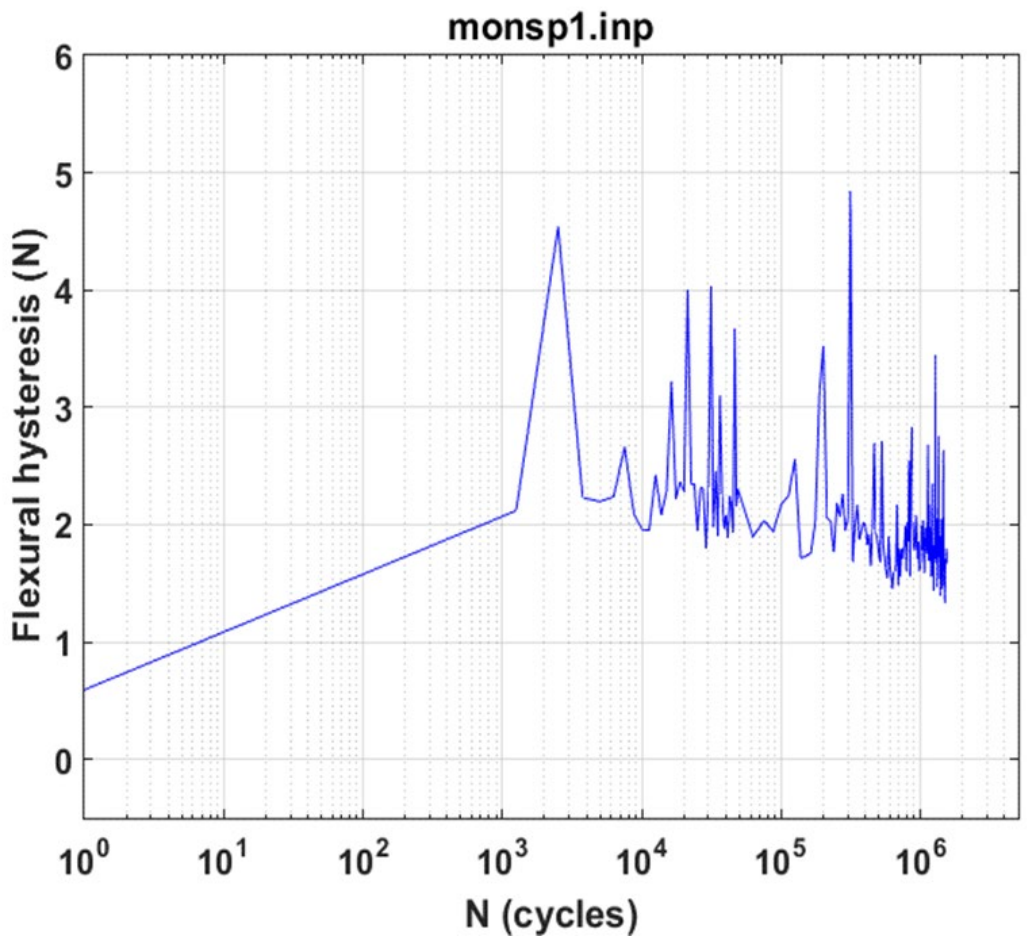

Real-time flexural hysteresis-cycle frequency history

Figure $97 \mathrm{C} 7$ core wires vibration fatigue CIRFT testing results. 



\section{DEVELOPING QUALIFICATION CRITERIA FOR C7 COMPOSITE CORE THERMAL PERFORMANCE}

\subsection{General considerations}

The proposed qualification criteria development for the $\mathrm{C} 7$ composite core thermal stability at the target $\mathrm{C} 7$ overhead conductor operating temperature are covered by the followings two major efforts, namely, (1) C7 composite core glass transition temperature (Tg) quantification, covered by TGA, DMA and TMA tests, and (2) C7 composite core material mechanical strength verification, covered by 3-point bending test, tensile test, creep test, and dynamic vibration test. The summary of the developed qualification test results, including DMA, TMA, 3-point bending and tensile tests, are provided in Tables 7-10.

Analysis of these qualification test results shows large data scatter due to inherited inhomogeneous and composite material characteristic. The general trend of the $\mathrm{C} 7$ composite core material testing response strongly depends on the followings:

(1) The properties of the individual components; such as PPS, PEEK, and carbon fibers, where different $\mathrm{Tg}$ values were revealed from DMA test as shown in Table 7.

(2) The relative quantities of different phases; such as the effect of carbon fiber volume ratio to the dynamic modulus evaluation in a DMA test.

(3) The orientation of various components; such as carbon fiber uniaxial orientation, embedded within PPS matrix, and the outer coating layer PEEK provided circumferential constraint, and their integrated response will affect the effective $\mathrm{C} 7$ core sample system thermal expansion evaluation in a TMA test.

(4) The degree of interface bonding between the polymer matrix/surface coating and the carbon fiber reinforcements; they will affect both DMA and TMA test results and the C7 core sample mechanical strength evaluation.

(5) The loading rate dependent material behavior was also revealed from tensile test; where at higher loading rate a significant $\mathrm{C} 7$ core tensile strength reduction was observed. This may imply $\mathrm{C} 7$ core material behavior at high rate loading, such as galloping condition, deserve our special attention.

(6) C7 composite core grip system induced lateral/circumferential constraint compressive residual stress fields; the loss of compressive residual stress to $\mathrm{C} 7$ composite core sample at high temperature can significantly reduce the $\mathrm{C} 7$ composite core system mechanical strength and C7 overhead conductor integrated performance at target operating temperature.

Further considerations on C7 composite core long-term operation stability, is that thermal plastics matrix composites can be affected by the irreversible property changes, induced by the following degradation agents:

1. Thermal - static heat aging, sub-zero exposure or thermal cycling;

2. Humidity (including hot/wet) exposures; 
3. Complete immersion in water at ambient and elevated temperatures;

4. Freeze/thaw and dry/wet cyclic conditions;

5. Continuous or intermittent saltwater immersion or spray;

6. Weathering (including rain and sand erosion);

7. Combined load (i.e. stress) and environmental exposures;

8. Chemical (including water, fuel, acids, alkalis, solvents and oxygen);

9. Ultraviolet and high-energy radiation;

10. Electrical stress (e.g. lightning stress and galvanic reactions) and Micro-organisms.

Table 7 C7 composite core samples DMA test results.

\begin{tabular}{|c|c|c|c|c|}
\hline Test \# & $\mathbf{T g}^{\left(\mathbf{E}^{\prime}\right),{ }^{\circ} \mathbf{C}}$ & $\mathbf{T g}^{\left(\mathbf{E}^{\prime}\right)}{ }^{\circ} \mathbf{C}$ & $\mathbf{T g}(\mathbf{T a n} \boldsymbol{\delta}),{ }^{\circ} \mathbf{C}$ & $\mathbf{T m}^{\circ} \mathbf{C}$ \\
\hline 1 & 154.6 & 166.8 & 172.9 & 289 \\
\hline 3 & 158.5 & 166.7 & 172.7 & 288 \\
\hline $3^{*}$ & 80.0 & 86.9 & 86.9 & \\
\hline 4 & & 169 & 172 & \\
\hline 5 & 155 & 167 & 174 & 291 \\
\hline $5 *$ & 176.6 & 176.6 & 91.7 & 291 \\
\hline 6 & 91.7 & 91.7 & 167.1 & 271.2 \\
\hline 7 & 167.1 & 167.1 & 173.5 & \\
\hline 8 & 155 & 168.5 & 174.7 & 288 \\
\hline $8^{*}$ & 162.8 & 171.1 & 113.9 & 288 \\
\hline 9 & & 113.9 & 168.8 & 288.2 \\
\hline $9 *$ & 168.8 & 168.8 & 112.3 & 288.2 \\
\hline 10 & & 112.3 & 172.1 & 290 \\
\hline $10 *$ & 100.0 & 108.5 & 108.5 & 290 \\
\hline Aged EPRI & & 181.3 & 181.3 & 282.7 \\
\hline
\end{tabular}

E'- Storage modulus, E”-Loss modulus, Tm-melting temperature, *Second peak's data

Table 8 C7 composite core samples TMA test results.

\begin{tabular}{|c|c|c|c|c|c|c|c|}
\hline Test \# & $\begin{array}{c}\text { length, } \\
\text { mm }\end{array}$ & $\begin{array}{c}\text { Thermal } \\
\text { expansion }^{1}, \mu \mathrm{m}\end{array}$ & $\begin{array}{c}\text { Thermal } \\
\text { expansion }{ }^{2}, \mu \mathrm{m}\end{array}$ & Alpha $1,{ }^{\circ} \mathbf{C}^{-1}$ & Alpha $2,{ }^{\circ} \mathbf{C}^{-1}$ & $\mathrm{Tg},{ }^{\circ} \mathrm{C}$ & $\mathbf{T m},{ }^{\circ} \mathrm{C}$ \\
\hline 1 & 21.21 & $3.78 \mathrm{E}-08$ & $1.03 \mathrm{E}-07$ & $1.78 \mathrm{E}-06$ & $4.85 \mathrm{E}-06$ & 157 & \\
\hline 2 & 19.59 & $5.23 \mathrm{E}-08$ & $1.27 \mathrm{E}-07$ & $2.66 \mathrm{E}-06$ & $6.49 \mathrm{E}-06$ & 157 & \\
\hline 3 & 8.4 & $2.10 \mathrm{E}-08$ & $4.78 \mathrm{E}-08$ & $2.50 \mathrm{E}-06$ & $5.69 \mathrm{E}-06$ & 158 & 255 \\
\hline 4 & 19.6 & $5.00 \mathrm{E}-08$ & $1.15 \mathrm{E}-07$ & $2.55 \mathrm{E}-06$ & $5.86 \mathrm{E}-06$ & 170 & \\
\hline 5 & 2.7 & $1.72 \mathrm{E}-08$ & $3.70 \mathrm{E}-08$ & $6.37 \mathrm{E}-06$ & $1.37 \mathrm{E}-05$ & 168 & \\
\hline 6 & 9.51 & $1.54 \mathrm{E}-08$ & $3.08 \mathrm{E}-08$ & $1.62 \mathrm{E}-06$ & $3.24 \mathrm{E}-06$ & 163 & \\
\hline 7-aged & 6.96 & $1.22 \mathrm{E}-08$ & $2.36 \mathrm{E}-08$ & $1.75 \mathrm{E}-06$ & $3.39 \mathrm{E}-06$ & 193 & \\
\hline
\end{tabular}

${ }^{1}$ pre Tg temperature, ${ }^{2}$ post Tg temperature. 
Table $9 \mathrm{C} 7$ composite core samples 3-point bending test results

\begin{tabular}{|l|l|c|c|c|c|c|}
\hline Sample & Thermal History & Max. Load $[\mathrm{lb}]$ & Deflection $[\mathrm{in}]$ & $\begin{array}{c}\text { Max. Stress } \\
{[\mathrm{ksi}]}\end{array}$ & $\begin{array}{c}\text { Strain } \\
{[\%]}\end{array}$ & $\begin{array}{c}\text { E } \\
{[\mathrm{msi}]}\end{array}$ \\
\hline B1 & Baseline & 32.49 & 0.24 & 129.5 & 0.835 & 10.249 \\
\hline B2 & Baseline & 34.99 & 0.276 & 139.5 & 0.956 & 9.598 \\
\hline B3 & Baseline & 30.44 & 0.308 & 121.3 & 1.062 & 7.482 \\
\hline B4 & Baseline & 36.15 & 0.385 & 144.0 & 1.310 & 7.108 \\
\hline B5 & Baseline & 32.99 & 0.295 & 131.5 & 1.019 & 8.466 \\
\hline B6 & Baseline & 30.0 & 0.251 & 119.6 & 0.872 & 9.048 \\
\hline Aged & $180 \mathrm{C} / 100 \mathrm{~h}$ & 33.87 & 0.302 & 134.9 & 1.042 & 8.490 \\
\hline Aged & $180 \mathrm{C} / 500 \mathrm{~h}$ & 33.44 & 0.294 & 133.3 & 1.016 & 8.611 \\
\hline Aged & $180 \mathrm{C} / 1000 \mathrm{~h}$ & 46.39 & 0.455 & 184.9 & 1.526 & 7.719 \\
\hline Aged & 225C/100h & 40.19 & 0.406 & 160.2 & 1.376 & 7.494 \\
\hline O-temp1 & RT-180C cycles & 38.5 & 0.368 & 153.5 & 1.256 & 7.920 \\
\hline O-temp2 & RT-180C cycles & 37.3 & 0.351 & 148.7 & 1.202 & 8.045 \\
\hline O-temp2 & RT-180C cycles & 35.4 & 0.315 & 141.1 & 1.085 & 8.508 \\
\hline O-temp4 & RT-180C cycles & 34 & 0.299 & 135.5 & 1.032 & 8.609 \\
\hline Zr-Al-1 & RT-180C cycles & 32.9 & 0.308 & 131.1 & 1.062 & 8.087 \\
\hline Zr-Al-2 & RT-180C cycles & 35.4 & 0.327 & 141.1 & 1.124 & 8.196 \\
\hline Zr-Al-3 & RT-180C cycles & 38.1 & 0.309 & 151.9 & 1.065 & 9.335 \\
\hline Zr-Al-4 & RT-180C cycles & 33.84 & 0.276 & 134.9 & 0.956 & 9.282 \\
\hline
\end{tabular}

Table $10 \mathrm{C} 7$ composite core samples tensile test results

\begin{tabular}{|l|c|c|c|c|c|c|c|}
\hline \multicolumn{1}{|c|}{ C7 core } & $\begin{array}{c}\text { Temp } \\
{\left[{ }^{\circ} \mathbf{C}\right]}\end{array}$ & $\begin{array}{c}\text { Grip. } \\
\mathbf{T e m p} \\
{\left[{ }^{\circ} \mathbf{C}\right]}\end{array}$ & $\begin{array}{c}\text { Loading rate } \\
{[\mathbf{i n} / \mathbf{s}]}\end{array}$ & $\begin{array}{c}\text { Gage length } \\
{[\mathbf{i n}]}\end{array}$ & $\mathbf{E}[\mathbf{m s i}]$ & $\begin{array}{c}\text { Max. Stress } \\
{[\mathbf{k s i}]}\end{array}$ & $\begin{array}{c}\text { Strain } \\
{[\%]}\end{array}$ \\
\hline Baseline & RT & RT & 0.3 & 4 & 5.8 & 189.6 & 3.827 \\
\hline Baseline & RT & RT & 0.03 & 4 & 7.17 & 273.8 & 3.863 \\
\hline Baseline & RT & RT & 0.003 & 4 & 8.13 & 248 & 4.106 \\
\hline Baseline & RT & RT & 0.003 & 4 & 7.76 & 248.8 & 4.072 \\
\hline Aged-Zr & RT & RT & 0.003 & 4 & 7.25 & 243.8 & 3.934 \\
\hline Aged-O-temp & RT & RT & 0.003 & 4 & 6.8 & 282.1 & 5.069 \\
\hline Baseline & RT & RT & 0.0003 & 4 & 7.37 & 280.4 & 4.701 \\
\hline Baseline & 100 & 86 & 0.003 & 4 & 3.47 & 48.7 & 1.888 \\
\hline Baseline & 100 & 86 & 0.003 & 4 & 5.78 & 214.3 & 4.463 \\
\hline Baseline* & 100 & RT & 0.003 & 17 & 10.5 & 227.8 & 2.327 \\
\hline Baseline & 180 & 161 & 0.003 & 4 & 5.54 & 154.9 & 3.003 \\
\hline Baseline & 180 & 161 & 0.003 & 4 & 5.73 & 121.9 & 2.422 \\
\hline Baseline* & 180 & RT & 0.003 & 17 & 10.4 & 248 & 2.474 \\
\hline Baseline & 225 & 202 & 0.003 & 4 & 5.73 & 80.3 & 1.5083 \\
\hline Baseline* & 225 & RT & 0.003 & 17 & 10.4 & 221.5 & 2.166 \\
\hline
\end{tabular}

* Grip is located out of environmental chamber. 


\subsection{Discussion}

\subsubsection{Transition Temperature Estimate for C7 Composite Core Material}

Tg results from DMA \& TMA Testing and lesson learned are stated below:

- From DMA Data

- Tg range is from $85^{\circ} \mathrm{C}$ to $172.9^{\circ} \mathrm{C}$ w. r. t. flexural bending strength measurement.

- From TMA Data

- Tg is around $160^{\circ} \mathrm{C}$ w. r. t. thermal expansion measurements.

- $\mathrm{Tg}$ serves as a temperature limit for $\mathrm{C} 7$ composite core high-temperature operation:

- The Tg either from both DMA or TMA is lower than the C7 overhead conductor operation temperatures, specified by the vendor as stated below:

- $180^{\circ} \mathrm{C}$ continuing operation, and

- $225^{\circ} \mathrm{C}$ contingency operation.

- The glass transition temperature does not occur at a single temperature; and depends on the definition in use and method to measure, it can be defined as the temperature at which the material

(a) suddenly loses mechanical strength,

(b) exhibits a step-change in specific heat capacity, or

(c) exhibits increased thermal expansion.

Thus, more definitions need to be considered depending on which properties are important for the end user.

- $85^{\circ} \mathrm{C}$ of $\mathrm{C} 7$ composite core is the limiting Tg set by PPS using DMA test methodology; this result is consistent with the lower end Tg value obtained from ORNL DMA tests.

- The lesson learned is that the contribution of PPS and PEEK to establish Tg criteria can be properly attributed under DMA testing with different loadings used in DMA tests.

- For the composite structure of $\mathrm{C} 7$ carbon composite core, the PEEK coating layer formed a protective layer around PPS composite matrix, which play a dominated effect w. r. t. C7 core sample thermal expansion displacement evaluation from a TMA test. This is the primary reason that $\mathrm{C} 7$ core $\mathrm{Tg}$ of $160^{\circ} \mathrm{C}$ estimated from TMA test is close to that of PEEK at $143^{\circ} \mathrm{C}$.

- Therefore, Tg from TMA test was primary dictated by PEEK coating layer under low axial compression loading condition provided in TMA test; and the temperature increased beyond PPS Tg, the induced PPS matrix and carbon fiber composite structure changes won't be readily revealed due to exterior confinement provided by PEEK coating layer.

- The observed twin-peaks from Tan $\delta$ of DMA method for Tg evaluations are consistent with that of the PPS and PEEK individual characteristic. 


\subsubsection{Mechanical strength verification at the target service temperature}

The lesson learned from 3-point bending and tensile tests are stated below.

\section{3-point bending test results}

- Baseline maximum flexural tensile stress is around $119 \mathrm{ksi}$ to $139 \mathrm{ksi}$, the corresponding maximum strain range is around $0.83 \%$ to $1.31 \%$.

- Maximum tensile stress range of the thermal aging samples is around $133 \mathrm{ksi}$ to $184 \mathrm{ksi}$, and the corresponding maximum strain at failure is around $1.01 \%$ to $1.52 \%$ strain ranges.

- Thermal aging data shows the most material softening occurred at $225^{\circ} \mathrm{C} / 100 \mathrm{~h}$ aging temperature, with Young's modulus of 7.71E+6 psi; next softening occurred at $180^{\circ} \mathrm{C} / 1000 \mathrm{~h}$ with Young's modulus of $7.72 \mathrm{E}+6 \mathrm{psi}$. Significant deflection and ductility were also observed from these two thermal aging data.

- For EPRI thermal cycling aged samples, the maximum stress range is around $131 \mathrm{ksi}$ to $153 \mathrm{ksi}$, and the corresponding maximum strain at failure is around $1.062 \%$ to $1.256 \%$.

- The Young's modulus of thermal aging C7 core samples appeared to be less than that of the baseline $\mathrm{C} 7$ core samples.

- The average Young's modulus of tested C7 core samples is around $8.65 \mathrm{msi}$, which is about $30 \%$ to that of steel with $30 \mathrm{msi}$.

- EPRI thermal cycle aged C7 core tested data with O-temp conductor has higher deflection/ductility than that of $\mathrm{Zr}-\mathrm{Al}$ conductor.

\section{$\underline{\text { Tensile test results }}$}

- The estimate average C7 core tensile strength is $206 \mathrm{ksi}$ and the associated maximum strain is about $3.32 \%$ (with relatively large uncertainty), which is similar to that from Southwire data. And is compatible with that of ASTM B498/B802 high strength steel.

- C7 core sample tensile failure appears to be catastrophic brittle fracture, where C7 core sample upon failure was completely disintegrated into fibrous form under medium or low loading rate; while at very high loading rate $\mathrm{C} 7$ fail at much lower load compared to that of low or medium loading rate and $\mathrm{C} 7$ core sample failed in a brittle failure mode with the $\mathrm{C} 7$ core sample cross-section nearly intact.

- The estimate Young's modulus of baseline C7 core samples is around $7.22 \mathrm{msi}$ and is about $24 \%$ to that of steel. Thus, a large deformation/displacement under load would be experienced by $\mathrm{C} 7$ core wire compared to that of conventional ACSS or ACSR steel core wire deformation.

- Tensile test results with 17 -inch gage section sample show similar tensile strength with the baseline $\mathrm{C} 7$ core sample of 4-inch gage section, but, with much less ductility.

- The EPRI thermal cycle aged data with O-temp aluminum conductor appeared to have more ductility and softening w. r. t. Young's modulus reduction compared to that of $\mathrm{Zr}$ $\mathrm{Al}$ conductor. 
- The tensile strength of the C7 overhead conductor with O-temp aluminum conductor and with a dead-end connector shows about 8,000 lb. tensile load reduction compared to that of $\mathrm{C} 7$ overhead conductor w/o dead-end connector. About 5,000 lb. tensile load capacity reduction was also observed for $\mathrm{C} 7$ overhead conductor with $\mathrm{Zr}$-Al conductor with deadend connector. This could be interrelated as that potential C7 core wire damage through dead-end connector crimp forming process. Furthermore, postmortem examination also confirmed that the $\mathrm{C} 7$ overhead conductor failure site was within the dead-end connector region.

- In order to understand C7 core wire and the associated grip connector system performance under high-temperature operation, the C7 core sample tensile tests were also performed with the $\mathrm{C} 7$ sample grips located inside the furnace; where the grip temperature is about $20^{\circ} \mathrm{C}$ lower than that of $\mathrm{C} 7$ core samples. This $\mathrm{C} 7$ core wireconnector grip system temperature profile seems to resemble that of $\mathrm{C} 7$ overhead conductor in a high-temperature service environment. Furthermore, from EPRI HTLS thermal cycling experiments, the thermal couple's data show higher conductor-connector interface temperature at the splice connector region.

The associated tensile test results showed a significant drop in tensile strength and stiffness compared to that of sample grips located outside the furnace. And all the C7 core sample and the associated grip system show significant slip phenomenon during the tensile tests. This phenomenon is primarily due to C7 core sample softening above $\mathrm{Tg}$ induced grip slip during tensile testing. This lack of sufficient grip strength for $\mathrm{C} 7 \mathrm{core}$ samples may indicate the potential weakness of applying the conventional crimping type core-grip connector system to the C7 carbon composite core wires designed for hightemperature operation. The Tg of PPS matrix is about $90^{\circ} \mathrm{C}$ for a $\mathrm{C} 7$ core sample, thus at $180^{\circ} \mathrm{C}$ operation temperature the induced PPS matrix softening can cause PPS matrix flow out of high pressure crimping grip region. The consequence is the significant reduction in the grip or connector crimping strength for secure $\mathrm{C} 7$ composite core wires system.

- It is also interesting to note that tensile test results from samples with 17-inch gage section appeared to have the highest Young's modulus and the lowest ductility upon failure compared to the rest of tensile test results; and its maximum strain upon failure is about half of that from typical baseline sample with 4-inch gage section, even 17-inch gage section samples are all used for high-temperature tensile testing. The rationale of this observed low ductility phenomenon is that for a long composite sample it is expected to have more flaws contained in the gage section than that of a relatively short sample. Thus, the probability of a more uniform elongation during the tensile testing will be much less for a long sample compared to that of a relatively short sample.

- The average Young's modulus of C7 tensile test results is at $7.19 \mathrm{msi}$, which is about $27 \%$ to that of steel of $29 \mathrm{msi}$. The average thermal expansion coefficient of $\mathrm{C} 7 \mathrm{core}$ samples from TMA test around $180^{\circ} \mathrm{C}$ is about $6.176 \mathrm{E}-06 /{ }^{\circ} \mathrm{C}$.

For a Drake conductor with span of $1000 \mathrm{ft}$ span, and each core wire experienced with an average of $1500 \mathrm{lb}$. tensile load, the estimate thermal expansions for the core wire made of $\mathrm{C} 7$ composite core wire and the steel core wire at a $180^{\circ} \mathrm{C}$ operating temperature are detailed below. 
(1) For C7 composite core wire - assumed perfect bond and no slip at grip connector

C7 core wire expansion under load $=$ Length $*$ Strain $=$ Length $*$ Stress $/ E$ $=1000 \mathrm{ft} *\left(1500 /\left(3.14 *(0.136 / 2)^{\wedge} 2\right) / 7.19 \mathrm{E} 6\right)=14.37 \mathrm{ft}$

$\mathrm{C} 7$ core wire thermal extension $=$ Length $* \alpha^{*} \Delta \mathrm{T}=1000 \mathrm{ft} * 6.176 \mathrm{E}-6 *(180-20)$ $=0.99 \mathrm{ft}$

The estimated $\mathrm{C} 7$ core wire total elongation is at $15.35 \mathrm{ft}$

(2) For steel core wire - at $180^{\circ} \mathrm{C}, \mathrm{E}=28 \mathrm{msi}, \alpha=11.5 \mathrm{E}-6 /{ }^{\circ} \mathrm{C}$

C7 core wire expansion under load $=$ Length $*$ strain $=$ Length $*$ Stress $/ E$ $=1000 \mathrm{ft} *\left(1500 /\left(3.14 *(0.136 / 2)^{\wedge} 2\right) / 28.0 \mathrm{E}+6\right)=3.69 \mathrm{ft}$

$\mathrm{C} 7$ core wire thermal extension $=$ Length $* \alpha * \Delta \mathrm{T}=1000 \mathrm{ft} * 11.5 \mathrm{E}-6 *(180-20)$ $=1.84 \mathrm{ft}$

The estimated steel core wire total elongation is at $5.53 \mathrm{ft}$

Thus, at $180^{\circ} \mathrm{C}$ and $1500 \mathrm{lb}$. core wire load, $\mathrm{C} 7$ core wire overall expansion in $1000 \mathrm{ft}$ span is about 2.8 times that of steel core wire. Thus, the consequence of much sever $\mathrm{C} 7$ overhead conductor sag is expected compared to that of ACSS or ACSR conductor.

For a Drake conductor with span of $1000 \mathrm{ft}$ span, and each core wire experienced with an average of $1000 \mathrm{lb}$. tensile load, the estimate thermal expansions for the core wire made of $\mathrm{C} 7$ composite core wire and the steel core wire at a $180^{\circ} \mathrm{C}$ operating temperature are stated below.

(1) For C7 composite core wire - assumed perfect bond and no slip at grip connector

The estimated $\mathrm{C} 7$ core wire total elongation is at $10.57 \mathrm{ft}$

(2) For steel core wire - at $180^{\circ} \mathrm{C}, \mathrm{E}=28 \mathrm{msi}, \alpha=11.5 \mathrm{E}-6 /{ }^{\circ} \mathrm{C}$

The estimated steel core wire total elongation is at $4.3 \mathrm{ft}$

Thus, at $180^{\circ} \mathrm{C}$ and $1000 \mathrm{lb}$. core wire load, $\mathrm{C} 7$ core wire overall expansion in $1000 \mathrm{ft}$ span is about 2.46 times that of steel core wire. 



\section{SUMMARY}

The general observation from the $\mathrm{C} 7$ composite core qualification testing protocols are the followings:

(1) The estimate $\mathrm{Tg}$ for C7 composite core material from DMA and TMA tests are lower than the vendor's recommended $180^{\circ} \mathrm{C}$ and $225^{\circ} \mathrm{C}$ operation temperatures.

(2) Higher thermal expansion coefficient, was observed from TMA test at post-Tg temperature range, for instance at $180^{\circ} \mathrm{C}$ the thermal expansion coefficient is about 3.6 times that of at ambient temperature.

(3) Relatively low Young's modulus with mean value of 7.18 msi was observed from C7 core sample tensile test results, compared to that of steel with $29.0 \mathrm{msi}$.

(4) C7 core grip effect induced C7 core strength reduction

(5) At $180^{\circ} \mathrm{C}$ and a $1000 \mathrm{lb}$. core wire load, the estimate $\mathrm{C} 7$ core wire total expansion in a $1000 \mathrm{ft}$ span is about 2.46 times that of steel core wire.

(6) Due to sever C7 core wire extension under loads, in addition to the consideration of C7 core wire-core grip system performance deficiency at high temperature, the conventional ACSS or ACSR conductor seems to outperform the advanced C7 Overhead Conductor.

Based on the above observations, C7 Overhead Conductor does not match its claimed superiority as a new generation high-temperature low sag conductor for high voltage power transmission. 



\section{ACKNOWLEDGMENTS}

The author would like to thank John Chan and Gary Sibilant of the Electric Power Research Institute (Charlotte, NC) for guidance and financial support. This project was funded by the EPRI High-Temperature Low Sag Conductor Program.

The author would like to thank Andres E. Marquez Rossy and Dana McClurg for DMA and TMA testing, Michael Lance for TGA testing, Shane Hawkins and Hong Wang for tensile and creep testing, and Randy Parten for machining components and sample preparation. 


\section{REFERENCES}

1 C7 Overhead Conductor with Celstran CFR-TPR C7, http://www.southwire.com/transmission/c7.htm 2 Innovation starts at the core, http://www.southwire.com/documents/SW_C7_sales_sheet_LO(1).pdf 3 Cox, W.P.; Merz, E.H., Understanding Rheology of Thermoplastic Polymers, J.Polym.Sci., 28, 118. (1958). http://www.tainstruments.com/pdf/literature/AAN013_V_1_U_Thermoplast.pdf

4 Dynamic Mechanical Analysis Basics: Part 2 Thermoplastic Transitions and Properties, Perkin Elmer, http://www.perkinelmer.com/lab-solutions/resources/docs/app_thermaldynmechanalybasicspart2.pdf

5 Basics of Thermomechanical Analysis with TMA 4000, Perkin Elmer. http://www.perkinelmer.com/lab-solutions/resources/docs/TCH_TMA_4000.pdf

6 Celstran CFR-TPR Composites, Continuous Fiber Reinforced Thermoplastic Rod, 2014 Celanese CFRTP-016R1 AM 03/14. http://studylib.net/doc/8143151/celstran\%C2\%AE-cfr-tpr-composites.

7 Fortron PPS for Thermoplastic Composites, 2013 Celanese. http://anyflip.com/ssvj/phzw/basic.

8 C7 Overhead Conductor technical specifications. http://www.southwire.com/documents/SW_C7_sales_sheet_LO(1).pdf

9 Jy-An Wang, Hong Wang, Hao Jiang, Bruce Bevard, "High burn-up spent nuclear fuel transport reliability investigation," Nuclear Engineering and Design Journal, Volume 330 (2018) pp. 497-515.

10 Jy-An Wang, Hong Wang, Bruce Bevard, Rob Howard, Michelle Flanagan, "Reversal bending fatigue test system for investigating vibration integrity of spent nuclear fuel during transportation," Journal of Packaging, Transport, Storage \& Security of Radioactive Material, Vol. 25 (3-4), p.p. 119-132, 2015. 